PNNL-11148

UC-404

\title{
BEATRIX-II, Phase II: Data Summary Report
}

O. D. Slagle

G. W. Hollenberg

Other Key Contributors:
R. J. Puigh(a)
D. E. Baker (a)
D. A. King(a)
D. R. Precechtel(a)
G. T. Taylor ${ }^{(\mathbf{a})}$
R. W. Truitt(a)

T. Kondo(b)

T. Kurasawa(b)

K. Noda(b)

N. M. Masaki $(\mathbf{b})$

T. Takahashi(b)

T. Tanifuji(b)

H. Watanabe ${ }^{(b)}$

I. J. Hastings (c)

J. M. Miller (c)

R. A. Verrall(c)

S. E. Berk(d)

D. L. Baldwin

N. J. Wildung

May 1996

Work supported by

The U. S. Department of Energy

under Contract DE-AC06-76RLO 1830

Pacific Northwest National Laboratory

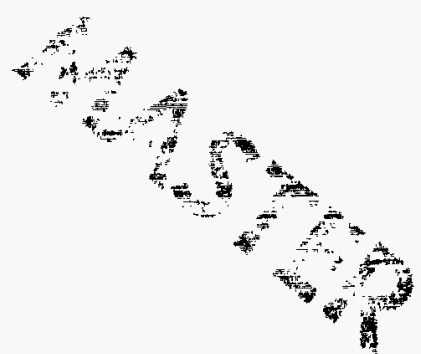

Richland, Washington 99352

(a) Westinghouse Hanford Company Richland, Washington

(b) Japanese Atomic Energy Research Institute Tokai-mura, Ibaraki-ken, Japan

(c) AECL Research

(d) U.S. Department of Energy Washington, D.C.

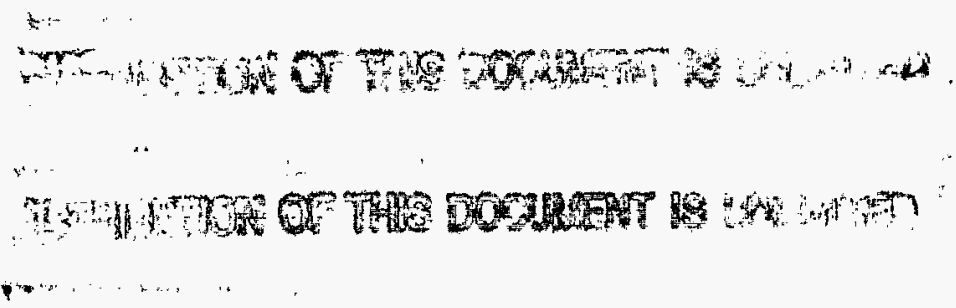




\section{DISCLAIMER}

This report was prepared as an account of work sponsored by an agency of the United States Government. Neither the United States Government nor any agency thereof, nor any of their employees, make any warranty, express or implied, or assumes any legal liability or responsibility for the accuracy, completeness, or usefulness of any information, apparatus, product, or process disclosed, or represents that its use would not infringe privately owned rights. Reference herein to any specific commercial product, process, or service by trade name, trademark, manufacturer, or otherwise does not necessarily constitute or imply its endorsement, recommendation, or favoring by the United States Government or any agency thereof. The views and opinions of authors expressed herein do not necessarily state or reflect those of the United States Government or any agency thereof. 


\section{DISCLAMMER}

Portions of this document may be illegible in electronic image products. Images are produced from the best available original document. 


\begin{abstract}
The BEATRIX-II experimental program was an International Energy Agency sponsored collaborative effort between Japan, Canada, and the United States to evaluate the performance of ceramic solid breeder materials in a fast-neutron environment at high burnup levels. This report addresses the Phase II activities, which included two in situ tritium-recovery canisters: temperaturechange and temperature-gradient. The temperature-change canister contained a $\mathrm{Li}_{2} \mathrm{O}$ ring specimen that had a nearly uniform temperature profile and was capable of temperature changes between 530 and $640^{\circ} \mathrm{C}$. The temperature-gradient canister contained a $\mathrm{Li}_{2} \mathrm{ZrO}_{3}$ pebble bed operating under a thermal gradient of 440 to $1100^{\circ} \mathrm{C}$. Postirradiation examination was carried out to characterize the Phase II in situ specimens and a series of nonvented capsules designed to address the compatibility of beryllium with lithium-ceramic solid-breeder materials.

The results of the BEATRIX-II, Phase II, irradiation experiment provided an extensive data base on the in situ tritium-release characteristics of $\mathrm{Li}_{2} \mathrm{O}$ and $\mathrm{Li}_{2} \mathrm{ZrO}_{3}$ for lithium burnups near $5 \%$. The composition of the sweep gas was found to be a critical parameter in the recovery of tritium from both $\mathrm{Li}_{2} \mathrm{O}$ and $\mathrm{Li}_{2} \mathrm{ZrO}_{3}$. In general, increasing the amount of hydrogen in the sweep gas resulted in a transient tritium recovery peak indicative of a decrease in tritium inventory in the specimen. The ability of the Phase II temperature-change canister to vary temperature between 530 and $630^{\circ} \mathrm{C}$ indicated that increasing temperature resulted in transient tritium-recovery peaks whose magnitude and duration were indicative of a relatively small tritium inventory in the Phase $\Pi \mathrm{Li}_{2} \mathrm{O}$ ring specimen at these temperatures. Throughout the Phase $I$ irradiation, the centerline temperature of the $\mathrm{Li}_{2} \mathrm{ZrO}_{3}$ specimen was nearly constant, inferring that the pebble bed remained physically the same throughout the irradiation.

Tritium inventories measured during postirradiation examination confirmed that $\mathrm{Li}_{2} \mathrm{O}$ and $\mathrm{Li}_{2} \mathrm{ZrO}_{3}$ exhibited very low tritium retention during the Phase II irradiation. The tritium inventories in $\mathrm{Li}_{2} \mathrm{ZrO}_{3}$ after Phase II tended to be larger than those found for $\mathrm{Li}_{2} \mathrm{ZrO}_{3}$ in other in situ experiments, but the larger values may reflect the larger generation rates in BEATRIX-II.

A series of 20 capsules was irradiated to determine the compatibility of lithium ceramics and beryllium under conditions similar to a fusion blanket. The lithium ceramics $\left(\mathrm{Li}_{2} \mathrm{O}, \mathrm{Li}_{2} \mathrm{ZrO}_{3}, \mathrm{LiAlO}_{2}\right.$, and $\mathrm{Li}_{4} \mathrm{SiO}_{4}$ ) in contact with beryllium resulted in no observable chemical interaction for lithium burnups up to $4 \%$ and irradiation times up to 500 effective full-power days.

The results of the Phase I and Phase II in situ tritium recovery and postirradiation examination provide insight on the physical stability and tritium-release behavior of $\mathrm{Li}_{2} \mathrm{O}$ and $\mathrm{Li}_{2} \mathrm{ZrO}_{3}$. Based on these results, it is concluded that $\mathrm{Li}_{2} \mathrm{O}$ and $\mathrm{Li}_{2} \mathrm{ZrO}_{3}$ should remain leading candidates for use in a solid-breeder fusion-blanket application.
\end{abstract}




\section{Executive Summary}

The BEATRIX-II (Breeder Exchange Matrix) experimental program was an International Energy Agency sponsored collaborative effort between Japan, Canada, and the United States. The experimental activities were carried out under ANNEX-III to the IEA Implementing Agreement on a Programmme of Research and Development in Fusion Materials. The purpose of the program is to evaluate the performance of ceramic solid-breeder materials in a fast-neutron environment at high burnup levels. The irradiations were carried out in the Fast Flux Test Facility which is operated by Westinghouse Hanford Company at the Hanford Site near Richland, Washington. The Pacific Northwest Laboratory together with the Japan Atomic Energy Research Institute and Atomic Energy of Canada Limited Research acted jointly to conduct the experiments.

The BEATRIX-II program was divided into two phases. This report addresses the Phase II activities that were based on irradiations carried out between May 27, 1991, and March 19,1992, for a total exposure of 200 effective full power days (EFPD). The final lithium burnups for the vented canisters were between 4.5 and $6 \%$. Postirradiation examination was carried out to characterize the Phase II vented canisters and the Phase I and II non-vented capsules.

In Phase II, the irradiation test assemblies included two in situ tritium-recovery canisters: temperature-change and temperature-gradient. These in situ canisters were installed on a materials open test assembly, which permitted not only thermocouple instrumentation, but also temperature control via changes in the gas composition of a gas gap. The temperature-change canister contained a $\mathrm{Li}_{2} \mathrm{O}$ ring specimen that had a nearly uniform temperature profile and was capable of temperature changes between 530 and $640^{\circ} \mathrm{C}$. The temperature-gradient canister contained a $\mathrm{Li}_{2} \mathrm{ZrO}_{3}$ pebble bed operating under a thermal gradient of 440 to $1100^{\circ} \mathrm{C}$. The data obtained from the temperaturegradient canister were prototypic of a worst-case thermal environment in a fusion blanket. Nonvented capsules designed to address the compatibility of beryllium with lithium-ceramic solid breeder materials that had been previously irradiated in Phase I received additional irradiation in Phase II.

The BEATRIX-II apparatus provided an excellent test bed for developing methods to monitor tritium and handle it safely during an in situ tritium-recovery experiment. The tritium handling system for Phase I and II divided the outlet streams from each of the two in situ tritiumrecovery-specimen canisters into two separate analysis streams. Each analysis gas stream provided continuous real-time monitoring of the flow rate, total moisture, tritium concentration, and proportion of reduced versus oxidized tritium in the sweep gas from the individual canisters. Throughout the irradiation, the ionization chambers provided a sensitive record of the tritium recovery with good response times and a slowly increasing background. The in situ calibration of the ionization chambers indicated that the ionization-chamber response was dependent on the sweep-gas composition, and specific correction factors were established throughout the course of the experiment. Ceramic electrolysis cells (CEC) were used to reduce the tritiated water (HTO) in one.of the analysis streams to HT for real-time determination of the total tritium. Overall, the efficiency of the CECs approached $99 \%$ except for two occasions when the operation of a cell was briefly interrupted. Tritium getter beds were designed to remove the tritium from the sweep gas before release to the environment, and these units performed better than specified in the original design requirements.

The results of the BEATRIX-II, Phase II irradiation experiment provided an extensive data base on the in situ tritium-release characteristics of $\mathrm{Li}_{2} \mathrm{O}$ and $\mathrm{Li}_{2} \mathrm{ZrO}_{3}$ for lithium burnups in the range of 4.5 to $6 \%$. Helium sweep gas with additions of $0 \%, 0.01 \%, 0.1 \%$, and $1.0 \%$ hydrogen were used to study the effect of sweep-gas composition on the tritium recovery. The composition of the 
sweep gas was found to be a critical parameter in the recovery of tritium from $\mathrm{Li}_{2} \mathrm{O}$ and $\mathrm{Li}_{2} \mathrm{ZrO}_{3}$. In general, decreasing the amount of hydrogen in the sweep gas decreased the measured tritium recovery rate. This decrease in recovery rate translates to higher tritium inventories for sweep gases with lower hydrogen concentrations.

The ability of the Phase II temperature-change canister to vary temperature between 530 and $640^{\circ} \mathrm{C}$ provided data that added confirmation to conclusions reached previously based on the Phase I data and resulted in additional insight on the irradiation behavior of $\mathrm{Li}_{2} \mathrm{O}$. The primary qualitative conclusions reached from the temperature-change results on $\mathrm{Li}_{2} \mathrm{O}$ were

- Tritium Inventories - Increasing the temperature resulted in transient tritium-recovery peaks whose magnitude and duration were indicative of a relatively small tritium inventory in the Phase $\Pi \mathrm{Li}_{2} \mathrm{O}$ ring specimen at these temperatures.

- $\quad$ Sweep-Gas Composition - As in Phase I, for a given temperature change, the Phase II transient tritium recovery peaks were successively larger for lower hydrogen concentrations. This behavior suggested that for $\mathrm{Li}_{2} \mathrm{O}$, larger changes in tritium inventories occurred for temperature transients carried out in sweep gases with lower hydrogen concentrations. These observations are consistent with the behavior observed for changing sweep-gas composition, i.e., decreasing hydrogen concentration in the sweep gas leads to higher tritium inventories in $\mathrm{Li}_{2} \mathrm{O}$.

- $\quad$ Lithium Burnup/Exposure - During Phase II, the temperature recovery peaks primarily consisted of HT, and no apparent change in recovery behavior occurred as seen in Phase I. At the start of Phase I, the tritium-recovery peaks for temperature increases were found to consist of an initial HT peak and a second larger peak of HTO. At the end of Phase I, the form of the tritium in the recovery peaks changed so that HT was the predominant species. Because Phase II did not exhibit the double peaks, this change in tritium-recovery behavior during Phase I probably resulted from changes such as lower surface moisture in the tritiumhandling system rather than from a change in $\mathrm{Li}_{2} \mathrm{O}$-specimen-release characteristics due to lithium burnup/exposure.

The temperature-gradient canister contained a $\mathrm{Li}_{2} \mathrm{ZrO}_{3}$ pebble bed that was irradiated under a large thermal gradient typical of fusion-blanket designs. The results of this irradiation provided verification of the viability of a $\mathrm{Li}_{2} \mathrm{ZrO}_{3}$ pebble bed as a candidate for a fusion solid blanket. Similar to the behavior of the Phase $\mathrm{I} \mathrm{Li}_{2} \mathrm{O}$ temperature-gradient canister, changing sweep-gas composition in the Phase II temperature-gradient canister led to higher tritium inventories in $\mathrm{Li}_{2} \mathrm{ZrO}_{3}$ for lower hydrogen concentration in the sweep gas. Throughout the 200 EFPD of irradiation, the centerline temperature of the specimen remained nearly constant when operated at full power, decreasing as the local neutron flux decreased with fuel burnup. This observation inferred that the pebble bed remained physically the same throughout the irradiation. Postirradiation examination indicated that limited sintering occurred between the pebbles, but this sintering resulted in no observable shrinkage of the bed.

Tritium inventories measured during postirradiation examination confirmed that $\mathrm{Li}_{2} \mathrm{O}$ exhibited very low tritium retention during the irradiation to $4.6 \%$ burnup. The Phase II experiment was shut down over a period of 10 hours in contrast to the 2-minute shutdown for Phase I. It was hypothesized that the Phase $\Pi$ inventory could be higher due to a buildup in the tritium while the specimen was operated at the lower temperatures during shutdown. However, for the $\mathrm{Li}_{2} \mathrm{O}$ in the Phase II temperature-change canisters, the measured tritium inventories (0.19 to 0.25 wppm) were lower than the Phase I inventories ( 0.2 to $0.7 \mathrm{wppm})$. A prediction of the tritium recovered versus the tritium generated during shutdown was not precise enough to determine whether the tritium inventory changed during shutdown. 
Postirradiation tritium-inventory measurements on the $\mathrm{Li}_{2} \mathrm{ZrO}_{3}$ pebble bed confirmed that the tritium inventory was very low after the $5.1 \%$ lithium burnup. For purposes of comparing the postirradiation tritium inventories, the Phase $\mathrm{II} \mathrm{Li} 2 \mathrm{ZrO}_{3}$ pebble-bed specimen was divided into three radial zones. The average tritium inventories in the three zones decreased from the lower temperature circumference to the higher temperature centerline: 0.32 wppm at 395 to $770^{\circ} \mathrm{C}, 0.15$ wppm at 770 to $945^{\circ} \mathrm{C}$, and 0.032 wppm at 945 to $1025^{\circ} \mathrm{C}$. A comparison of the tritium recovered during the final shutdown versus the predicted tritium generated indicated that no significant change in the inventory occurred during shutdown. The tritium inventories in $\mathrm{Li}_{2} \mathrm{ZrO}_{3}$ after Phase II tended to be larger than those found for $\mathrm{Li}_{2} \mathrm{ZrO}_{3}$ in other in situ experiments, but the larger values may reflect the larger generation rates in BEATRIX-II.

A series of 20 capsules was irradiated to determine the compatibility of lithium ceramics and beryllium under conditions similar to a fusion blanket. The lithium ceramics $\left(\mathrm{Li}_{2} \mathrm{O}, \mathrm{Li}_{2} \mathrm{ZrO}_{3}, \mathrm{LiAlO}_{2}\right.$, and $\mathrm{Li}_{4} \mathrm{SiO}_{4}$ ) in contact with beryllium resulted in no observable chemical interaction for lithium burnups up to $4 \%$ and irradiation times up to 500 EFPD.

The results of the Phase I and Phase II in situ tritium recovery provide insight on the effects of temperature and sweep-gas composition on the tritium-release behavior of $\mathrm{Li}_{2} \mathrm{O}$ and $\mathrm{Li}_{2} \mathrm{ZrO}_{3}$. Postirradiation examination of the specimens indicated that the material underwent extensive microstructural changes, but remained physically intact while efficiently releasing the generated tritium to maintain a low tritium inventory. Based on these results, it is concluded that $\mathrm{Li}_{2} \mathrm{O}$ and $\mathrm{Li}_{2} \mathrm{ZrO}_{3}$ should remain leading candidates for use in a solid-breeder fusion-blanket application. 



\section{Contents}

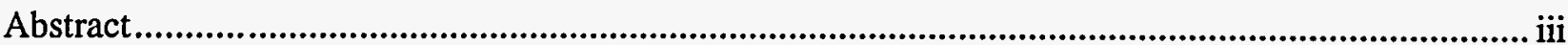

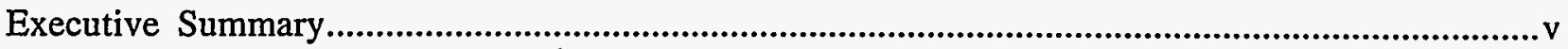

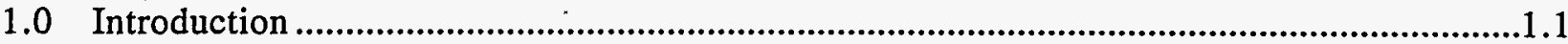

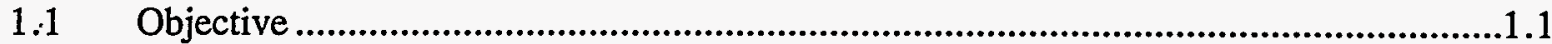

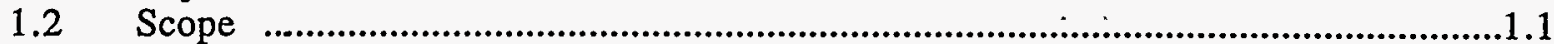

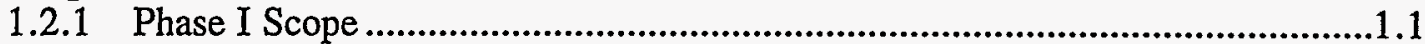

1.2 .2 Phase II Scope .....................................................................................

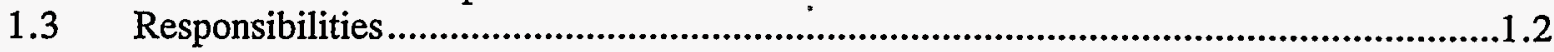

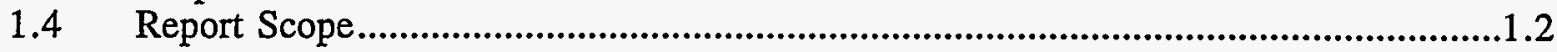

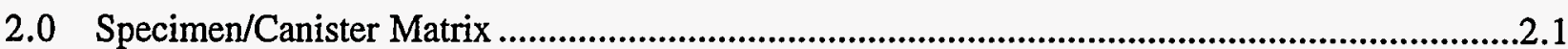

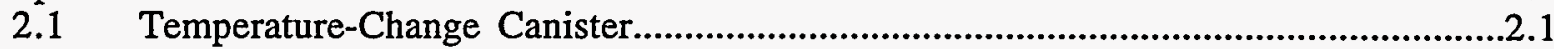

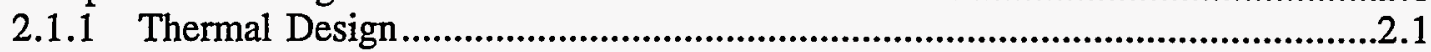

2.1.2 Specimen Fabrication/Loading................................................................2.3

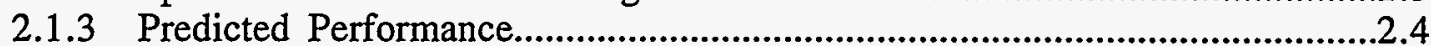

2.2 Temperature-Gradient Canister..............................................................................2.4

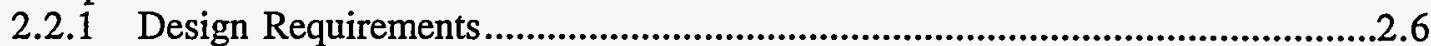

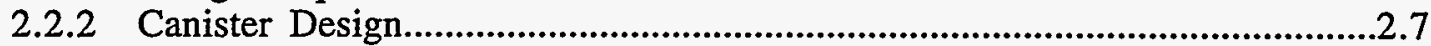

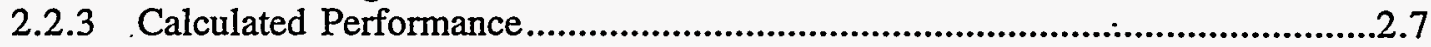

2.2.4 Specimen Fabrication/Loading............................................................2.9

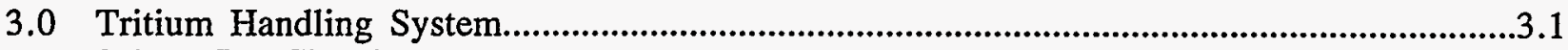

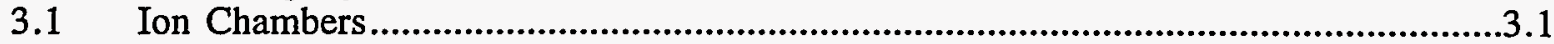

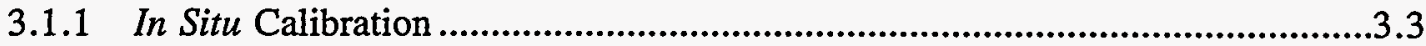

3.1.2 Sweep Gas Composition Effect on Ion chamber Response

(In Situ Data)...............................................................................................3.4

3.1.3 Sweep Gas Composition Effect on Ionization-Chamber

Response (Laboratory Experiment) ...........................................................3.4

3.1.4 Enhancement-Factor-Correction Relationship .................................................

3.1.5 Ion-Chamber Background Correction...............................................................3.5

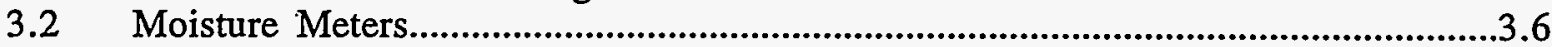

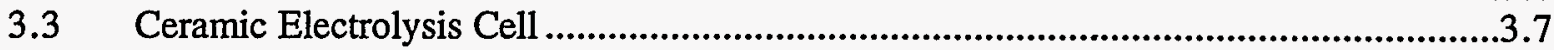

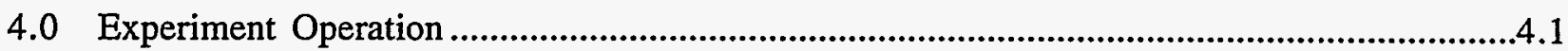

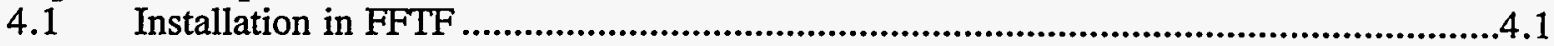

4.2 Experimental Test Plan ...................................................................................

4.2.1 Temperature-Change Canister......................................................................4.4

4.2.2 Temperature-Gradient Canister................................................................4.4

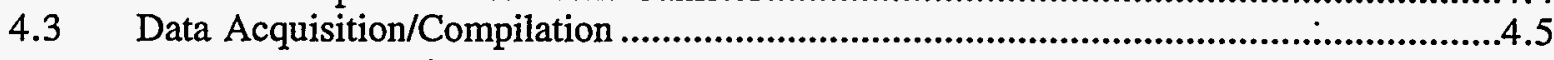

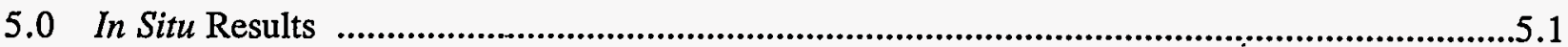

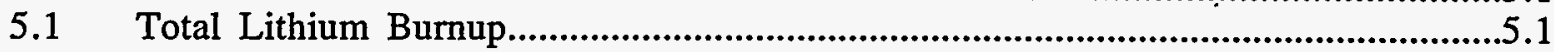

5.2 Temperature-Change Specimen .........................................................................

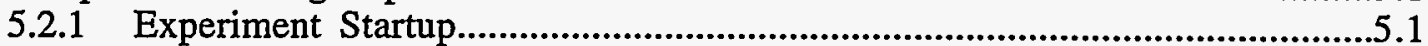

5.2.2 Temperature-Change Effects ...............................................................

5.2.3 Sweep-Gas Composition ........................................................................5.5

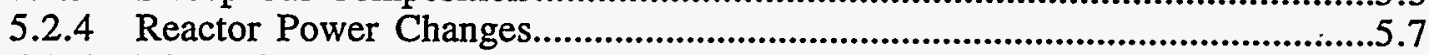

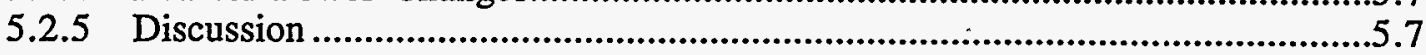

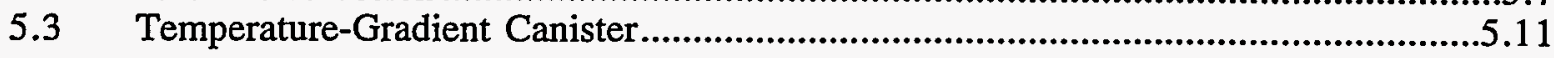


5.3.1 Centerline Temperatures........................................................................5.11

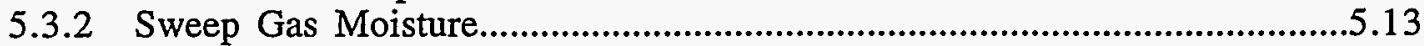

5.3.3 Sweep Gas Composition Changes....................................................................5.13

5.3.4 Flow Rate..........................................................................................5.17

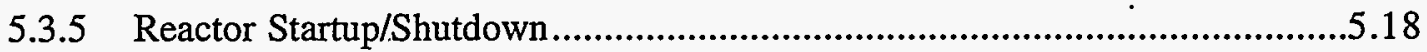

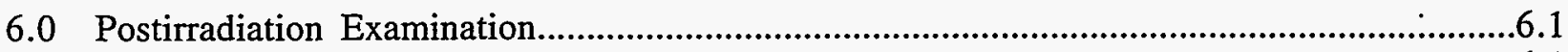

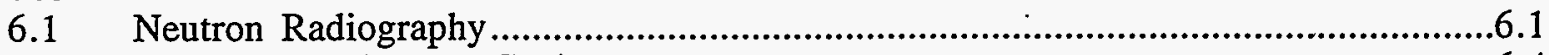

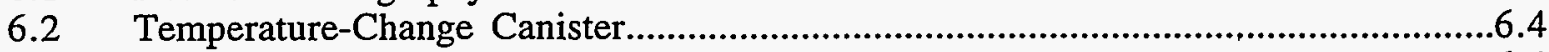

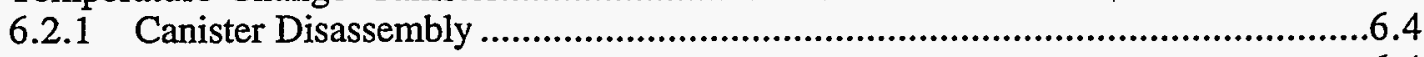

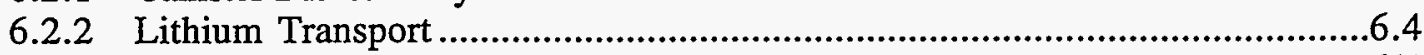

6.2.3 Density and Microstructural Characterization.............................................6.4

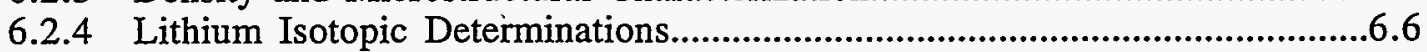

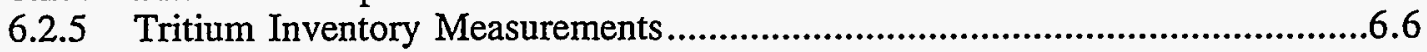

6.2.6 Tritium Retention Predicted from Shutdown Data......................................6.10

6.3 Temperature-Gradient Canister.............................................................................6.11

6.3.1 Tritium-Inventory Measurements.....................................................6.12

6.3.2 X-ray Diffraction..................................................................................6.18

6.3.3 Scanning Electron Microscopy .............................................................6.18

6.4 Lithium Oxide Single Crystals ............................................................................6.20

6.4.1 Plenum Gas Analysis ........................................................................6.20

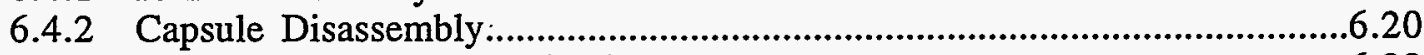

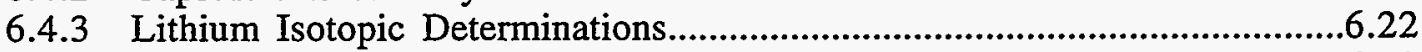

6.4.4 Tritium/Helium Retention ...................................................................6.23

6.5 Lithium Ceramic-Beryllium Compatibility Capsules..........................................6.24

6.5.1 Capsule Disassembly................................................................................6.25

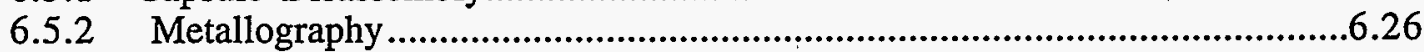

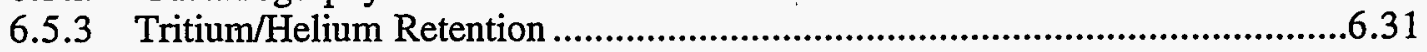

7.0 Data Transfers to Modelers and Code Developers ...............................................................7.1

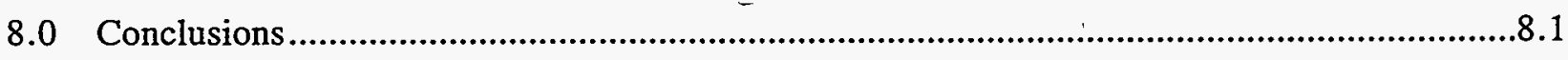

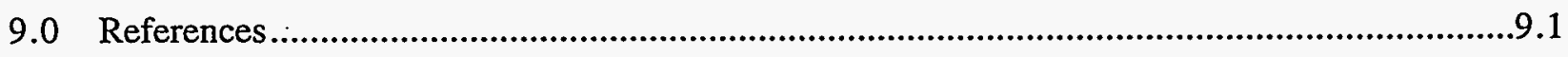

Appendix A

Appendix B 
6.15. Photographs of the Enriched Single Crystal after Irradiation in Phase I

6.16 thematic Diagram of the Lithium Ceramic-Beryllium Compatibility Capsules

6.17. Micrographs of a Beryllium Disk Adjacent to $\mathrm{Li}_{2} \mathrm{O}$ (Group IV) after Polishing on $1-\mu \mathrm{m}$ Diamond

6.18. Micrographs of a Beryllium Disk Adjacent to $\mathrm{Li}_{2} \mathrm{ZrO}_{3}$ (Group I) after Polishing on $1-\mu \mathrm{m}$ Diamond.

6.19. Micrographs of a Beryllium Disk Adjacent to $\mathrm{LiAlO}_{2}$ (Group I) after Polishing on $1-\mu \mathrm{m}$ Diamond.

6.20. Micrographs of a Beryllium Disk Adjacent to $\mathrm{Li}_{4} \mathrm{SiO}_{4}$ (Group I) after Polishing on $1-\mu \mathrm{m}$ Diamond.

B.1 Corrected Tritium Concentration and the Ion-Chamber Correction Factors Applied to the As-Measured Data for the Temperature-Change Canister in Phase II-A.

B.2 Ratio of Recovered/Generated Tritium and the Average Inner Temperature for the Temperature-Change Canister in Phase II-A.

B.3 Corrected Tritium Concentration and the Ion-Chamber Correction Factors Applied to the As-Measured Data for the Temperature-Change Canister in Phase II-B

B.4 Ratio of Recovered/Generated Tritium and the Average Inner Temperature for the Temperature-Change Canister in Phase II-B

B.5 Corrected Tritium Concentration and the Ion-Chamber Correction Factors Applied to the As-Measured Data for the Temperature-Change Canister in Phase II-C

B.6 Ratio of Recovered/Generated Tritium and the Average Inner Temperature for the Temperature-Change Canister in Phase II-C.

B.7 Corrected Tritium Concentration and the Ion-Chamber Correction Factors Applied to the As-Measured Data for the Temperature-Change Canister in Phase II-D

B.8 Ratio of Recovered/Generated Tritium and the Average Inner Temperature for the Temperature-Change Canister in Phase II-D

B.9 Corrected Tritium Concentration and the Ion-Chamber Correction Factors Applied to the As-Measured Data for the Temperature-Gradient Canister in Phase II-A

B.10 Ratio of Recovered/Generated Tritium and the Average Inner Temperature for the Temperature-Gradient Canister in Phase II-A

B.11 Corrected Tritium Concentration and the Ion-Chamber Correction Factors Applied to the As-Measured Data for the Temperature-Gradient Canister in Phase II-B.

B.12 Ratio of Recovered/Generated Tritium and the Average Inner Temperature for the Temperature-Gradient Canister in Phase II-B

B.13 Corrected Tritium Concentration and the Ion-Chamber Correction Factors Applied to the As-Measured Data for the Temperature-Gradient Canister in Phase II-C. 
B.14 Ratio of Recovered/Generated Tritium and the Average Inner Temperature for the Temperature-Gradient Canister in Phase II-C

B.15 Corrected Tritium Concentration and the Ion-Chamber Correction Factors Applied to the As-Measured Data for the Temperature-Gradient Canister in Phase II-D

B.16. Ratio of Recovered/Generated Tritium and the Average Inner Temperature for the Temperature-Gradient Canister in Phase II-D. 


\section{Figures}

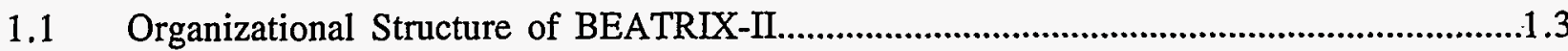

2.1 Schematic Diagram of the Temperature-Change Canister for Phase II...............................2.2

2.2. Temperature-Change Capsule with the Loaded Specimen, the backup" Specimen, and the Inner Perforated Tube Before Final Assembly ..........................................................

2.3. X-Ray Radiograph of the Temperature-Change Canister As-Fabricated .............................2.6

2.4 Schematic Diagram of the Temperature-Gradient Canister for

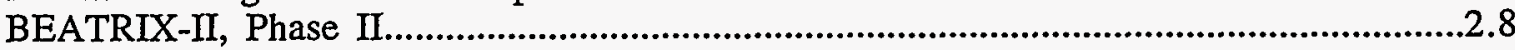

2.5. $\mathrm{Li}_{2} \mathrm{ZrO}_{3}$ Pebbles (a) As-Fabricated by AECL and (b) As-Loaded in the Temperature-Gradient Canister.

2.6. SEM Microstructure of a Fracture Surface for the $\mathrm{Li}_{2} \mathrm{ZrO}_{3}$ Pebbles As-Fabricated by AECL.

2.7. X-Ray Radiograph of the Temperature-Gradient Canister As-Fabricated...........................2.13

3.1. Diagram of the Sweep-Gas Stream from One of the In Situ Canisters.................................3.2

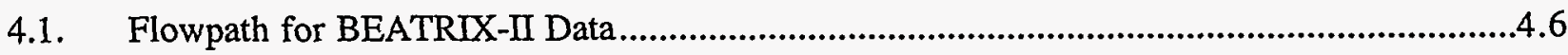

5.1. Inner Temperatures and Sweep-Gas Moisture for the First 550 Hours of Operation of the Temperature-Change Canister in Phase II-A

5.2. Tritium Recovery Peaks for a Temperature Change Series of $640-530-640^{\circ} \mathrm{C}$

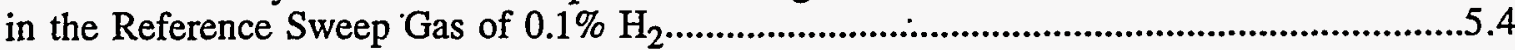

5.3. Progression of Tritium Recovery Peaks for a 550 to $640^{\circ} \mathrm{C}$ Temperature

Transient in Phase I Versus a 530 to $640^{\circ} \mathrm{C}$ Temperature Transient in Phase II.....................5.5

5.4. Tritium Recovery Curves for a Temperature Change from 530 to $640^{\circ} \mathrm{C}$ in the Three Different Sweep Gases: $0.1 \% \mathrm{H}_{2}, 0.01 \% \mathrm{H}_{2}$, and Helium.

5.5. Tritium-Recovery Peaks for Temperature Transient 530 to $640^{\circ} \mathrm{C}$ at $4,51,61$, 142,151 , and 200 EFPD

5.6. Tritium-Recovery Curves Measured at Temperatures of 640 and $530^{\circ} \mathrm{C}$ for the Gas-Composition Sequence of 4 Days in Helium Followed by 2 Days in $0.01 \% \mathrm{H}_{2} \ldots \ldots . . . . .5 .9$

5.7. Comparison of $640^{\circ} \mathrm{C}$ Tritium Recovery Curves for the Phase I and II Sweep-Gas Composition Sequences of 8 Days in Helium Followed by 2 Days in $0.01 \% \mathrm{H}_{2}$

5.8. Recovered-Tritium Concentration and Inner Specimen Temperature During Shutdown in Helium Sweep Gas....

5.9. Center Temperatures and Sweep-Gas Moisture for the Startup of the Phase II Temperature-Gradient Canister. 
5.10. Center Temperatures of the Phase II Temperature-Gradient Canister for the Four

Irradiation Cycles

5.11. Superposition of the Results of Three Tests in Helium for 2, 4, and 8 Days in Helium Sweep Gas, Preceded and Followed by $\mathrm{He}-0.1 \% \mathrm{H}_{2}$.

5.12. Superposition of the Results of Two Tests, One Using Helium and One Using $\mathrm{He}-0.01 \% \mathrm{H}_{2}$ Sweep Gas .

5.13. Recovered Tritium during Sweep- Gas Composition Changes for 4 Days in Helium Followed by 2 Days in $0.01 \% \mathrm{H}_{2}$ for the Temperature-Gradient Canister

5.14. Tritium Recovery Curve for a 1-Day Change to $1.0 \% \mathrm{H}_{2}$

5.15 Superposition of the Results of Two Tests, both. Using Helium Sweep Gas for 4 Days.

6.1. Neutron Radiograph of the Phase II -Temperature-Change Canister after Irradiation

6.2. Neutron Radiograph of the Phase II Temperature-Gradient Canister after Irradiation

6.3. Typical Specimen Fragments Removed from Different Axial Locations of the Phase II Temperature-Change Canister after Irradiation.

6.4. Ceramographic Cross Section from a Region near the Center of the Phase II Temperature-Change Specimen

6.5. SEM Micrographs from an Area near the Axial Center of the Phase II

Temperature-Change Specimen.

6.6. Comparison of the Tritium Recovered During the Phase II Shutdown with

Two Different Assumptions for the Tritium Generated.

6.7. Axial Location of the 11 Wafers Cut from the Impregnated $\mathrm{Li}_{2} \mathrm{ZrO}_{3}$ Pebble Bed

6.8. Cutting Diagram used to Divide the Wafers from the $\mathrm{Li}_{2} \mathrm{ZrO}_{3}$ Pebble Bed into $1.8-\mathrm{x} 1.8-\mathrm{mm}$ Sections

6.9. Tritium Inventory Measurements for the Sections from All Five Wafers

6.10. Histogram of Tritium Inventories Measured in the Three Radial Ranges,

1.15 to $2.95 \mathrm{~mm}, 2.95$ to $4.75 \mathrm{~mm}$, and 4.75 to $6.55 \mathrm{~mm}$

6.11. Polished Surface of the Unirradiated Archive $\mathrm{Li}_{2} \mathrm{ZrO}_{3}$ Pebble

6.12. Polished Surface of Section Through Two Pebbles of $\mathrm{Li}_{2} \mathrm{ZrO}_{3}$ Located near the Center of Pebble-Bed (Wafer G).

6.13. Fracture Surface from Wafer E near the Center of the Bed.

6.14. Fracture Surface of Center of Pebble in Wafer E, near the Edge (Radially) of the Bed. 


\section{Tables}

2.1. Description of BEATRIX-II, Phase II Ring Specimen ...........................................................

2.2. Predicted Thermal and Neutronic Performance of BEATRIX-II $\mathrm{Li}_{2} \mathrm{O}$ Ring

Specimen in FFTF/MOTA Cycle 12......................................................................................2.4

2.3. Predicted Thermal and Neutronic Performance of the BEATRIX-II $\mathrm{Li}_{2} \mathrm{ZrO}_{3}$

Pebble-Bed Temperature-Gradient Canister

3.1. Results for In Situ Calibration in $0.1 \% \mathrm{H}_{2}$ and Helium for the Ion Chamber on

the CEC Flow Stream from the Phase II Temperature-Change Canister

3.2. Hydrogen Enhancement Factors Determined from Test Series A2 for the

Temperature-Gradient Canister

4.1. Test Plan Overview for BEATRIX-II, Phase II, Temperature-Change Canister ........................4.2

4.2 Test Plan Overview for BEATRIX-II, Phase II, Temperature-Gradient Canister......................4.3

4.3. Prime Data Set for BEATRIX-II, Phase I...........................................................................

5.1. Predicted Amount of Tritium Generated Compared to Measured Amount Recovered ..........5.1

6.1. Amount of Lithium Found in the Analysis of Wash Solution from Selected

Components of the Phase I Temperature-Change Capsule.......................................................6.4

6.2. Wall Thickness Changes, Densities, and Porosities for the Postirradiation Phase II

Ring Specimen

6.3. Pre- and Postirradiation Percentages of ${ }^{6} \mathrm{Li}$ in the Phase II Temperature-Change

Specimen and the Resulting Lithium Burnup.

6.4. Measured Tritium Inventories for the Phase $\mathrm{I}$ and Phase II $\mathrm{Li}_{2} \mathrm{O}$ Temperature-Change Specimens.

6.5. Summary of Tritium Inventory Data...........................................................................16

6.6. Relative Ratio of Dominant XRD Peaks for an Irradiated Wafer ........................................6.18

6.7. Calculation of Lithium Burnups Based upon Pre- and Postirradiation Measurements of ${ }^{6} \mathrm{Li} \%$.

6.8. Tritium/Helium Retention in Single Crystals Irradiated in Phase I.......................................6.24

6.9. Lithium Burnup Calculated for the Tritium/Helium Retention Results for the Phase I Single Crystal

6.10 ${ }^{6} \mathrm{Li}$ Enrichments of the Lithium Ceramics in the Lithium Ceramic-Beryllium Compatibility Canisters.

6.11. Description of the Group I - V Lithium Ceramic-Beryllium Compatibility Capsules...........6.26 
6.12. Tritium/Helium Assay for Beryllium Disks in the BEATRIX-II Lithium Ceramic-Beryllium Compatibility Capsules.

B.1 Data Channels Selected for Final Compilation........................................................... B.2

B.2 Calculated Columns in the Data Compilation Spreadsheet.......................................... B.3 


\subsection{Introduction}

The BEATRIX-II (Breeder Exchange Matrix) program is an International Energy Agency (IEA) sponsored collaborative effort between Japan, Canada, and the United States conducted under ANNEX-III to the IEA Implementing Agreement on a Programmme of Research and Development on Radiation Damage in Fusion Materials. The purpose of the program was to evaluate the performance of ceramic solid-breeder materials in a fast-neutron environment at high burnup levels. The irradiation of selected solid breeder materials was carried out in the Fast Flux Test Facility (FFTF) operated by Westinghouse Hanford Company (WHC) at the Hanford Site near Richland, Washington. The Pacific Northwest National Laboratory (PNNL) ${ }^{(a)}$ together with the Japan Atomic Energy Research Institute (JAERD) and Atomic Energy of Canada, Limited (AECL) Research acted as experimenter.

\subsection{Objective}

The objective of the BEATRIX-II program was to design, fabricate, and conduct an irradiation experiment to evaluate the in situ recovery of tritium from solid-breeder materials during neutron irradiation. To accomplish this, the performance of selected candidate solid-breeder materials was continuously monitored with respect to temperature stability and tritium release, and after irradiation, the materials were examined to characterize the effect of the irradiation.

\subsection{Scope}

The BEATRIX-II program consisted of two Phases: 1) Phase I irradiation activities were carried out in Cycle 11 of FFTF between January 4, 1990, and March 20, 1991, for a total irradiation exposure of 300 effective full-power days (EFPD), and 2) Phase II irradiations were carried out between May 27, 1991, and March 19, 1992, for a total irradiation exposure of 203 EFPD.

The lithium burnups for both Phase I and Phase II were in the range of 4.5 to $6 \%$. Postirradiation examination of Phase I and II followed the irradiation periods.

\subsubsection{Phase I Scope}

The scope of the Phase I experiment included the irradiation of two $\mathrm{Li}_{2} \mathrm{O}$ in situ tritium recovery canisters: temperature-change and temperature-gradient. The temperature-change canister contained a $\mathrm{Li}_{2} \mathrm{O}$ ring specimen that had a nearly uniform temperature and was capable of temperature changes between 550 and $640^{\circ} \mathrm{C}$. The temperature-gradient canister contained a solid column of $\mathrm{Li}_{2} \mathrm{O}$ operating with a radial temperature difference of 440 to $1000^{\circ} \mathrm{C}$. The data obtained from the temperature-change canister are more useful for understanding the intrinsic behavior of the ceramic, and those from the temperature-gradient canister are more directly applicable to the performance of $\mathrm{Li}_{2} \mathrm{O}$ in a fusion-blanket environment. Nonvented capsules were included to determine the mechanisms of radiation damage in single crystals and the compatibility of beryllium with solid-breeder materials.

\subsubsection{Phase II Scope}

The scope of the Phase II experiment also included the irradiation of two in situ tritiumrecovery canisters: a temperature-change canister containing a $\mathrm{Li}_{2} \mathrm{O}$ ring specimen and a

(a) Pacific Northwest National Laboratory (previous name was Pacific Northwest Laboratory) is operated for the U. S. Department of Energy (DOE) by Battelle under Contract DE-AC06-76RL0 1830. 
temperature-gradient canister containing a solid $\mathrm{Li}_{2} \mathrm{ZrO}_{3}$ pebble-bed specimen composed of 1 -mm pebbles. To achieve the desired burnup in Phase II, the ${ }^{6} \mathrm{Li}$ enrichment was higher than Phase I for both specimens, and the canister containing the $\mathrm{Li}_{2} \mathrm{ZrO}_{3}$ pebble-bed specimen was located in a higher fluence position. Nonvented capsules included selected beryllium-lithium ceramic compatibility specimens from Phase I.

\subsection{Responsibilities}

The BEATRIX-II program involved contributors from a wide range of organizations. The organization of the program is diagrammed in Figure 1.1. The IEA Executive Committee had the overall responsibility for approving and signing the ANNEX-III. The BEATRIX-II Working Group was a technical steering committee responsible for the preparation and supervision of budgets, schedules, and scientific activities. Each of the participating countries is represented in the working group. The original working group members were $\mathrm{H}$. Watanabe (JAERD), I. J. Hastings (AECL), and S. E. Berk (DOE). During the operation of the experiment, the JAERI and AECL representatives changed and are currently K. Noda and R. A. Verrall, respectively. The operating agent for the experiment is DOE, who is responsible for executing the program. The DOE person originally responsible for this interaction was T. C. Reuther (retired); he was replaced by R. E. Price. The BEATRIX-II Task Manager, G. W. Hollenberg (PNNL), coordinated the operation of the experiment following the guidance of the working group and the operating agent.

The operation of the experiment was carried out by WHC with oversight by the BEATRIX-II Experimenters. The operations at the reactor site were conducted by D. E. Baker, D. A. King, and the reactor operations personnel of FFTF under the cognizance of R. J. Puigh. Major contributors to the design and fabrication of the experiment at WHC were D. E. Baker, M. M. Paxton, R. W. Truitt, R. E. Bauer, R. C. Knight, and R. D. Redekop. J. Miller (AECL) played a major role in developing and fabricating the ionization chambers (hereafter referred to as ion chambers) and the tritium-removal system. T. Takahashi (JAERI) and J. D. Sullivan (AECL) fabricated the lithium ceramic specimens for the Phase II in situ tritium-recovery canisters.

Technical planning and data analysis were carried out by the BEATRIX-II Experimenters: O. D. Slagle (PNNL), T. Kurasawa (JAERD), and R. A. Verrall (AECL). The BEATRIX-II experimenters for the postirradiation examination were O. D. Slagle (PNNL), T. Takahashi, K. Noda , T. Tanafugi, and N. M. Masaki (JAERI), and R. A. Verrall (AECL).

\subsection{Report .Scope}

This report specifically addresses the BEATRIX-II, Phase II experiment and not Phase I. It includes a description of

- the specimens/canisters

- the operation of the experiment in the FFTF

- $\quad$ the in situ tritium-recovery results

- the Phase II postirradiation examination, which included

- $\quad$ the Phase II in situ canisters

- the lithium ceramic-beryllium compatibility capsules irradiated in Phase I and II

- $\quad$ the Phase I single-crystal capsules (completing the examination).

Details of the Phase I specimen matrix and experiment operation are given in the Phase I Data Summary Report (Slagle and Hollenberg 1994), 


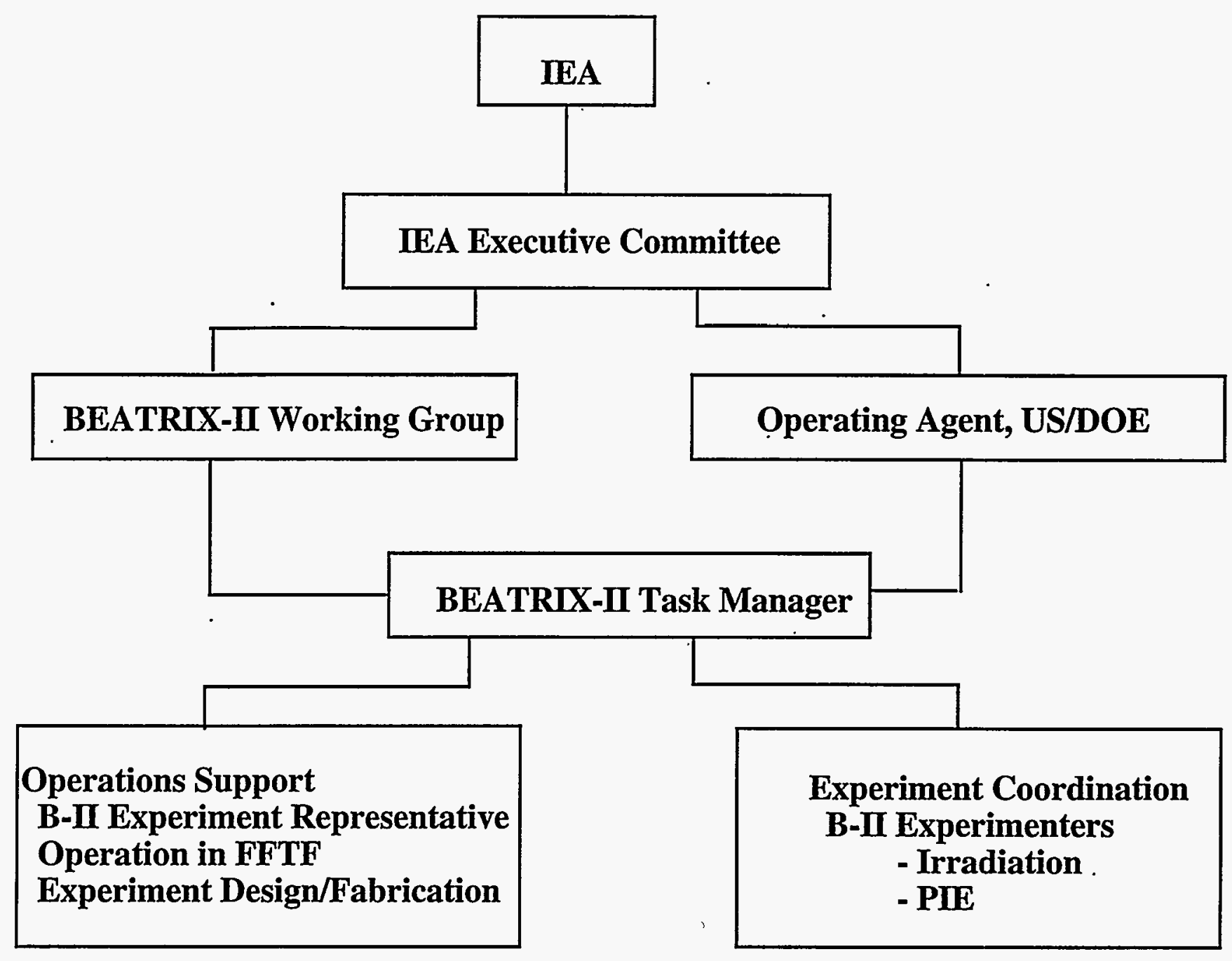

Figure 1.1. Organizational Structure of BEATRIX-I 



\subsection{Specimen/Canister Matrix}

Phase II of the BEATRIX-II in situ tritium-recovery experiment contained a $\mathrm{Li}_{2} \mathrm{O}$ ring specimen and $\mathrm{Li}_{2} \mathrm{ZrO}_{3}$ solid specimen, the latter in the form of $1-\mathrm{mm}$ pebbles. The Phase $\mathrm{I} \mathrm{Li}_{2} \mathrm{O}$ ring specimen had been prepared in the United States, but the ring specimen for Phase II was prepared in Japan. Improved fabrication techniques. were used to give a higher density, larger grain size material that would allow fabrication of a ring specimen with a thinner wall. The alternative ternary breeder material most suitable for additional characterization was determined to be $\mathrm{Li}_{2} \mathrm{ZrO}_{3}$. In previous vented (Briec et al. 1988) and nonvented (Hollenberg and Baldwin 1985; Slagle et al. 1991) tests, $\mathrm{L}_{2} \mathrm{ZrO}_{3}$ had been found to be dimensionally and chemically stable during irradiations and to have relatively short tritium-residence times. The material used was 1 - to 1.5 -mm-diameter $\mathrm{Li}_{2} \mathrm{ZrO}_{3}$ pebbles prepared by AECL Research.

\subsection{Temperature-Change Canister}

The Phase II temperature-change canister was nearly identical to the Phase I temperaturechange canister. The primary emphasis in establishing the Phase II design was to achieve a higher lithium burnup and to lower the minimum specimen temperature. These requirements together with other improvements identified during the operation of Phase I presented challenges to the designers.

\subsubsection{Thermal Design}

The design requirements for the Phase II temperature-change specimen extended those for Phase I and included considerations such as the sensitivity of tritium measurements, minimizing the loss of tritium to the reactor, and the temperature of the specimen. A major change in the requirements was an increase in the end-of-life lithium burnup. This increase in burnup rate was partially achieved by increasing the ${ }^{6} \mathrm{Li}$ enrichment from 61 to 95 at $\%$.

The design objectives of Phase II were to achieve temperatures in the range from 450 to $650^{\circ} \mathrm{C}$. The pre-test thermal analysis for the Phase I design had predicted temperatures in the range from 468 to $645^{\circ} \mathrm{C}$. The temperatures, however, were in the range from 510 to $680^{\circ} \mathrm{C}$. These higher temperatures were attributed to the existence of larger-than-expected gaps between the capsule and the specimen wall and a lower specimen density (Slagle and Hollenberg 1994). Achieving lower temperatures for the ring specimen was given a high priority in Phase $\Pi$.

Figure 2.1 is a schematic diagram of a cross section of the temperature-change canister for Phase II. The tritium sweep gas entered at the bottom end of the canister, flowed along the inner diameter of the specimen, and exited out of the upper plenum. A perforated inner stainless steel sleeve ensured that if the specimen should fracture during testing, the cylindrical geometry would be maintained. This sleeve also positioned the two inner thermocouples. In Phase I, this inner sleeve was fabricated from a nickel screen, but a stainless steel tube was chosen for Phase II to reduce the types of metal surfaces interacting with the sweep gas. This simplification reduces the number of surface reactions that must be taken into account in the data interpretation. The temperature in the specimen is controlled by varying the conductance of the thermal gap of the canister by adjusting the composition of the argon-helium gas in the gap. A computer-controlled gas-blending system allows temperature control continuously throughout the 300-day irradiation.

A major goal of Phase II was to achieve temperatures as low as possible for the ring specimen. The following design changes were made to the Phase I design to achieve the lower temperatures: 
1. The wall thickness of the ring specimen was decreased from $0.15 \mathrm{~cm}$ in Phase $I$ to $0.10 \mathrm{~cm}$ in Phase II, and the specimen density was increased from $80 \%$ theoretical density (TD) for Phase I to $85 \%$ for Phase II. The heating rate in the Phase II specimen was kept constant by keeping the total amount of ${ }^{6} \mathrm{Li}$ approximately constant. A reduction in wall thickness resulted in a smaller volume of $\mathrm{Li}_{2} \mathrm{O}$ and compensated for the increase in ${ }^{6} \mathrm{Li}$ enrichment. The higher density increased the thermal conductivity. Both of these changes should reduce the temperature drop across the specimen.

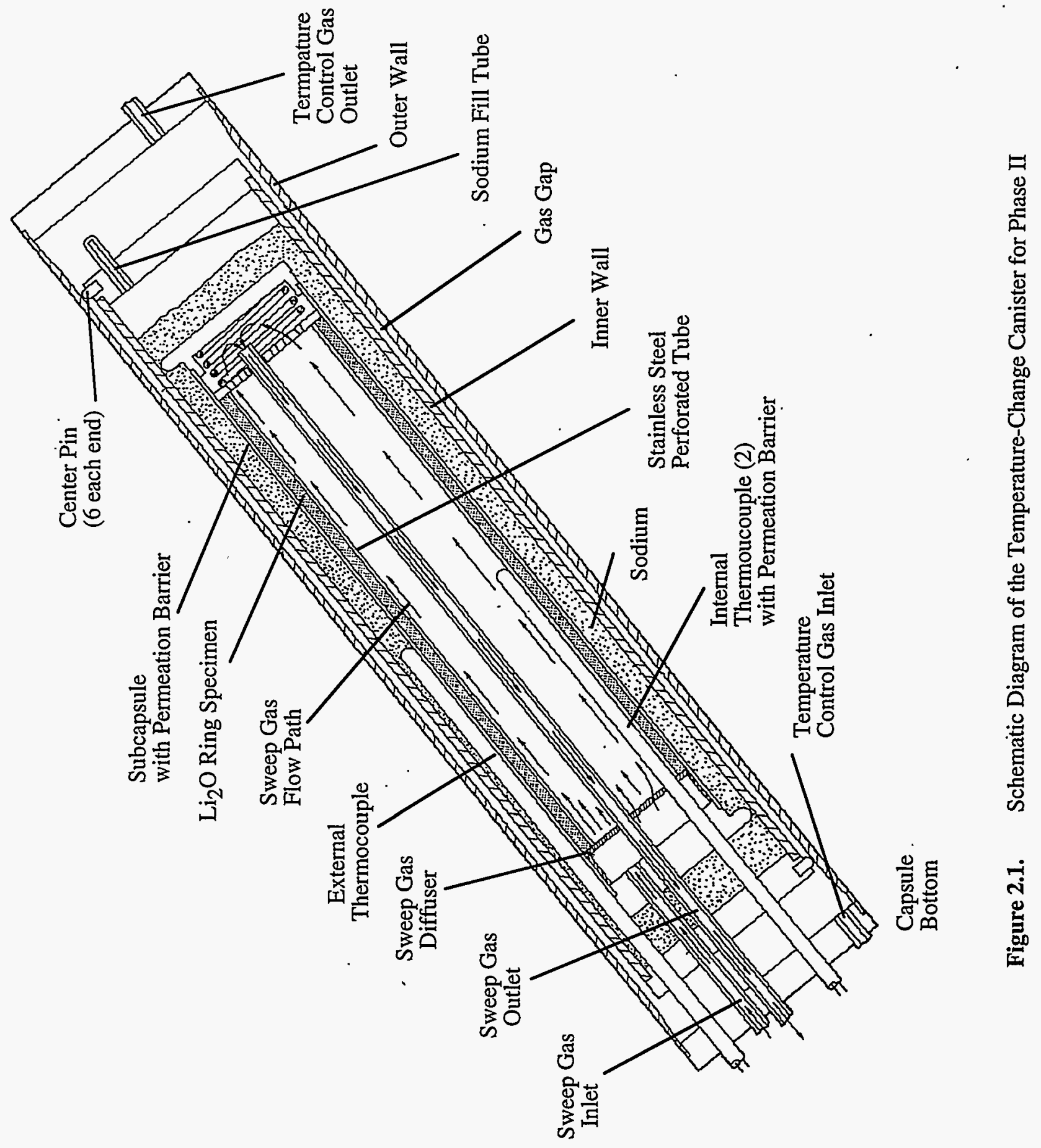


2. The specimen-capsule gap was minimized by placing a closer tolerance on the specimen outer diameter. The previous tolerance of $0.013 \mathrm{~cm}$ was reduced to $0.005 \mathrm{~cm}$. The inner diameter of the capsule was machined $0.010 \mathrm{~cm}$ larger than the largest specimen diameter. This radial gap $(0.005 \mathrm{~cm})$ is predicted to ensure closure at $500^{\circ} \mathrm{C}$. Final machining on the capsule was done to fit the as-fabricated specimen. This design change required that the tritium-barrier coating not be applied to the inner diameter of the canister.

3. The inner nickel liner used previously as a compatibility barrier between the specimen and the capsule was removed. This eliminated the possibility that the nickel liner would separate from the capsule and form a thermal gap. The expected interaction of the specimen and the 316 stainless steel subcapsule wall was estimated to be 2 to $10 \mu \mathrm{m}$ of general surface corrosion and possibly $25 \mu \mathrm{m}$ of intergranular attack (Porter et al. 1984).

\subsubsection{Specimen Fabrication/Loading}

A description of the final Phase II ring specimen is given in Table 2.1. The Phase II ring specimen was a single section of tube, $8.85 \mathrm{~cm}$ long in contrast to the Phase I specimen, which consisted of two sections. The final density was $87.3 \% \mathrm{TD}$ with a grain size of $22 \mu \mathrm{m}$. The variation in diameter along the specimen was $0.003 \mathrm{~cm}$, which is within the specified range of $0.005 \mathrm{~cm}$. The wall thickness was $0.10 \mathrm{~cm}$, as specified.

Table 2.1. Description of BEATRIX-II, Phase II Ring Specimen Phase II Ring Specimen

${ }^{6}$ Li Enrichment
Outer Diameter
Inner Diameter
Straightness
Wall Thickness
Length
Weight
Density
Grain Size

95 at $\%$
1.850 to $1.853 \mathrm{~cm}$
1.651 to $1.653 \mathrm{~cm}$
$0.003 \mathrm{~cm}$
$0.100 \mathrm{~cm}$
$8.850 \mathrm{~cm}$
$8.103 \mathrm{~g}$
$87.3 \% \mathrm{TD}$
$22 \mu \mathrm{m}$

The $\mathrm{Li}_{2} \mathrm{O}$ used to fabricate the ring specimen was prepared by decomposing 95 at $\%{ }^{6} \mathrm{Li}$ enriched $\mathrm{Li}_{2} \mathrm{CO}_{3}$ to a $\mathrm{Li}_{2} \mathrm{O}$ powder. The powder preparations and sintering procedures were similar to those used for preparing the temperature-gradient specimen in Phase I (Slagle et al. 1990; Takahashi and Watanabe 1989). The $\mathrm{Li}_{2} \mathrm{CO}_{3}$ powder was decomposed to the oxide by heating to $700^{\circ} \mathrm{C}$ in a vacuum of $6 \times 10^{-2} \mathrm{~Pa}$ in the initial stage and to $5 \times 10^{-5} \mathrm{~Pa}$ in the final stage. The ring specimen was fabricated by sintering a cylindrical-shaped compact from which the final specimen was machined. The compact was formed by isostatic pressing at $200 \mathrm{MPa}$ and sintering at $1170^{\circ} \mathrm{C}$ for 8 hours. The as-sintered compact was a $2.1-\mathrm{cm}$-diameter cylinder with a $1.15-\mathrm{cm}$ inner annulus and a length of $9.43 \mathrm{~cm}$.. A "rock lathe" was used to machine the final thin-walled specimen in an atmosphere of dry air. Because of the inherently fragile nature of the thin-ring specimen, a second specimen of the same dimensions was also prepared to serve as a backup.

Figure 2.2 shows the capsule with the specimen in place, the "backup" specimen, and the inner perforated sleeve before final loading. The specimen slid easily into the capsule, which had an inner diameter of $1.863 \mathrm{~cm}$ or a $0.010-\mathrm{cm}$ diametral gap. The inner sleeve was a perforated stainless steel tube. Stainless steel was used to minimize the types of metal surfaces interacting with the purge 
gas. A perforated tube was chosen over the screen used in Phase I because the tube was a more rigid structure and allowed a more definite positioning of the thermocouples than the screen.

Figure 2.3 is an x-ray radiograph of the capsule after loading. This radiograph shows clearly the configuration of the different components. The positioning of the inner thermocouples in the slots provided by the inner sleeve can be seen. The assembly shown in Figure 2.3 was thermally bonded with sodium inside the gas-gaped thermally controlled canister. The sodium also serves to minimize axial temperature gradients. The thermocouple in the center of the radiograph is the outer . thermocouple, which measures the temperature in the sodium used as a thermal contact.

\subsubsection{Predicted Performance}

The thermal and neutronic performance of the ring specimen was calculated on the basis of the expected neutron flux in the materials open test assembly (MOTA) Cycle 12, and the heat generation in the $\mathrm{Li}_{2} \mathrm{O}$ ring specimen $(110 \mathrm{~W} / \mathrm{g})$. Using this heat generation rate, the specimen temperatures were calculated for two different control gases in the canister temperature-control gap. The results are summarized in Table 2.2. The minimum temperatures were calculated for $100 \% \mathrm{He}$, and the temperature range across the specimen was determined to be 485 to $503^{\circ} \mathrm{C}$. These temperatures were substantially less than the temperatures achieved in Phase I, which were 500 to $540^{\circ} \mathrm{C}$ across the specimen. The upper temperature in the Phase I test matrix was $650^{\circ} \mathrm{C}$, and this temperature was found to be achievable with a 1:7 ratio of He:Ar temperature-control gas. The total tritium generation for $203 \mathrm{EFPD}$ was predicted to be $850 \mathrm{Ci}$. This corresponds to a $5.3 \%$ burnup in the total lithium.

\subsection{Temperature-Gradient Canister}

The $\mathrm{Li}_{2} \mathrm{ZrO}_{3}$ specimen in the Phase II temperature-gradient canister was a pebble bed composed of 1-mm particles. This "solid" specimen with its inherent temperature gradient is similar to the $\mathrm{Li}_{2} \mathrm{O}$ specimen used in Phase I and provides a comparison for evaluating the relative merits of the two materials. The diameters of the $\mathrm{Li}_{2} \mathrm{ZrO}_{3}$ pebbles were specified to be in the range from 1 to $1.5 \mathrm{~mm}$ with a ${ }^{6} \mathrm{Li}$ enrichment of 85 at $\%$ and were provided by AECL Research.

Table 2.2. Predicted Thermal and Neutronic Performance of BEATRIX-II Li2 2 O Ring Specimen in FFTF/MOTA Cycle 12

$\begin{array}{ll}\text { Thermal Heat Generation } & 110 \mathrm{~W} / \mathrm{gm} \\ \text { Specimen-Capsule Diametral Gap } & 0.005 \mathrm{~cm} \\ \text { Specimen Minimum Temperature (100\% He) } & \\ \text { Outer Diameter } & 485^{\circ} \mathrm{C} \\ \text { Inner Diameter } & 503^{\circ} \mathrm{C} \\ \text { Specimen Maximum Temperature }(1: 7, \mathrm{He}: \mathrm{Ar}) & \\ \quad \begin{array}{l}\text { Outer Diameter } \\ \text { Inner Diameter }\end{array} & 632^{\circ} \mathrm{C} \\ \end{array}$

During the initial stages of planning, a temperature-change canister using a ring-type specimen was considered. However, the low thermal conductivity of a lithium zirconate pebble bed resulted in a calculated thermal difference across the ring that was on the order of $100^{\circ} \mathrm{C}$ for a ring with a wall thickness equal to a pebble diameter. Such a large temperature difference limits the usefulness of a temperature-change canister, and a temperature-gradient canister was chosen. The low thermal conductivity of the pebble bed also placed restraints on the maximum diameter of the "solid" specimen in the temperature-gradient canister. 


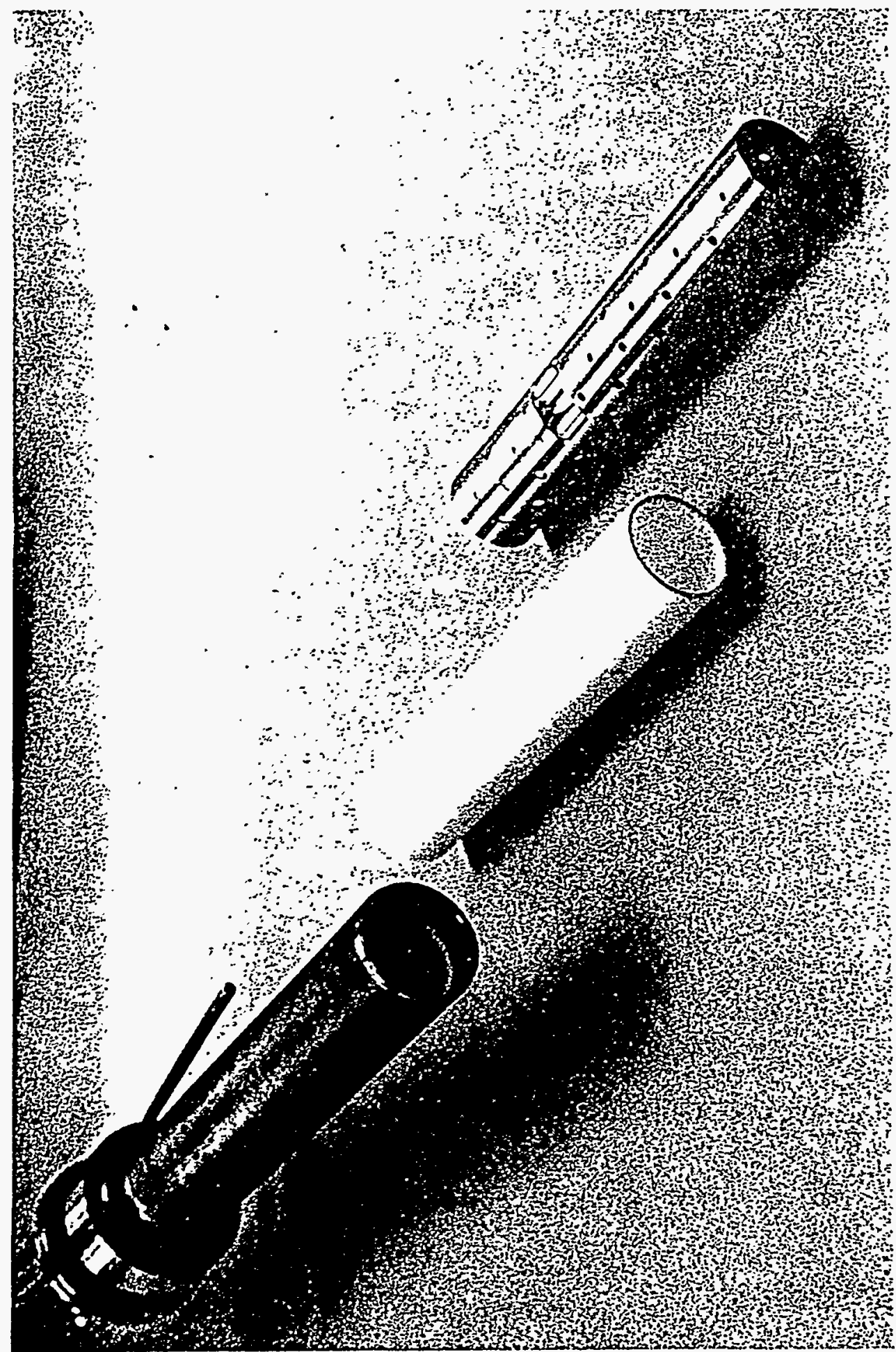

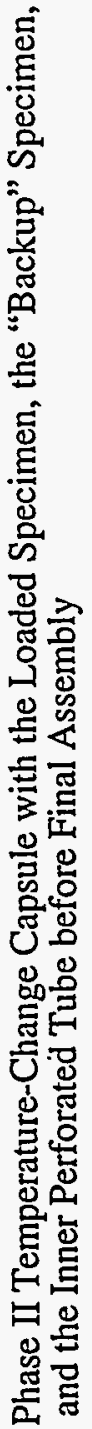

弪 


\subsubsection{Design Requirements}

The desired centerline temperature in the pebble bed was in the range from 1000 to $1200^{\circ} \mathrm{C}$. These limits were chosen based on the desire to obtain data at temperatures as high as possible without changing the microstructure of the lithium zirconate. Confirming the reliability of the solid breeder material over a broad range of temperatures minimizes the design restrictions imposed in the future when actual blanket designs are being considered. Achieving these temperatures was dependent on the neutron environment and the diameter of the pebble bed or capsule.

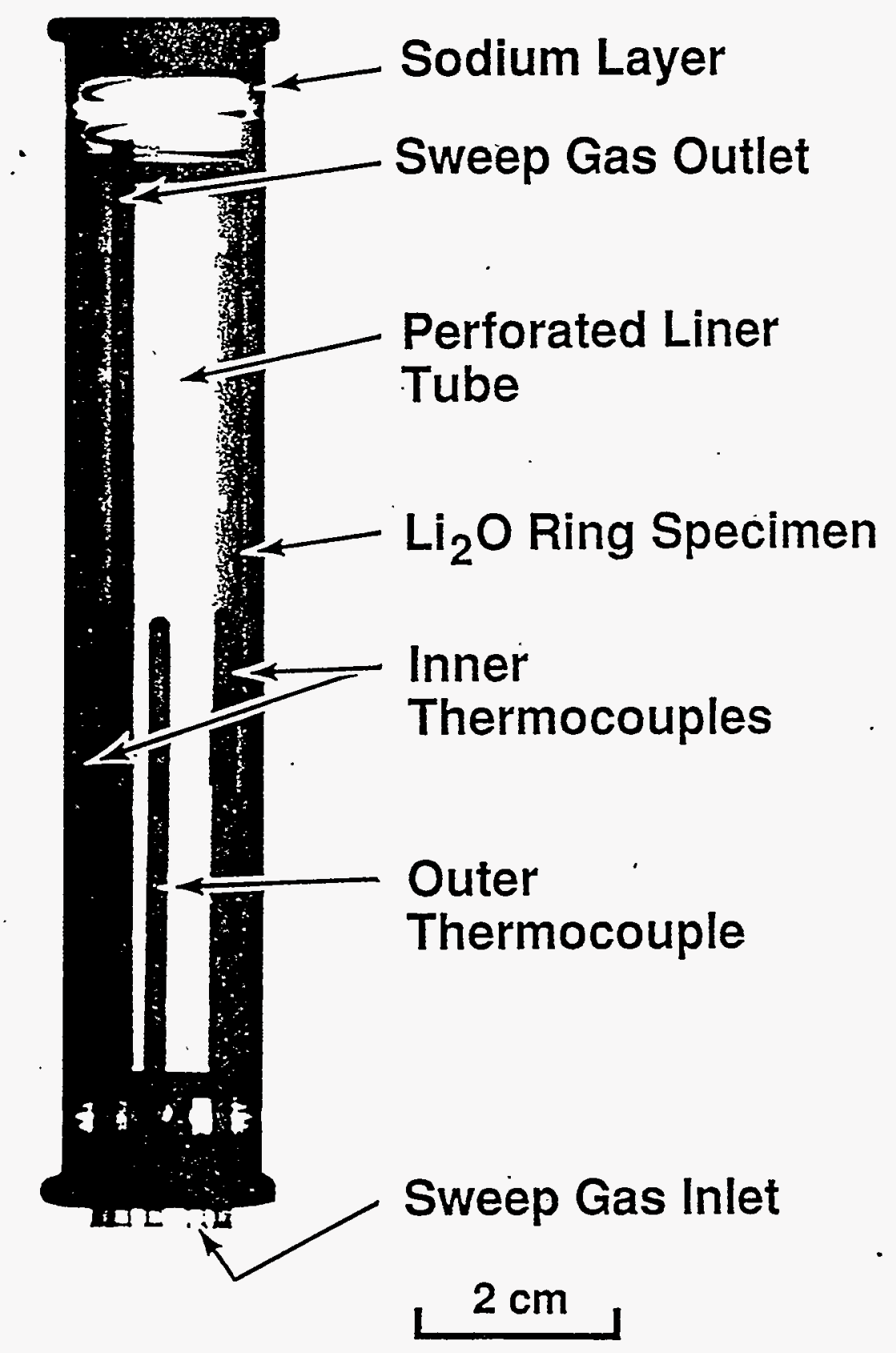

Figure 2.3. X-Ray Radiograph of the Temperature-Change Canister As-Fabricated 
A total tritium generation of $650 \mathrm{Ci}$ for the $203 \mathrm{EFPD}$ cycle was desired to achieve tritium concentration levels compatible with the flow rates and ion chambers currently being used in the tritium measurement system. Because of the lower lithium density in $\mathrm{Li}_{2} \mathrm{ZrO}_{3}$ relative to $\mathrm{Li}_{2} \mathrm{O}$, the temperature-gradient canister was placed in a higher flux position, nearer the center of the reactor core than the temperature-change canister, to increase the tritium production rate.

\subsubsection{Canister Design}

The design of the temperature-gradient canister is shown schematically in Figure 2.4. The $\mathrm{Li}_{2} \mathrm{ZrO}_{3}$ pebble bed was contained in a stainless steel capsule between porous nickel screens at either end. The porous nickel screens allow the passage of sweep gas into and out of the bed. A high temperature spring was used to hold the pebble bed in place, especially during handling operations before loading the MOTA into the reactor. The spring was designed to withstand the $600^{\circ} \mathrm{C}$ outgassing of the canister before irradiation. A center tube was used for inserting the thermocouple into the centerline of the specimen after the pebble bed had been loaded to the required density by vibrating.

A type $\mathrm{K}$ thermocouple was chosen for one of the thermocouples with an alternative, higher temperature thermocouple for the other end of the canister. Type $K$ thermocouples have performed well up to fluences equivalent to 300 EFPD in FFTF, but have a limited lifetime as temperatures approach and exceed $1200^{\circ} \mathrm{C}$. A Nb-1\% $\mathrm{Zr} / \mathrm{Mo}$ thermocouple was under development at WHC and appeared to offer good stability in a neutron field plus reliability at the higher temperatures.

Irradiation testing of this thermocouple has been described by Knight and Greenslade (1991). As the alternative thermocouple for the solid specimen canister, the operation of Phase II provided additional confirmation of the suitability of this thermocouple for high-temperature applications in a high-fluence neutron environment.

\subsubsection{Calculated Performance}

From the predicted heat generation and the thermal conductivity of the pebble bed, a pebble bed diameter was determined that would result in the desired centerline temperatures. The specimen parameters and the resulting operational predictions are given in Table 2.3. The thermal conductivity of the individual $\mathrm{Li}_{2} \mathrm{ZrO}_{3}$ pebbles $\left(\mathrm{k}_{\text {sphere }}\right)$ was taken from the data for $80 \%$ TD polycrystalline $\mathrm{Li}_{2} \mathrm{ZrO}_{3}$ obtained by Hollenberg and Baker (1982) and Kennedy et al. (1986). The data were interpolated to the anticipated experimental conditions using the expression of Billone et al. (1993). 


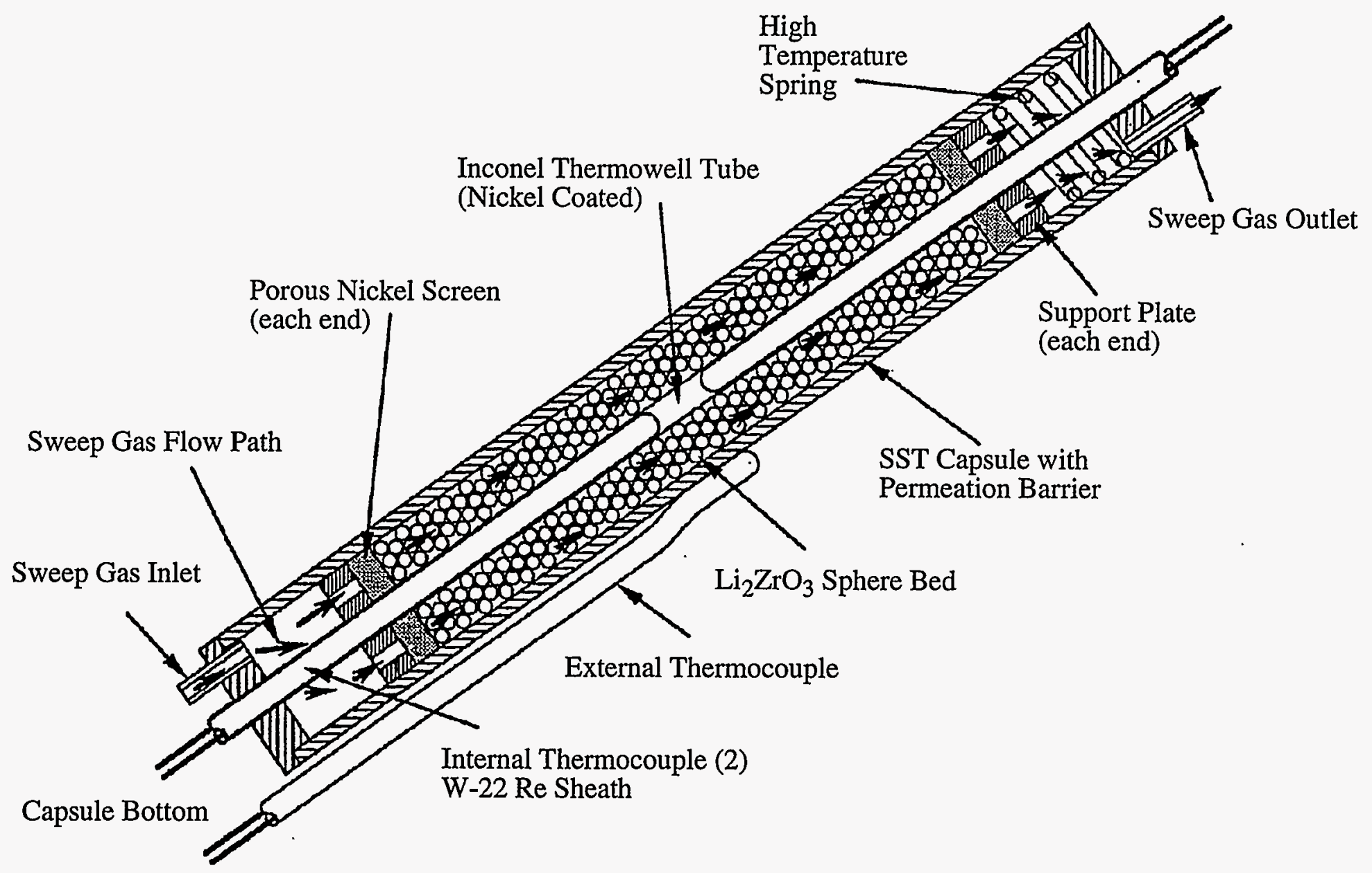

Figure 2.4. Schematic Diagram of the Temperature-Gradient Canister for BEATRIX-II, Phase II 
Table 2.3. Predicted Thermal and Neutronic Performance of the BEATRIX-II $\mathrm{Li}_{2} \mathrm{ZrO}_{3}$ Pebble-Bed Temperature-Gradient Canister

Thermal Heat Generation

Properties of the Pebble Bed

Pebble Diameter

6Li Enrichment

Pebble Matrix Density

Pebble Packing Density

Outer Diameter

Inner Diameter

Specimen Length

Specimen Centerline Temperature

Tritium Generation (203 EFPD)

Total Lithium Burnup

\section{$27.3 \mathrm{~W} / \mathrm{gm}$}

1 to $1.5 \mathrm{~mm}$

85 at \%

$80 \%$ TD

$60 \%$ TD

$1.32 \mathrm{~cm}$

$0.23 \mathrm{~cm}$

$10.34 \mathrm{~cm}$

$1095 \pm 65^{\circ} \mathrm{C}$

$560 \mathrm{Ci}$

6.0 Atom \%

$$
\mathrm{k}_{\text {sphere }}=(1-\mathrm{p})^{5 / 3}\left(\frac{3.643}{(1+0.001549 \mathrm{~T})}+7.579 \times 10^{-10} \mathrm{~T}^{3}\right)
$$

where $\mathrm{p}$ is the fractional porosity of the pebbles, in this case $20 \%$, and $\mathrm{T}$ is temperature. The thermal conductivity of the predominantly helium sweep gas was calculated from the following expression from Gandhi and Saxena (1968):

$$
k_{g}=3.36 \times 10^{-3} \mathrm{~T}^{0.688}
$$

Packing tests were performed using a plexiglas model of the capsule, employing both steel and zirconia spheres. It was found that both sphere types packed to a packing fraction of $60 \%$ in this geometry.

The thermal conductivities of the packed bed were calculated using the model proposed by Hall and Martin (1981). The results of these calculations indicated that for a canister inner diameter of $33.5 \mathrm{~mm}$, a centerline temperature of $1095 \pm 65^{\circ} \mathrm{C}$ would be expected. The uncertainties include both thermal conductivity and neutronic heating.

The calculated tritium generation for the temperature-gradient canister during the 300 EFPD cycle was $828 \mathrm{Ci}$. This tritium production was less than one-fourth the tritium generated in the Phase I $\mathrm{Li}_{2} \mathrm{O}$ solid specimen. The factors tending to increase the tritium production, such as higher neutron flux and ${ }^{6} \mathrm{Li}$ enrichment, were not sufficient to offset the smaller volume and lower lithium density in the $\mathrm{Li}_{2} \mathrm{ZrO}_{3}$ pebble bed. However, the tritium generation rate was only slightly less than that of the temperature-change capsule, and it was adequate to allow characterization of the tritium recovery from the temperature-gradient canister during the Phase II irradiation.

\subsubsection{Specimen Fabrication/Loading}

The $\mathrm{Li}_{2} \mathrm{ZrO}_{3}$ pebbles are shown in Figure 2.5(a) as received from AECL Research before loading. The diameters of the slightly nonspherical $\mathrm{Li}_{2} \mathrm{ZrO}_{3}$ pebbles fell approximately in the range of 1 to $1.5 \mathrm{~mm}$ with a nominal diameter of $1.2 \mathrm{~mm}$. Figure $2.5(\mathrm{~b})$ shows the top of the pebble bed as loaded into the temperature-gradient canister. This view gives an indication of the pebble diameters 


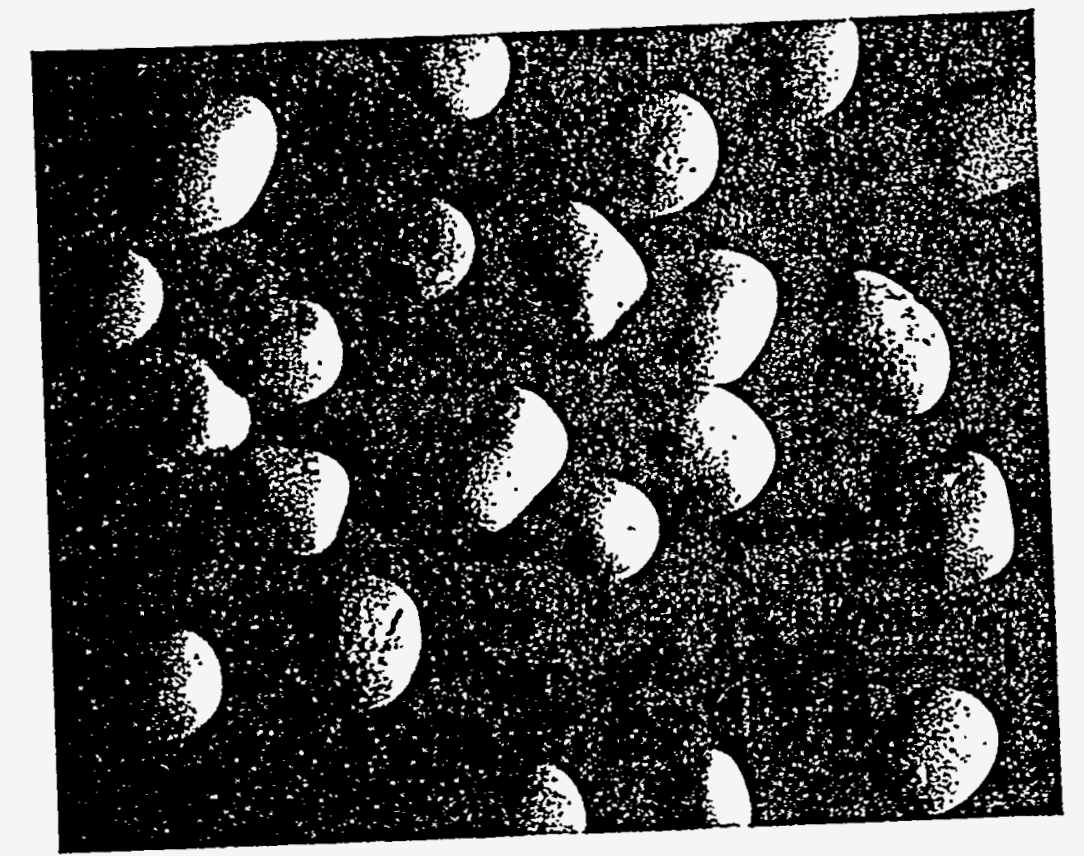

(a)

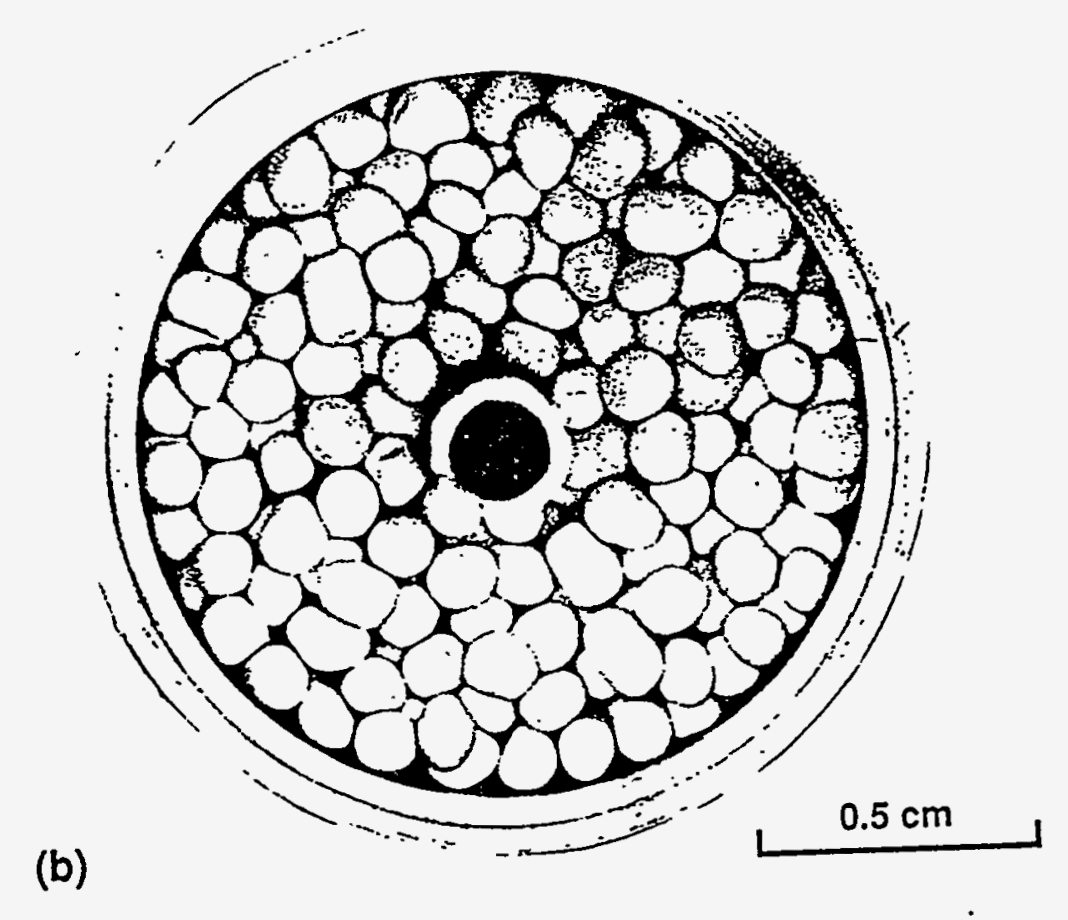

Figure 2.5. . $\mathrm{Li}_{2} \mathrm{ZrO} 3$ Pebbles (a) As-Fabricated by AECL and (b) As-Loaded in the Temperature-Gradient Canister 
relative to the capsule dimensions. 'The center tube is the thermal well into which the upper thermocouple was inserted to complete the assembly.

The pebble porosity was characterized by a mercury porosimeter analysis. The density of the individual pebbles was 80 to $82 \% \mathrm{TD}$, indicating a total porosity of 18 to $20 \%$. Approximately $4.5 \%$ of the porosity was closed. Open porosity was found to be in the range of 0.03 to $2.0 \mu \mathrm{m}$. Two scanning electron microscope (SEM) microstructures (see Figure 2.6) of a fracture surface in an individual $\mathrm{Li}_{2} \mathrm{ZrO}_{3}$ pebble indicates that the grain size was approximately $10 \mu \mathrm{m}$ with an intergranular porosity consistent with the $2-\mu \mathrm{m}$ upper limit determined from the porosimetry results.

The capsule was loaded by vibrating $29.47 \mathrm{~g}$ of pebbles into a volume of $13.75 \mathrm{~cm}^{3}$. The resultant density was $2.143 \mathrm{~g} / \mathrm{cm}^{3}$ indicating a packing density of $63 \%$. The density of the individual pebbles was $82 \% \mathrm{TD}\left(\mathrm{TD}=4.112 \mathrm{~g} / \mathrm{cm}^{3}\right)$. The higher density of $\mathrm{Li}_{2} \mathrm{ZrO}_{3}$ in the capsule compared to the design density was predicted to not significantly change the resulting temperature distribution. The increase in heat generation from the higher ${ }^{6} \mathrm{Li}$ loading was offset by the anticipated increase in thermal conductivity. The centerline temperatures observed during the irradiation testing served as a check on the effect of this increased packing density and on the assumptions made in the design calculations.

Figure 2.7 is an x-ray radiograph of the final assembled canister. The pebble-bed nature of the specimen and the size of the pebbles relative to the total pebble-bed dimension can be seen. Because of the small size and brittle nature of the W-Re thermocouple sheath, the alignment of the thermocouples relative to the end caps was a very critical operation to ensure that the thermocouple sheathes remained intact during assembly.

For the temperature-gradient canister, the diameter of the specimen was constrained by the comparatively low thermal conductivity of the $\mathrm{Li}_{2} \mathrm{ZrO}_{3}$ pebble bed together with the maximum temperature limit. These constraints resulted in the volume of the temperature-gradient specimen being nearly half that of the $\mathrm{Li}_{2} \mathrm{O}$ specimen in Phase $\mathrm{I}$. This smaller volume, together with the lower lithium density in $\mathrm{Li}_{2} \mathrm{ZrO}_{3}$ pebble bed results in a predicted tritium generation rate that was only $25 \%$ of the rate for the Phase I temperature-gradient canister. However, the predicted tritium generation rate was more than adequate to allow characterization of the tritium recovery during the Phase II irradiations. 

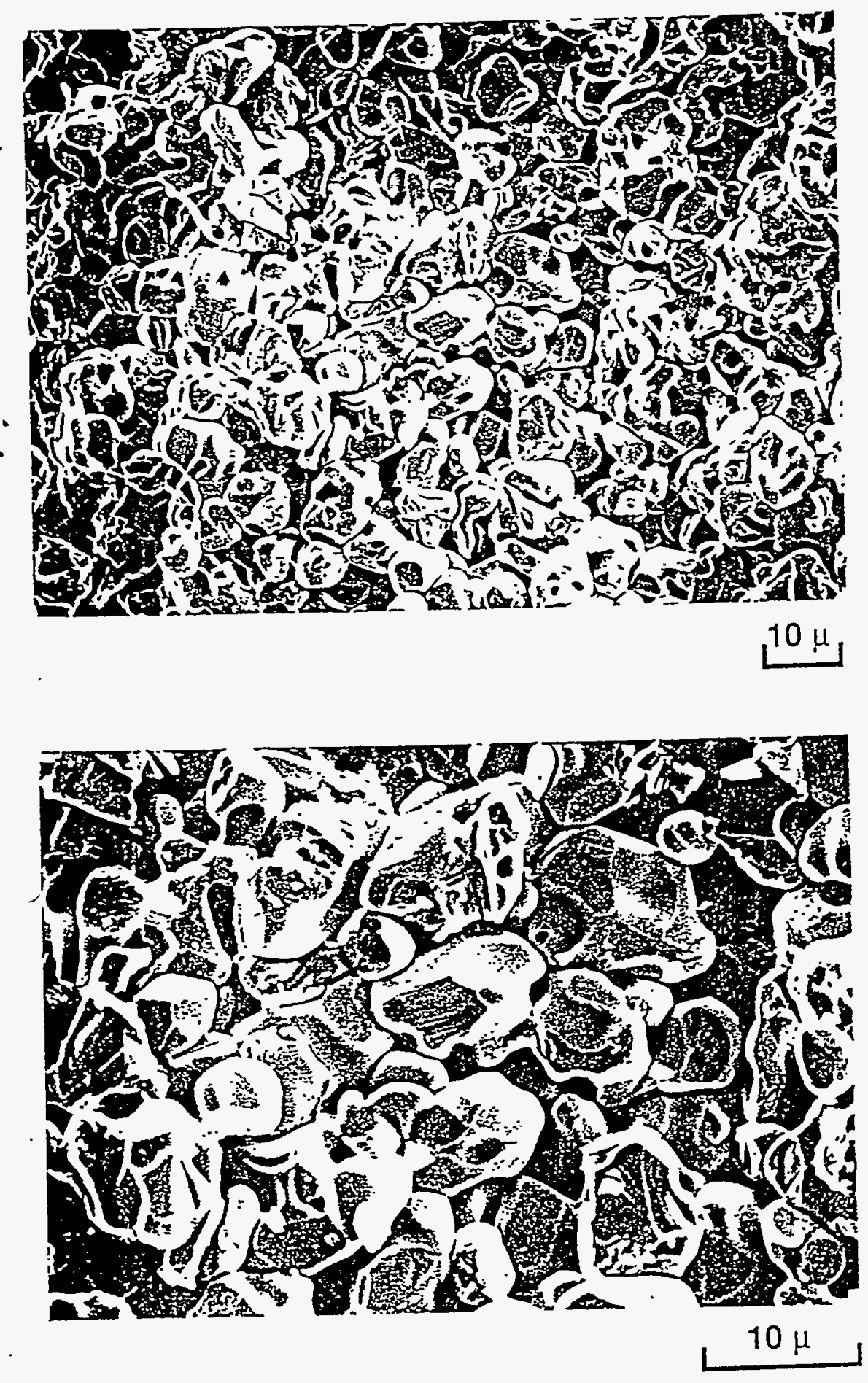

Figure 2.6. SEM Microstructure of a Fracture Surface for the $\mathrm{Li}_{2} \mathrm{ZrO}_{3}$ Pebbles As-Fabricated by AECL 


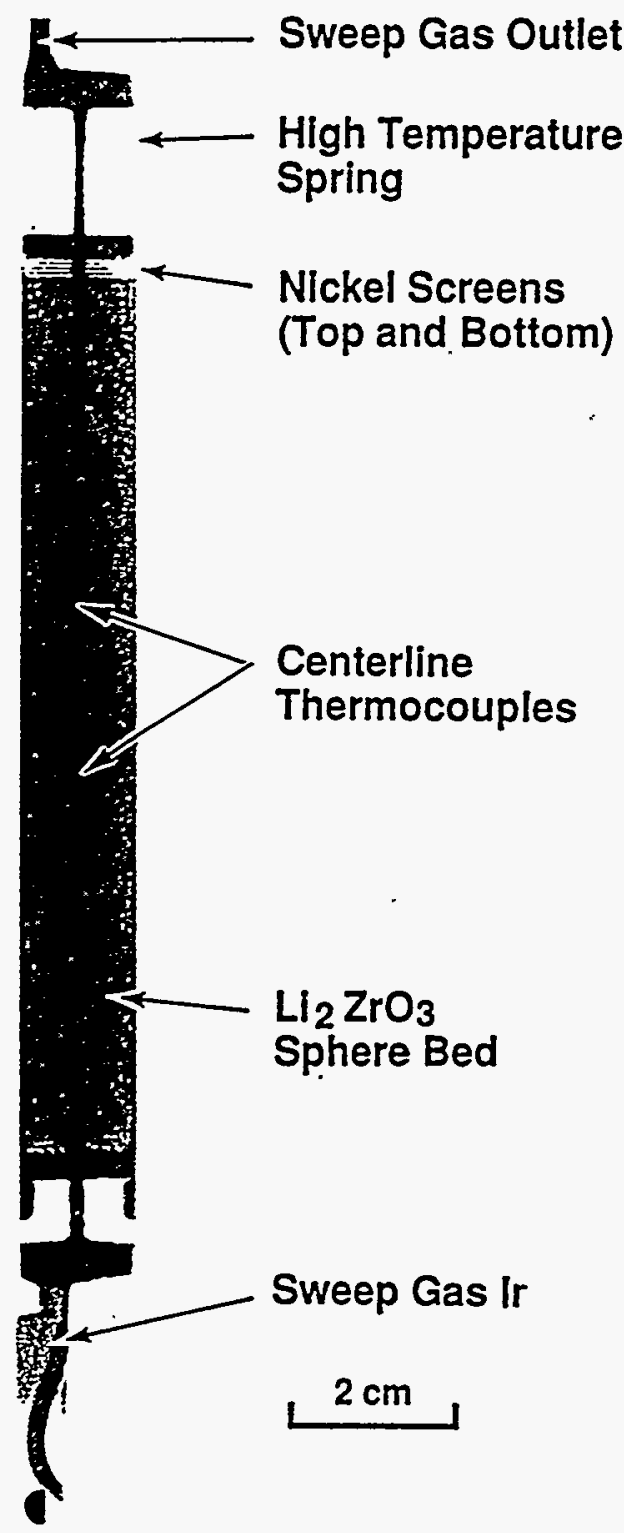

Figure 2.7. X-Ray Radiograph of the Temperature-Gradient Canister As-Fabricated 



\subsection{Tritium Handling System}

The tritium handling system for the BEATRIX-II, Phase $I$ irradiation experiment was the same system used for the Phase I experiment, and the reader is referred to the Phase I Data Summary report for a detailed description (Slagle and Hollenberg 1994). The system was designed to provide on-line measurements of tritium in the sweep gas recovered from either of the two in situ vented canisters. Two separate gas-analysis systems were devoted to monitoring the exit sweep gas flow streams from each of the two in situ vented canisters. Figure 3.1 is a diagram of the sweep-gas streams from one of the canisters. Each system provided continuous monitoring of the flow rate, total moisture, total tritium concentration, and oxidized tritium concentration. The gas streams from both canisters were combined before reaching the tritium removal system that removed the tritium from the sweep gas before it was released into the environment.

The sweep-gas inlet system provided for the selection of a reference or an alternate sweep gas for each canister. The reference gas for the experiment was helium with $0.1 \% \mathrm{H}_{2}$; the alternative gas was helium with either $0,0.01$, or $1 \% \mathrm{H}_{2}$. After passing through the in situ vented canister in the MOTA vehicle, the sweep gas was routed to the tritium glovebox where it entered the respective tritium measurement system (Figure 3.1). The sweep gas from each canister was monitored for moisture and then split into two branches. The reference flow rate was $50 \mathrm{~mL} / \mathrm{min}$ through either branch for $\dot{a}$ total flow through the canister of $100 \mathrm{~mL} / \mathrm{min}$. One branch flowed through a ceramic electrolysis cell (CEC) that decomposed water vapor, ensuring that all the tritium was in the form of HT rather than HTO. In the other branch, the water vapor was removed using a molecular sieve so that only tritium in the form of $\mathrm{HT}$ or $\mathrm{T}_{2}$ continued in the flow stream. The ion chamber in the CEC gas stream monitored the total tritium concentration recovered from the canister. The ion chamber following the molecular sieve measured the concentration of tritium that was in the reduced or elemental form. The difference in the response of the ion chambers in these two branches indicated the amount of tritium removed by the molecular sieve, i.e., the HTO.

The tritium-removal system was based on tritium getters that were designed to reduce the tritium level in the sweep gas by a factor greater than 4000 . This reduction was necessary to achieve tritium levels acceptable for release into the environment. Provisions were made for purging selected regions of the gas handling system with an optional "injection gas"-for example, purging the ion chambers before calibration to accurately determine the background at that time. When sweep gases of helium and $0.01 \% \mathrm{H}_{2}$ were used, an injection gas of $0.1 \% \mathrm{H}_{2}$ was added to the sweep gas before the tritium getter beds to increase the hydrogen concentration. This higher concentration of hydrogen provided "isotopic swamping" and ensured that the tritium getter beds would operate effectively. The glovebox containing the tritium-handling system was located within the FFTF reactor containment on the operating deck.

\subsection{Ion Chambers}

Ion chambers were used to continuously monitor the tritium concentrations in the sweep gas recovered from the in situ canisters. During Phase II, the sweep-gas composition varied from helium to helium with hydrogen concentrations up to $1 \%$. Two ion chambers were in the measurement systems for both temperature-change and temperature-gradient canisters. Although ion chambers were also located at the inlet to the tritium removal system and after the first getter bed, this report will only discuss those four chambers used to record the tritium levels recovered in the four individual streams. During the experiment, several corrections were mathematically applied to the apparent ionchamber reading, $\mathrm{T}_{\mathrm{IC}}$, to obtain the corrected tritium concentration in the sweep gas. 
In Phase I, the in situ calibrations indicated that the ion chamber response was enhanced when small amounts of hydrogen were added to the helium sweep gas. Because the original calibration curves were done for a helium sweep gas, a discrepancy was found when these calibration curves were used for tritium recovery using the reference sweep gas $\left(0.1 \% \mathrm{H}_{2}\right)$. This discrepancy was not fully resolved during the operation of Phase I, and the following tests were carried out during Phase II to resolve the discrepancy: 1) in situ ion chamber calibrations were conducted in both $0.1 \% \mathrm{H}_{2}$ and helium; 2) during the temperature-gradient canister Test Series A2, a helium sweep gas was maintained while injecting specific levels of hydrogen into the sweep gas before entering the ion chamber, and 3) a laboratory experiment was conducted to study the effect of hydrogen additions on

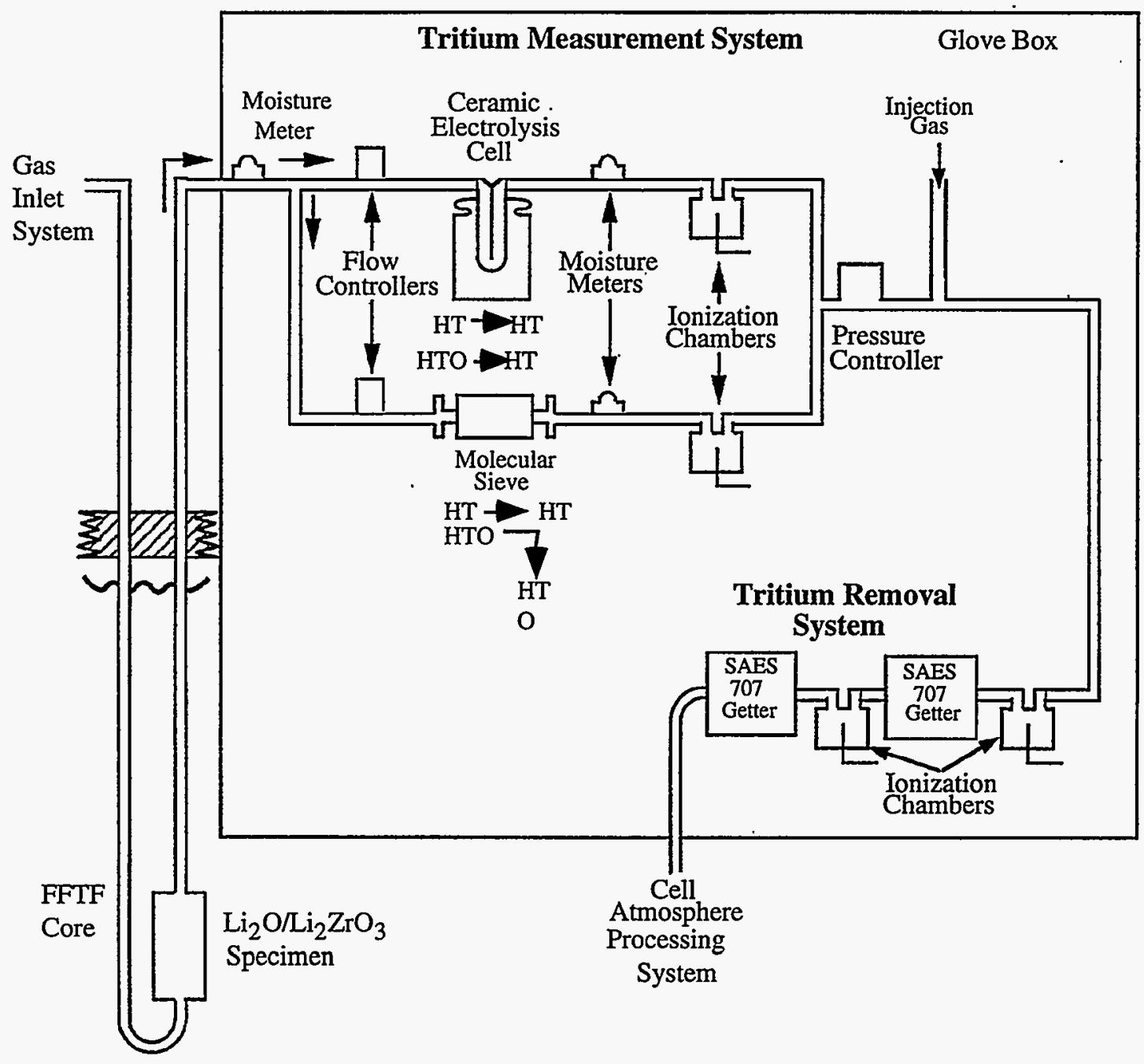

Figure 3.1. Diagram of the Sweep-Gas Stream from One of the In Situ Canisters 
the response of an ion chamber (Rodrigo and Yin 1993). The results of these tests were used to define a "hydrogen enhancement factor" $(F)$, which was a function of hydrogen additions to the helium sweep gas. This enhancement factor for a given sweep gas composition was defined by

$$
\mathrm{F}_{\mathrm{x}}=\frac{\left(\text { ion - chamber response in helium }-\mathrm{x} \% \mathrm{H}_{2}\right)}{(\text { ion - chamber response in helium })}
$$

The ion-chamber response includes the response from the tritium concentration $(T)$ in the sweep gas plus the ion chamber background (BG). Equation 3.1 becomes

$$
F_{x}=\frac{\left(T_{x}+B G_{x}\right)}{\left(T_{H e}+B G_{H e}\right)}
$$

\subsubsection{In Situ Calibration}

In situ calibration of the ion chambers during Phase II was carried out both in $0.1 \% \mathrm{H}_{2}$, as was done in Phase I, and also in helium. The procedures were the same as in Phase I (Slagle and Hollenberg 1994) except that in the case of helium, both the specimen sweep gas and the injection gas used to purge the ion chamber were helium. Table 3.1 is a compilation of the results.

Table 3.1. Results for In Situ Calibration in $0.1 \% \mathrm{H}_{2}$ and Helium for the Ion Chamber on the CEC Flow Stream from the Phase II Temperature-Change Canister

Phase II-A

Scintillation Analysis $\left(\mathrm{Ci} / \mathrm{m}^{3}\right)$

Ion-Chamber Reading $\left(\mathrm{Ci} / \mathrm{m}^{3}\right)$

Ratio (Ion Chamber/Scintillation)

Phase II-B

Scintillation Analysis $\left(\mathrm{Ci} / \mathrm{m}^{3}\right)$

Ion-Chamber Reading $\left(\mathrm{Ci} / \mathrm{m}^{3}\right)$

Ratio (Ion Chamber/Scintillation)

Phase II-C

Scintillation Analysis $\left(\mathrm{Ci} / \mathrm{m}^{3}\right)$

Ion-Chamber Reading $\left(\mathrm{Ci} / \mathrm{m}^{3}\right)$

Ratio (Ion Chamber/Scintillation)

Phase II-D

Scintillation Analysis $\left(\mathrm{Ci} / \mathrm{m}^{3}\right)$

Ion-Chamber Reading $\left(\mathrm{Ci} / \mathrm{m}^{3}\right)$

Ratio (Ion Chamber/Scintillation)

$\begin{array}{crr}0.1 \% \mathrm{H}_{2} & & \mathrm{He} \\ 20.00 & & 19.40 \\ 36.30 & & 24.20 \\ 1.82 & & 1.24 \\ & & \\ 29.80 & & - \\ 36.40 & & - \\ 1.22 & & - \\ & & \\ 27.50 & & 19.00 \\ 35.90 & & 23.70 \\ 1.31 & & 1.25\end{array}$

28.70

22.30

34.26

1.19
21.71

0.97

The in situ calibration results in Table 3.1 lists the 1) tritium concentrations determined from a scintillation analysis of a liquid solution prepared by oxidizing a sample of the sweep gas taken during the calibration and bubbling through water and 2) tritium concentration as read from the ion chamber (uncorrected for hydrogen additions). The ratio of the ion-chamber reading to the scintillation analysis is an indicator of the enhancement in the ion-chamber reading that resulted from adding hydrogen to the sweep gas. From the initial calibration data, it was expected that for $0.1 \% \mathrm{H}_{2}$, the ratio would be 1.3 , and for helium the ratio would be 1 . For $0.1 \% \mathrm{H}_{2}$, three of the four results were close to 1.3 , but the 1.82 value of Phase II-A was much too large. For helium only the Phase II- 
$\mathrm{D}$ result of 0.97 was close to 1 with the other two values being closer to 1.3 than 1 . The results indicate difficulties associated with in situ calibration. The 1.82 ratio for Phase I-A may be an experimental error. The larger ratio values for helium were attributed to difficulties associated with the slow response of the system to pure helium with no hydrogen additions.

\subsubsection{Sweep Gas Composition Effect on Ion chamber Response (In Situ Data)}

During Phase I, substantial evidence was obtained that ion-chamber response was affected by sweep-gas composition. Test Series A2 on the temperature-gradient canister was carried out to quantify the enhancement of ion-chamber response by additions of hydrogen. The test was described previously by Slagle et al. (1992) and in the Phase I Data report because they were used to explain the correction procedures used in Phase I. The results of the test will be summarized in this report. The sweep gas through the temperature-gradient canister during the test was helium, and it was assumed that the tritium concentration in the sweep gas coming from the canister remained constant. An injection gas of $1 \% \mathrm{H}_{2}$ was added to the helium sweep gas after the specimen canister, but ahead of the ion chamber, to give successively higher levels of hydrogen in the sweep gas through the ion chamber. The response of the ion chamber was observed at various levels of hydrogen concentration from 0.05 to $0.5 \% \mathrm{H}_{2}$ and a return to helium. From the ion chamber response, hydrogen enhancement factors $\left(\mathrm{F}_{\mathrm{x}}\right)$ were calculated and are listed in Table 3.2 for 100\% power.

A test series similar to Test Series A2 was carried out during the time when the reactor was shut down between Phase II-A and II-B. Since the tritium concentration was zero, the ion-chamber response reflected changes in the ion-chamber background. Variations in the ion-chamber background with changes in hydrogen concentration were used to calculate hydrogen enhancement factors that are listed in Table 3.2 for $0 \%$ power. The close agreement of the enhancement factors for $100 \%$ and $0 \%$ power suggest that the enhancement factors apply both to the response of the ion chamber to tritium in the sweep gas and to the background.

\subsubsection{Sweep Gas Composition Effect on Ion-Chamber Response (Laboratory Experiment)}

Rodrigo and Yin (1993) at AECL Research conducted a series of experiments to investigate the effect of various impurities on ion-chamber response. They found that adding hydrogen to a helium sweep gas increases the response of an ion chamber, and for hydrogen concentrations of $0.01 \%, 0.1 \%$, and $1.0 \%$, the enhancement was determined to be $1.10,1.31$, and 1.43 , respectively. Rodrigo and Yin's experimental results supplied a fundamental understanding of the effects observed in the BEATRIX-II system and provided justification for using hydrogen-enhancement factors to correct the ion-chamber response in different sweep gases.

Because of the measurements during the BEATRIX-II experiment and the results of Rodrigo and Yin, a decision was made to use hydrogen enhancement factors to correct the BEATRIX-II in situ tritium-recovery data for operation in sweep gases containing hydrogen additions. These correction factors apply to the ion-chamber response both for the tritium in the sweep gas and the effect of the ion-chamber background. For $0.1 \% \mathrm{H}_{2}$, a value of 1.3 was chosen as a compromise between Rodrigo and Yin's result, the Phase I results (Slagle and Hollenberg 1994), the results in Table 3.2, and the ion-chamber calibrations in Table 3.1. For $0.01 \% \mathrm{H}_{2}$, their value of 1.1 was considered to be more accurate than the 1.04 factor obtained in Phase I (Slagle and Hollenberg 1994), and the factor of 1.1 was adopted for $0.01 \% \mathrm{H}_{2}$. For $1.0 \% \mathrm{H}_{2}$, a value of 1.43 , from the data of Rodrigo and Yin, was rounded to 1.4 . 
Table 3.2. Hydrogen Enhancement Factors Determined from Test Series A2 for the Temperature-Gradient Canister

\section{Hydrogen Additions (\%)}

0

0.05

0.10

0.20

0.50

0
Enhancement Factors

100\% Power $\quad \underline{0 \% \text { Power }}$

1.00

1.27

1.20

$1.29 \quad 1.30$

$1.34 \quad 1.37$

$1.42 \quad 1.44$

$0.97 \quad 1.00$

\subsubsection{Enhancement-Factor-Correction Relationship}

The effect of sweep-gas composition on the response of the ion chamber was taken into account using the same expression used in Phase I. Equation 3.2 can be rearranged to give

$$
\mathrm{T}_{\mathrm{He}}=\frac{\left(\mathrm{T}_{\mathrm{x}}+\mathrm{BG}_{\mathrm{x}}\right)}{\mathrm{F}_{\mathrm{x}}}-\mathrm{BG}_{\mathrm{He}}
$$

To be consistent with the Phase I Data Summary Report, the total tritium concentration indicated by the ion chamber in a sweep gas of $\mathrm{x} \% \mathrm{H}_{2}$ is denoted as $\mathrm{T}_{\mathrm{IC}}$. That is

$$
\mathrm{T}_{\mathrm{IC}}=\mathrm{T}_{\mathrm{x}}+\mathrm{BG}_{\mathrm{x}}
$$

Equation 3.3 then becomes

$$
\mathrm{T}_{\mathrm{He}}=\frac{\mathrm{T}_{\mathrm{IC}}}{\mathrm{F}_{\mathrm{x}}}-\mathrm{BG}_{\mathrm{He}}
$$

Because the ion chamber was calibrated in a helium sweep gas, the tritium concentration in a helium sweep gas $\left(\mathrm{T}_{\mathrm{He}}\right.$ is the corrected tritium concentration in the sweep gas. Equation 3.5 is identical to Equation 3.5 in the Phase I Data Summary Report (Slagle and Hollenberg 1994).

\subsubsection{Ion-Chamber Background Correction}

At the start of the Phase II in situ testing, significant ion-chamber background levels remained from the Phase I testing. During the 300 EFPD operation of Phase I, the ion-chamber backgrounds $\left(B G_{X}\right)$ reached levels as high as $45 \%$ of the total response of the ion chamber. A method was developed for correcting the Phase I ion-chamber response for changes in background. All of the BEATRIX-II, Phase II tritium recovery data were corrected for sweep-gas composition and ionchamber background using the same technique described in the Phase I Data Summary Report (Slagle and Hollenberg 1994). The Phase II correction was done in combination with the data compilation discussed in Section 5 and Appendix B.

In the background correction process, a set of procedures to derive an equivalent ionchamber background in helium $\left(\mathrm{BG}_{\mathrm{He}}\right)$ was developed (Equation 3.5). During times when the tritium concentration through the ion chambers $\left(\mathrm{T}_{\mathrm{He}}\right)$ was known to be zero, the background $\left(\mathrm{BG}_{\mathrm{He}}\right)$ was set equal to the ion chamber reading corrected for the sweep gas enhancement $\left(\mathrm{T}_{\mathrm{IC}} / \mathrm{F}_{\mathrm{X}}\right)$. At other times in the experiment when the background was not zero, but could be expected to change, an 
alternative method was used. During these times, the background was established by comparing the concentration of recovered tritium $\left(\mathrm{T}_{\mathrm{He}}\right)$ under reference conditions $\left(0.1 \% \mathrm{H}_{2}\right.$ sweep gas, 100 $\mathrm{mL} / \mathrm{min}$ flow rate, and the temperature-change specimen at $640^{\circ} \mathrm{C}$ ) to the tritium concentration in the sweep gas that would be recovered due to the expected generation of tritium in the specimen.

Deriving the ion-chamber backgrounds then becomes a problem of calculating the expected generation for the specimen. We define the generation concentration $(G)$ to be the tritium concentration in the recovered sweep gas due to the generation rate in the specimen (at a reference flow rate of $100 \mathrm{~mL} / \mathrm{min}$ ). During ion-chamber calibration, $\mathrm{BG}_{\mathrm{He}}$ was determined by purging the ion chamber, and the tritium concentration in the sweep gas is assumed to equal the generation concentration. The tritium recovery concentration at calibration (for a flow rate of $100 \mathrm{~mL} / \mathrm{min}$ ) was set equal to the generation concentration at the time of the calibration, $\mathrm{G}_{\mathrm{C}}$. At times of ion chamber calibration,

$$
\mathrm{G}=\mathrm{G}_{\mathrm{C}}=\mathrm{T}_{\mathrm{He}}
$$

The generation concentration for other times in the irradiation cycle was calculated from the generation concentration at calibration, $G_{C}$, by the following relationship:

$$
\mathrm{G}=\mathrm{N} \bullet \mathrm{BU} \cdot \mathrm{G}_{\mathrm{C}}
$$

where $\mathrm{N}$ is a correction for the relative neutron flux as determined from the response of a selfpowered neutron detector (SPND) located in the region of the canister, and BU is a factor that accounts for the burnup of lithium. Equation 3.7 is the same as Equation 3.6 in the Phase I Summary Data Report. The notation for the generation concentration $\left(G_{E x}\right)$ in the Phase I report was changed to $G$ in this report. The change was made to clarify the description of how the correction was made.

Because the self-powered neutron detector in Phase II was not operative, temperature variations in the temperature-gradient specimen were used to account for variations in flux level. For small changes in power generation, heat generation in the solid specimen is proportional to the temperature difference across the solid specimen $\left(\Delta \mathrm{T}_{\mathrm{s}}\right)$. The heat generation in the solid specimen was proportional to the relative flux level $(\phi)$ and lithium enrichment $(E)$. This gives a relationship:

$$
\Delta \mathrm{T}_{\mathrm{s}} \propto \phi \cdot \mathrm{E}
$$

Rearranging we have:

$$
\phi \propto \frac{\Delta T_{s}}{E}
$$

The relative flux $\phi$ was used to establish the ion-chamber background as described above.

\subsection{Moisture Meters}

The sweep gas from each in situ canister was first monitored for moisture content when it reached the tritium-handling system (see Figure 3.1). The accuracy of the moisture meters at installation, before Phase I, was $\pm 1 \mathrm{ppm}$ with a resolution limit of $0.01 \mathrm{ppm}$. At the start of the Phase II irradiation, both moisture meters registered significant levels of moisture consistent with offgassing during heatup to the operating temperature. After an initial peak of $2300 \mathrm{ppm}$, the indicated moisture from the meter on the Phase II temperature-gradient-canister sweep gas went to zero. Following parameter changes where moisture peaks were observed in Phase I, such as increasing hydrogen concentration in the sweep gas, very small peaks were observed. These peaks were 
typically 0.01 to $0.03 \mathrm{ppm}$ where $0.01 \mathrm{ppm}$ is the detection limit. The moisture levels recorded for the Phase II temperature-change canister were similar to the Phase I temperature-change canister operation, and after an initial 5500-ppm peak, peaks after transient changes were on the order of several ppm.

The low moisture levels for the Phase II temperature-gradient canister are of concern if they indicate that the moisture meter for the Phase II temperature-gradient canister was not operating correctly. Although the moisture meters can be expected to decalibrate over time, the meter on the Phase II temperature-gradient-canister flow stream appeared to operate correctly during the startup. Hence, it is likely that the low moisture levels are indicative of low moisture levels in the sweep gas from this canister.

\subsection{Ceramic Electrolysis Cell}

The function of the ceramic electrolysis cells was to decompose the water in the sweep gas to $\mathrm{HT}, \mathrm{H}_{2}$, and $\mathrm{T}_{2}$ using a solid ceramic electrolyte of yttria-stabilized zirconia. The solid electrolyte operated at a temperature of $600^{\circ} \mathrm{C}$ with a nominal voltage bias of 1.6 volts to remove oxygen out of the sweep gas stream.

During Phase II, the operation of the CEC on the temperature-change-canister flow stream was interrupted after 11 days of operation. On June 7, 1991, a loss of current indicated that the CEC had failed. The power to the cell was immediately turned off. After a delay of approximately onehalf hour, power was restored. The cell resumed operation, and no further problems concerning the operation of the cell were experienced during Phase II. 



\subsection{Experiment Operation}

The operation of the BEATRIX-II experiment in the FFTF was conducted primarily by WHC. The operational activities included the initial setup, operation in the FFTF, removal of the canisters from the MOTA vehicle, and delivery of the canisters to PNNL in the 324 Building hot cells. PNNL interfaced with WHC, the BEATRIX-II experimenters, and the BEATRIX-II Working Group to coordinate the experiment and, in particular, to define the experimental requirements and test matrices. In addition, PNNL developed test plans, monitored the experimental operation, compiled/analyzed the data, executed the postirradiation examination, and distributed the data to the BEATRIX-II participants and the BEATRIX-II Modelers and Code Developers (see Section 7).

\subsection{Installation in FFTF}

Installation of the out-of-reactor BEATRIX-II apparatus in the FFTF was carried out before Phase I. The Phase II design was established at the Final Design Review in September 1990, and fabrication of the canisters was initiated at that time. The finished canisters were installed on the MOTA-2B vehicle in March 1991. The vehicle was inserted into the reactor in May 1991, and reactor startup occurred on May 25, 1991.

\subsection{Experimental Test Plan}

The operation of the experiment was defined by a test plan that was established before the start of each reactor operation cycle. The test plan was prepared by the BEATRIX-II experimenters with additional input solicited during BEATRIX-II working group and experimenters' meetings. The test plan established at the start of each reactor cycle was continuously modified, based on the results of the experiments. The test plan specified temperature, sweep-gas compositions, flow rate, ion-chamber purges/calibrations, and startup/ shutdown procedures. The design of the inlet gas system limited the system to only one alternative sweep gas (helium, $0.01 \% \mathrm{H}_{2}$, or $1.0 \% \mathrm{H}_{2}$ ) at a time. To limit the tritium concentration in the sweep gas arriving at the tritium recovery system, situations were avoided in which large tritium recovery peaks could be expected to occur simultaneously from both specimens.

The BEATRIX-II experimental test plan was based on a rapid change of selected system parameters, i.e., temperature, sweep-gas flow rate, and sweep-gas composition) with subsequent monitoring of the resultant transients in tritium recovery. These changes were completed in logical sets that were designed to efficiently use the available irradiation time (203 EFPD) and yet provide systematic data for analysis. A detailed record of the experiment was compiled in the experimenter's $\log$, which was a chronological record of the parameter changes that were made during the operation of the experiment. The experimenter's log for Phase $\Pi$ is included in Appendix A. Individual parameter changes in this report are referenced using the parameter change numbers $(P C N)$ in Appendix A. Descriptive overviews of the test plans for the Phase II temperature-change and temperature-gradient specimen are given in Tables 4.1 and 4.2. These tables describe changes in operating parameters away from parameters for operation in the reference condition. The reference sweep-gas conditions are a helium sweep gas with a $0.1 \%$ addition of hydrogen and a flow rate of $100 \mathrm{~mL} / \mathrm{min}$. The reference temperature for the temperature-change specimen is an inner temperature of $640^{\circ} \mathrm{C}$. The relationship of Tables 4.1 and 4.2 to the experimenter's log in Appendix $A$ is indicated by including the PCN from Appendix A in brackets, [], in Tables 4.1 and 4.2. 
Table 4.1. Test Plan Overview for BEATRIX-II, Phase II, Temperature-Change Canister. (Sweep gas composition changes are from the reference sweep of $0.1 \% \mathrm{H}_{2}$. Numbers in Brackets [] refer to PCN in Appendix B.)

Phase II-A May 27, 1991, to July 20, 1991 (52.8 EFPD)

A1. Temperature Transients in $0.01 \% \mathrm{H}_{2}$ [11-13] $640-590-530-640^{\circ} \mathrm{C}$

A2. Ion-Chamber Calibration in Helium and $0.01 \% \mathrm{H}_{2}$ [14-21]

A3. Temperature Transients in $0.01 \% \mathrm{H}_{2}$ [22-28] $640-590-530-640^{\circ} \mathrm{C}$

A4. Temperature Transients in $0.01 \% \mathrm{H}_{2}$ [31-33] $640-590-530-640^{\circ} \mathrm{C}$

A5. Temperature Transients in Helium [36-39] $640-590-530-640^{\circ} \mathrm{C}$

A6. Temperature Transients in $0.01 \% \mathrm{H}_{2}$ [43-45] $640-590-530-640^{\circ} \mathrm{C}$

Phase II-B July 30, 1991, to September 21, 1991 (48.6 EFPD)

B1. Burnup Effect [57-61]. Reference Sweep-Gas Conditions 640-590-530$640-530-640^{\circ} \mathrm{C}$

B2. Sweep-Gas Composition Effect at $640^{\circ} \mathrm{C}$

1) 2 days Helium, 2 days $0.01 \% \mathrm{H}_{2}$ [62-65]

2) 4 days Helium, 2 days $0.01 \% \mathrm{H}_{2}$ [66-68]

3) 8 days Helium, 2 days $0.01 \% \mathrm{H}_{2}$ [70-74]

B3. Ion-Chamber Calibration in $0.01 \% \mathrm{H}_{2}$ [76-79]

B4. Shutdown in $\mathrm{He}$

Phase II-C November 21, 1991, to January 14, 1992 (50.3 EFPD)

C1. Startup in Helium

C2. Ion Chamber Calibration in Helium and $0.01 \% \mathrm{H}_{2}$ [106-111]

C3. Sweep Gas Composition Effect at $530^{\circ} \mathrm{C}$

1) 2 days Helium, 2 days $0.01 \% \mathrm{H}_{2}$ [113-115]

2) 4 days Helium, 2 days $0.01 \% \mathrm{H}_{2}$ [117-119]

3) 2 days $0.01 \% \mathrm{H}_{2}$, 4 days Helium, [120-123]

C4. Burnup Effect [128-132]. Reference Sweep Gas Conditions 640-590-530$640-530-640^{\circ} \mathrm{C}$

Phase II-D January 29, 1992, to March 19, 1992 (51.6 EFPD)

Di. Ion-Chamber Calibration in Helium and $0.01 \% \mathrm{H}_{2}$ [137-141]

D2. Temperature Transients (640-590-530-640-530-640 $\left.{ }^{\circ} \mathrm{C}\right)$

1) $0.01 \% \mathrm{H}_{2}$ Sweep Gas [143-151]

2) Helium Sweep Gas [154-159]

D3. Burnup Effect [166-170]. Reference Sweep Gas Conditions $640-590-530-640-530-640^{\circ} \mathrm{C}$ 
Table 4.2 Test Plan Overview for BEATRIX-II, Phase II, Temperature-Gradient Canister. (Sweep gas composition changes are from the reference sweep gas of $0.1 \% \mathrm{H}_{2}$. Numbers in Brackets [] refer to PCN in Appendix B.)

Phase II-A May 27, 1991, to July 20, 1991 (52.8 EFPD)

A1. Sweep Gas Flow Test: $200 \mathrm{~mL} / \mathrm{min}$ [18-21]

A2. Effect of Sweep-Gas Composition on Ion-Chamber Behavior [22-28]

A3. Sweep-Gas Composition Effects

1) 2 days in $0.01 \% \mathrm{H}_{2}$ [34-35]

2) 2 days in $\mathrm{He}[38-40]$

Phase II-B July 30, 1991, to September 21, 1991 (48.6 EFPD)

B1. Sweep-Gas Composition Effects

1) 4 days in $0.01 \% \mathrm{H}_{2}$ [63-65]

2) 4 days in Helium [66-67]

3) 8 days in Helium [69-71]

B2. Effect of Sweep-Gas Flow Rate on Ion-Chamber Behavior [73-77]

B3. Ion-Chamber Purges [80-81]

B4. Shutdown in $\mathrm{He}$

Phase II-C November 21, 1991, to January 14, 1992 (50.3 EFPD)

C1. Startup in Helium

C2. Sweep-Gas Flow Test: $200 \mathrm{~mL} / \mathrm{min}$ [108-111]

C3. Sweep-Gas Composition Effect

1) 2 days Helium, 2 days $0.01 \% \mathrm{H}_{2}$ [113-115]

2) 4 days Helium, 2 days $0.01 \% \mathrm{H}_{2}$ [117-119]

3) 2 days $0.01 \% \mathrm{H}_{2}, 2$ days Helium, [120-122]

C4. Ion-Chamber Purges [129-130]

Phase II-D January 29, 1992, to March 19, 1992 (51.6 EFPD)

D1. Sweep-Gas Flow Test: $200 \mathrm{~mL} / \mathrm{min}$ [139-141]

D2. Ion-Chamber Purges [145-149]

D3. Sweep-Gas Flow Test: $50 \mathrm{~mL} / \mathrm{min}$ [152]

D4. Sweep-Gas Composition Change: $1 \% \mathrm{H}_{2}$ [162-163]

Parameter-change sequences are denoted by using the number sequences from the Tables 4.1 and 4.2. For instance, Test Series B2.3 of the temperature-change canister refers to the Phase II-B Test Series described as

B2. - Sweep-Gas-Composition Effect at $535^{\circ} \mathrm{C}$

B2.3. -8 days helium, 2 days $0.01 \% \mathrm{H}_{2}$.

This test is described in the Phase II experimenter's log by PCN 70 to PCN 74. The test plans for each of the four cycles are also illustrated graphically in Appendix B where plots of tritium recovery data and temperature include labels indicating sweep-gas composition for each of the two canisters. 


\subsubsection{Temperature-Change Canister}

The initial test series in Phase II-A was a series of temperature transients in the reference sweep gas, $0.1 \% \mathrm{H}_{2}$. The temperature sequence was in the order of $640-590-530-640^{\circ} \mathrm{C}$. This series established the shape of the recovery peaks after a temperature-change characteristic of the start of the experiment. Test Series A2 was the calibration of the ion chamber on the CEC flow stream in both helium and $0.01 \% \mathrm{H}_{2}$. Calibration in both gases was done to establish the difference in response of the ion chamber in the two different gases. The results of these tests were used to derive the enhancement factors for each sweep gas that were then used to correct the data. Test Series A3 to A6 was a systematic series of temperature transients $\left(640-590-530-640^{\circ} \mathrm{C}\right)$ carried out in the three different sweep gases: $0.01 \% \mathrm{H}_{2}, 0.01 \% \mathrm{H}_{2}$, and helium. The test series in $0.1 \% \mathrm{H}_{2}$ was repeated at the end to determine if changes in specimen response had occurred during irradiation.

The first test series in.Phase II-B was a temperature-transient series in the reference gas that was identical to the series used in Phase I to monitor the change in behavior with burnup. The temperature transients $\left(640-590-530-640-530-640^{\circ} \mathrm{C}\right)$ were similar to that used in Phase II-A with the addition of a $640-530-640^{\circ} \mathrm{C}$ series at the end. Test Series B2 addressed the effect of sweep-gas composition changes for a specimen temperature of $640^{\circ} \mathrm{C}$. The tests all began in $0.1 \% \mathrm{H}_{2}$ with a transition to helium. The time duration in helium varied, starting at 2 days and increasing to 4 days and then 8 days. After helium, the sweep gas was changed to $0.1 \% \mathrm{H}_{2}$ for 2 days before returning to $0.1 \% \mathrm{H}_{2}$ to end the test. Test Series B3 was a series of operations to calibrate the ion chamber on the CEC flow stream in a $0.1 \% \mathrm{H}_{2}$ sweep gas. Because of the limited time remaining in the cycle, the calibration was not able to be carried out in helium. Test Series B4 involved changing the sweep gas to helium two days before the end of Phase II-B so that the shutdown behavior in helium could be recorded.

The startup of Phase II-C was carried out in helium as a continuation of the shutdown of Phase II-B. Test Series C2 was the calibration of the ion chamber on the CEC flow stream in both helium and $0.1 \% \mathrm{H}_{2}$ identical to Test Series A2. Test series $\mathrm{C} 3$ addressed the effect of sweep-gas composition changes for a specimen temperature of $530^{\circ} \mathrm{C}$. The first two tests began in $0.1 \% \mathrm{H}_{2}$ with a transition to helium. The time duration in helium was 2 days for Test C3.1 and 4 days for Test C3.2. After helium, the sweep gas was changed to $0.1 \% \mathrm{H}_{2}$ for 2 days before returning to $0.1 \% \mathrm{H}_{2}$ to end the test. Test $\mathrm{C} 3.3$ reversed the sequence of helium and $0.01 \% \mathrm{H}_{2}$, starting with 2 days in $0.01 \% \mathrm{H}_{2}$ and switching to 4 days in helium. Test Series $\mathrm{C} 4$ was a temperature transient series (640$590-530-640-530-640^{\circ} \mathrm{C}$ ) in the reference gas to monitor the change in behavior with burnup.

Phase II-D started with the calibration of the ion chamber on the CEC flow stream in both helium and $0.1 \% \mathrm{H}_{2}$ as was done in Phase $\Pi=\mathrm{A}$ and $\mathrm{C}$. The temperature transient series (640-590$530-640-530-640^{\circ} \mathrm{C}$ ) was carried out in $0.1 \% \mathrm{H}_{2}$ and helium in Test Series D2 with a return to 0.1\% $\mathrm{H}_{2}$ for Test Series D3. Final shutdown was in $0.1 \% \mathrm{H}_{2}$.

\subsubsection{Temperature-Gradient Canister}

In Phase II-A, the initial Test Series, A1, for the operation of the temperature-gradient canister in Phase I-A involved increasing the flow rate from 100 to $200 \mathrm{~mL} / \mathrm{min}$. The increase in flow rate through the temperature-gradient canister coincided with the calibration of the temperature-change canister in a helium sweep gas. This flow rate increase through the temperature-gradient canister was used to increase the hydrogen in the sweep gas to the tritium recovery system. Normally when helium sweep gas was used, additional $0.1 \% \mathrm{H}_{2}$ sweep gas was introduced into the tritium recovery system using a provision for introducing an injection gas. During the calibration in helium, the injection-gas system was used for purging the ion chamber with helium and therefore was not available to introduce $0.1 \% \mathrm{H}_{2}$ into the tritium recovery system. Test Series A2 was designed to introduce a sequence of sweep gases with varying levels of hydrogen into the ion chamber while 
maintaining a known amount of tritium in the sweep gas. These data were used to determine the response of the ion chambers to tritium for different levels of hydrogen additions. Test Series A3 addressed the effect of changing sweep-gas composition on the tritium recovery behavior. Test Series A3.1 changed from $0.1 \% \mathrm{H}_{2}$ to $0.01 \% \mathrm{H}_{2}$ for 2 days before returning to $0.1 \% \mathrm{H}_{2}$ while the Test Series A3.2 changed from $0.1 \% \mathrm{H}_{2}$ to helium for 2 days before returning to $0.1 \% \mathrm{H}_{2}$.

In Phase II-B, the Test Series B1 extended the times for alternative sweep-gas additions. Test Series B1.1 changed from $0.1 \% \mathrm{H}_{2}$ to $0.01 \% \mathrm{H}_{2}$ for 4 days before returning to $0.1 \% \mathrm{H}_{2}$ while the Test Series B1.2 and B1.3 changed from $0.1 \% \mathrm{H}_{2}$ to helium for 4 and 8 days, respectively, before returning to $0.1 \% \mathrm{H}_{2}$. Test Series $\mathrm{B} 2$ addressed the question of flow-rate effects on ion-chamber operation by changing the relative distribution of the flow rate between the ion chambers on the CEC and molecular-sieve flow streams. In Test Series B3, the ion chambers on both the CEC and molecular-sieve flow streams were purged to reduce and establish backgrounds. Two days before shutdown, the sweep gas was changed to helium (Test Series B4) to determine the effect of helium sweep gas on the tritium recovery during a reactor shutdown.

The startup of Phase II-C was a continuation of the shutdown of Phase II-C in that it was carried out in a helium sweep gas. Test Series C2 was a flow test similar to Test Series A1 in which the flow rate was increased to the temperature-gradient canister to compensate for the helium purge/calibration of the temperature-change ion chamber. Test Series C3 addressed the effect of sweep gas composition changes with all tests beginning and ending in $0.1 \% \mathrm{H}_{2}$. Test Series $\mathrm{C} 3.1$ and C3.2 began with a change to helium with respective durations of 2 and 4 days. The helium sweep gas was then changed to $0.1 \% \mathrm{H}_{2}$ for 2 days before returning to $0.1 \% \mathrm{H}_{2}$ to end the test. Test Series C3.3 began with a change to $0.1 \% \mathrm{H}_{2}$ for 2 days and then a change to $0.1 \% \mathrm{H}_{2}$ for 2 days before returning to $0.1 \% \mathrm{H}_{2}$ to end the test. In Test Series $\mathrm{C} 3$, the ion chambers on both the CEC and molecular-sieve flow streams were purged to reduce and establish backgrounds.

At the start of Phase II-D, Test Series D1 was a flow test similar to Test Series A1 in which the flow rate was increased to the temperature-gradient canister to compensate for the helium purge/calibration of the temperature-change ion chamber. In Test Series D2, the ion chambers on both the CEC and molecular-sieve flow streams were purged to reduce and establish backgrounds. Test Series D3 involved a change in sweep-gas flow rate to $50 \mathrm{~mL} / \mathrm{min}$ to aid in locating a leak in the tritium recovery system in the glovebox. Test Series D4 was a change in sweep-gas composition from $0.1 \%$ to $1 \% \mathrm{H}_{2}$ for 1 day and then a return to $0.1 \% \mathrm{H}_{2}$.

\subsection{Data Acquisition/Compilation}

The experiment was continuously monitored in the FFTF using the BEATRIX-II data acquisition system (DAS) that recorded the specified data channels and, in addition, provided operational information for assessing the performance of the test equipment. The DAS was in direct communication with the reactor control room, and an alarm signal was activated if selected signals exceeded specified limits. Figure 4.1 is a diagram of the flow path of the data. A total of 59 data channels were monitored by the DAS during the experiment. The continuously monitored data set was compiled on a data disc at the FFTF site. When the disc was full, or at shorter intervals if requested by the experiment coordinator (PNNL), the disc was removed from the DAS and processed. The complete set of 59 channels in time intervals as short as 10 seconds was converted to specified experimental units and retained as the complete operational database at WHC.

Twenty-six channels of data were designated as the prime data set on the basis that they were the data that were specifically needed to characterize the behavior of the solid-breeder specimens. The prime data set and the units in which they were supplied are given in Table 4.3. The prime data set was normally transferred from WHC to PNNL in time increments. of 2 minutes, although shorter intervals were supplied when requested. At PNNL, the prime data set was used to generate the more 
concise experimental database and a series of data plots. The experimental database was distributed to the BEATRIX-II experimenters. The data plots were used as the basis for evaluating the progress of the experiment and for formulating future test plans. The Phase II experimental database consisted of 45 individual LOTUS 123 data files, each about 5 to 8 days. The PNNL experimental database was used to generate the final corrected/compiled databases for the temperature-change and temperature-gradient databases.

Because of the complexity of the database, an overall compilation of the experimental database was carried out to create a manageable set of data that could be used by modelers and code developers needing access to the information. To facilitate this compilation, the experimental database was reduced by one third by increasing the time interval between data points from 2 minutes to 6 minutes. The original 26 prime data channels were reduced to 20 channels based on which channels were most important for understanding the tritium-release behavior of the solid breeder. The database was then divided into individual databases for the temperature-change and the temperature-gradient canisters. The resulting compiled spreadsheets for the individual canisters are

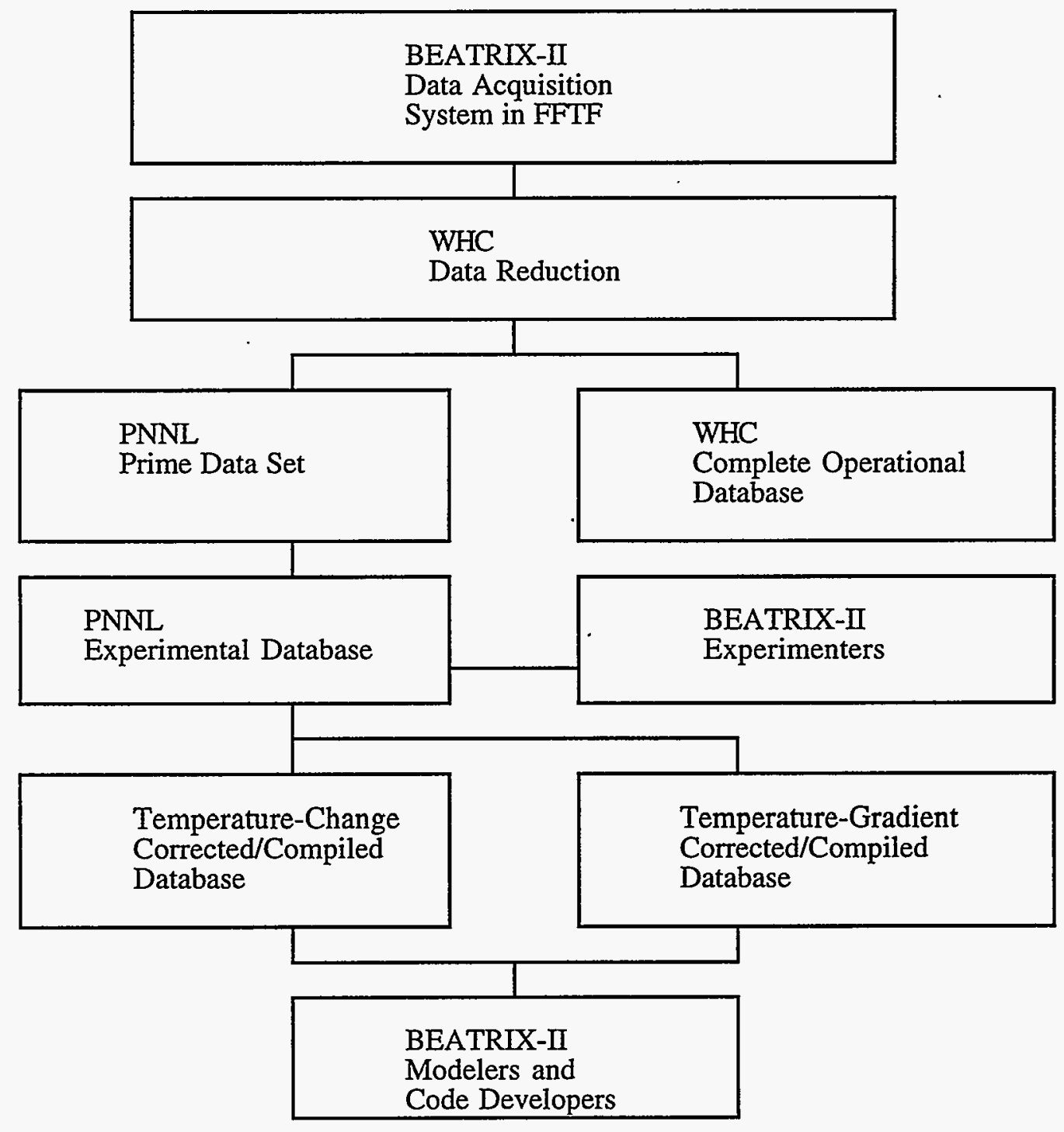

Figure 4.1. Flowpath for BEATRIX-II Data 
Table 4.3. Prime Dàta Set for BEATRIX-II, Phase I

\begin{tabular}{|c|c|c|}
\hline Channel & Units & Description \\
\hline $\begin{array}{l}1 \\
2\end{array}$ & $\begin{array}{l}\text { atm } \\
\text { atm }\end{array}$ & $\begin{array}{l}\text { Ring-specimen inlet gas pressure } \\
\text { Solid-specimen inlet gas pressure }\end{array}$ \\
\hline $\begin{array}{l}3 \\
4 \\
5 \\
8\end{array}$ & $\begin{array}{l}\text { ppm } \\
\text { ppm } \\
\text { ppm } \\
\text { ppm }\end{array}$ & $\begin{array}{l}\text { Reference-gas inlet moisture } \\
\text { Alternate-gas inlet moisture } \\
\text { Ring-specimen sweep-gas moisture } \\
\text { Solid-specimen sweep-gas moisture }\end{array}$ \\
\hline $\begin{array}{l}11 \\
12\end{array}$ & $\begin{array}{l}\text { atm } \\
\text { atm }\end{array}$ & $\begin{array}{l}\text { Ring-specimen sweep-gas pressure } \\
\text { Solid-specimen sweep-gas pressure }\end{array}$ \\
\hline $\begin{array}{l}17 \\
18 \\
19 \\
20 \\
21 \\
22\end{array}$ & $\begin{array}{l}\mathrm{cc} / \mathrm{min}(\mathrm{STP}) \\
\mathrm{cc} / \mathrm{min} \text { (STP) } \\
\mathrm{cc} / \mathrm{min}(\mathrm{STP}) \\
\mathrm{cc} / \mathrm{min} \text { (STP) } \\
\mathrm{cc} / \mathrm{min} \text { (STP) } \\
\mathrm{cc} / \mathrm{min} \text { (STP) }\end{array}$ & $\begin{array}{l}\text { Ring-specimen injection sweep-gas flow } \\
\text { Ring-specimen sweep-gas flow, CEC } \\
\text { Ring-specimen sweep-gas flow, MS } \\
\text { Solid-specimen injection sweep-gas flow } \\
\text { Solid-specimen sweep-gas flow, CEC } \\
\text { Solid-specimen sweep-gas flow, MS }\end{array}$ \\
\hline 35 & Relative Intensity & Self-powered neutron detector \\
\hline $\begin{array}{l}43 \\
44 \\
45 \\
46 \\
47 \\
48 \\
49\end{array}$ & $\begin{array}{l}{ }^{\circ} \mathrm{C} \\
{ }^{\circ} \mathrm{C} \\
.{ }^{\circ} \mathrm{C} \\
{ }^{\circ} \mathrm{C} \\
{ }^{\circ} \mathrm{C} \\
{ }^{\circ} \mathrm{C} \\
{ }^{\circ} \mathrm{C}\end{array}$ & $\begin{array}{l}\text { Glovebox Temperature } \\
\text { Solid-specimen outer temperature } \\
\text { Solid-specimen center temperature - top } \\
\text { Solid-specimen center temperature - bottom } \\
\text { Ring-specimen outer temperature } \\
\text { Ring-specimen inner temperature, CEC } \\
\text { Ring-specimen inner temperature, MS }\end{array}$ \\
\hline $\begin{array}{l}1001 \\
1002 \\
1003 \\
1004\end{array}$ & $\begin{array}{l}\mathrm{Ci} / \mathrm{m}^{3} \\
\mathrm{Ci} / \mathrm{m}^{3} \\
\mathrm{Ci} / \mathrm{m}^{3} \\
\mathrm{Ci} / \mathrm{m}^{3}\end{array}$ & $\begin{array}{l}\text { Ring-specimen sweep-gas tritium, CEC } \\
\text { Ring-specimen sweep -gas tritium, MS } \\
\text { Solid-specimen sweep-gas tritium, CEC } \\
\text { Solid-specimen sweep-gas tritium, MS }\end{array}$ \\
\hline
\end{tabular}

CEC and MS refer to the sweep-gas flow stream through the ceramic electrolysis cell and the molecular sieve.

described in Appendix B. The Phase I tritium-recovery data were then corrected for the effect of sweep-gas composition on ion-chamber response and for the buildup of ion-chamber background. These corrections were carried out as described in the Phase I Data Summary Report, Section 3.1.4.1 (Slagle and Hollenberg 1994) and in Section 3.1.3 of this report. The final spreadsheets are referred to as the Phase II Corrected/Compiled Database. In Appendix B, the results of the data correction/compilation are presented in two different types of data plots versus time. The first series of plots are the recovered-tritium concentration, the ion-chamber correction factor, and the ionchamber background. The other series of plots is the ratio of recovered to generated tritium and the inner-specimen temperatures. These plots also include a description of the sweep-gas-composition changes. These two types of plots are included in Appendix B for each of the four irradiation cycles for each of the two in situ recovery canisters. 


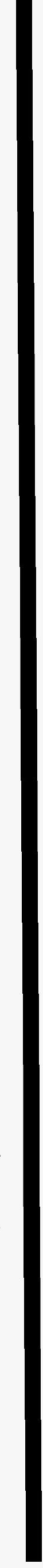




\subsection{In Situ Results}

The BEATRIX-II Phase II in situ tritium recovery experiment was carried out in Cycle 12 of the FFTF between May 1991 and March 1992. The in situ testing included the operation of the temperature-change and temperature-gradient canisters. Details of the test plan are given in Tables 4.1 and 4.2. This section describes the in situ results and discusses some of the implications.

\subsection{Total Lithium Burnup}

The tritium recovery rates in the corrected/compiled database (Section 4.3) were integrated to determine the total tritium recovered from each cycle of Phase I. The total recovered tritium from the integration is compared to the value of total tritium generated based on the predicted neutronics for each reactor cycle $(\mathrm{a})$ in Table 5.1. In all cases, the predicted value is higher than the measured value. The difference between the overall totals of predicted versus measured tritium for both canisters is over $10 \%$, but they agree within the expected uncertainties: $\pm 10 \%$ for the prediction of the amount generated and $\pm 10 \%$ for the accuracy of the ion-chamber measurements. The total lithium burnup was calculated on the basis of the predicted/measured tritium.

Table 5.1. Predicted Amount of Tritium Generated Compared to Measured Amount Recovered

\begin{tabular}{|c|c|c|c|c|c|}
\hline \multirow[b]{2}{*}{ Cycle } & \multirow[b]{2}{*}{ EFPD } & \multicolumn{2}{|c|}{ Predicted $(\mathrm{Ci})$} & \multicolumn{2}{|c|}{ Measured (Ci) } \\
\hline & & $\begin{array}{l}\text { Temperature } \\
\text { Change }\end{array}$ & $\begin{array}{c}\text { Temperature } \\
\text { Gradient }\end{array}$ & $\begin{array}{c}\text { Temperature } \\
\text { Change }\end{array}$ & $\begin{array}{c}\text { Temperature } \\
\text { Gradient }\end{array}$ \\
\hline Phase II-A & 52.8 & 221.8 & 158.9 & 203.8 & 149.2 \\
\hline Phase II-B & 48.6 & 204.1 & 146.3 & 192.6 & 134.0 \\
\hline Phase II-C & 50.3 & 216.3 & 156.4 & 186.9 & 143.5 \\
\hline Phase II-D & 51.6 & 216.7 & 160.5 & 185.4 & 149.2 \\
\hline Total & 203.3 & 858.9 & 622.1 & 768.5 & 575.9 \\
\hline Lithium $\mathrm{Bu}$ & & $5.3 \%$ & $5.7 \%$ & $4.6 \%$ & $5.1 \%$ \\
\hline
\end{tabular}

\subsection{Temperature-Change Specimen}

The test plan for the irradiation of the Phase II temperature-change canister is detailed in Table 4.1. The primary parameter changes are temperature, sweep-gas composition, and sweep-gas flow rate. The reference condition was selected to be an inner specimen temperature of $640^{\circ} \mathrm{C}$, a sweep gas of helium with $0.1 \% \mathrm{H}_{2}$, and a flow rate of $100 \mathrm{~mL} / \mathrm{min}$. An inner surface temperature of $640^{\circ} \mathrm{C}$ corresponds to a specimen outer surface temperature of $620^{\circ} \mathrm{C}$. In the following discussion, the inner specimen temperature was used to designate the temperature of the temperature-change specimen.

\subsubsection{Experiment Startup}

During reactor startup, the temperature history of the temperature-change specimen suggested that unexpected changes occurred in the specimen/canister configuration. At reactor startup, the sweep gas through the temperature-change canister was $0.1 \% \mathrm{H}_{2}$ and the mixture of helium and argon in the thermal-conductance gas gap was $100 \% \mathrm{He}$. Figure 5.1 is a plot of the

(a) R. C. Knight. "Actual and Predicted BEATRIX Phase 2 Tritium Production Rates." Letter to O. D. Slagle, August 3, 1992. WHC-9255855. Westinghouse Hanford Company, Richland, Washington. 
temperatures recorded from the two inner specimen thermocouples for the first 550 hours of Phase II-A. The two inner thermocouples were located $180^{\circ}$ apart on opposite sides of the inner diameter. During the initial heatup, the two temperatures were identical. However, when the reactor reached full power (approximately 110 hours), the temperatures of the two thermocouples diverged by $15^{\circ} \mathrm{C}(548$ and $533^{\circ} \mathrm{C}$ ). When the gas in the thermal conductance gap was changed to $3 \% \mathrm{He}-97 \% \mathrm{Ar}$, the temperatures increased, resulting in temperatures of 651 and $644^{\circ} \mathrm{C}$ for a difference of only $7^{\circ} \mathrm{C}$. When the temperature was again reduced by returning to $100 \% \mathrm{He}$ in the gas gap, the temperatures remained substantially different: 550 and $536^{\circ} \mathrm{C}$. The sample temperature was then raised back up to $645^{\circ} \mathrm{C}$ and held for the duration of the 550-hour plot. Throughout this latter period, the difference in temperature between the thermocouples appeared to decrease with time. It is to be noted that the thermocouples were labeled as \#1 and \#2, and the one labeled \#1 was always less than \#2 during the operation shown in Figure 5.1. At the end of Phase II-A, the readings for a gap gas of $100 \%$ He were very close: $528^{\circ} \mathrm{C}(\# 1)$ and $533^{\circ} \mathrm{C}(\# 2)$. At the upper temperature, the order was reversed with \#1 reading $647^{\circ} \mathrm{C}$ and $\# 2$ reading $645^{\circ} \mathrm{C}$.

One possible explanation for the temperature behavior of the temperature-change canister during reactor startup is that sintering caused the specimen's diameter to decrease. This decrease in diameter introduced larger specimen-subcapsule gaps. This sintering appeared to have started sometime before the reactor reached full power at approximately 110 hours. A large peak in the sweep-gas moisture flowing out of the temperature-change canister at 110 hours suggests that the sintering could have occurred concurrently with the decomposition of residual LiOH. When the proposed sintering occurred, it is possible that the specimen did not remain centered in the capsule. If the gap on one side was larger than the other, a temperature difference would result. Because $\mathrm{Li}_{2} \mathrm{O}$ has a higher thermal expansion than steel, increasing the temperature of the specimen reduces the total gap and this tighter fit of the specimen in the capsule could have effected a centering of the specimen in the capsule. The disappearance of the temperature difference by the end of Phase II-A may have resulted because the specimen swelled and reduced or possibly eliminated the gap.

The design calculations (Section 2) indicated that inner temperatures would be $503^{\circ} \mathrm{C}$ for $100 \% \mathrm{He}$ and $654^{\circ} \mathrm{C}$ for $12 \% \mathrm{He}-88 \%$ Ar. During operation the inner temperatures were $530^{\circ} \mathrm{C}$ for $100 \% \mathrm{He}$ and $640^{\circ} \mathrm{C}$ for $3 \% \mathrm{He}-97 \% \mathrm{Ar}$. It appears as if the lowest and highest temperatures were off by approximately $20^{\circ} \mathrm{C}$, but in opposite directions. That is, the lowest temperature was high while the highest temperature was low. The design calculations were carried out assuming no thermal gap between the specimen and the capsule. The decrease associated with the maximum temperature could have been associated with the incomplete closure of the specimen-subcapsule gap and/or a lower power generation rate, as suggested by the lower measured tritium generation rate in Table 5.1. The higher temperatures at the minimum temperature could result from an increase of the specimencapsule gaps during cool-down from the higher temperatures.

To interpret the data, two calculated values from the design will be used: 1) the temperatures of the inner thermocouples are $6^{\circ} \mathrm{C}$ higher than the inner surface of the ring, and 2) the temperature drop across the specimen is $20^{\circ} \mathrm{C}$. The temperature drop across the specimen could be expected to increase as the specimen swells. Specimen swelling was observed during the postirradiation examination in Section 6.

\subsubsection{Temperature-Change Effects}

As was observed in Phase I, temperature transients in Phase II were followed by positive tritium recovery peaks for temperature increases and negative recovery peaks for temperature decreases. Figure 5.2 shows typical tritium recovery peaks for a temperature-change series of 640 $530-640^{\circ} \mathrm{C}$ in the reference sweep gas of $0.1 \% \mathrm{H}_{2}$. These temperature changes were included in Test Series B1 of the test plan, were carried out at 61 EFPD, and were typical of the first 100 EFPD of operation. 
The tritium recovery peaks in Figure 5.2 consisted of tritium primarily in the reduced form (HT) and are similar to the tritium recovery peaks found after temperature transients at the end of Phase I. Figure 5.3 shows a progression of recovery peaks for a $550-640^{\circ} \mathrm{C}$ temperature transient during Phase I compared with a $530-640^{\circ} \mathrm{C}$ transient at the start of Phase $\Pi$ (Test Series A1). At the start of Phase I, the recovery consisted of two peaks: an initial HT peak followed by an extended HTO peak. By the end of Phase I, (300 EFPD) the HT peak dominated the recovery. What caused this change was uncertain. Two proposed explanations were burnup effects in the specimen or a.drying out of the system (Slagle and Hollenberg 1994). The occurrence of a predominantly HT peak at the start of Phase II suggested that the effect seen in Phase I was not due to burnup effects in the specimen. Therefore, the cause of the change in Phase I may be due to a drying out of the system that continued into Phase II.

\section{Effect of Sweep-Gas Composition}

During the first 50-day cycle of irradiation, the temperature-change sequence 640-590-530$640^{\circ} \mathrm{C}$ was carried out in different sweep-gas compositions. Figure 5.4 compares recovery curves for the temperature change from 530 to $640^{\circ} \mathrm{C}$ in the three different sweep gases: 1) $0.1 \% \mathrm{H}_{2}$ (Test Series A3), 2) $0.01 \% \mathrm{H}_{2}$ (Test Series A4), and 3) helium (Test Series A5). Decreasing the hydrogen in the sweep gas resulted in a larger tritium recovery. Integration over the peaks was used to determine the respective amount of tritium associated with the three peaks: $0.04,0.23$, and $0.76 \mathrm{Ci}$, respectively. This trend of increasing inventory with decreasing hydrogen concentration is consistent

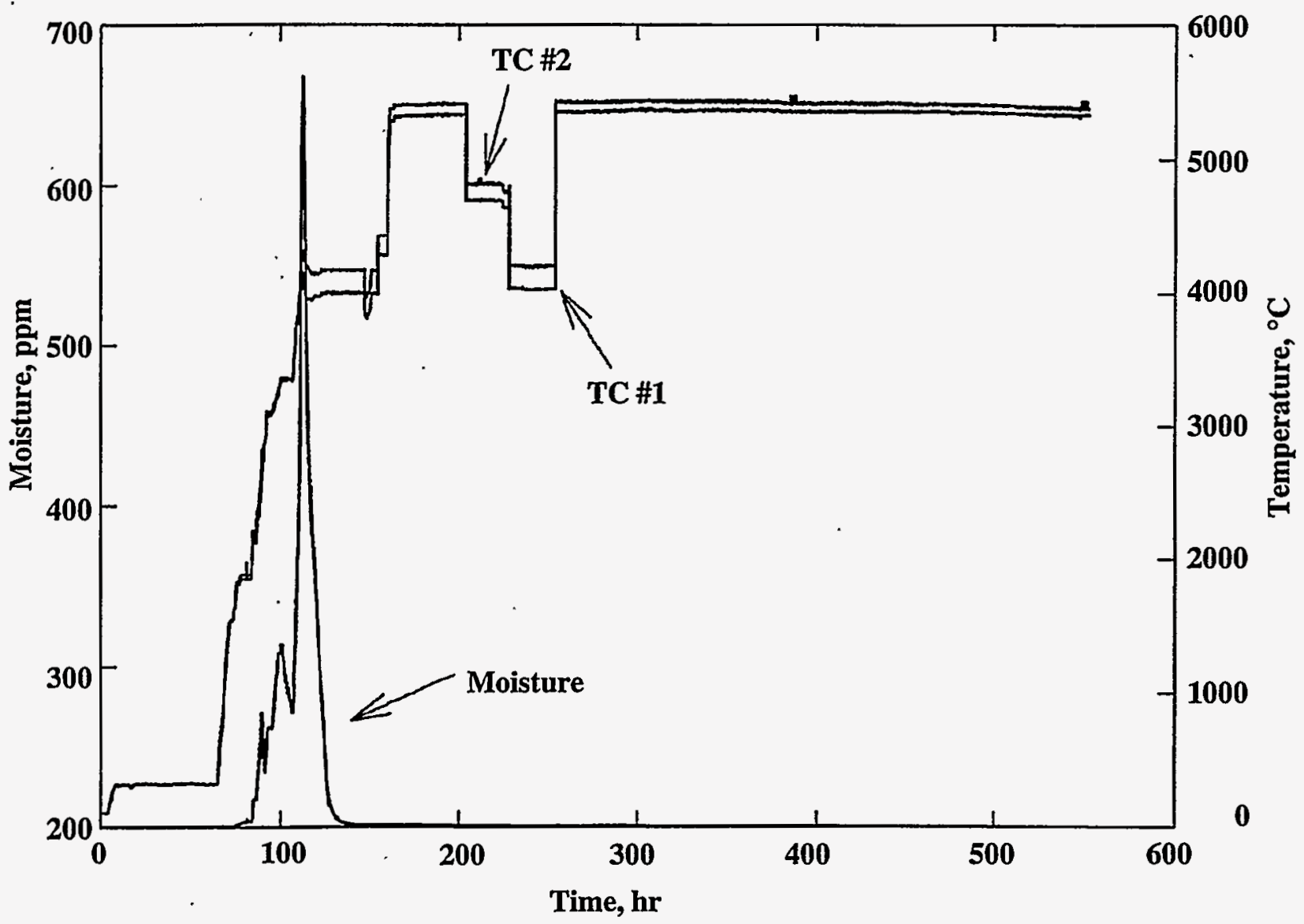

Figure 5.1. Inner Temperatures and Sweep-Gas Moisture for the First 550 Hours of Operation of the Temperature-Change Canister in Phase II-A 
with the increasing tritium inventories in the $\mathrm{Li}_{2} \mathrm{O}$ specimen found for decreasing hydrogen seen previously in Phase I (Slagle and Hollenberg 1994).

\section{Effect of Burnup}

Burnup does not appear to affect tritium release from $\mathrm{Li}_{2} \mathrm{O}$, but other historic factors do seem to influence the release rate. A series of temperature transients was carried out at different stages of the test (Test Series B1, C4, and D3) to characterize the effect of burnup. These series were carried out in $0.1 \% \mathrm{H}_{2}$ and consisted of temperature changes in the order of $640-590-530-640-530-640^{\circ} \mathrm{C}$. The tritium recovery peaks from the last 530 to $640^{\circ} \mathrm{C}$ temperature change in this series are compared in Figure 5.5. Similar peaks from Test Series A1 and A6 are included as examples at the lower EFPDs. The first three peaks at 4, 51, and 61 EFPD are similar in shape, as was expected. The last two peaks at 151 and 200 EFPD are preceded by small negative peaks. The peak at 142 EFPD was not a part of a series of temperature transients, but was for an isolated 530 to $640^{\circ} \mathrm{C}$ temperature transient following an extended period of operation at $530^{\circ} \mathrm{C}$ in helium and $0.01 \% \mathrm{H}_{2}$. This transient (PCN \# 124) recovery peak at 142 EFPD was preceded by a small negative peak followed by a large positive peak consisting primarily of HTO in contrast to the previous temperature transient peaks that were primarily HT. The subsequent peak in a temperature-transient series was carried out at 151 EFPD and was appreciably smaller than the peak at 142 EFPD. Although the 151 EFPD peak

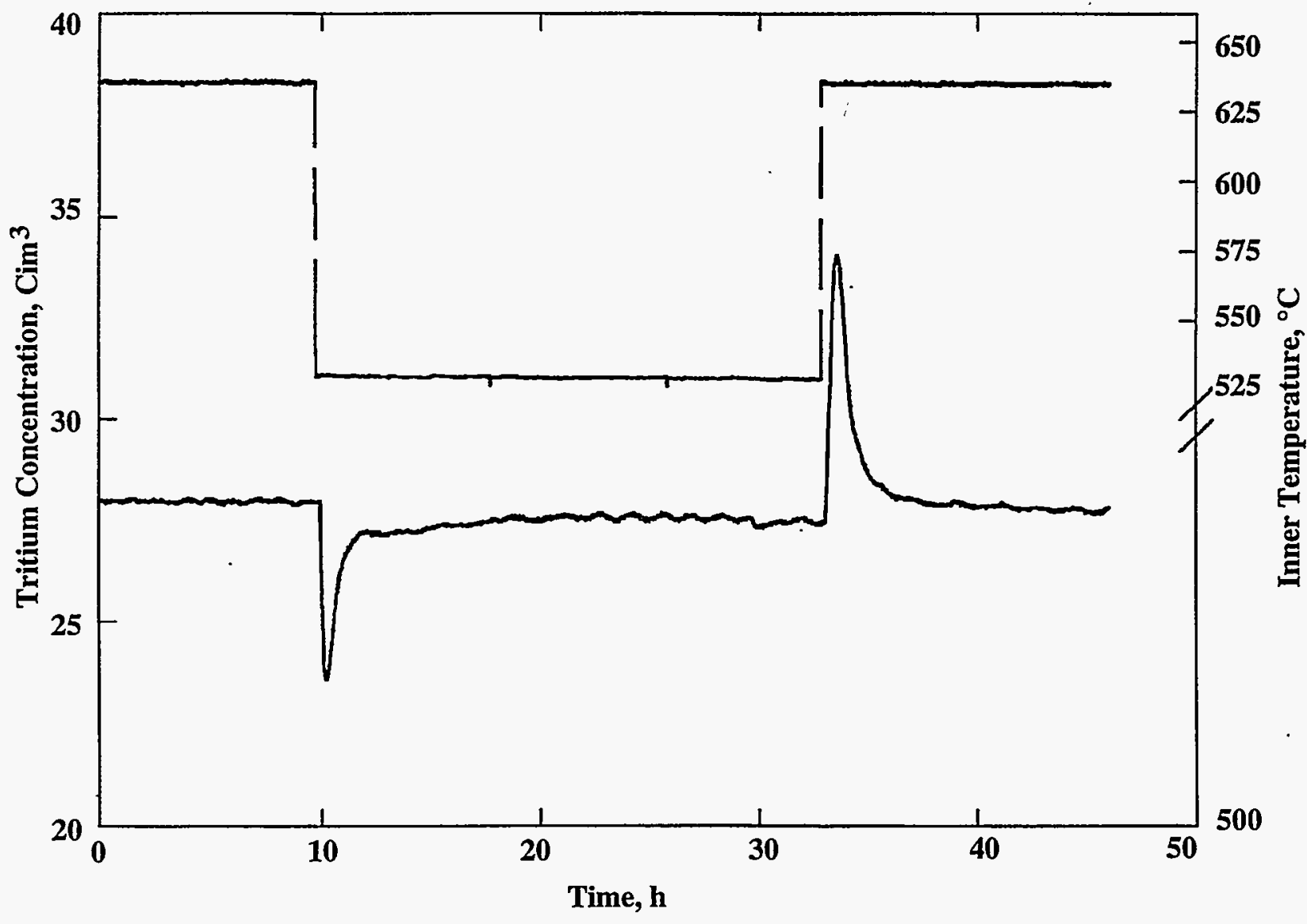

Figure 5.2. Tritium Recovery Peaks for a Temperature Change Series of $640-530-640^{\circ} \mathrm{C}$ in the Reference Sweep Gas of $0.1 \% \mathrm{H}_{2}$ 
consisted primarily of HT, it retained the initial negative peak feature. The peak at 200 EFPD continues to have the initial negative peak, suggesting that changes had been effected in the specimen during the low temperature operation in helium or $0.01 \% \mathrm{H}_{2}$ sweep gases and that these changes were not annealed out during the subsegient irradiation.

\subsubsection{Sweep-Gas Composition.}

The effect of increasing hydrogen concentration in the helium sweep gas was to decrease the tritium inventory in the specimen. This decrease in inventory occurs by an increase in the tritium release rate reflected in a positive transient tritium recovery peak. Conversely, decreasing hydrogen concentration in the sweep gas resulted in a steep drop in recovery rates followed by a slowly increasing recovery rate. The behavior following a decrease in hydrogen concentration could be considered to be a broad negative peak that required a longer time to reach equilibrium than in the case of an increase in the hydrogen concentration. Temperature transients in a helium sweep gas typically required 2 days to establish equilibrium compared to less than a day for $0.1 \% \mathrm{H}_{2}$. Similarly, the faster recovery times observed for increasing hydrogen concentrations to final sweep gas of $0.1 \% \mathrm{H}_{2}$ (as compared to a change to helium) is probably due to a faster return to equilibrium in the higher hydrogen concentration rather than indicating that inventory decreases in the $\mathrm{Li}_{2} \mathrm{O}$ occurred more rapidly than inventory increases.

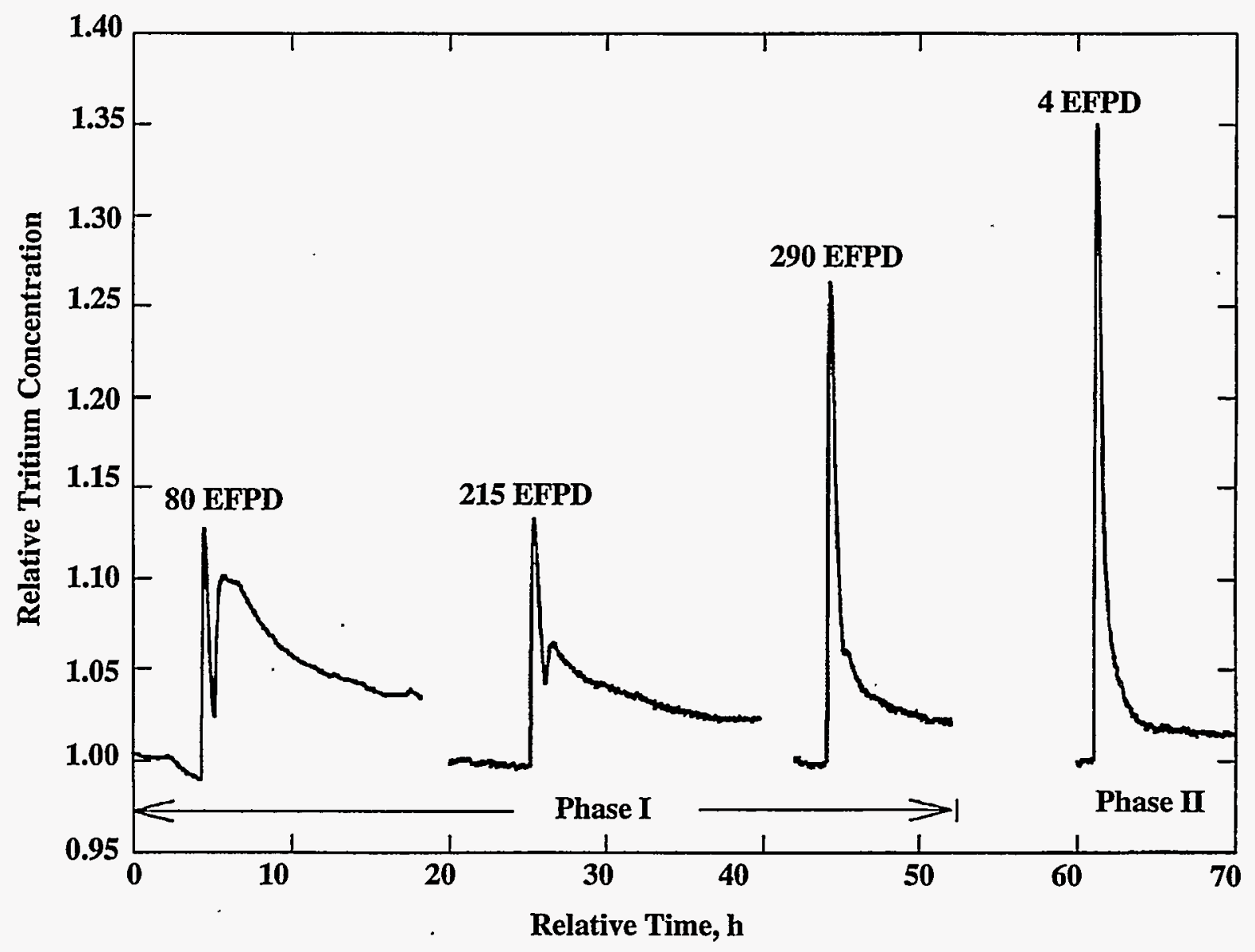

Figure 5.3. Progression of Tritium Recovery Peaks for a 550 to $640^{\circ} \mathrm{C}$ Temperature Transient in Phase I Versus a 530 to $640^{\circ} \mathrm{C}$ Temperature Transient in Phase II 
Sequences of sweep-gas-composition changes described in the test plan (Table 4.1) started and ended with $0.1 \% \mathrm{H}_{2}$ sweep gas. Figure 5.6 compares the tritium recovery curves measured during the sequence of four days in helium followed by two days in $0.01 \% \mathrm{H}_{2}$ at temperatures of 640 and $530^{\circ} \mathrm{C}$. These are Test Series B2.2 and C3.2, respectively. The tritium recovery for $640^{\circ} \mathrm{C}$ test series involved smaller peaks with faster returns to a steady-state recovery rate than for the series at $530^{\circ} \mathrm{C}$. Note also that the $530^{\circ} \mathrm{C}$ recovery peak for the return to $0.1 \% \mathrm{H}_{2}$ had an initial peak followed by a smaller secondary peak. The second peak corresponded to a peak in sweep-gas moisture, and this suggests that the first peak was HT and the second peak HTO. This is analogous to the separation of the HT and HTO peaks observed in the Phase I temperature transient (Slagle and Hollenberg 1994). The larger recovery peaks at $530^{\circ} \mathrm{C}$ reflect a larger buildup in tritium inventory than occurred for the $650^{\circ} \mathrm{C}$ tests for the cases of helium or $0.01 \% \mathrm{H}_{2}$. The occurrence of an HTO peak at $530^{\circ} \mathrm{C}$ also suggested that an appreciable part of the inventory buildup was in the form dissolved of moisture. This importance of dissolved moisture in the inventory buildup at $530^{\circ} \mathrm{C}$ is also indicated by the large $\mathrm{HTO}$ peak found for the 530 to $640^{\circ} \mathrm{C}$ temperature transient at $142 \mathrm{EFPD}$ noted above (Figure 5.5).

Phase I and Phase II behavior are compared in Figure 5.7, which is a plot of tritium recovery during a sweep-gas-composition sequence of 8 days in helium followed by 2 days in $0.01 \% \mathrm{H}_{2}$ at $640^{\circ} \mathrm{C}$ for Phase I and II (Test Series B2.1). The tritium-recovery behavior for Phase II exhibited sharper, smaller tritium-recovery peaks than Phase I.

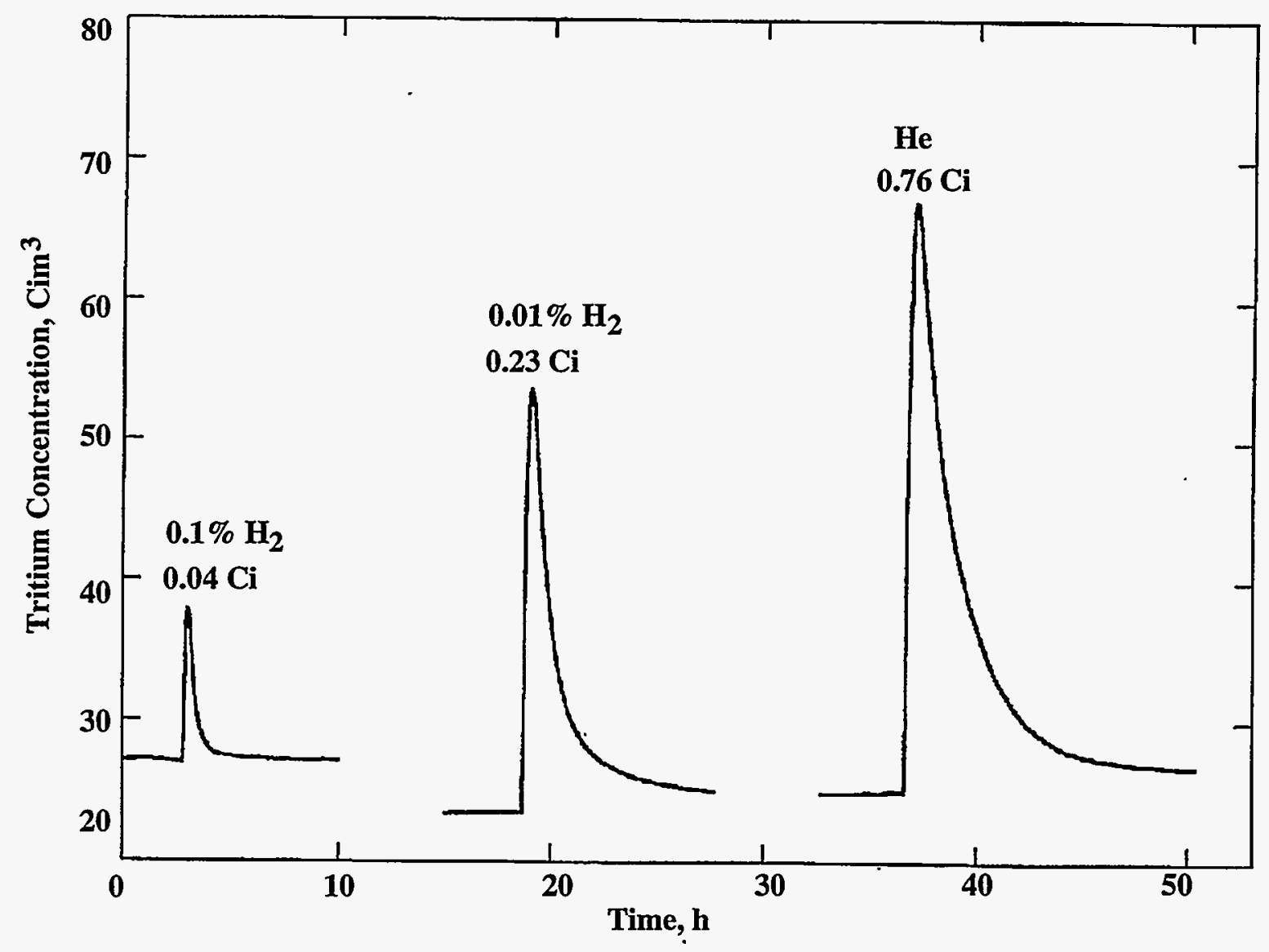

Figure 5.4. Tritium Recovery Curves for a Temperature Change from 530 to $640^{\circ} \mathrm{C}$ in the Three Different Sweep Gases: $0.1 \% \mathrm{H}_{2}, 0.01 \% \mathrm{H}_{2}$, and Helium 


\subsubsection{Reactor Power Changes}

Reactor power changes resulted in complex tritium recovery data that were influenced by associated tritium generation and thermal variations. However, power changes, particularly startup and shutdown, did provide an opportunity to study temperature changes in the specimen that are outside the range of normal operating conditions. Power changes resulted in changes in the neutron flux, resulting in associated changes in tritium and heat generation rates, and it is difficult to know which change was the dominant parameter change affecting the tritium-recovery behavior. In Phase $\mathrm{I}$, reactor startup and shutdown behavior of both canisters containing $\mathrm{Li}_{2} \mathrm{O}$ was strongly dependent on the composition of the sweep gas (Slagle and Hollenberg 1994). In a $0.1 \% \mathrm{H}_{2}$ sweep gas, decreasing the power (tritium generation rate/specimen temperature) resulted in a decrease in the tritium recovery rate as expected. However, in a helium sweep gas, the recovered tritium-concentration curve during decreasing power contained two positive.recovery peaks. Such an observation suggests a decreasing tritium inventory in the $\mathrm{Li}_{2} \mathrm{O}$ specimen with decreasing temperature. For the Phase I temperature-change canister, the major peak started at about $470^{\circ} \mathrm{C}$ and continued to the end of shutdown. A much smaller recovery peak occurred near the start of the shutdown at about $620^{\circ} \mathrm{C}$.

Phase II reactor shutdowns and startups were typically carried out using a $0.1 \% \mathrm{H}_{2}$ sweep gas. At the end of Phase II-B (103 EFPD), the sweep gas was changed to helium before the shutdown (Test Series B4) and was then also used during the startup of the next cycle. The recovered tritium concentration curve and inner specimen temperature during the shutdown are shown in Figure 5.8. The deviation of tritium-recovery concentration from a decreasing curve occurs near the middle of the curve and at the bottom. These peaks or deviations are much smaller than the major recovery peak in Phase I that started at $470^{\circ} \mathrm{C}$. In Phase II, the peaks started at 580 and $450^{\circ} \mathrm{C}$ versus 620 and $470^{\circ} \mathrm{C}$ in Phase I. No discernible anomalous behavior occurred during the startup of Phase II-B. Analysis of startups was more difficult than shutdowns because during shutdowns, the power increments were in smaller more uniform steps than those occurring in startups.

\subsubsection{Discussion}

The tritium-recovery behavior for the BEATRIX-II, Phase $I I \mathrm{Li}_{2} \mathrm{O}$ canister was similar to the behavior previously observed in Phase I. Transient recovery peaks indicated reduced inventories at higher temperatures or at higher hydrogen concentrations in the sweep gas. Two more detailed observations common to both Phase I and II invite further discussion. The first was the occurrence of small "negative" peaks preceding the positive recovery peaks that resulted from temperature changes from 530 to $640^{\circ} \mathrm{C}$ occurring after 142 EFPD in Phase II. The other observation was the reduction in inventory as the temperature was being decreased during shutdown in a helium sweep gas, i.e., "inverted" peaks.

\section{Negative Recovery Peaks}

The occurrence of small negative peaks preceding the larger positive peaks after temperature increases was observed in BEATRIX-II, Phase I, in the CRITIC-I experiment by Miller et al. (1988); Verrall, et al. (1989a); and Tanaka et al. (1994). In BEATRIX-II, Phase I, these negative peaks were only observed early in the experiment. In CRITIC-I, the behavior was observed before conditioning at 800 to $850^{\circ} \mathrm{C}$, and it was proposed that conditioning of the specimen decomposed a surface layer of $\mathrm{Li}_{2} \mathrm{CO}_{3}$. Kopasz et al. (1990) have shown that the CRITIC-I behavior could be modeled using a desorption activation energy that varies with surface coverage. Tanaka et al. (1994) found a strong relationship between the occurrence of the negative peaks and water vapor in the recovered sweep gas. Alternatively, Asaoka et al. (1992) have shown a correlation of these negative peaks with the production of $\mathrm{F}^{\mathrm{O}}$ centers. 
In BEATRIX- $\Pi$, Phase $\Pi$, the occurrence of negative peaks appeared to have been brought on by the extended operation in helium and $0.01 \% \mathrm{H}_{2}$ at the lower temperature of $530^{\circ} \mathrm{C}$. Upon returning to the reference state $\left(0.1 \% \mathrm{H}_{2}\right.$ at $\left.640^{\circ} \mathrm{C}\right)$ after operation at the lower temperature in sweep gases with reduced hydrogen $\left(\ll 0.1 \% \mathrm{H}_{2}\right)$, the tritium recovery peaks had a large component of HTO. Analogous to the conditioning of the CRITIC-I specimen at 800 to $850^{\circ} \mathrm{C}$, this recovery behavior suggests that a "reverse" conditioning of the specimen may have occurred at the lower temperatures in reduced hydrogen sweep gases. This reverse conditioning in the $\mathrm{Li}_{2} \mathrm{O}$ specimen may have been associated with a buildup of tritium inventory in the form of dissolved moisture. The occurrence of the large component of HTO in the recovery peaks during a return to the reference state is consistent with Tanaka et al. (1994) findings of the association of the phenomena with higher moisture levels.

\section{Inverted Recovery Peaks}

The observed peaks found during reactor shutdown in a helium sweep gas for Phase II confirm the behavior seen earlier in Phase I, although the Phase II peaks are much smaller. For the Phase I temperature-change canister, a major recovery peak was observed to start at about $470^{\circ} \mathrm{C}$. A much smaller recovery peak was observed at the start of shutdown at a temperature of approximately $620^{\circ} \mathrm{C}$, but it is believed that this was caused by temperature fluctuations in the specimen. In Phase II, the peaks observed at $580^{\circ} \mathrm{C}$ and $450^{\circ} \mathrm{C}$ are considerably smaller than the Phase I peak observed starting at $470^{\circ} \mathrm{C}$. A comparison of the temperatures across the ring specimen indicated that the Phase II peak starting at a temperature of $450^{\circ} \mathrm{C}$ is consistent with the $470^{\circ} \mathrm{C}$ peak in Phase I.

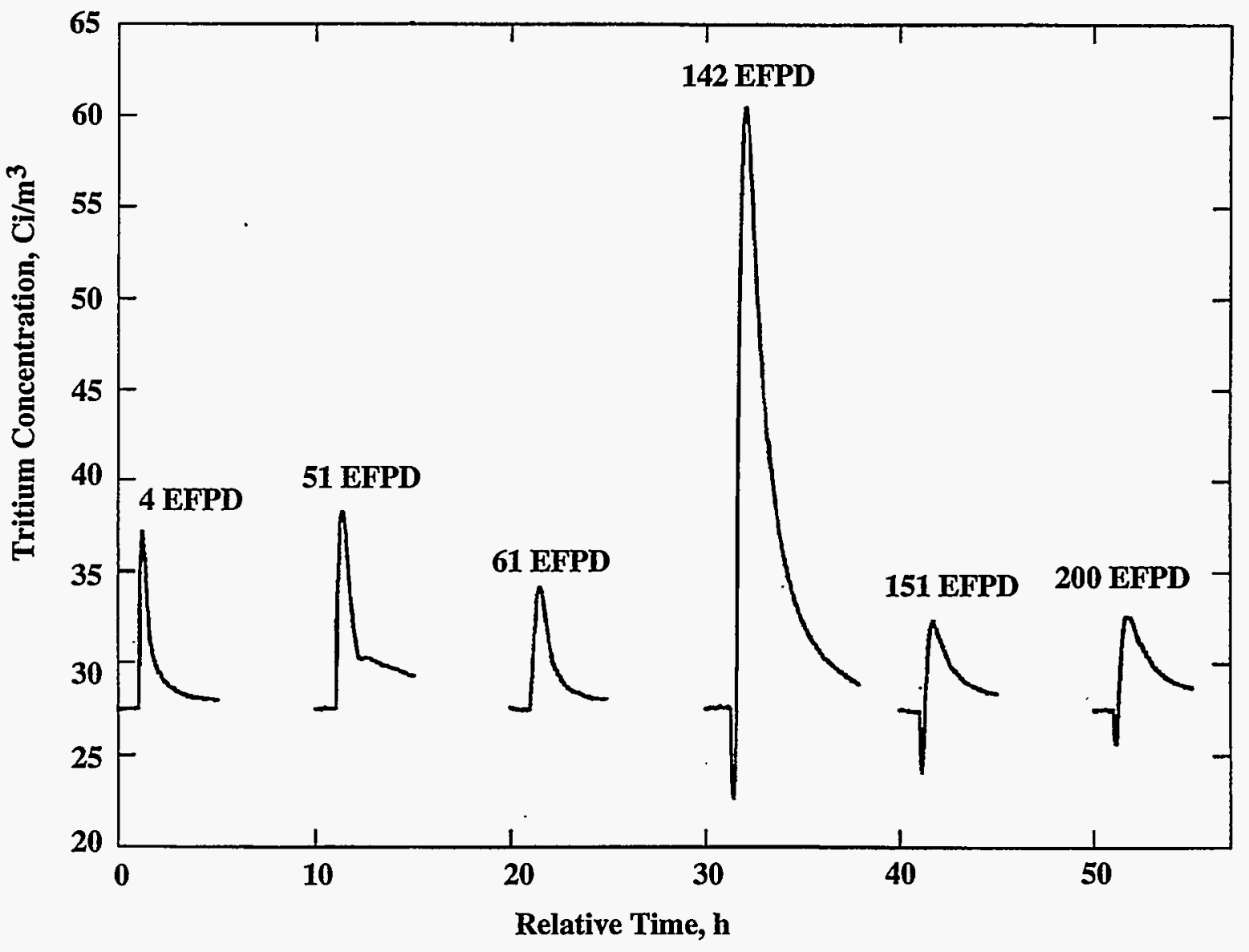

Figure 5.5. Tritium-Recovery Peaks for Temperature Transient 530 to $640^{\circ} \mathrm{C}$ at $4,51,61$, 142,151 , and $200 \mathrm{EFPD}$ 
The Phase I specimen had a $40^{\circ} \mathrm{C}$ temperature difference across the specimen while the Phase II Specimen had a $20^{\circ} \mathrm{C}$ difference. An inner temperature of $450^{\circ} \mathrm{C}$ in Phase II was equivalent to a specimen temperature of 450 to $430^{\circ} \mathrm{C}$. A $470^{\circ} \mathrm{C}$ temperature in Phase I was equivalent to a specimen temperature of 470 to $430^{\circ} \mathrm{C}$. The temperature overlap between Phase I and Phase II suggests that the data are in very good agreement.

The tritium-recovery peaks that occurred during reactor shutdowns in helium suggest that if temperature transients had been carried out in the specific temperature regions associated with these peaks, temperature decreases would result in tritium-inventory decreases. The fact that such decreases were not seen during the temperature transients carried out from $640-590-530^{\circ} \mathrm{C}$ may have been because the temperature intervals were too broad and/or the decreases were masked by the overall increase. The Phase II shutdown peak in the vicinity of $580^{\circ} \mathrm{C}$ (Figure 5.8) was not a particularly large peak and could easily be overshadowed by a larger temperature drop. However, in Phase I, the shutdown peak in the 470 to $430^{\circ} \mathrm{C}$ temperature range was much larger, and one could expect to see such an "inverse" effect in temperature transients carried out at these lower temperatures. Because these lower temperatures were not achievable in BEATRIX-II, no data are available. However, the CRITIC-I experiment on $\mathrm{Li}_{2} \mathrm{O}$ did carry out temperature transients at these lower temperatures. During the initial part of the experiment, low temperature transients in the range of 460 to $620^{\circ} \mathrm{C}$ resulted in inverted peaks. That is, a decrease in temperature resulted in a positive peak in the tritiumrecovery curve. The CRITIC-I experimental observations included a temperature transient from 540

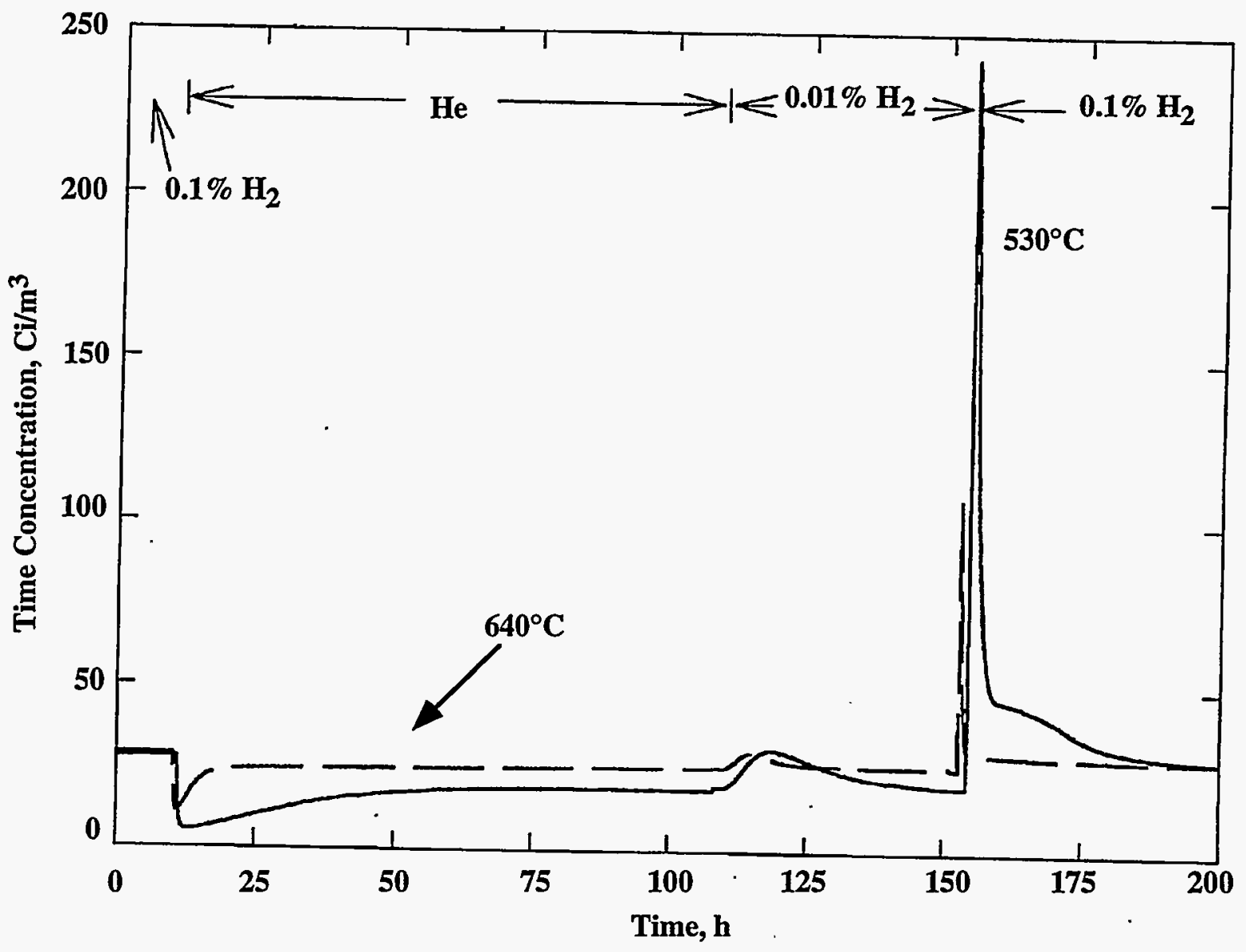

Figure 5.6. Tritium-Recovery Curves Measured at Temperatures of 640 and $530^{\circ} \mathrm{C}$ for the Gas-Composition Sequence of 4 Days in Helium Followed by 2 Days in $0.01 \%$ $\mathrm{H}_{2}$ 
to $480^{\circ} \mathrm{C}$ in helium sweep gas that resulted in a positive tritium-recovery peak. This behavior is very consistent with the behavior seen in the BEATRIX-II, Phase I and II shutdown curves in helium. As noted above for the "negative" peaks, the inverted peaks in the CRITIC-I test occurred in the first part of the test and were not observed later on in the experiment after the 800 to $850^{\circ} \mathrm{C}$ conditioning. It was proposed that the inverted peaks were associated with the solubility of tritium in a surface layer that was decomposed or eliminated during conditioning.

The inverted tritium recovery peaks in the 470 to $430^{\circ} \mathrm{C}$ temperature range correspond to a temperature range where LiOT or dissolved moisture is an important factor in determining the tritium inventory in $\mathrm{Li}_{2} \mathrm{O}$ (Billone et al. 1991; Tetenbaum and Johnson 1984). Because the moisture levels in the BEATRIX-II sweep gas are typically less than $0.1 \mathrm{~Pa}$, the amount of moisture in the specimen is expected to remain below the $\mathrm{LiOH}$ solubility limit as the temperature is decreased. A previous discussion of the Phase I behavior (Slagle et al. 1992) suggested that the variation of water vapor pressure over $\mathrm{LiOT}$ dissolved in $\mathrm{Li}_{2} \mathrm{O}$ may have contributed to the shutdown behavior. At the present time, the explanation of the inverse peaks is not complete. However, operation in helium and the subsequent buildup of tritium inventory does appear to be associated with a buildup of dissolved moisture in the specimen as suggested by the large HTO peaks observed when the specimen is returned to the reference condition. This buildup of tritium inventory in the $\mathrm{Li}_{2} \mathrm{O}$ is one of the primary differences in the specimens operated in helium versus $0.1 \% \mathrm{H}_{2}$. The occurrence of these inverse peaks during the shutdown in helium and not in $0.1 \% \mathrm{H}_{2}$ suggests that the buildup of tritium

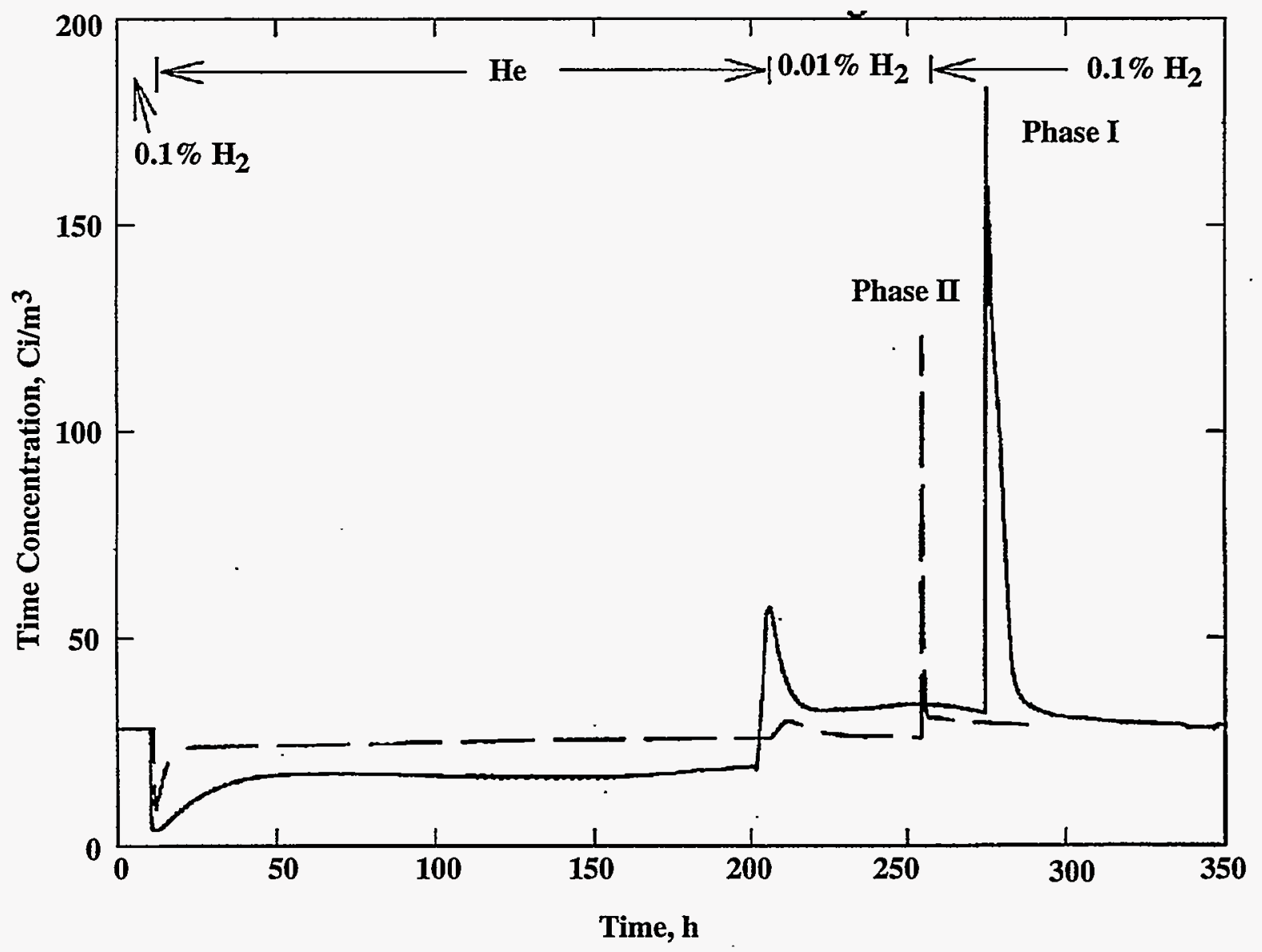

Figure 5.7. Comparison of $640^{\circ} \mathrm{C}$ Tritium Recovery Curves for the Phase I and II Sweep-Gas Composition Sequences of 8 Days in Helium Followed by 2 Days in $0.01 \% \mathrm{H}_{2}$ 
inventory during operation in helium, possibly in the form of dissolved moisture, may contribute to this behavior.

\subsection{Temperature-Gradient Canister}

The test plan for the irradiation of the Phase II temperature-gradient canister is detailed in Table 4.1. The primary parameter changes are sweep-gas composition and sweep-gas flow rate. The reference condition was selected to be a sweep gas of helium with $0.1 \% \mathrm{H}_{2}$, and a flow rate of $100 \mathrm{~mL} / \mathrm{min}$.

\subsubsection{Centerline Temperatures}

Figure 5.9 is a plot of center temperatures and sweep-gas moisture for the startup of the Phase II temperature-gradient canister. The center temperatures are the output of the two thermocouples in the center annulus of the specimen. The upper thermocouple was a Mo-Nb thermocouple designed to operate at higher temperatures than the lower thermocouple that was a Type $\mathrm{K}$ thermocouple as were the thermocouples used in the Phase I temperature-gradient canister. The upper thermocouple recorded consistently higher temperatures during startup with a final temperature at $100 \%$ power of $1115^{\circ} \mathrm{C}$ versus $1060^{\circ} \mathrm{C}$ for the lower thermogouples. After the power-reduction test carried out by reactor operations at 150 hours (Figure 5.9), the upper thermocouple had a $10^{\circ} \mathrm{C}$ lower reading while

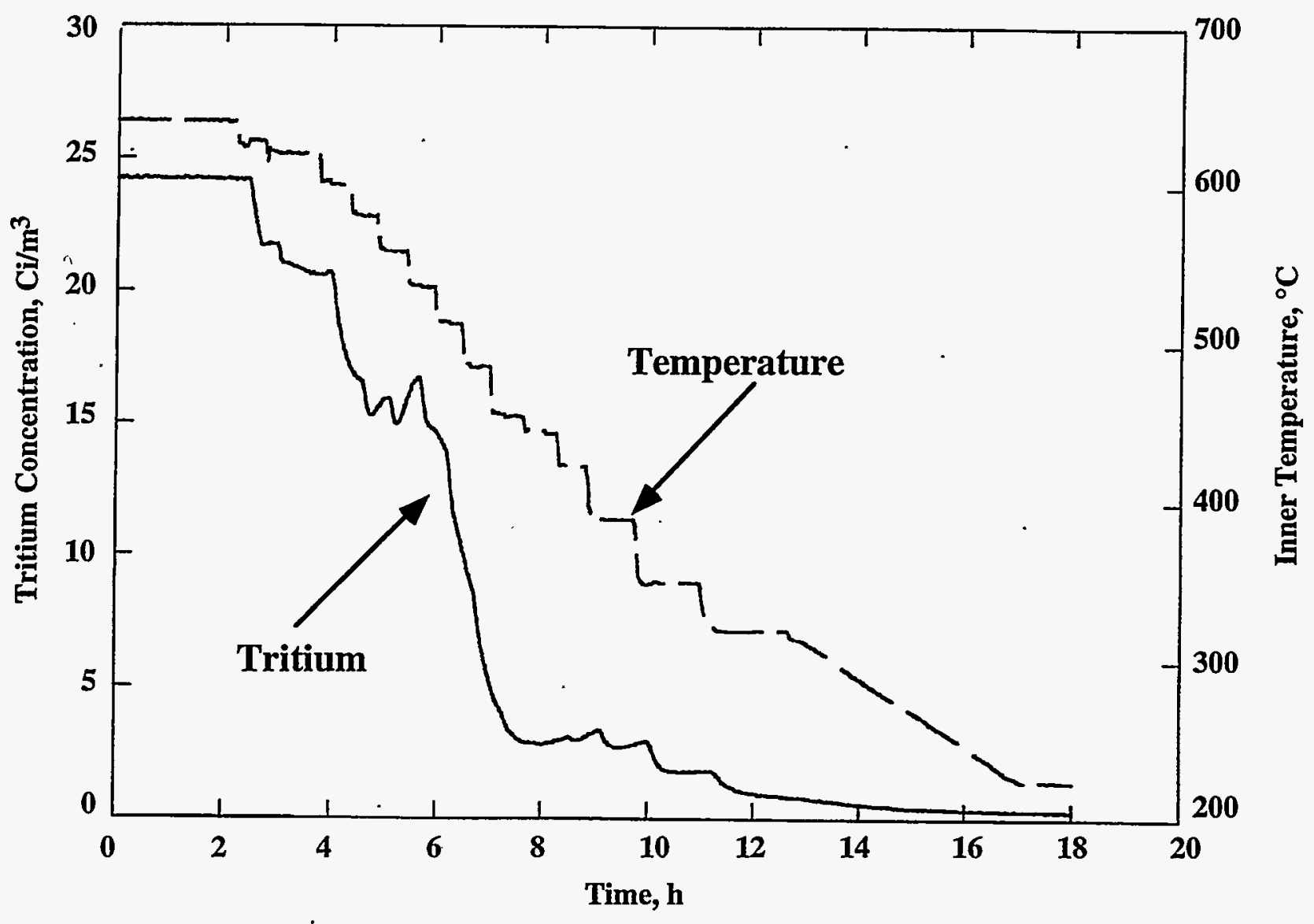

Figure 5.8. Recovered-Tritium Concentration and Inner Specimen Temperature During Shutdown in Helium Sweep Gas 
the lower thermocouple remained the same. This difference of $45^{\circ} \mathrm{C}$ remained constant for the remainder of the operation shown in Figure 5.9. The higher reading for the upper thermocouple was attributed to the increase in neutron flux from the bottom to the top of the canister. The separation between the ends of the thermocouple sheaths from the pretest radiograph (Figure 2.8) was less than $1 / 3 \mathrm{~cm}$, but the actual point of contact for the wires may have been as far apart as $2 \mathrm{~cm}$.

The thermal and neutronic performance-analysis prediction (Section 2) carried out for the initial design of the canister had a predicted centerline temperature of $1095 \pm 65^{\circ} \mathrm{C}$. The temperatures found at the start of the irradiation lie within the predicted range. This range of predicted temperatures was due primarily to uncertainties in the thermal conductivity of the pebble bed. The good agreement of the predicted and measured temperature adds additional confidence in the ability to model the thermal properties of a $\mathrm{Li}_{2} \mathrm{ZrO}_{3}$ pebble bed.

Figure 5.10 is a plot of the readings from the two central thermocouples for the four irradiation cycles. The gradual decrease in temperature during each reactor cycle was attributed to burnup of the fuel and a decreasing flux at this position in the reactor. Similar thermal behavior was also observed in the Phase I irradiation of $\mathrm{Li}_{2} \mathrm{O}$, and the absence of drastic changes during irradiation was interpreted as an indicator of stable performance for the specimen. This stable performance is also confirmation of the physical stability of the $\mathrm{Li}_{2} \mathrm{ZrO}_{3}$ pebble bed and its suitability for use as a fusion blanket material.

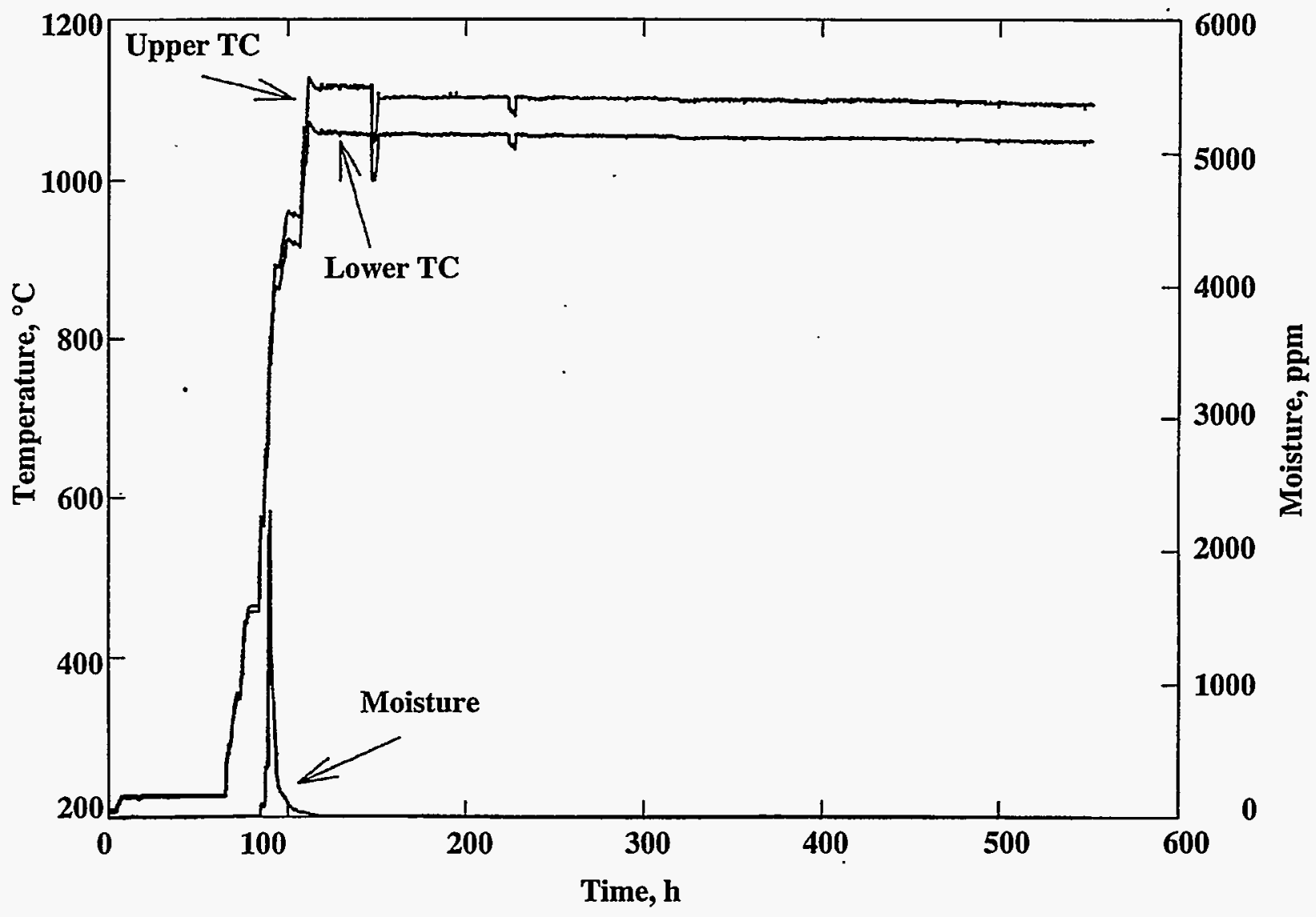

Figure 5.9. Center Temperatures and Sweep-Gas Moisture for the Startup of the Phase II Temperature-Gradient Canister 


\subsubsection{Sweep Gas Moisture}

During the initial reactor startup at the beginning of the experiment, a 2400 -ppm spike in the sweep-gas moisture concentration was observed (Figure 5.9). The moisture concentration then decreased to less than $1 \%$ of that value after 1 EFPD of operation. After 7 EFPD, the reading was less than $0.02 \mathrm{ppm}$ (nominal), well below the instrument's limit of accuracy. Because sweep gas had been flowing for several days before reactor startup to dry all system components, it is assumed that the moisture release during startup emanated from the ceramic. This moisture release was much smaller than that observed in a similar experiment on $\mathrm{Li}_{2} \mathrm{ZrO}_{3}$ - CRITIC-II (Miller and Verrall 1994). In CRITIC-II, the specimen had been pre dried in air at $200^{\circ} \mathrm{C}$. The source for the moisture for both experiments is believed to have been residual $(\mathrm{OH})^{-1}$ in the ceramic remaining after dry out. For the rest of the Phase II irradiation, the release of moisture was extremely low. During steady state operation, the meter output was zero. Following changes in sweep-gas composition when the hydrogen concentration was increased, small apparent peaks of moisture were recorded, but the indicated levels were less than $0.05 \mathrm{ppm}$. These small peaks in moisture release were consistently observed during sweep-gas-composition changes and coincided with a rise in both total tritium release and tritiated water release. Although the absolute accuracy of standard moisture meters does not extend to these low levels, these peaks probably indicated a real release of moisture. Low moisture release was a notable feature of the Phase $\Pi \mathrm{Li}_{2} \mathrm{ZrO}_{3}$ test. Low levels of moisture were also released by $\mathrm{Li}_{2} \mathrm{O}$ in the BEATRIX-II Phase $\mathrm{I}$ and Phase II tests, but not as low as $\mathrm{Li}_{2} \mathrm{ZrO}_{3}$.

\subsubsection{Sweep Gas Composition Changes}

Systematic changes in the sweep-gas composition were made to determine the effect of composition on tritium release. Observed changes in tritium recovery rate could potentially be due to inventory changes elsewhere in the system, e.g., the piping. However, laboratory tests at AECL have

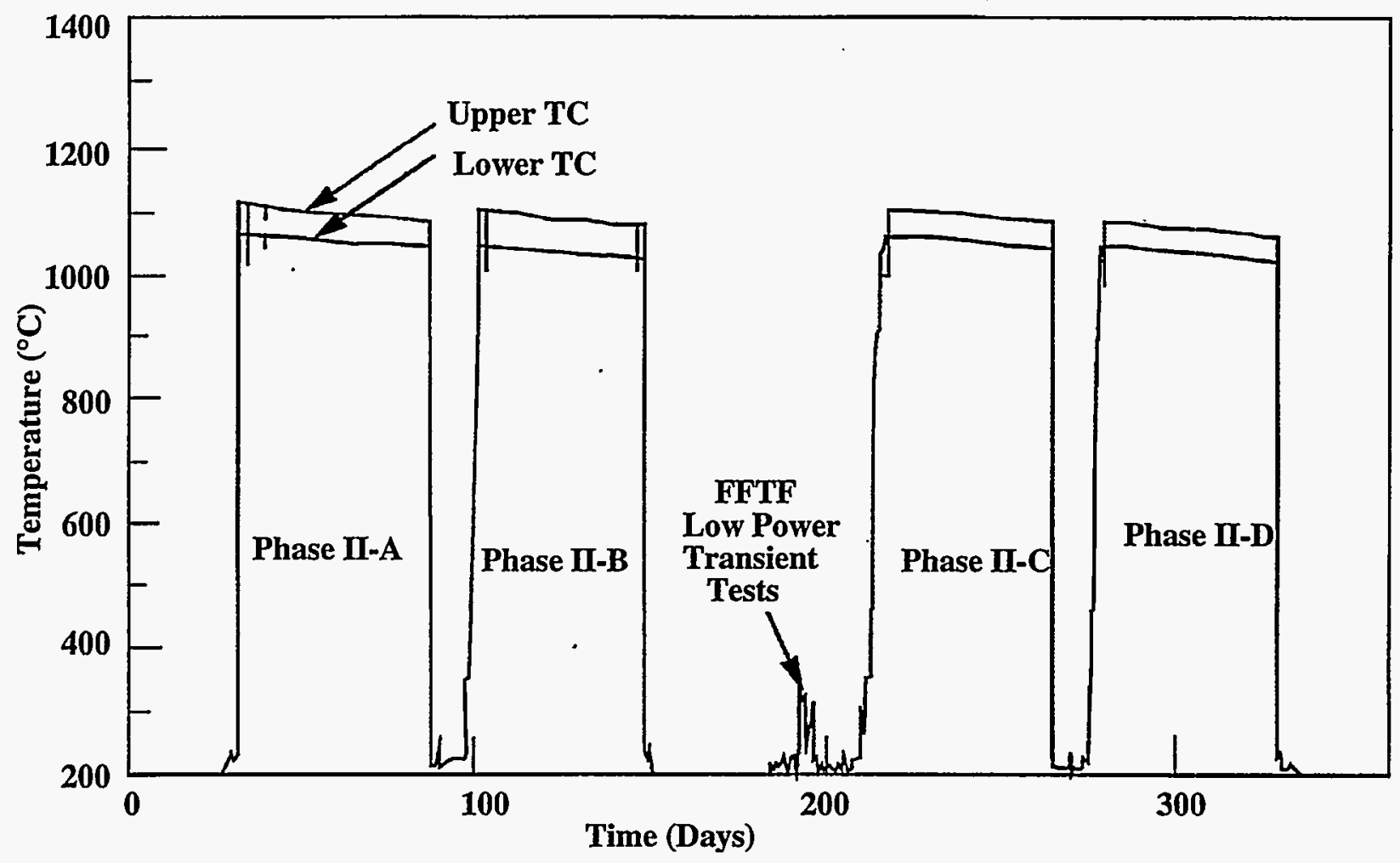

Figure 5.10. Center Temperatures of the Phase II Temperature-Gradient Canister for the Four Irradiation Cycles 
shown that changes in inventory on piping do not readily occur from changes in hydrogen concentration in the sweep gas (Rodrigo et al. 1992). Moisture additions to the sweep gas are required to effect sizable inventory changes on the piping. For this reason, the observed tritiumrecovery data can be expected to reflect the tritium release from the $\mathrm{Li}_{2} \mathrm{ZrO}_{3}$ pebbles.

\section{Effect of Time in Helium}

The buildup of tritium inventory with time in a helium sweep gas was investigated by switching to helium for varying lengths of time. Periods of 2,4 , and 8 days in helium were used. These tests are described in the test plan as A3.2, B1.2, and B1.3, respectively. The results are shown in Figure 5.11 and indicate the following:

- When switching from the reference sweep gas to pure helium, all tests showed a sharp transient drop in tritium recovery rate, followed by a return to a new steady-state rate, slightly lower than in the reference gas.

- All exhibited two distinct peaks or a "double" peak upon reintroduction of the reference sweep gas and a return to the same steady-state recovery rate as in the original reference condition.

- $\quad$ Following the $\mathrm{He}-0.1 \% \mathrm{H}_{2}$ transition, the peak height and integrated areas under the peaks increased with the duration in the helium sweep gas. The areas were $0.18 \mathrm{Ci}$ ( 2 days), $0.77 \mathrm{Ci}$ (2 days), and $1.63 \mathrm{Ci}$ (8 days).

The double peak was thought to be due to a rapid HT peak and a slower HTO peak. The rapidity of the HT peak may reflect the kinetics of release from the ceramic or a more rapid transit through the piping to the ion chamber, due possibly to an "open-tube chromatographic" effect of the HTO gas. That is, the HTO continuously adsorbs and desorbs from the walls as it moves through the piping. The HT is less reactive with the walls.

After only a few hours in the helium sweep gas, the tritium recovery rate was approximately constant at a value that appeared to be slightly lower than the value in the reference sweep gas. This implies a steady buildup of tritium inventory in the specimen with time in helium. The steady-state recovery rates in the helium and $0.1 \% \mathrm{H}_{2}$ sweep gases have an uncertainty of 5 to $10 \%$ because of the uncertainty in the enhancement factors (Section 3.1) for the ion chambers. Despite this uncertainty, the tritium recovery rate in helium must be lower than the steady-state recovery rate in reference gas because of the tritium recovery peaks that occur after returning to $0.1 \% \mathrm{H}_{2}$. The size of these peaks does not appear to be approaching a limiting value after 8 days, suggesting that inventory buildup in the specimen is occurring even after 8 days in helium.

\section{Tritium Recovery in $0.01 \% \mathrm{H}_{2}$ versus Helium}

The tritium recovery for 4 days in $0.01 \% \mathrm{H}_{2}$ (B1.1) was compared to the recovery for 4 days in helium sweep gases (B1.2). The tritium-recovery curves are given in Figure 5.12. The steady-state recovery in $0.01 \% \mathrm{H}_{2}$ appears to be approximately equal to that in helium, but the smaller recovery peak for $\mathrm{He}-0.01 \% \mathrm{H}_{2}$ upon reintroduction of the reference gas is a clear indication that the inventory buildup in $\mathrm{He}-0.01 \% \mathrm{H}_{2}$ gas was less than in helium. This suggests that the recovery rate for helium may be slightly less than that for $\mathrm{He}-0.01 \% \mathrm{H}_{2}$.

Tritium Recovery in Helium Followed by $0.01 \% \mathrm{H}_{2}$

The inventory in helium versus $0.01 \% \mathrm{H}_{2}$ was investigated by following 4 days of operation in helium with 2 days in $0.01 \% \mathrm{H}_{2}$ (C3.1). The tritium-recovery curves in Figure 5.13 indicated that a $20 \%$ reduction of recovery rate occurred in helium (versus $0.1 \% \mathrm{H}_{2}$ ) followed by a recovery rate in 
$\mathrm{He}-0.01 \% \mathrm{H}_{2}$ gas that was only $8 \%$ less than initial recovery rate in the reference gas. Upon reintroduction of reference gas, the recovery rate returned to its original value. One interesting feature of the recovery curve is the shape of the curve following the change from helium to $0.01 \% \mathrm{H}_{2}$. Instead of increasing to the new higher recovery rate, the curve first decreases. This type of "negative peak" was observed for temperature increases in the Phase I and Phase II temperature change canister and has been referred to as "negative peaks." Negative peaks were observed not only for Test Series C3.1, but also for similar Test Series C3.2 and A2.

Observations of the tritium recovery as a function of sweep-gas composition are consistent with a tritium release rate that decreases with decreasing hydrogen concentration in the helium sweep gas. In the reference gas, tritium was assumed to have been released and recovered at or near the generation rate in the ceramic. Residual tritium-inventory measurements during postirradiation examination (PIE) that confirm this will be discussed in Section 6. Measurements during PIE on Phase $\mathrm{I} \mathrm{Li}_{2} \mathrm{O}$ showed no large tritium inventory buildup, which was also consistent with this interpretation.

Tritium Recovery in $1.0 \% \mathrm{H}_{2}$

Decreasing hydrogen concentration from the reference sweep gas $\left(0.1 \% \mathrm{H}_{2}\right)$ resulted in an increase in the tritium inventory of $\mathrm{Li}_{2} \mathrm{O}$ and $\mathrm{Li}_{2} \mathrm{ZrO}_{3}$. An obvious question is whether increasing the hydrogen concentration above $0.1 \% \mathrm{H}_{2}$ would result in a lower tritium inventory in the specimen. Figure 5.13 is the tritium recovery curve obtained for a 1-day change to $1.0 \% \mathrm{H}_{2}$. The total tritium, reduced tritium $(\mathrm{HT})$ are plotted.

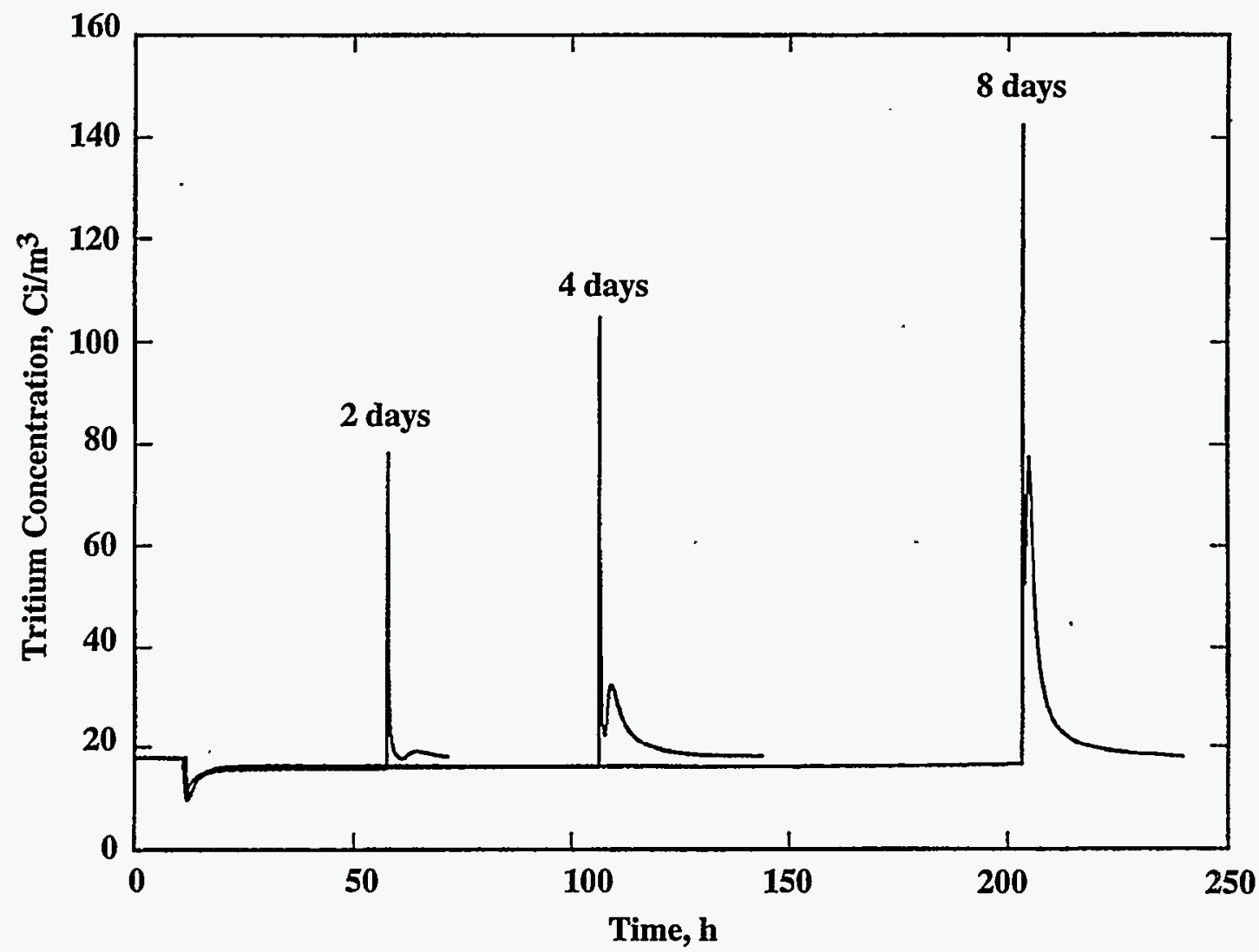

Figure 5.11. Superposition of the Results of Three Tests in Helium for 2, 4, and 8 Days in Helium Sweep Gas, Preceded and Followed by $\mathrm{He}-0.1 \% \mathrm{H}_{2}$ 
Compared to peaks recovered during transitions from helium and $0.01 \% \mathrm{H}_{2}$ to $0.1 \% \mathrm{H}_{2}$, the peaks for the transition from $0.1 \% \mathrm{H}_{2}$ to $1.0 \% \mathrm{H}_{2}$ are small. At the end of the one day period, the recovery rate in $1.0 \% \mathrm{H}_{2}$ appears larger than the steady-state recovery rate in $0.1 \% \mathrm{H}_{2}$. However, this larger recovery rate in $1.0 \% \mathrm{H}_{2}$ more likely results from the uncertainty of the ion-chamber correction factor used for $1.0 \% \mathrm{H}_{2}$. The same enhancement factor was used in this analysis as was used in Phase $\mathrm{I}: 1.4$.

The general shape of the total recovered tritium peak in Figure 5.14 is the same as that observed for the Phase $\mathrm{I} \mathrm{Li}_{2} \mathrm{O}$ temperature-gradient capsule after a transition to $1.0 \% \mathrm{H}_{2}$ sweep gas. The occurrence of the initial negative peaks in the transition from $0.1 \% \mathrm{H}_{2}$ to $1.0 \% \mathrm{H}_{2}$ is similar to that observed in the transition from $\mathrm{He}$ to $0.01 \% \mathrm{H}_{2}$ for the Phase II temperature-gradient canister (Figure 5.13).

\section{Phase $\mathrm{II}_{\mathrm{Li}_{2}} \mathrm{ZrO}_{3}$ Versus Phase $\mathrm{I} \mathrm{Li}_{2} \mathrm{O}$}

Figure 5.15 is a superposition of the tritium recovery data for 4 days in helium for the Phase II temperature-gradient canister containing $\mathrm{Li}_{2} \mathrm{ZrO}_{3}$ pebbles (Test Series B1.2) and a very similar test series for the Phase I temperature-gradient canister containing solid $\mathrm{Li}_{2} \mathrm{O}$. The main difference in the recovery curves is in the integrated areas under the peaks. Both the negative peak at the introduction of He sweep gas and the positive peak at the return to helium- $0.1 \% \mathrm{H}_{2}$ are smaller for $\mathrm{Li}_{2} \mathrm{ZrO}_{3}$. The inventory change for the large positive $\mathrm{Li}_{2} \mathrm{O}$ peak is $14.4 \mathrm{Ci}$, while that for the $\mathrm{Li}_{2} \mathrm{ZrO}_{3}$ peak is 0.76 Ci. Centerline temperatures in the Phase $I \mathrm{Li}_{2} \mathrm{O}$ were less than $1000^{\circ} \mathrm{C}$, and the tritium generation rate was about 3 times as large in the $\mathrm{Li}_{2} \mathrm{O}$. Thus, tritium inventory increases in a helium sweep gas for

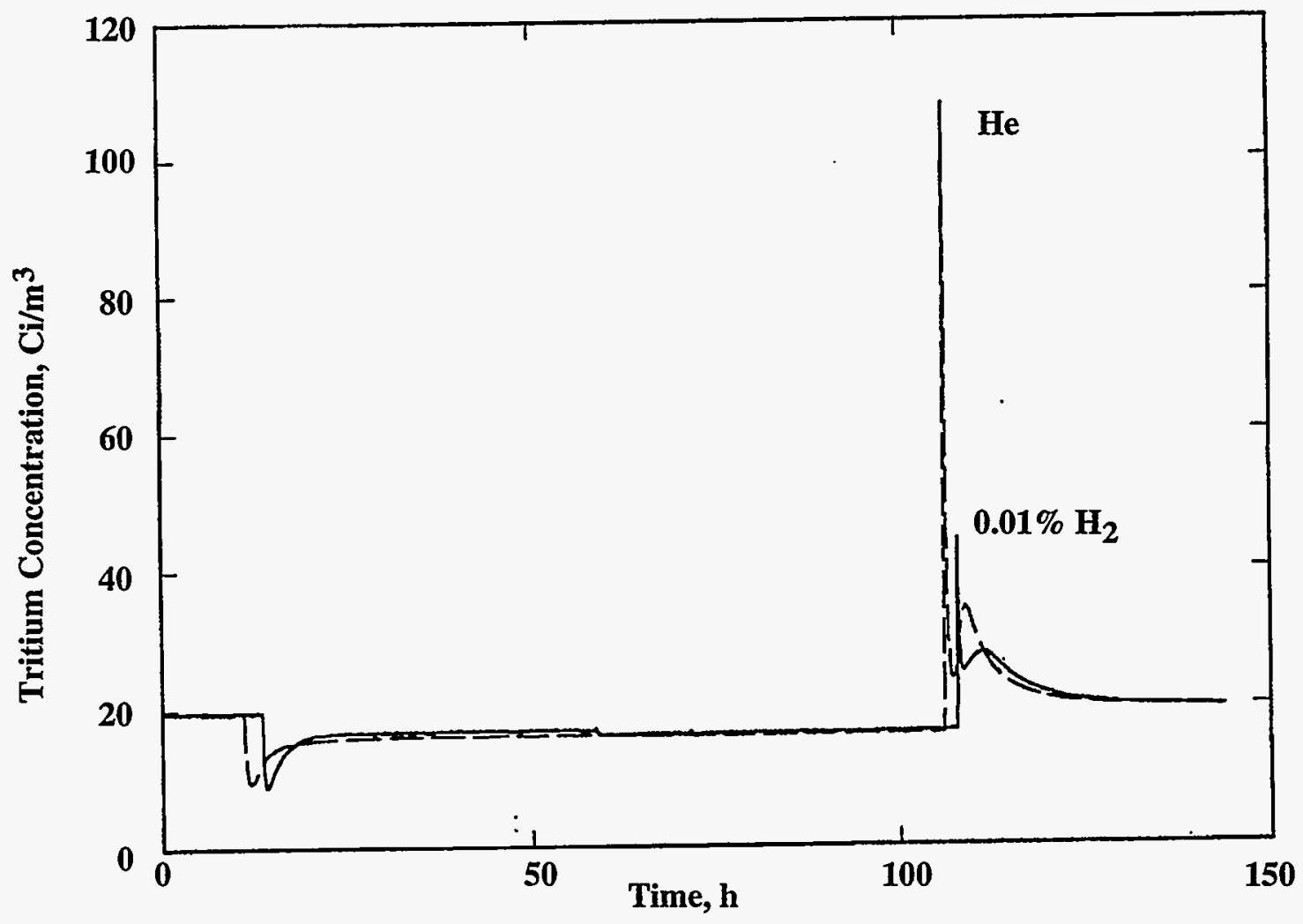

Figure 5.12. Superposition of the Results of Two Tests, One Using Helium and One Using He$0.01 \% \mathrm{H}_{2}$ Sweep Gas 
both ceramics, but the buildup is smaller for the lithium zirconate. Note that a small secondary HTO peak does occur for $\mathrm{Li}_{2} \mathrm{O}$ at reintroduction of $\mathrm{He}-0.1 \% \mathrm{H}_{2}$ but it is masked by the width of the large HT peak. These data indicate that, compared to $\mathrm{Li}_{2} \mathrm{O}$, the tritium inventory in $\mathrm{Li}_{2} \mathrm{ZrO}_{3}$ is less sensitive to the amount of hydrogen in the sweep gas.

\subsubsection{Flow Rate}

During the time periods when the ion chamber on the CEC flow stream for the temperaturechange canister was being calibrated in helium sweep gas, the sweep-gas flow rate in the temperaturegradient canister was increased to $200 \mathrm{~mL} / \mathrm{min}$ of $0.1 \% \mathrm{H}_{2}$ sweep gas. Immediately after the increase, the recovery rate increased about 3 to $4 \%$, but then slowly decreased. Similarly, upon dropping the flow rate from 200 to $100 \mathrm{~mL} / \mathrm{min}$, the recovery rate decreased and then slowly increased. The data suggest that increasing the flow rate may cause a slight reduction in the inventory of the specimen or system. Such a reduction may have been associated with a "purging" effect due to the drop in tritium concentration in the sweep gas.

One of the difficulties in interpreting the changes in tritium recovery rates with changes in flow rate is that the effect of flow rate on the ion-chamber response is not known. Test Series B.2 for the temperature-gradient canister involved a change in flow rate through the CEC and the molecular sieve flow streams while keeping the total flow through the canister the same. The flow rate through the CEC was changed from 50 to $25 \mathrm{~mL} / \mathrm{min}$, and the flow rate through the molecular sieve was

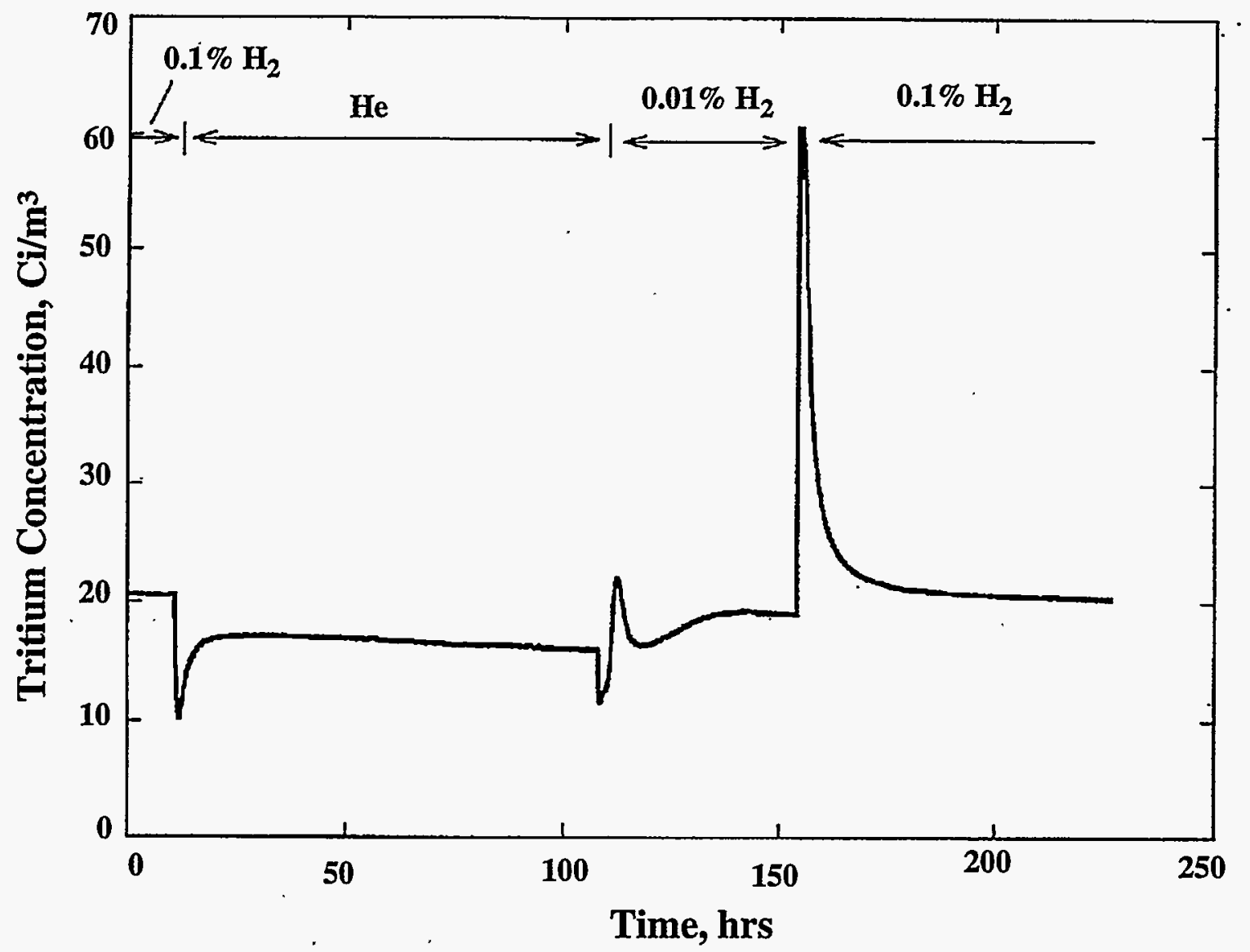

Figure 5.13. Recovered Tritium during Sweep Gas Composition Changes for 4 Days in Helium Followed by 2 Days in $0.01 \% \mathrm{H}_{2}$ for the Temperature-Gradient Canister 
changed from 50 to $75 \%$. No change occurred in the response of the ion chamber on the CEC flow stream, but the ion-chamber response on the molecular-sieve flow stream decreased $1.4 \%$ with the $50 \%$ increase in flow rate. These limited results suggest that for flow rates in the range of 25 to 75 $\mathrm{mL} / \mathrm{min}$, the effect of flow rate on the ion-chamber response was negligible.

\subsubsection{Reactor Startup/Shutdown}

The Phase II temperature-gradient canister was shutdown in helium at the end of Phase II-B and restarted in helium in Phase II-C. Temperature decreases were accompanied by decreases in the tritium recovery rate, and no unexpected behavior was observed as was seen in Phase I. This observation supports the conclusion reached from the comparison of Phase I and Phase II in Figure 5.15: compared to $\mathrm{Li}_{2} \mathrm{O}$, the tritium inventory in $\mathrm{Li}_{2} \mathrm{ZrO}_{3}$ is less sensitive to the amount of hydrogen in the sweep gas.

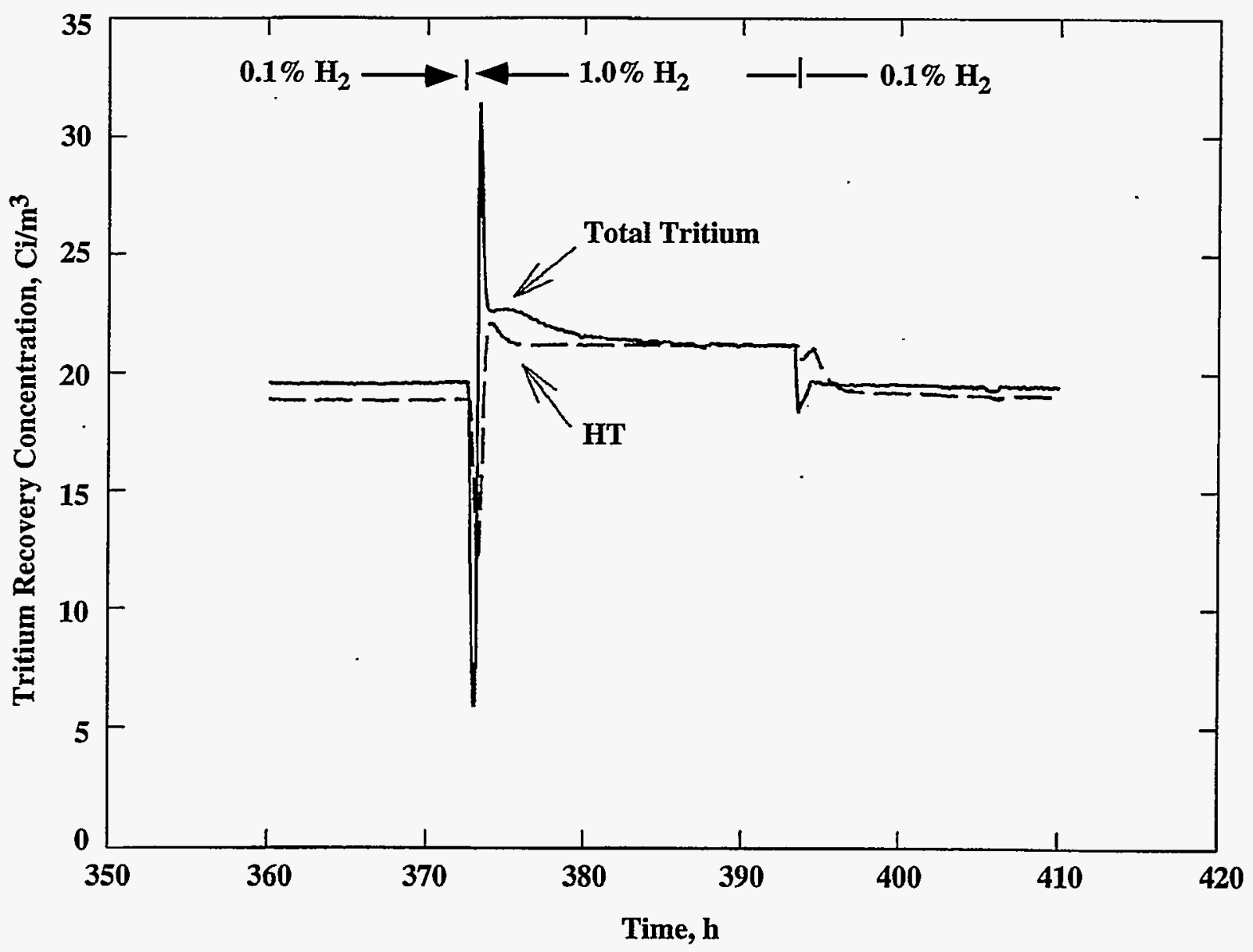

Figure 5.14. Tritium Recovery Curve for a 1-Day Change to $1.0 \% \mathrm{H}_{2}$ 


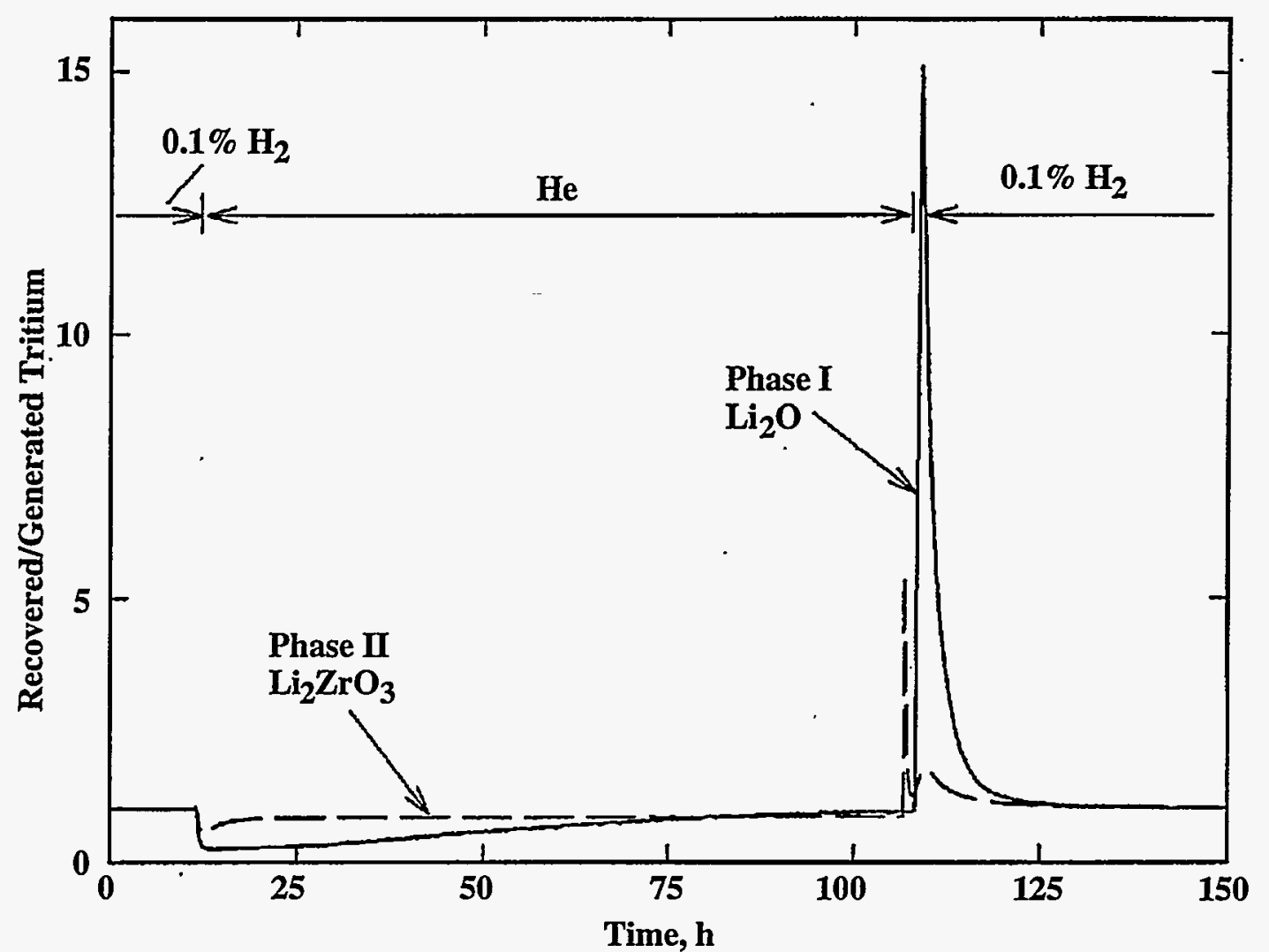

Figure 5.15. Superposition of the Results of Two Tests, both Using Helium Sweep Gas for 4 Days. One is for the BEATRIX-II, Phase II lithium zirconate, and one is for BEATRIX-II, Phase $I \mathrm{Li}_{2} \mathrm{O}$. The tritium-recovery-rate axis is normalized to the generation rates for the two materials. 


\subsection{Postirradiation Examination}

Postirradiation examination of the lithium ceramics irradiated in BEATRIX-II was carried out to evaluate their physical and chemical stability during irradiation and to contribute to understanding the tritium/helium behavior. The final tritium inventory was used to establish a baseline at reference conditions that can be used to extrapolate to the tritium inventory at other testing temperatures and sweep-gas compositions. Postirradiation examination carried out after the Phase II in situ testing

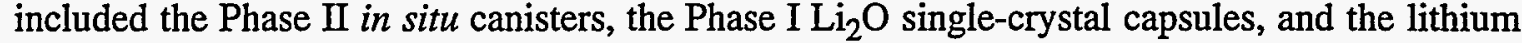
ceramic-beryllium compatibility capsules irradiated in Phase I and II.

The chemical and physical integrity of the in situ $\mathrm{Li}_{2} \mathrm{O}$ and $\mathrm{Li}_{2} \mathrm{ZrO}_{3}$ specimens were expected to be influenced by the temperature and sweep-gas compositions under which the materials operated. The irradiation was concluded by a reactor shutdown over 10 hours during which time approximately $0.6 \mathrm{Ci}$ of tritium were generated in the $\mathrm{Li}_{2} \mathrm{O}$ temperature-change specimen, and $0.5 \mathrm{Ci}$ of tritium in the $\mathrm{Li}_{2} \mathrm{ZrO}_{3}$ temperature-gradient specimen. This generation of tritium at the lower temperatures may have contributed to a change in the tritium inventory in the specimen as compared to the steady-state inventory at the time of shutdown. After shutdown, the canisters remained at a temperature of $220^{\circ} \mathrm{C}$ for 9 months in a helium sweep gas until the irradiation vehicle was removed from the reactor.

Postirradiation examination of the in situ canisters included neutron radiography, lithium transport to the plenum, lithium isotopic, miscrostructural characterization, and tritium inventory. The results for the $\mathrm{Li}_{2} \mathrm{O}$ single crystals include final lithium isotopic ratios and tritium/helium inventories. For the lithium ceramic-beryllium capsules, the postirradiation examination included microstructural examination and tritium/helium retention measurements.

\subsection{Neutron Radiography}

After removal from the irradiation test vehicle and before disassembly, the two vented canisters were shipped to Argonne National Laboratory, West (Idaho Falls, Idaho) for neutron radiography. Figures 6.1 and 6.2 include the resulting radiographs obtained for the temperaturechange and temperature-gradient canisters, respectively. Because of the large neutron absorption cross section of ${ }^{6} \mathrm{Li}$, the lithium ceramics are highlighted in the neutron radiographs (i.e., they appear dark in the prints). Two different exposures of the radiographs are shown. The radiograph on the left is lighter and shows the internal details of the specimen; the radiograph on the right shows the details of the metal canister.

The temperature-change-canister radiograph shows that the $\mathrm{Li}_{2} \mathrm{O}$ ring specimen remained in its initial cylindrical geometry throughout the experiment. Although the neutron radiograph for the Phase I ring specimen had been found to contain a number of cracks, the Phase II specimen has no apparent cracks. Both the inlet and outlet gas plenums contain neutron absorbing residue, nominally lithium-containing material and likely $\mathrm{Li}_{2} \mathrm{O}$. Note that the capsule was radiographed in a vertical position, upside-down, so that the residue was in the bottom of the plenums at the time of radiography.

The low-contrast neutron radiograph (on the left) of the temperature-gradient canister after irradiation shows the pebble bed and the center thermocouple well. In the higher-contrast radiograph, the sweep-gas plenums at either end are clearly delineated, and no observable neutron absorbing residue is present. The pebble bed did not appear to have expanded or shrunk due to sintering during irradiation. 

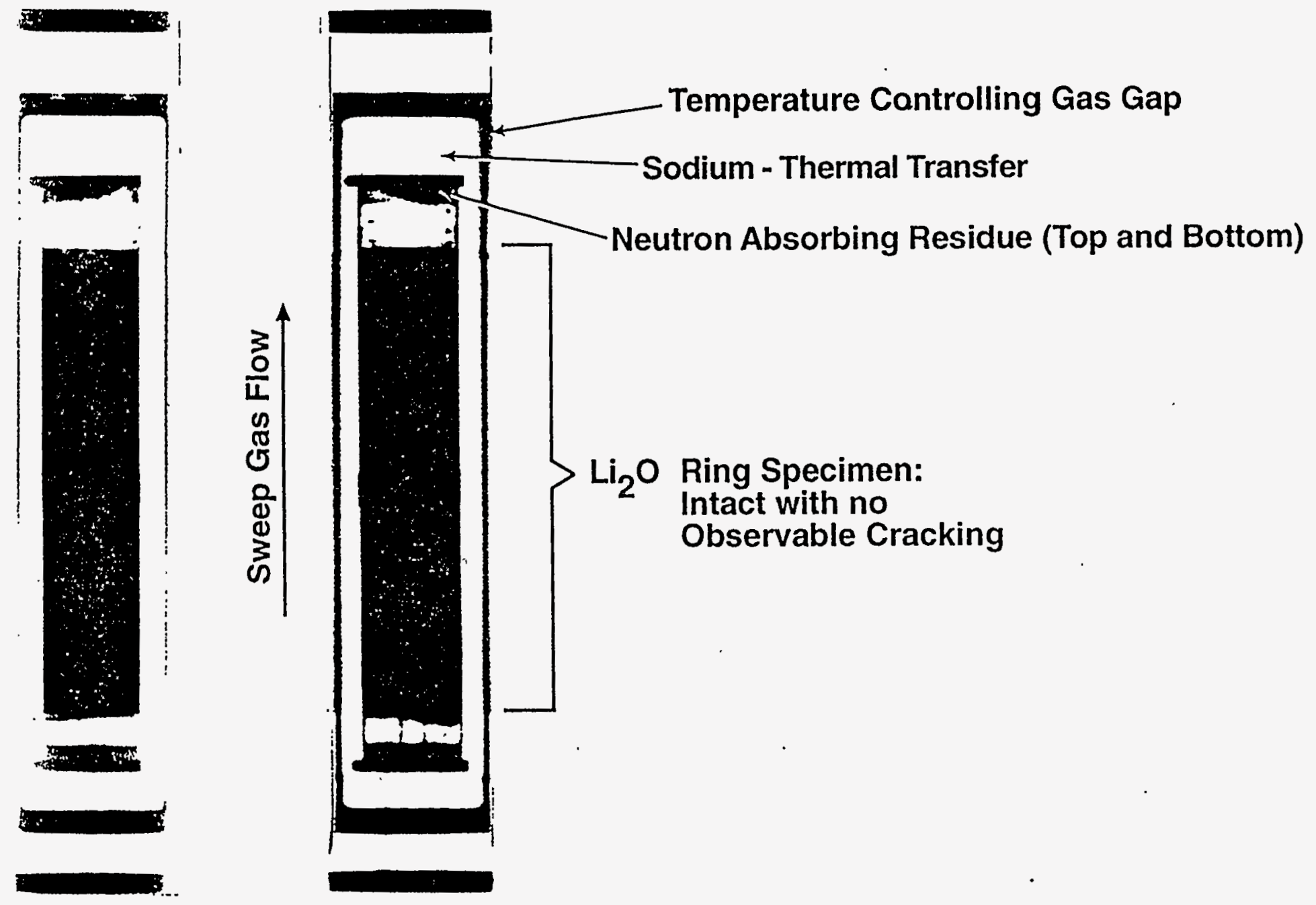

Figure 6.1. Neutron Radiograph of the Phase II Temperature-Change Canister after Irradiation 


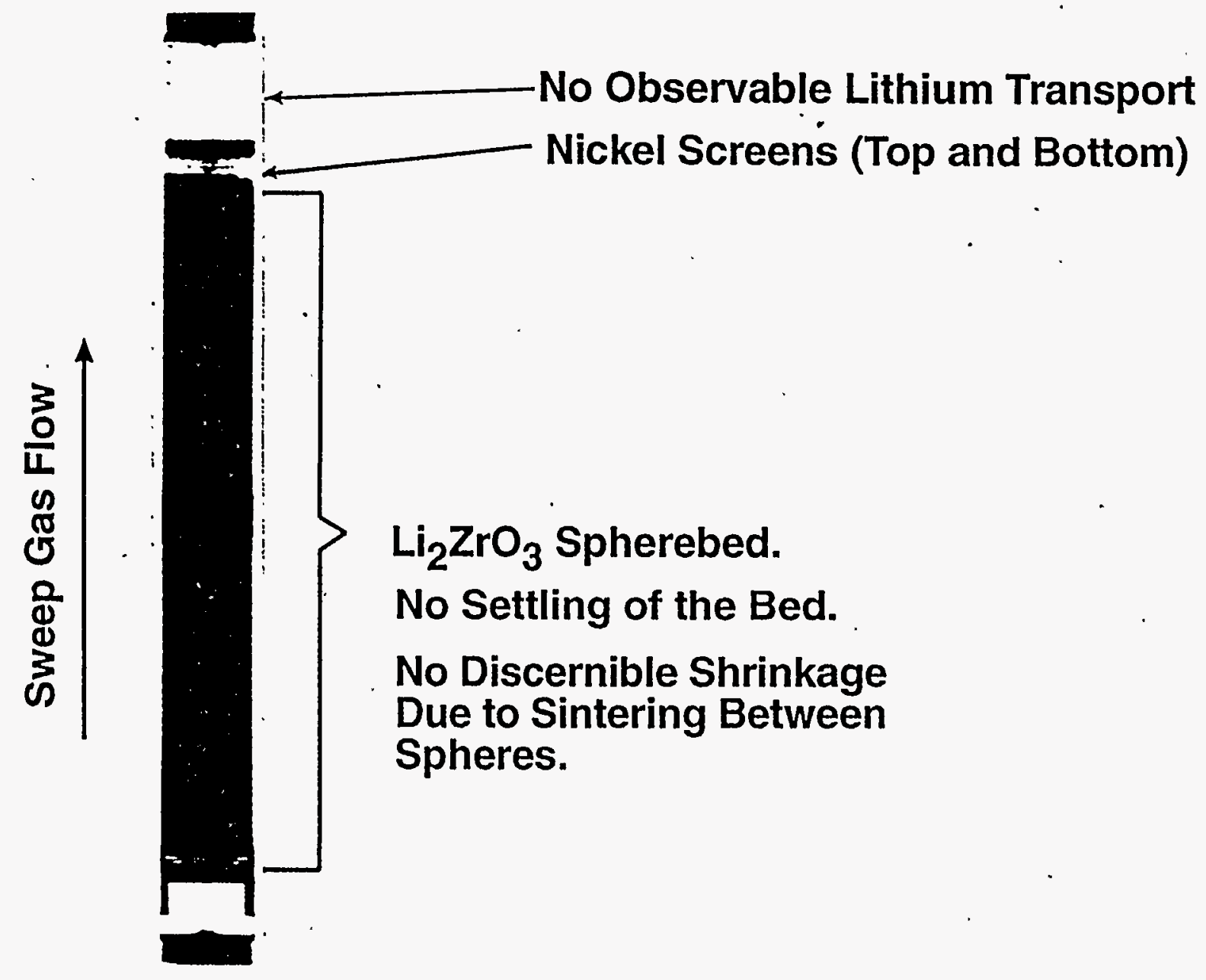

Figure 6.2. Neutron Radiograph of the Phase II Temperature-Gradient Canister after Irradiation 
Neutron radiography was also carried out on the lithium ceramic-beryllium capsules. However, the size of these specimens was so small that whether or not the lithium migration had occurred could not be resolved.

\subsection{Temperature-Change Canister}

Postirradiation examination of the temperature-change canister was carried out at PNNL. This work involved canister disassembly, density measurements, microstructural examination, tritium transport to the plenums, final lithium isotopic ratios, and tritium retention in the $\mathrm{Li}_{2} \mathrm{O}$ ring specimen.

\subsubsection{Canister Disassembly}

The canister was disassembled by slitting the inner capsule lengthwise adjacent to the specimens so that the cladding could be separated, resulting in as little disturbance to the specimens as possible. The ring specimen was found to be fragmented into pieces $1 \mathrm{~cm}^{2}$ or smaller. Figure 6.3 is a photograph of typical specimen fragments removed from the temperature-change canister. Both surfaces of specimens from the bottom of the canister were light tan in color. Specimens taken from locations above this position had black inner surfaces and tan outer surfaces. Note that on the inner surfaces, a small circular region was lighter in color. These "dots" were thought to represent $\mathrm{Li}_{2} \mathrm{O}$ that was extruded through the $1.5-\mathrm{mm}$ holes in the stainless steel liner tube during irradiation.

\subsubsection{Lithium Transport}

In the operation of a solid-breeder fusion blanket, lithium in the vapor form should not transported out of the solid-breeder region into other components of the blanket. For this reason, it was useful to study the BEATRIX- $\Pi$ behavior and determine if lithium was transported from the $\mathrm{Li}_{2} \mathrm{O}$ temperature-change specimens to the plenum regions of the capsule. For Phase $\Pi$, the upper and lower plenums of the temperature-change canister consisted of the end caps and the diffuser plates separating the specimen from the plenums in the end caps. All four components were acid-washed and the resulting solutions analyzed for lithium. Table 6.1 lists the results of the analysis of the wash solutions. The results for the upper diffuser indicated considerably more lithium than the results from the other components. This observation was reasonable because the sweep gas passes through the upper diffuser immediately after passing along the inner diameter of the specimen. The $0.1 \%$ of lithium is much higher than the amount of lithium found for the Phase I canisters where the combined amount of lithium in the upper and lower end caps and on the associated diffuser was $0.0035 \%$ of the total lithium in the specimen.

Table 6.1: $\quad$ Amount of Lithium Found in the Analysis of Wash Solution from Selected Components of the Phase I Temperature-Change Capsule

Component

Upper End Cap

Upper Diffuser

Lower End Cap

Lower Diffuser
Total Lithium (mg)

0.05

3.60

0.35

0.31

\section{Percent of Specimen Weight}

0.100

0.010

0.010

\subsubsection{Density and Microstructural Characterization}

Density and microstructural characterizations of the specimen were carried out to determine the changes in microstructure that occurred during irradiation and to establish the microstructural parameters associated with the final tritium inventories. A more detailed description of the density and microstructural changes in the Phase II ring specimen was presented by Takahashi et al. (1995). 


\section{BEATRIX-II, Phase II $\mathrm{Li}_{2} \mathrm{O}$ Temperature-Change Specimen}


- Figure 6.3. Typical Specimen Fragments Removed from Different Axial Locations of the Phase II Temperature-Change Canister after Irradiation 
The postirradiation thickness of the ring specimen was measured and used to determine the radial swelling during irradiation. The thicknesses were measured for selected fragments from different axial locations along the ring specimen, and the resultant changes during irradiation are listed in Table 6.2. The wall-thickness swelling varied from 15.1 to 25.5 with an average value of $21.5 \%$.

The density of the selected specimens was determined by immersion density measurements in xylene. Vacuum impregnation was used to determine the relative amounts of open and closed porosity. The densities and porosities are listed in Table 6.2. The initial densities ranged from 87 to $88 \%$ TD compared to final densities in the range from 61 to $66 \%$ TD. The main contribution to this decrease in density appears to be an increase in the open porosity from 3 to $30 \%$.

Table 6.2. Wall Thickness Changes, Densities, and Porosities for the Postirradiation. Phase II Ring Specimen. Densities and porosities for an unirradiated archive specimen are included for comparison.

\begin{tabular}{|c|c|c|c|c|}
\hline $\begin{array}{c}\text { Axial } \\
\text { Location }\end{array}$ & $\begin{array}{l}\text { Wall Thickness } \\
\text { Swelling (\%) }\end{array}$ & $\begin{array}{c}\text { Bulk } \\
\text { Density (\%TD) }\end{array}$ & $\begin{array}{c}\text { Open } \\
\text { Porosity (\%) }\end{array}$ & $\begin{array}{c}\text { Closed } \\
\text { Porosity (\%) }\end{array}$ \\
\hline Top & 15.1 & 62.9 & 31.3 & 5.8 \\
\hline Near Top & 25.5 & 61.3 & 26.2 & 12.5 \\
\hline Upper Center & 21.2 & 65.7 & 25.0 & 9.3 \\
\hline Lower Center & 20.4 & 61.6 & 33.2 & 5.1 \\
\hline Near Bottom & 24.8 & 63.3 & 32.6 & 3.9 \\
\hline Bottom & 22.1 & 63.3 & 32.5 & 4.2 \\
\hline Average & 21.5 & 63.0 & 30.1 & 6.8 \\
\hline Unirradiated & - & 88.4 & 2.6 & 8.9 \\
\hline
\end{tabular}

Ceramographic examination was carried out on a series of fragments taken from axial locations similar to those in Table 6.2. Figure 6.4 is a cross section taken from a fragment near the center of the specimen. No large grains were visible, but rather the structure appeared to have an open overall "spongelike" appearance. The microstructure appeared coarser (larger porosity) toward the inner surface. This coarseness tended to be more apparent in the upper part of the specimen. Figure 6.5 includes SEM micrographs taken at two different magnifications of an area near the center of the specimen. This view shows in more detail the open "spongelike" microstructure. The individual grains in the network appeared to be platelets with cross sections on the order of $5 \mu \mathrm{m}$ or less across and thicknesses of $0.1 \mu \mathrm{m}$. The platelets were arranged in stacks to make up the microstructure of the material. These small grains were characteristic of the majority of the ring sample, but specimens taken from the top of the ring specimen showed regions of larger grain size (Takahashi et al. 1995).

\subsubsection{Lithium Isotopic Determinations}

Mass spectroscopy was used to determine the relative amounts of ${ }^{6} \mathrm{Li}$ and ${ }^{7} \mathrm{Li}$ at selected locations along the ring specimen. These values were used to determine the total lithium burnup during the irradiation. The pre- and postirradiation amounts of ${ }^{6} \mathrm{Li}$ and the calculated burnups are listed in Table 6.3. The calculated lithium burnup varies from 2.1 to $3.8 \%$. This is considerably less than the burnup value of $4.6 \%$ determined from the total amount of tritium recovered (Table 5.1). Because of the large uncertainties in the burnups calculated from the $\%$ of ${ }^{6} \mathrm{Li}$ and the fact that the initial ${ }^{6} \mathrm{Li}$ values were not made on the same specimen as the final measurements, the agreement is as good as can be expected. The primary conclusion to be reached here is that isotopic measurements on high-enrichment ceramics are not reliable methods for determining burnups. 


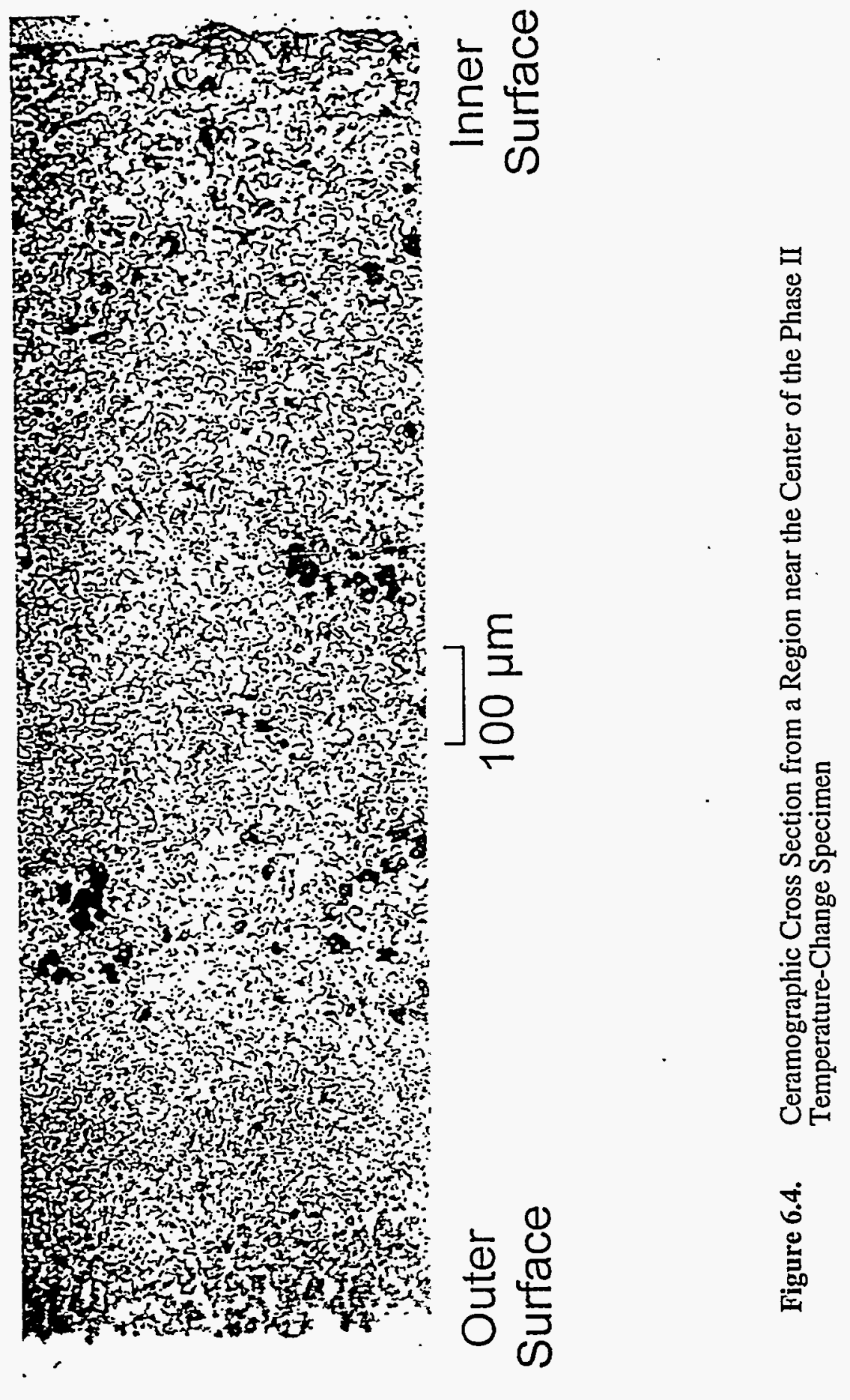



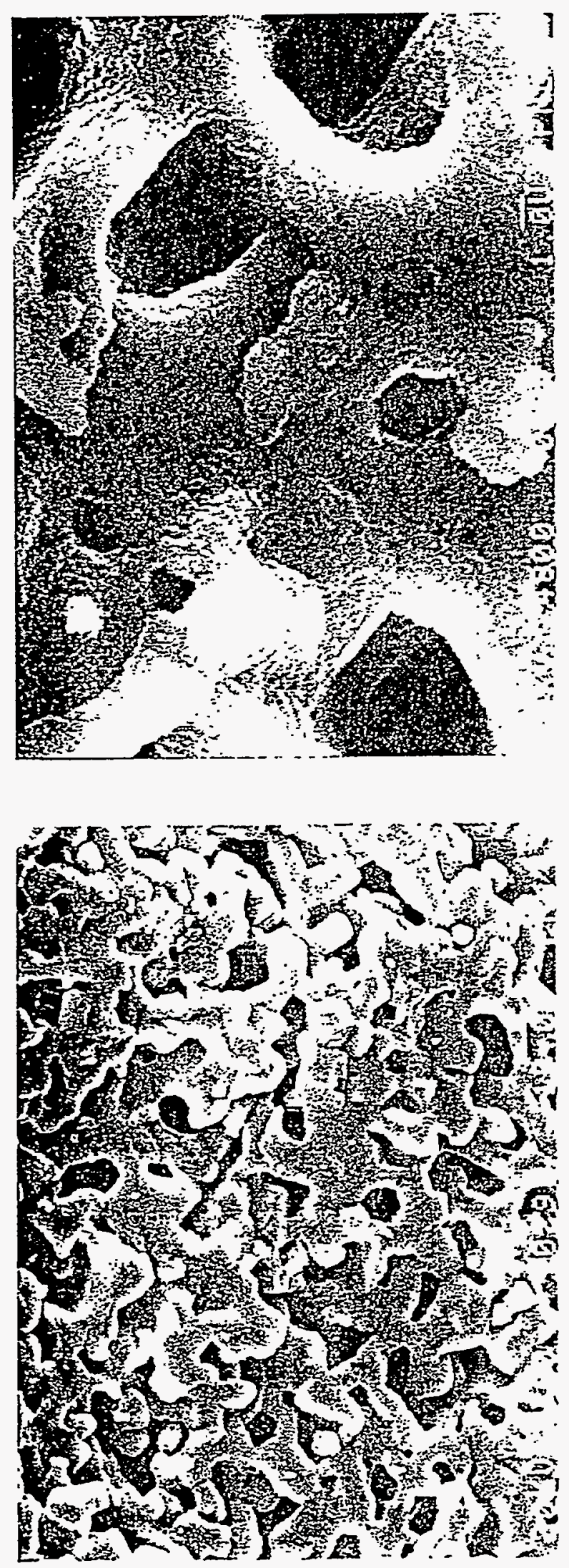

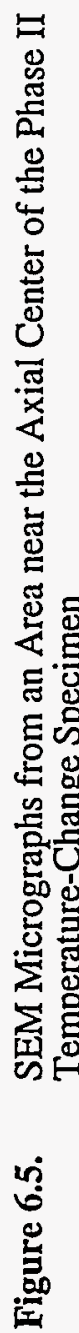


Table 6.3. Pre- and Postirradiation Percentages of ${ }^{6} \mathrm{Li}$ in the Phase II Temperature-Change Specimen and the Resulting Lithium Burnup

\begin{tabular}{|c|c|c|c|c|c|}
\hline Description & Initial ${ }^{6} \mathrm{Li}(\%)$ & Final $6 \mathrm{Li}(\%)$ & Lithiur & $\mathrm{Bu}$ & $\operatorname{lup}(\%)$ \\
\hline Top & $95.26 \pm 0.02$ & $95.12 \pm 0.02$ & 2.9 & \pm & 0.8 \\
\hline Upper Center & $95.26 \pm 0.02$ & $95.08 \pm 0.03$ & 3.7 & $\overline{ \pm}$ & 1.0 \\
\hline Lower Center & $95.26 \pm 0.02$ & $95.16 \pm 0.02$ & 2.1 & \pm & 0.8 \\
\hline Bottom & $95.26 \pm 0.02$ & $95.07 \pm 0.03$ & 3.8 & \pm & 1.0 \\
\hline Average & $95.26 \pm 0.02$ & $95.11 \pm 0.025$ & 3.1 & \pm & 0.9 \\
\hline
\end{tabular}

\subsubsection{Tritium Inventory Measurements}

The tritium inventory along the length of the ring specimen was measured using specimens taken from four different axial locations. The top and bottom sections were selected on the basis of having an end surface and hence represented material within $1 \mathrm{~cm}$ from the end. Upper center and lower center are only approximate locations. The analysis was done by two different methods. In the first method, the selected specimens were-melted, and the tritium released was determined using a variation of the method previously described (Baldwin and Hollenberg 1986). The present analysis technique used a gas sweep rather than vacuum extraction for obtaining the gas sample. In the second method, the $\mathrm{Li}_{2} \mathrm{O}$ specimens were dissolved in heated water within a closed system that was swept by a sweep gas flowing through a copper oxidizer and into collection bubblers. Tritium was measured by liquid-scintillation counting both in the dissolution liquid and in the collection bubblers and then combined for the final result. Aliquots of the dissolution solutions were titrated with acid to determine the extent of hydrolysis at the time of specimen weighing, and the results were $0.068 \pm$ $0.001 \mathrm{moles} \mathrm{OH} / \mathrm{g}$. Unhydrated $\mathrm{Li}_{2} \mathrm{O}$ has $0.067 \mathrm{moles} \mathrm{OH} / \mathrm{g}$; fully hydrated $\mathrm{Li}_{2} \mathrm{O}(\mathrm{LiOH})$ is expected to have $0.042 \mathrm{moles} \mathrm{OH} / \mathrm{g}$. The titration results indicate that the specimens were unhydrated.

The Phase II results of postirradiation tritium inventories for the temperature-change specimen in Table 6.4 are compared with results from Phase I. The Phase I inventories determined by melting have been reported previously (Slagle et al. 1994). The inventories determined by dissolution were carried out as an over check. Two differences in the data sets are significant: 1) the inventories for the Phase II specimens are smaller than for the Phase I specimens even though the Phase II shutdown occurred over a much longer time and 2) the measured tritium inventory for the Phase I specimens decreased from the top to the bottom of the specimen, but for the Phase II specimens, the inventory was essentially constant.

Table 6.4. Measured Tritium Inventories for the Phase I and Phase $I I \mathrm{Li}_{2} \mathrm{O}$ TemperatureChange Specimens. All inventories were corrected for tritium decay to represent the inventories at the time of shutdown.

\section{$\underline{\text { Axial Position }}$}

Top Upper Center Lower Center Bottom Average

\begin{tabular}{ll} 
& \\
Phase I & Tritiu \\
\hline Melt & Dissolution
\end{tabular}

\subsection{6}

0.48

0.29

0.25

0.42
0.68

0.42

0.32

0.21

0.41
Tritium Inventory (wppm)

\begin{tabular}{cc}
\multicolumn{2}{c}{ Phase II } \\
\hline Melt & Dissolution \\
0.19 & 0.25 \\
0.20 & 0.24 \\
0.20 & 0.22 \\
0.22 & 0.23 \\
0.20 & 0.24
\end{tabular}


Because the Phase $\Pi$ experiment was shut down over a period of 10 hours versus the 2-minute controlled scram for Phase I, it was hypothesized that the Phase II inventory would be higher due to a buildup in the tritium inventory while the specimen was operated at the lower temperatures. The data in Table 6.4 suggest that this was not the case. One of the reasons why the Phase I and II data were analyzed by dissolution/titration was to ensure that the differences in the melt-determined inventories were not a result of weight changes during postirradiation handling.

The measured post-irradiation tritium inventories of the Phase II ring specimen were smaller than similar inventories measured previously for the Phase I specimen. Compared to Phase I, the in situ tritium recovery from the Phase II ring specimen was very similar to Phase I. During the first half of the Phase II irradiation period, the tritium recovery peaks following temperature transients were very similar to those observed at the end of the Phase I irradiation (Figure 5.3). During the second half of the Phase II experiment, after extended operation in sweep gases with a concentration of hydrogen less than $0.1 \%$, the tritium recovery peaks after a temperature transient became broader and less sharp. However, the total peak size or change in tritium inventory remained essentially the same. On the basis of the in situ recovery results, no reason existed why the inventory of the Phase II specimen should have been significantly different than the Phase I specimen.

The measured tritium inventories in Table 6.4 for Phase I temperature-change specimen increase from bottom to top, but the currently measured Phase II inventories are essentially constant. In fact, the Phase II inventories are in very good agreement with the Phase I inventories from the bottom half of the specimen. Previously, the increasing inventories at the top of the Phase I specimen were thought to have resulted from the sweep gas flow from the bottom to the top of the canister (Slagle et al. 1994). At the top of the specimen, the sweep gas would have contained a higher partial pressure of $\mathrm{HTO} / \mathrm{HT}$, and this higher partial pressure would have tended to decrease the tritium recovery rate. The constancy of the Phase II inventories is inconsistent with the previous explanation, and therefore, the axial variation of the Phase I inventories remains an open question.

\subsubsection{Tritium Retention Predicted from Shutdown Data}

In situ tritium recovery data from the Phase I and Phase II temperature-change canisters indicated that decreasing temperatures during shutdown could have resulted in an increase in the tritium inventory in the specimen (see Section 5.2.2). It is possible that during the slow shutdown of Phase II, the inventory increased as the temperature decreased. As a check on whether such an increase may have occurred, a comparison was made between the recovered tritium and the amount of tritium generated during that time. Since the flux monitor was inoperable during shutdown, an alternative means of estimating the tritium generation was needed. The amount of tritium generated was estimated from the power or heat generation using two different methods:

1. Reactor power versus time during the shutdown. This is the average power for the reactor and not specifically for location of the temperature-change canister that was near the bottom of the core region.

2. Power or heat generation in the specimen. The temperature difference across the $\mathrm{Li}_{2} \mathrm{O}$ ring specimen was assumed to reflect changes in the heat generation. For the Phase II temperature-change canister, the available temperature difference is between a thermocouple on the inner diameter of the specimen and a thermocouple outside the specimen subcapsule in the sodium thermal-bonding region. To better approximate the power generation in the specimen, the temperature difference across the specimen was corrected for the change in thermal conductivity of the $\mathrm{Li}_{2} \mathrm{O}$ during shutdown (Takahashi and Kikuchi 1980; Hollenberg and Baker 1982). This approximation does not take into account specimen to capsule gaps forming/increasing during shutdown. 
Figure 6.6 is a comparison of the recovered tritium for the temperature-change canister with the calculated tritium generation. The difference between the tritium recovery and the tritium generation curves gives a means of predicting the change in tritium inventory in the specimen from the start of shutdown to the end. Integrating over the recovery curve indicates that $0.607 \mathrm{Ci}$ of tritium were recovered during the shutdown. For the reactor power case, $0.549 \mathrm{Ci}$ were generated for an inventory decrease of $0.059 \mathrm{Ci}(0.74 \mathrm{wppm})$. For the specimen temperature case, $0.637 \mathrm{Ci}$ were generated to effect a $0.029 \mathrm{Ci}(0.36 \mathrm{wppm})$ increase in specimen inventory. Because both of these cases represent an approximation to the tritium generation during cool down and because both predictions are opposite and within the $10 \%$ uncertainty of the tritium recovery measurements, an analysis of the shutdown curves does not provide conclusive evidence that the tritium inventory changed during shutdown.

\subsection{Temperature-Gradient Canister}

After neutron radiography, the Phase II temperature-gradient canister was shipped to AECL Research at Chalk River, Ontario, where the postirradiation examination was carried out. This report includes the results of post-irradiation examination of the $\mathrm{Li}_{2} \mathrm{ZrO}_{3}$ pebble bed, including neutron radiography, $x$-ray diffraction, tritium-inventory measurements, and SEM.

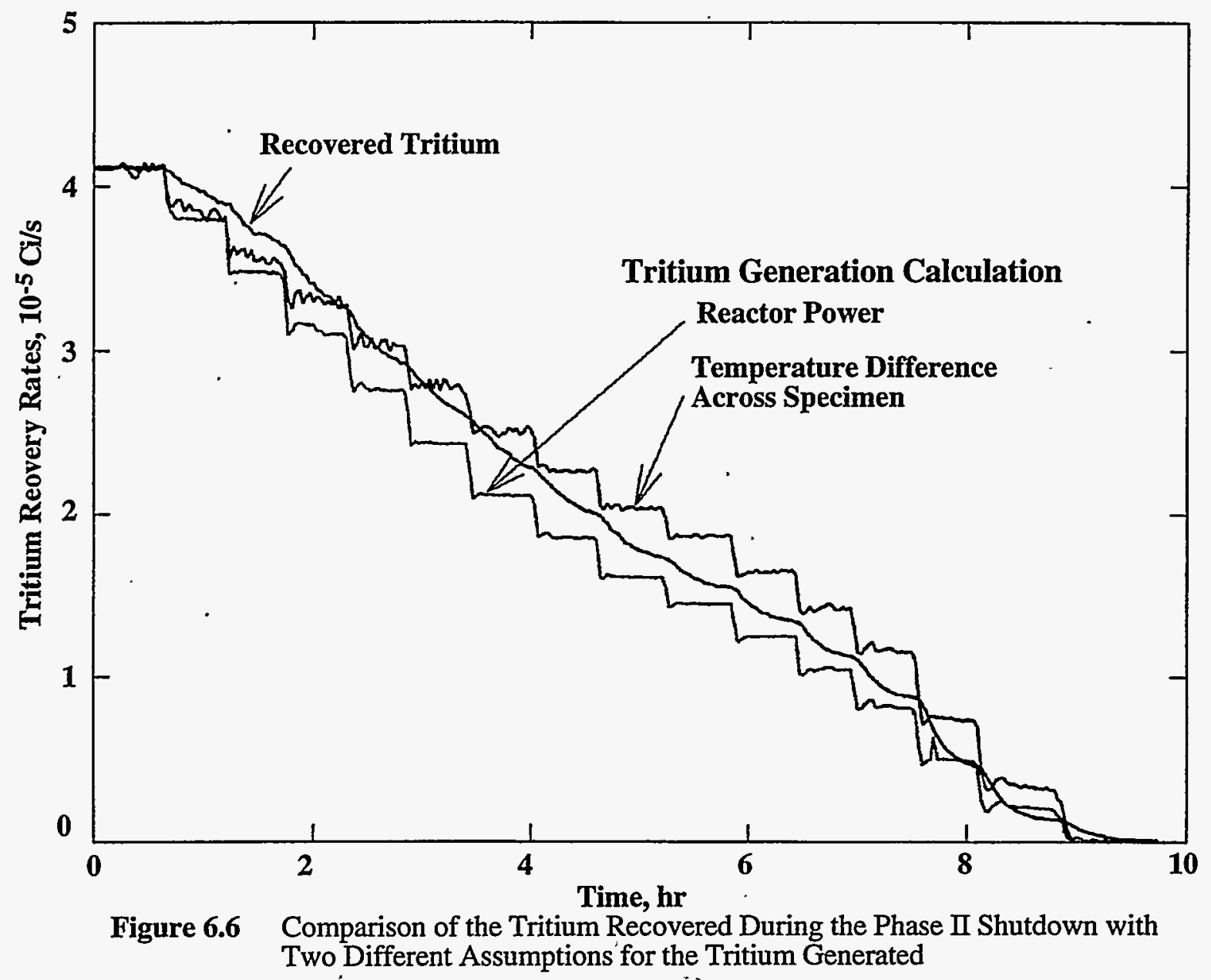




\subsubsection{Tritium-Inventory Measurements}

Because of the large temperature variation from the edge of the specimen $\left(400^{\circ} \mathrm{C}\right)$ to the center $\left(>1000^{\circ} \mathrm{C}\right.$ at shutdown), the tritium inventory was expected to vary significantly with radial position in the specimen. Determining the inventory as a function of radial position became the primary focus of the tritium-inventory measurements.

\section{Disassembly Procedures}

To obtain tritium inventory data as a function of temperature and location, the $\mathrm{Li}_{2} \mathrm{ZrO}_{3}$ pebbles were immobilized with a low-temperature curing resin, Castoglass ${ }^{\circledR}$, to fix the position of the pebbles before removing the pebble bed from the irradiation canister. With the canister in a hot cell, the resin was added to the pebble bed through the purge-gas line. At various positions along the length of the solidified pebble bed, 2-mm-thick wafers were cut from the bed. Figure 6.7 shows the axial location of the 11 wafers. The wafers were designated $\mathrm{A}, \mathrm{B}$, and $\mathrm{K}$ with wafer $\mathrm{A}$ at the top. Figure 6.8 is the cutting diagram used to divide each of the wafers into $1.8-\mathrm{x} 1.8-\mathrm{mm}$ sections. The sections were cut from the wafers using a computerized numerical control (CNC) machine fitted with a diamond saw. To maintain wafer strength for subsequent cutting and handling, each saw cut was filled with Castoglass ${ }^{\circledR}$ resin and allowed to set.

The cutting diagram was designed to divide the 13.2-mm-diameter wafers from the pebblebed into a fine grid of specimens that would minimize the temperature variation in any one section. Conversely, it was necessary to make the individual sections large enough to allow handling and provide sufficient section weight for carrying out the tritium-inventory measurements. The sectioning pattern allowed the tritium inventory to be determined as a function of the radial direction to distinguish possible angular differences in temperature or neutron flux.

The sectioned wafers were removed from the hot cell and placed in a fume hood. The stainless-steel sheath and inner thermocouple segment were removed using methylene chloride to dissolve the resin holding them in contact with the ceramic. The orientation of the wafer with respect to its position in the capsule was retained in the procedure. The 1.8- $x 1.8-\mathrm{mm}$ samples were also separated along the cut lines by dissolving the resin. Each section was then placed in methylene chloride to dissolve the resin from the pebbles. After approximately 24 hours, the methylene chloride was evaporated, and the resin was separated from the dry pebbles. The pebbles (and pebblepieces cut by the CNC saw) for each section were weighed and then reweighed approximately 1 hour later to confirm the measured dry weights. Agreement within $\pm 0.1 \mathrm{mg}$ was considered acceptable. Section weights ranged from 5 to $17 \mathrm{mg}$; the average for the 40 sections analyzed was $10.6 \mathrm{mg}$.

Several measurements of weight and tritium inventory were made on samples containing two or three sections. The sections were combined to give increased sample size and tritium inventory and therefore determine if sample size contributed to scatter.

To release the tritium from the $\mathrm{Li}_{2} \mathrm{ZrO}_{3}$ matrix, the samples were refluxed in a solution of ${ }^{-}$ $10 \mathrm{~mL}$ aqua regia/ $0.5 \mathrm{~mL} \mathrm{HF}$ for approximately 90 minutes. A portion of the reflux solution was then neutralized and distilled. The tritium content of the distillate was measured by liquidscintillation counting, and the inventory of the sample was calculated. This procedure was developed and tested using non-irradiated wafer samples from a mock-up capsule with a known quantity of tritium added to the samples. Procedures for refluxing, sampling, and counting were developed that gave an accuracy and repeatability to within $\pm 10 \%$ for the mock-up samples. The distillation procedure removed gamma and beta contaminants, present mainly from handling in the hot cell. The liquid-scintillation counting procedures were selected to ensure that only tritium was being counted and measured. 


\section{Results and Discussions}

Tritium inventory data were obtained for one wafer (A) at the top and for four wafers (B, C, $D$, and F) from the interior of the pebble bed. The axial locations of these wafers is shown in

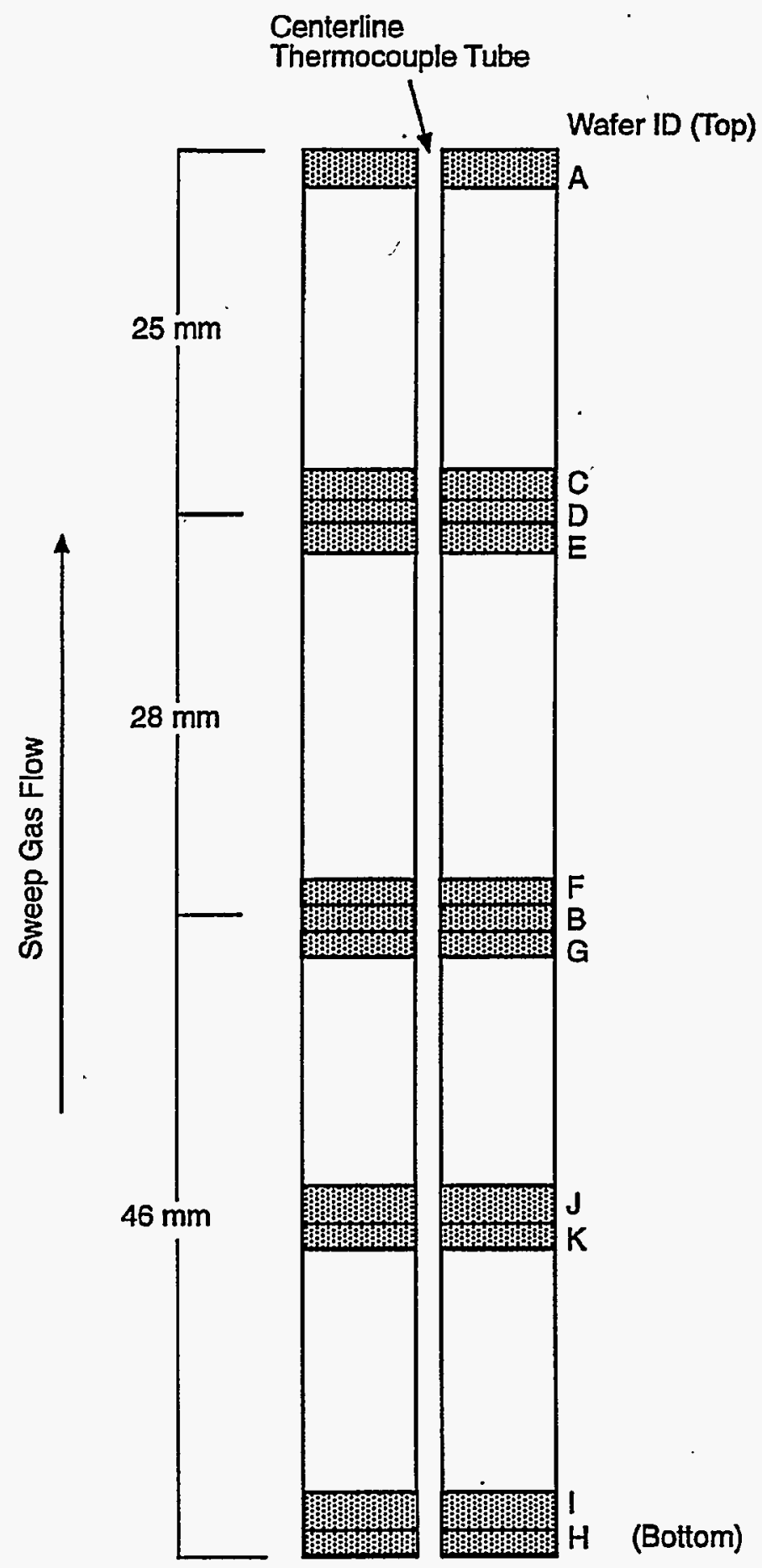

Figure 6.7. Axial Location of the 11 Wafers Cut from the Impregnated $\mathrm{Li}_{2} \mathrm{ZrO}_{3}$ Pebble Bed 
Figure 6.7. The wafers from the interior of the pebble bed had similar in-reactor temperature profiles, and a comparison of their tritium inventories was expected to indicate if the inventory varied with vertical position in the capsule. The wafer cut from top of the pebble bed had a different radial temperature profile than the inner wafers because of end effects. The tritium-inventory measurement results are given in Figure 6.9. Measurements made on samples containing a single section are shown on the section. Measurements made on samples containing more than one section are given below the wafer and are identified using * and \# symbols. These samples will be referred to as singlesection and multi-section, respectively.

All measurements were assigned to one of three radial zones identified by the dotted lines. Wafer A at the top-left was cut from the top of the canister, and data from this wafer were not used, either in calculations of average values or in the histograms below. Comparing the inventory data from the four interior wafers indicates that no discernible variation in tritium inventory occurs with vertical position or radial direction in the capsule.

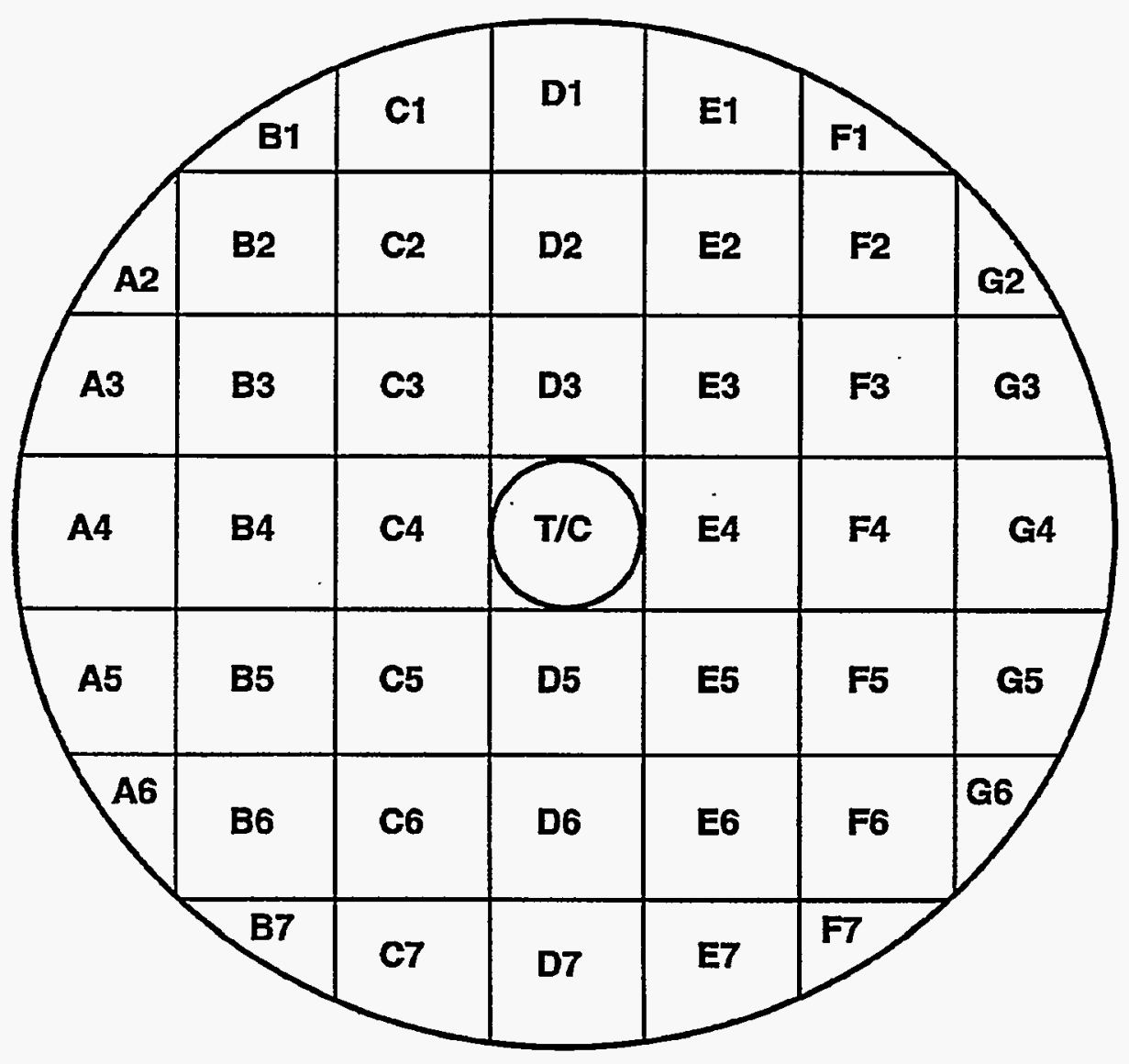

Figure 6.8. Cutting Diagram used to Divide the Wafers from the $\mathrm{Li}_{2} \mathrm{ZrO}_{3}$ Pebble Bed into 1.8- x 1.8-mm Sections. 

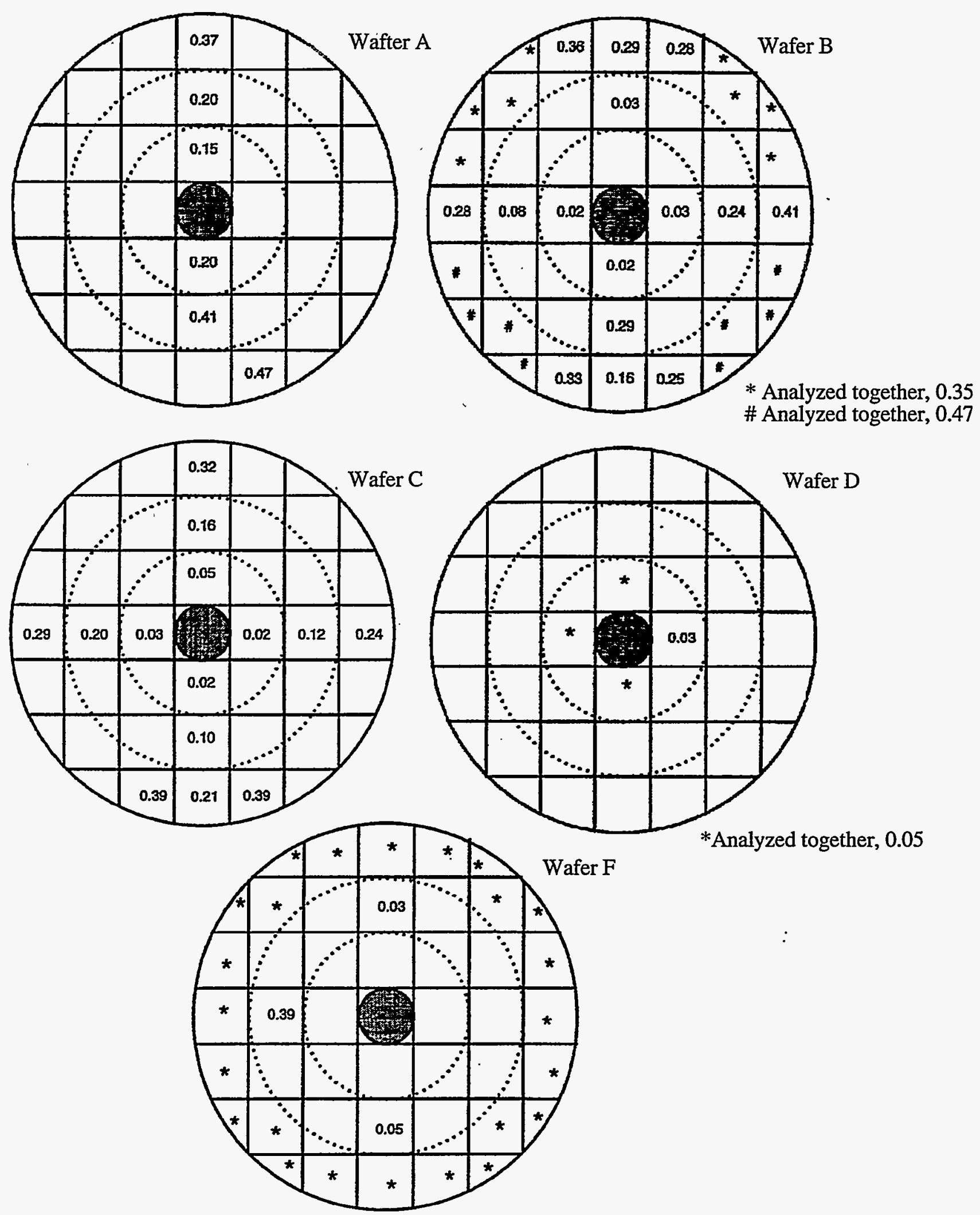

*Analyzed together, 0.05

*Analyzed as two samples; $0.35,0.40$

Figure 6.9. Tritium Inventory Measurements for the Sections from All Five Wafers 
For comparative purposes, the radial position of the individual sections (distance from the canister centerline) were grouped into three zones: inner (1.15 to $2.95 \mathrm{~mm})$, middle ( 2.95 to 4.75 $\mathrm{mm}$ ), and outer ( 4.75 to $6.55 \mathrm{~mm}$ ). For the outer zone, the four multi-section samples showed a smaller range of inventories ( 0.35 to $0.47 \mathrm{wppm})$, compared to the 14 single-section samples $(0.167$ to $0.47 \mathrm{wppm}$ ) at similar radii. The multi-section samples also had a higher average tritium inventory, $0.39 \mathrm{wppm}$ versus $0.30 \mathrm{wppm}$ for the single-section samples. However, since there were only four of the multi-sectioned samples, confidence in the statistics is low. Both the multi-section and single-section samples from the four interior wafers were used to determine the radial profile of tritium inventory.

Table 6.5 gives the average and standard deviation for the tritium inventories in each of the three radial zones, incorporating all data from single- and multi-section samples except those from the end wafer (see Figure 6.9). The average tritium inventory for the whole pebble-bed (weighting the data in Table 6.5 for the relative amounts of material in each radial range) is $0.22 \pm 0.08 \mathrm{wppm}$. Figure 6.10 is a histogram of tritium inventories measured in the three radial zones, inner (1.15 to $2.95 \mathrm{~mm}$ ), middle (2.95 to $4.75 \mathrm{~mm}$ ) and outer ( 4.75 to $6.55 \mathrm{~mm}$ ). The divisions on the $\mathrm{x}$-axis demarcate the ranges in tritium inventory that are represented by the individual histogram's position between the divisions.

Table 6.5. Summary of Tritium Inventory Data

\begin{tabular}{|c|c|c|c|c|c|}
\hline \multirow{2}{*}{$\begin{array}{l}\text { Radius } \\
\text { Inner }\end{array}$} & \multirow[t]{2}{*}{$\begin{array}{l}\text { Temperature Range at } \\
\text { time of Shutdown }(\mathrm{a})\left({ }^{\circ} \mathrm{C}\right)\end{array}$} & \multicolumn{3}{|c|}{$\begin{array}{c}\text { Tritium Inventory: } \\
\text { No. of Average and } \\
\text { Standard Deviation (wppm) }\end{array}$} & \multirow[t]{3}{*}{ Measurements } \\
\hline & & & & & \\
\hline 1.15 to $2.95 \mathrm{~mm}$ & $1025-945$ & 0.032 & \pm & 0.01 & \\
\hline Middle & & & & & \\
\hline 2.95 to $4.75 \mathrm{~mm}$ & $945-770$ & 0.15 & \pm & 0.12 & 11 \\
\hline $\begin{array}{l}\text { Outer } \\
4.75 \text { to } 6.55 \mathrm{~mm}\end{array}$ & $770-395$ & 032 & + & 008 & 18 \\
\hline
\end{tabular}

(a) See discussion below on effects of extended shutdown on tritium inventories.

Two points are evident from Table 6.5 and the histogram in Figure 6.10:

1. The scatter in the data is significantly larger than the $10 \%$ experimental error associated with the tritium-inventory measurements. The scatter is thought to be due mainly to pebble relocation that occurred during transfer of the canister from Richland, Washington, to Chalk River, Ontario, and during the procedure of flooding the pebble-bed with resin. An additional factor would be the variations in temperature within the bed due to the macroscopic nature of the pebble bed.

2. The distribution of tritium-inventory measurements for the middle zone (2.95 to $4.75 \mathrm{~mm})$ is not a normal peaked distribution around the average value. Instead, they range from 0.03 to 0.39 wppm, with the peak of the distribution at the lowest values. Again, this is thought to be due to pebble relocation. 
Tritium-inventory measurements of $\mathrm{Li}_{2} \mathrm{ZrO}_{3}$ after irradiation for SIBELIUS and EXOTIC-6 experiments at 485 to $550^{\circ} \mathrm{C}$ gave values by up to a factor of ten lower (Kopasz et al. 1995) than those in the outer zone ( 4.75 to $6.55 \mathrm{~mm}$ ) of this test. Direct comparison is not simple, however, because the tritium generation rates in SIBELIUS were about a factor of 10 lower than in this BEATRIX-II lithium zirconate irradiation. In EXOTIC-6, there were self-shielding effects, and the local tritium generation rates were uncertain at the locations where the temperatures were in the range of 485 to $550^{\circ} \mathrm{C}$.

\section{Effects of Final Shutdown On Tritium Inventory}

The Phase II experiment was terminated by a reactor shutdown that occurred over a period of 10 hours, and it is possible that during shutdown, a change in the tritium inventory in the lithium zirconate occurred so that the final inventory after shutdown was different than the steady-state values present at the start of the shutdown. A similar consideration for the temperature-change canister was given in Section 6.2.6. Gierszewski (1995b) has calculated the tritium generation for the Phase II temperature-gradient canister during shutdown by using thermal analysis and the measured temperatures across the pebble bed. He found that $0.43 \mathrm{Ci}$ of tritium were generated during shutdown versus 0.40 recovered. With a $10 \%$ uncertainty in the amount recovered, the difference between generated and recovered becomes $0.03 \pm 0.10 \mathrm{Ci}$ or $0.10 \pm 0.14 \mathrm{wppm}$. This means that it is possible that anywhere from none of to all of the average residual tritium inventory measured in the pebbles ( 0.22 wppm average) is due to inventory buildup during the shutdown. As was the case for

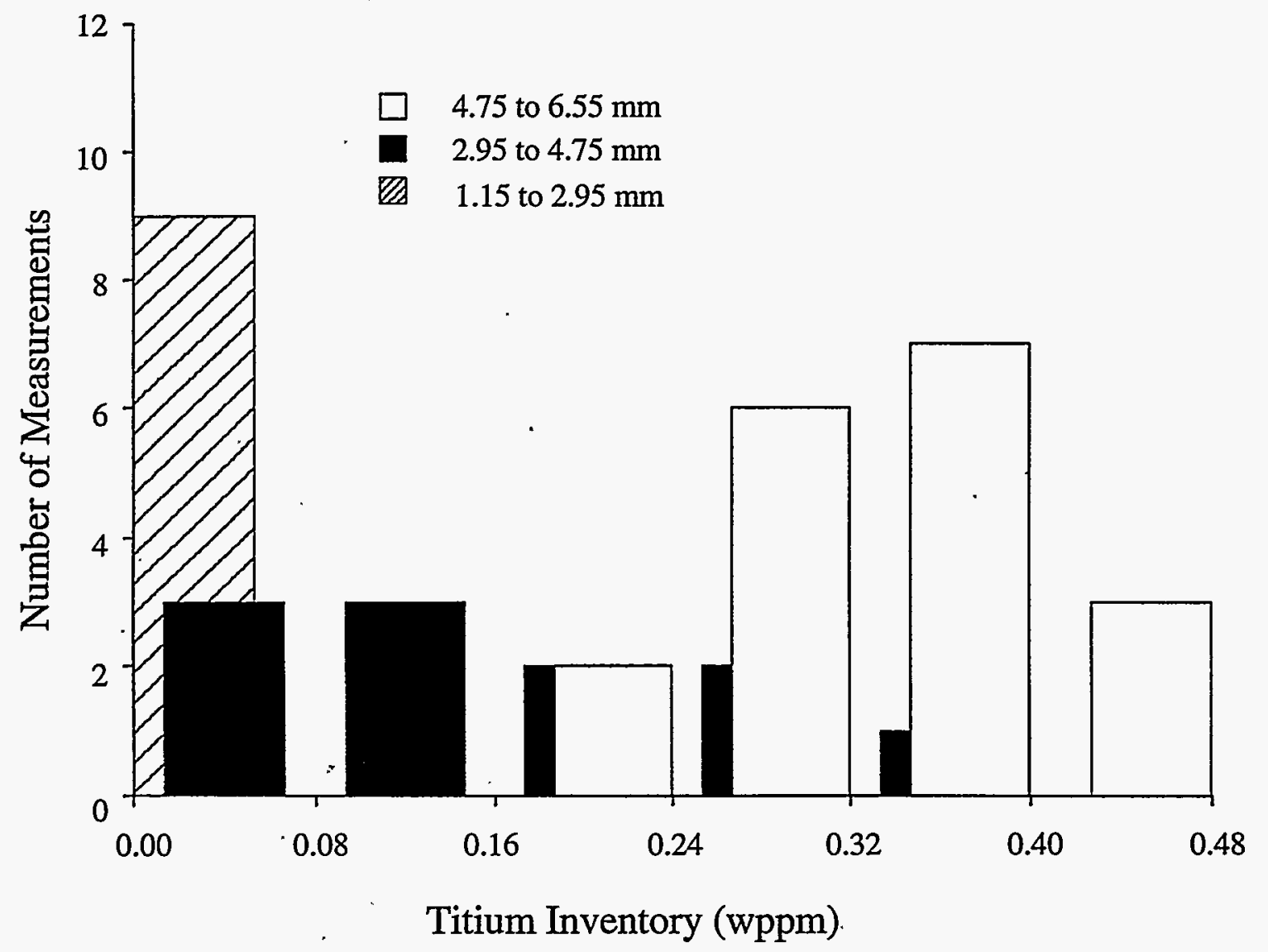

Figure 6.10. Histogram of Tritium Inventories Measured in the Three Radial Ranges, 1.15 to $2.95 \mathrm{~mm}, 2.95$ to $4.75 \mathrm{~mm}$, and 4.75 to $6.55 \mathrm{~mm}$ 
the Phase II temperature-change canister, an analysis of the shutdown curves does not provide conclusive evidence that the tritium inventory changed during shutdown.

After the FFTF reactor had been shut down, the temperature-gradient canister remained at elevated temperatures in a helium sweep gas for an extended period of time: 8 hours at temperatures of over $220^{\circ} \mathrm{C}$, and 6000 hours at $200^{\circ} \mathrm{C}$. Gierszewski (1995b) has indicated that current models that predict residence times for tritium in lithium zirconate in $0.1 \% \mathrm{H}_{2}{ }^{(a)}$ suggest that most of the tritium inventory could have been released from the zirconate during the extended period of time in the reactor after shutdown. However, no evidence existed for substantial tritium release during subsequent cool down and hold at $200^{\circ} \mathrm{C}$ for several months. The use of helium sweep gas during the extended period after shutdown seems to have prevented any significant reduction in the tritium inventory.

\subsubsection{X-Ray Diffraction}

An X-ray diffraction analysis was carried out on wafer $\mathrm{G}$ (see Figure 6.7) to determine if neutron irradiation of $\mathrm{Li}_{2} \mathrm{ZrO}_{3}$ resulted in the formation of other phases. The X-ray diffraction pattern (XRD) of unirradiated archive lithium zirconate contained all the lines for lithium zirconate and only the strongest line for monoclinic zirconium oxide. The line for zirconium oxide was for a d-spacing of $3.16 \AA$ and had a peak height of only $1 \%$ of the strongest peak for lithium zirconate.

After irradiation, the XRD pattern contained two sets of lines: one for lithium zirconate and one for monoclinic zirconium oxide. The $3.16 \AA$ peak for zirconium oxide was about $15 \%$ of the largest lithium zirconate peak. The radial dependence of these phases was determined by masking, alternatively, the central part of the lithium zirconate wafer and then the peripheral part of the wafer, and then qualitatively comparing the radial variation in the amount of zirconium oxide. The respective XRD patterns indicate that more zirconium oxide was in the central part of the pebble-bed than in the periphery (Table 6.6).

Table 6.6. Relative Ratio of Dominant XRD Peaks for an Irradiated Wafer

$\begin{array}{lr}\text { Sample Portion } & \text { Ratio of Dominant.P } \\ \text { All } & 0.15 \\ \text { Edge } & 0.10 \\ \text { Center } & 0.28\end{array}$

\subsubsection{Scanning Electron Microscopy}

Both the polished surfaces and the fracture surfaces of the irradiated $\mathrm{Li}_{2} \mathrm{ZrO}_{3}$ pebbles, as well as samples of unirradiated archive pebbles, were subjected to SEM. Figure 6.11 is a micrograph of a polished surface of the unirradiated archive $\mathrm{Li}_{2} \mathrm{ZrO}_{3}$ pebble. Figure 6.12 is a polished surface of section through two pebbles of $\mathrm{Li}_{2} \mathrm{ZrO}_{3}$ located near the center of the pebble-bed (wafer $\mathrm{G}$ ). The white phase is thought to be the $\mathrm{ZrO}_{2}$ phase, both because it was found to be present from the XRD results and because the lighter appearance suggests a higher density of high-atomic-mass elements, i.e., zirconium. The occurrence of the $\mathrm{ZrO}_{2}$ phase did not appear to give rise to any internal cracking. The contact point between the pebbles appeared to exhibit "necking" and grain growth. Both of these effects are associated with sintering phenomena between the two pebbles.

(a) M. C. Billone. "Algorithms for Estimating Tritium Inventory in ITER Solid-Breeder $\left(\mathrm{Li}_{2} \mathrm{O}\right.$ and $\left.\mathrm{Li}_{2} \mathrm{ZrO}_{3}\right)$ Blanket Designs." Letter to Y. Gohar, march 20, 1995. 


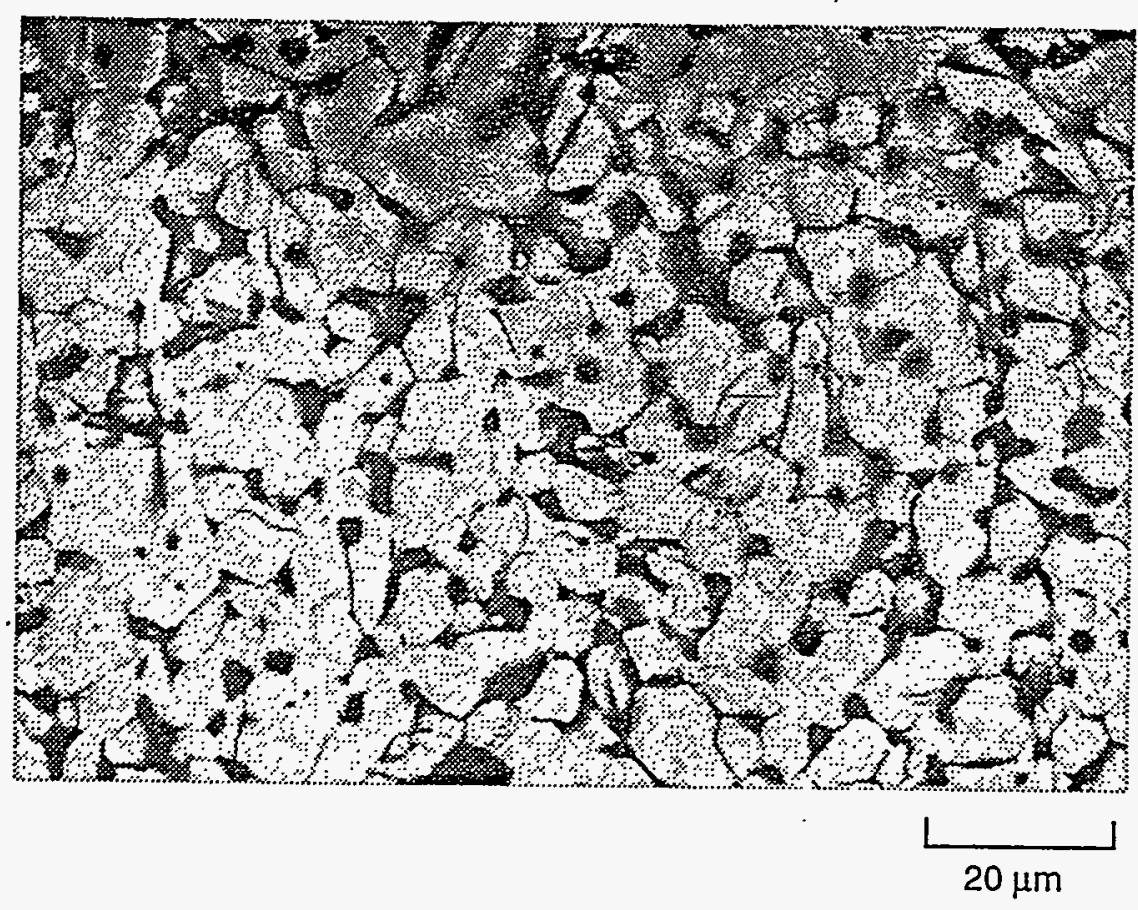

Figure 6.11. Polished Surface of the Unirradiated Archive $\mathrm{Li}_{2} \mathrm{ZrO}_{3}$ Pebble

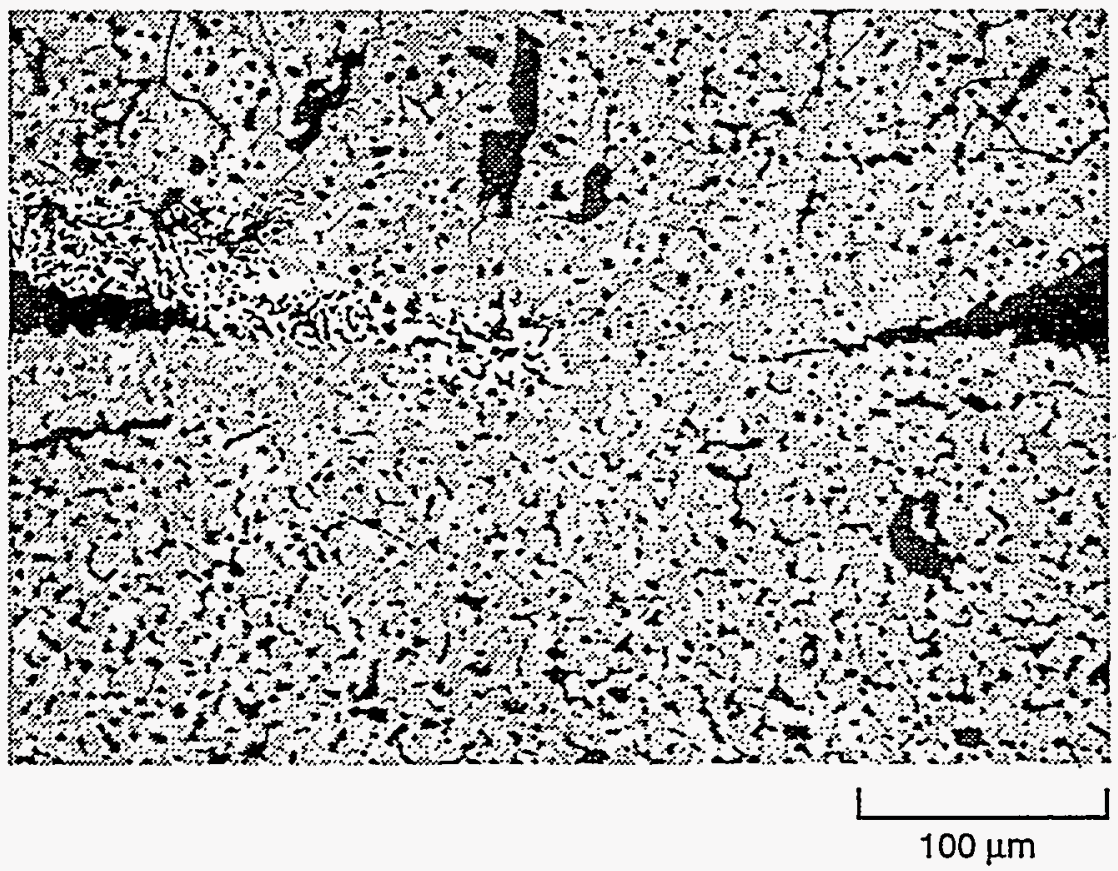

Figure 6.12. Polished Surface of Section Through Two Pebbles of $\mathrm{Li}_{2} \mathrm{ZrO}_{3}$ Located near the Center of Pebble-Bed (Wafer $G$ ). Note sinter-neck between particles and white phase throught to be $\mathrm{ZrO}_{2}$. 
Figure 6.13 is a micrograph of a fracture surface from wafer $E$ near the center of the bed. A large number of small bubbles $(<1 \mu \mathrm{m})$ appeared on the fractured grain surface and are most likely a result of helium generation. Helium bubbles in lithium ceramics were first seen in $\mathrm{Li}_{2} \mathrm{O}$ (Verrall et al. 1989) and confirmed by Takahashi et al. (1995). At low magnification, the bubbles tended to form along lines (not necessarily. straight lines) in the hot central zone, which is typical of helium bubbles in ceramics at high temperatures.

Figure 6.14 is a fracture surface of the center of the pebble in Wafer $E$, near the circumference of the bed. .The grain near the center of the displays indicates the occurrence of microcracking. It is to be noted that severe damage in the form of extensive fracturing or friability that might be associated with second phase formation or anisotropic thermal expansion was lacking. Alvani et al. (1994) have proposed that extensive microcracking can originate from these phenomena.

\subsection{Lithium Oxide Single Crystals}

Single crystals of $\mathrm{Li}_{2} \mathrm{O}$ were irradiated in BEATRIX-II, Phase I, to determine the fundamental mechanisms of radiation damage. The single crystals were grown by the floating zone technique at JAERI (Slagle et al. 1990) with ${ }^{6} \mathrm{Li}$ enrichments of $0.07,1.8$, and 61 at\%. They were hand ground to an approximate uniform cylindrical shape and sized using a ring gauge. The 61 at $\%$ enriched crystals were ground to a 7-mm diameter, while the others were ground to an 8-mm diameter. Lengths ranged from 1 to $2.5 \mathrm{~cm}$.

The radiation damage in the 0.07 and $1.8 \%$ enriched single crystals has been characterized by a series of electron spin resonance (ESR), optical absorption and microstructural characterization. Masaki et al. (1994) have reported the results of ESR and optical absorption and concluded that colloidal lithium metal was formed in $\mathrm{Li}_{2} \mathrm{O}$ under fast neutron irradiation. Microstructural characterization was reported by Takahashi et al. (1994), and the results indicate that although extensive microstructural and density changes occur during irradiation, these changes had no significant impact on the integrity of $\mathrm{Li}_{2} \mathrm{O}$ during irradiation. This report includes the postirradiation results of the tritium and helium retention measurements for all three enrichments. The plenum gas analysis, and the lithium isotopic analysis are also presented for the $61 \%{ }^{6} \mathrm{Li}$ enriched single crystal.

\subsubsection{Plenum Gas Analysis}

A plenum gas analysis of the capsule containing the enriched single crystal $\left(61 \%{ }^{6} \mathrm{Li}\right)$ was carried out to determine the burnup incurred during irradiation. The gas was sampled by drilling through the top portion of the capsule and expanding the gas into a known volume at ambient temperature. Subsequent expansions into known volumes were used to determine the volume of the capsule. The amount of helium generated in the $0.7007 \mathrm{~g} \mathrm{Li}_{2} \mathrm{O}$ specimen and released to the plenum was $55.54 \mathrm{cc}$ at standard temperature and pressure (STP) or $79.26 \mathrm{cc} \mathrm{STP/g}$.

\subsubsection{Capsule Disassembly}

The capsules containing the lower enrichment single crystals $(0.07$ and $1.8 \%)$ were disassembled in a hot cell that had been purged with argon to minimize the moisture and prevent hydration of the $\mathrm{Li}_{2} \mathrm{O}$. One of the four $0.07 \%$-enriched single crystals was intact, and several of the remaining sections had a full cross section. The two $1.8 \%$-enriched single crystals were broken into pieces with dimensions smaller than $5 \mathrm{~mm}$, and no fragment possessed a full cross section. Crystals of both enrichments were dark in color, but had the appearance on being single crystals. Archive crystals were transparent and colorless. 


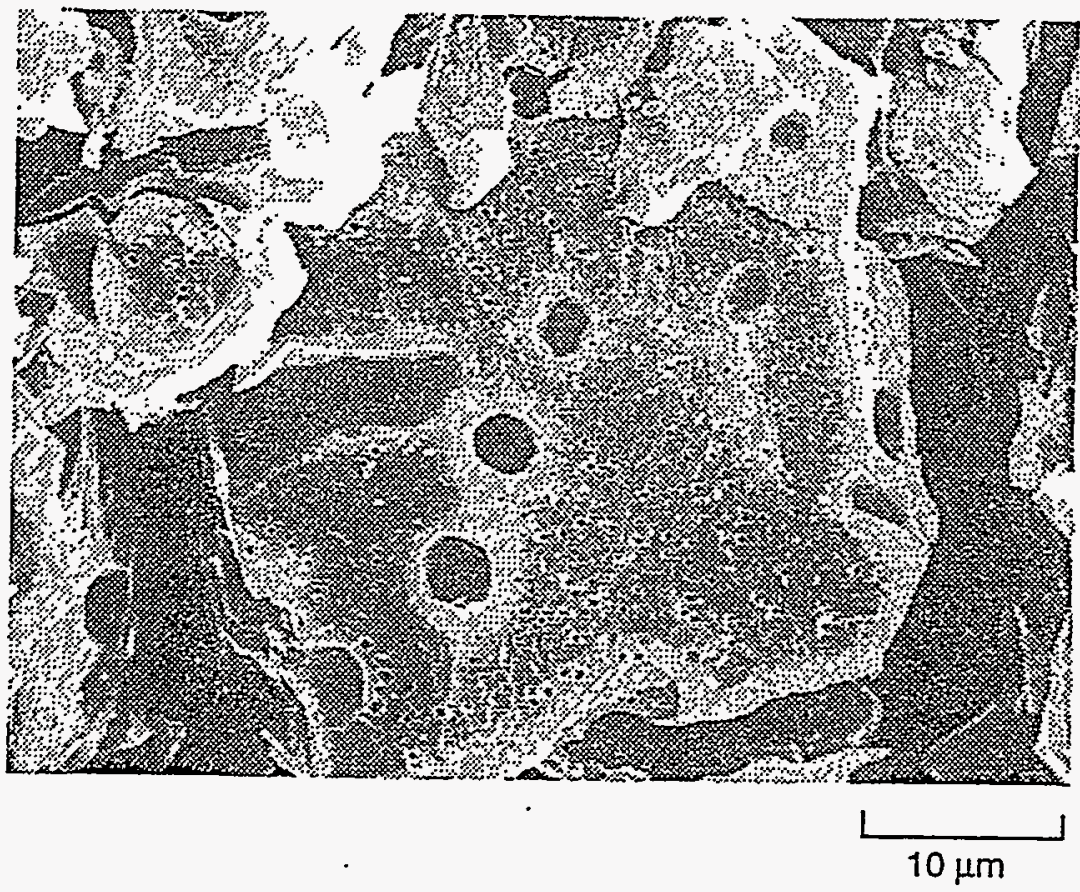

Figure 6.13. Fracture Surface from Wafer E near the Center of the Bed. Bubbles are clearly visible (small spots); large spots are probably residual sintering porosity.

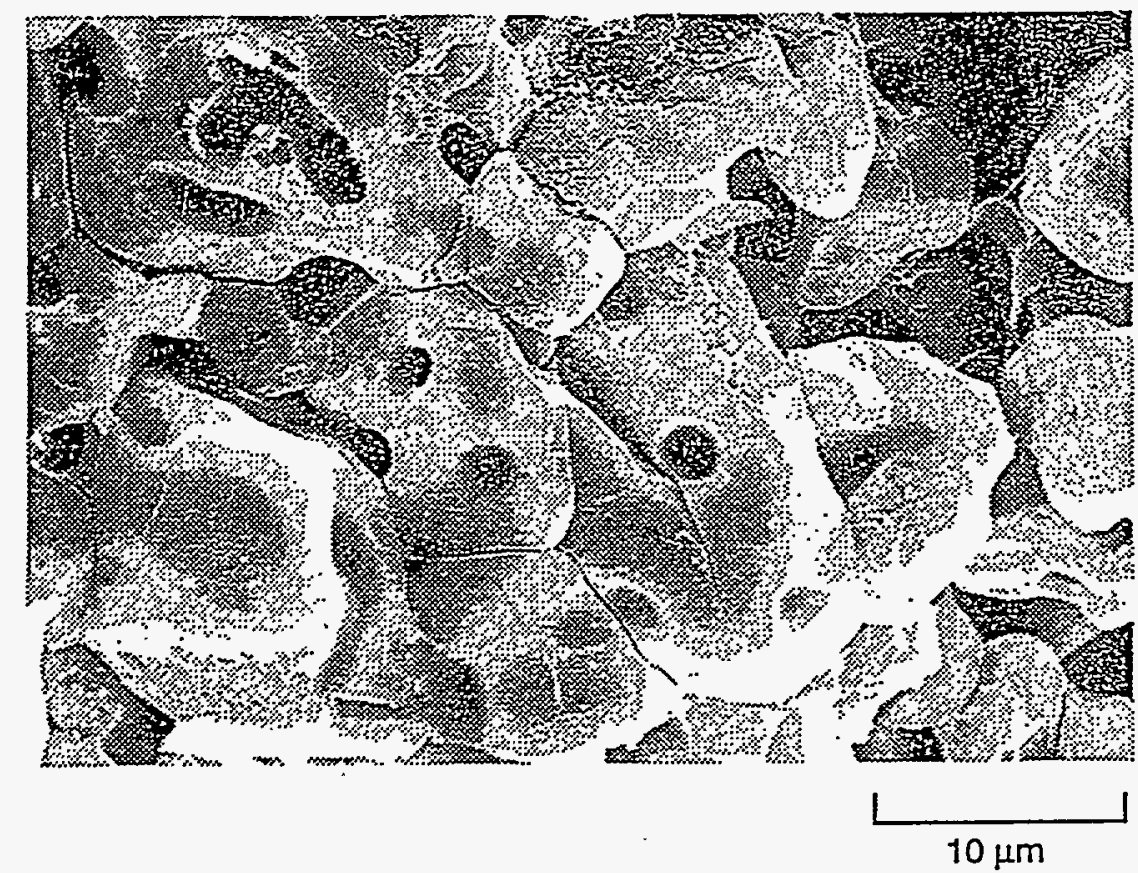

Figure 6.14. Fracture Surface of Center of Pebble in Wafer E, near the Edge (Radially) of the Bed. It shows signs of microcracking. 
The enriched single-crystal capsule was disassembled in an air atmosphere. The capsule was cut above and below the specimen, and the specimen was pushed out. The specimen appeared to be intact upon removal, but subsequently broke into several smaller sections during subsequent handling. Figure 6.15 shows photographs of the specimen. During irradiation, the specimen had changed from a clear transparent crystal to an opaque white material resembling a polycrystal. The center of the material was black.

\subsubsection{Lithium Isotopic Determinations}

The change in the ${ }^{6} \mathrm{Li}$ enrichment during irradiation provides a means for determining the lithium burnup. Mass spectroscopy was used to determine the relative amounts of ${ }^{6} \mathrm{Li}$ and ${ }^{7} \mathrm{Li}$ in the enriched single crystal before and after irradiation. The pre- and postirradiation amounts of ${ }^{6} \mathrm{Li}$ are listed in Table 6.7 for several Phase $\mathrm{ILi}_{2} \mathrm{O}$ single-crystal specimens. Also included in Table 6.7 are the results from two different isotopic measurements on the Phase I temperature-change specimen. The enriched single crystal and the Phase I temperature-change specimen were irradiated in Level 1 of cycle 11 of FFTF and hence are expected to have similar burnups. The Phase I temperaturegradient specimen was also irradiated in level 1, but inter-diffusion of $6 \mathrm{Li}$ from the $61 \%$ enriched specimen to the depleted insulator pellets resulted in low final ${ }^{6} \mathrm{Li}$ values and predicted burnups that were too large.

The calculated lithium burnup for the single crystal is $5.5 \%$ with an uncertainty of $\pm 0.7 \%$. This burnup is in agreement with the averages of the two series of measurements for the Phase I ring specimen, $6.3 \%$ and $5.8 \%$, when the uncertainties of the individual measurements are considered. The average burnups of the Phase I ring specimen calculated from the lithium isotopic results are slightly larger than the burnup obtained from the recovered tritium, $4.8 \pm 0.5 \%$ (Slagle and Hollenberg 1994), but again well within the uncertainty limits.
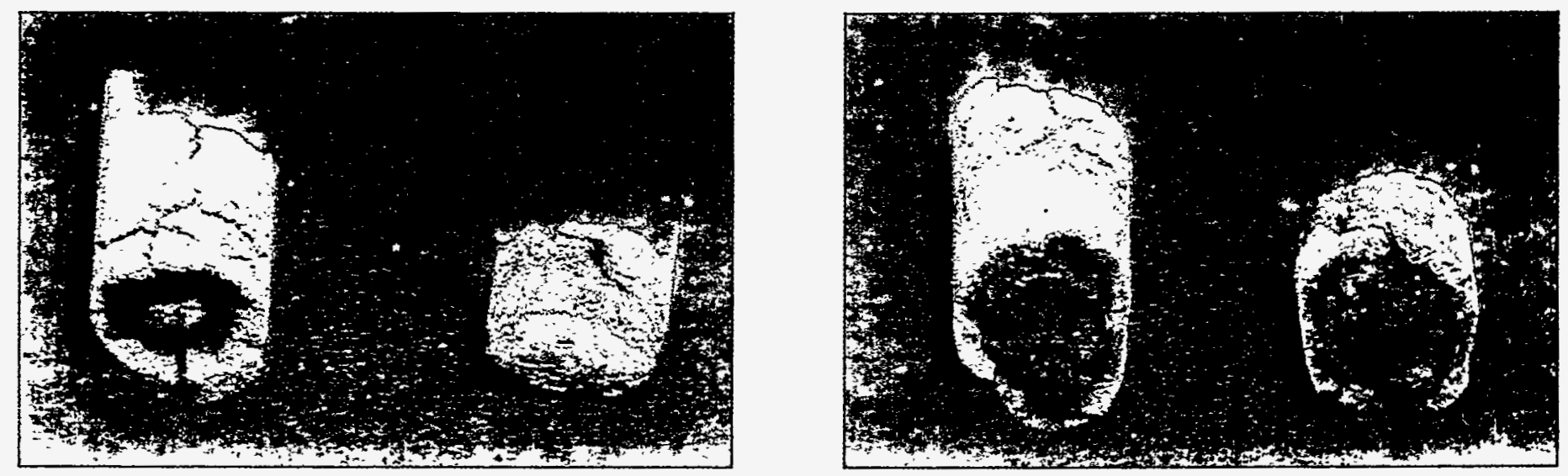

\section{$1 \mathrm{~cm}$}

Figure 6.15. Photographs of the Enriched Single Crystal after Irradiation in Phase I 
Table 6.7. Calculation of Lithium Burnups Based upon Pre- and Postirradiation Measurements of ${ }^{6} \mathrm{Li} \%$

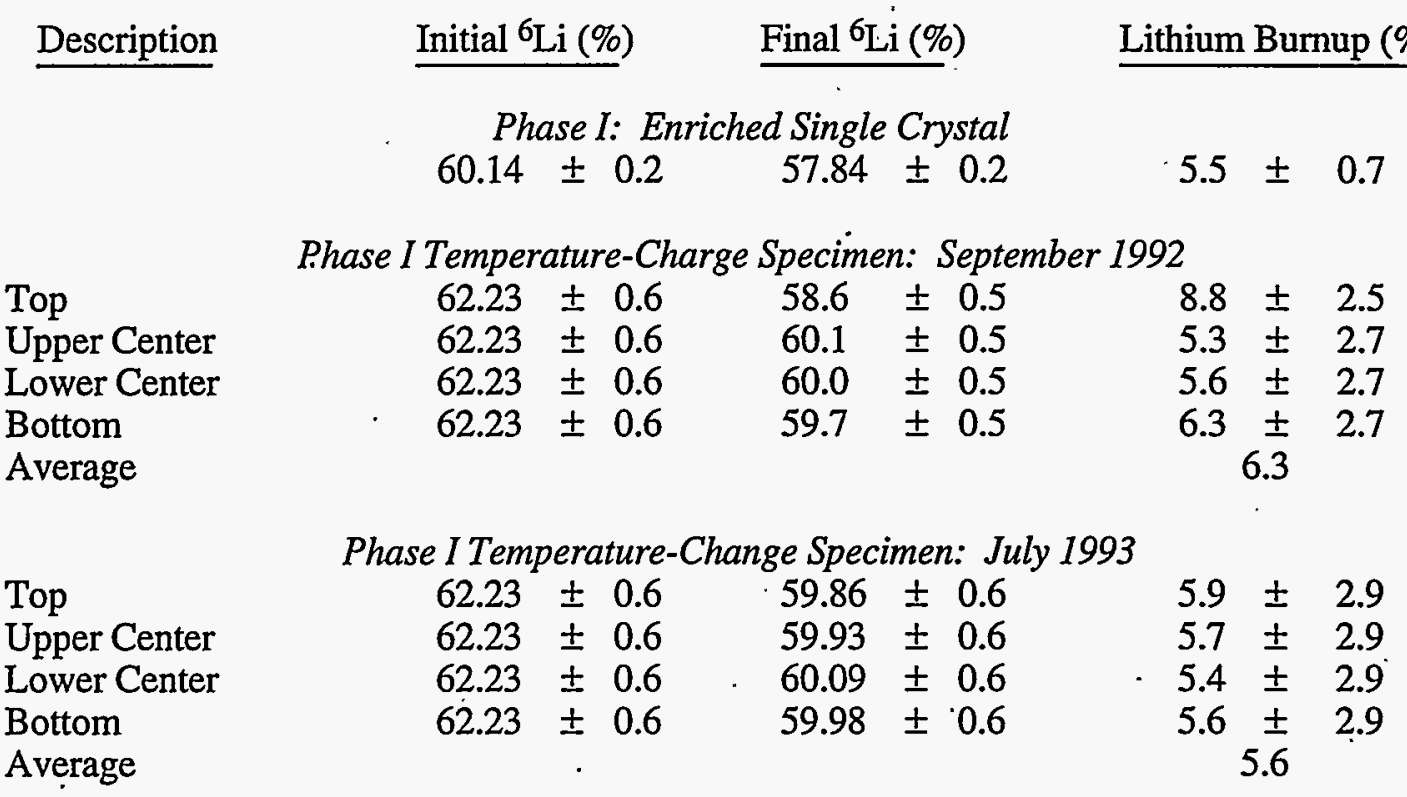

\subsubsection{Tritium/Helium Retention}

The retained tritium and helium in the single crystals after irradiation was determined by melting the specimens and determining the amounts of gases released. The procedure for determining the retained tritium was described in Section 6.2.5. The procedure for helium analysis involved the injection of ${ }^{3} \mathrm{He}$ and measurement of the ${ }^{3} \mathrm{He} /{ }^{4} \mathrm{He}$ ratio (Baldwin and Hollenberg 1986).

The tritium/helium retention results for the single crystals irradiated in Phase I are given in Table 6.8 The tritium/helium retention increased with increasing enrichment. The two tritiuminventory measurements for the $1.8 \%$ enriched specimen differed by a factor of 2 . Such a difference could be related to temperature differences within the specimen. Higher temperatures could be expected to lead to lower inventories. For the $61 \%$ enriched specimen, samples representing a full cross section (Edge + Center) had higher inventories (both tritium and helium) than samples having only the edge portion. This suggests that the center had a higher inventory than the edge. Since the center is expected to be at a higher temperature than the edge, this result implies a higher inventory for a higher temperature. This observation is opposite to the behavior found from in situ testing (Section 5) and the Phase $\mathrm{I} \mathrm{Li}_{2} \mathrm{O}$ temperature-gradient specimen (Slagle et al. 1994).

The retained tritium and helium results in Table 6.8 were used to calculate the amount of lithium burnup, assuming no tritium and helium had been released from the 0.07 and $1.8 \%$ enriched crystals. In the case of the enriched single crystal, the amount of helium in the plenum gas was added to the retained helium to give the total generated. Table 6.9 lists the resulting burnup calculated in this manner. The total burnup calculated for the enriched single crystal is $5.6 \%$, which is very good agreement with the $5.5 \%$ burnup found from the isotopic analysis. The burnup for the $0.07 \%$ enriched crystal is higher than the $61 \%$ enriched crystal on a proportioned basis. The calculated burnups indicate that $1 / 3$ of the ${ }^{6} \mathrm{Li}$ in the $0.07 \%$ enriched crystal has been converted to tritium while $10 \%$ of the ${ }^{6} \mathrm{Li}$ in the $1.8 \%$ enriched single crystal has been converted. The $10 \%$ conversion is in good agreement with what occurred in the $61 \%$ enriched crystal, that is, $9 \%$. The relatively high burnup in the $0.07 \%$ crystal suggests that the initial enrichment may have been higher than $0.07 \%$. 
Table 6.8. Tritium/Helium Retention in Single Crystals Irradiated in Phase I. The uncertainties in the tritium-retention measurements are $6 \%$ and for the helium measurements are $2 \%$.

\begin{tabular}{|c|c|c|c|}
\hline$\underline{\mathrm{ID}}$ & Location & Tritium wppm & Helium ccSTP/g \\
\hline \multicolumn{4}{|c|}{ Depleted Single Crystals $\left(0.07 \%{ }^{6} \mathrm{Li}\right)$} \\
\hline 1 & NA & 38.4 & \\
\hline 2 & NA & 39.6 & \\
\hline 3 & NA & & 0.376 \\
\hline 4 & NA & & 0.300 \\
\hline \multicolumn{4}{|c|}{ Depleted Single Crystals $\left(1.8 \%{ }^{6} \mathrm{Li}\right)$} \\
\hline 1 & NA & 86.2 & \\
\hline 2 & NA & 163.6 & \\
\hline 3 & NA & & 2.79 \\
\hline 4 & NA & & 2.87 \\
\hline \multicolumn{4}{|c|}{ Enriched Single Crystals } \\
\hline 1 & $E+C$ & 134.7 & \\
\hline 3 & $E+C$ & & 7.2 \\
\hline 4 & $E+C$ & & 7.1 \\
\hline 5 & $\mathrm{E}$ & 86.4 & \\
\hline 6 & $\mathrm{E}$ & & 0.94 \\
\hline 7 & $\mathrm{E}$ & & 1.35 \\
\hline
\end{tabular}

Table 6.9. Lithium Burnup Calculated for the Tritium/Helium Retention Results for the Phase I Single Crystals. The uncertainties are the same as the uncertainties in Table 6.8

\begin{tabular}{|c|c|c|c|c|}
\hline \multirow{3}{*}{$\begin{array}{l}\text { Single Crystal } \\
\text { Enrichment }\end{array}$} & \multicolumn{2}{|c|}{ Tritium Retention } & \multicolumn{2}{|c|}{ Helium Retention } \\
\hline & Tritium & Burnup & Helium & Burnup \\
\hline & $(\mathrm{Ci} / \mathrm{g})$ & (\% Total Li & (ccSTP/g) & (\% Total Li) \\
\hline 0.07 & 0.38 & 0.019 & 0.034 & 0.023 \\
\hline 1.8 & 0.83 & 0.043 & 2.83 & 0.19 \\
\hline 1.8 & 1.57 & 0.081 & - & - \\
\hline 61 & 1.22 & 0.060 & 86.4 & $5.6 \pm 0.6$ \\
\hline
\end{tabular}

\subsection{Lithium Ceramic-Beryllium Compatibility Capsules}

A series of 20 capsules was irradiated to test the compatibility of lithium ceramics and beryllium, which is a candidate neutron multiplier for blanket applications. The lithium ceramics specimens fabricated for this experiment included depleted and enriched $\mathrm{Li}_{2} \mathrm{O}, \mathrm{LiAlO}_{2}, \mathrm{Li}_{2} \mathrm{ZrO}_{3}$, and $\mathrm{Li}_{4} \mathrm{SiO}_{4}$. The ceramic specimen size was $0.325+.000 /-.005 \mathrm{~cm}$ in diameter and $0.3 \pm 0.025 \mathrm{~cm}$ thick. The target density was $85 \pm 3 \% \mathrm{TD}$. The beryllium specimens were 0.30 -cm-diameter discs punched from 0.035-cm-thick foil obtained from Brush-Wellman Inc. (Wellman, Ohio). A more detailed description of the specimens is given in the Phase I Data Summary Report (Slagle and Hollenberg 1994). Figure 6.16 is a schematic diagram of the lithium ceramic-beryllium capsules 
showing the arrangement of the specimens and the nomenclature used to identify the specimens. The capsules contained no cerium getters as the single crystal capsules had. The outer beryllium disks on either end were in contact with 316 stainless steel.

The specimen matrix included depleted and enriched $\mathrm{Li}_{2} \mathrm{O}, \mathrm{LiAlO}_{2}, \mathrm{Li}_{2} \mathrm{ZrO}_{3}$, and $\mathrm{Li}_{4} \mathrm{SiO}_{4}$. Table 6.10 lists the respective ${ }^{6} \mathrm{Li}$ enrichments. There were five different groups of capsules. Each group is characterized by the type of lithium ceramics (depleted/enriched) and the irradiation history. The five different groups are described in Table 6.11 with a description of the ${ }^{6} \mathrm{Li}$ enrichment of the lithium ceramics, the irradiation history, the tritium/helium retention measurement carried out and the calculated tritium/helium generation in the beryllium. The irradiation history includes the position of the capsule in the irradiation vehicle and whether it was irradiated in Phase I or Phase I and II. The position of the capsule in the irradiation vehicle refers to the position in the reactor core. Level 5 is at the top of the core, and level 8 is the highest level above the core. The tritium/helium measurement indicates whether.tritium- or helium-retention measurements were included in the postirradiation examination. The last column is the calculated tritium or helium generated in the specimen for comparison with the postirradiation examination measurements.

\subsubsection{Capsule Disassembly}

The capsules were disassembled by cutting the capsule above and below the specimen stack between the outer beryllium disk and the stainless steel end cap. The beryllium lithium-ceramic specimen stack was then pushed into a vial using a specially designed fixture. The purpose of the disassembly was to remove the specimen stack from the highly radioactive stainless steel capsule so. that postirradiation examination could be done in an unshielded glovebox. The disassembly procedure was designed to maintain the specimen order during push-out so that the positions of the individual disks could be identified and assigned as $\mathrm{Be}-1, \mathrm{Be}-2$, or $\mathrm{Be}-\mathrm{M}$, according to Figure 6.16.

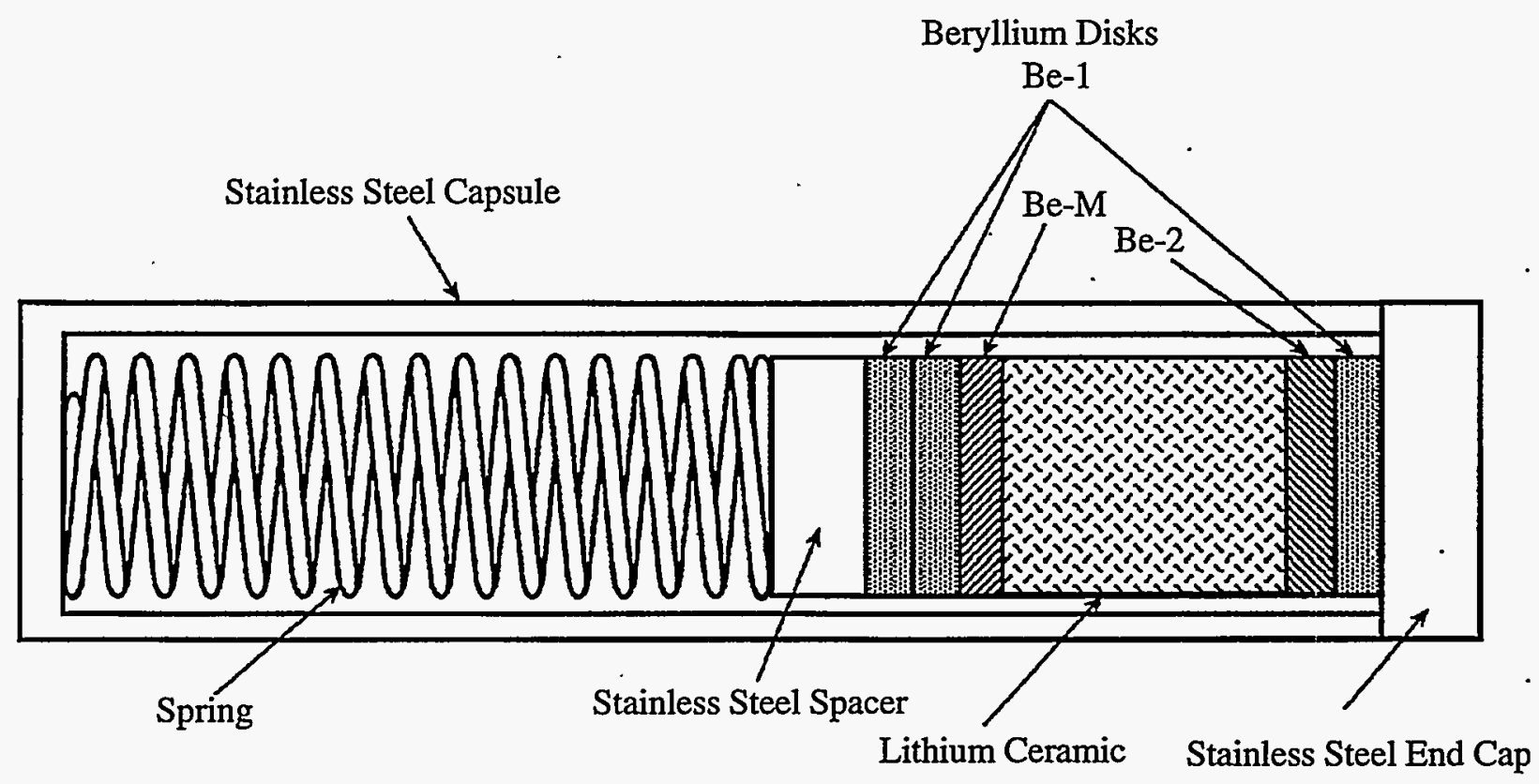

Figure 6.16. Schematic Diagram of the Lithium Ceramic-Beryllium Compatibility Capsules 
Table 6.10. ${ }^{6} \mathrm{Li}$ Enrichments of the Lithium Ceramics in the Lithium CeramicBeryllium Compatibility Canisters

\begin{tabular}{|c|c|c|}
\hline & Depleted $\left(\%{ }^{6} \mathrm{Li}\right)$ & Enriched $(\% 6 \mathrm{Li})$ \\
\hline $\mathrm{Li}_{2} \mathrm{O}$ & 0.2 & 61 \\
\hline $\mathrm{Li}_{2} \mathrm{ZrO}_{3}$ & 2.0 & 69 \\
\hline $\mathrm{LiAlO}_{2}$ & 2.0 & 95 \\
\hline $\mathrm{Li}_{4} \mathrm{SiO}_{4}$ & 2.0 & 68 \\
\hline
\end{tabular}

Table 6.11. Description of the Group I - V Lithium Ceramic-Beryllium Compatibility Capsules

$\begin{array}{ll}\text { Group } & \begin{array}{c}\text { Lithium } \\ \text { Ceramic }\end{array} \\ \text { I } & \text { Enriched } \\ \text { II } & \text { Depleted } \\ \text { III } & \text { Depleted } \\ \text { IV } & \text { Enriched } \\ \text { V } & \text { Depleted }\end{array}$

MOTA Level,
B-II Phase

Level 5, Phase I

Level 5, Phase I

Level 5, Phases I \& II

Level 8, Phase I

Level 8, Phases I \& II
Tritium/Helium in $\mathrm{Be}$

\begin{tabular}{cc} 
Retention & Calculated \\
Measurements & Generation (appm) \\
\hline
\end{tabular}

Helium

1750

Helium $\quad 930$

Tritium 45

Observations made during disassembly indicated that, in general, the individual disks were not stuck to each other, to the lithium ceramic, or to the stainless steel end caps. The small size of the beryllium disks made handling in the hot cell difficult, and in several instances, the positions for the individual disks were lost. This resulted in some uncertainty in the specimen identification as specified in Figure 6.16.

The general appearance of the beryllium discs was bright and shiny. Some of the beryllium disks appeared bluish; others appeared bronze-colored. Several of the surfaces had small regions of white-colored residues. Although it was inferred that this residue was from the lithium ceramics, the occurrence of these regions was not always on surfaces adjacent to the ceramics.

\subsubsection{Metallography}

The beryllium dișs identified as Be-M were adjacent to the ceramic and were chosen for ceramography. These disks were broken in half, mounted in resin, ground on $\mathrm{SiC}$ paper, and polished with $1-\mu \mathrm{m}$ diamond. No discernible interaction layer could be seen between the beryllium and the lithium ceramic. The only observable phenomena was that in the beryllium surface adjacent to the $6_{\mathrm{Li}}$ enriched ceramics, a region of fine bubbles was seen along the surface. Group I and Group IV capsules contained enriched ceramics (See Table 6.11). Figures 6.17 through 6.20 are a combination of low- and high-magnification micrographs of beryllium adjacent to enriched ceramics: $\mathrm{Li}_{2} \mathrm{O}$ (Group IV), $\mathrm{Li}_{2} \mathrm{ZrO}_{3}$ (Group I), $\mathrm{LiAlO}_{2}$ (Group I), and $\mathrm{Li}_{4} \mathrm{SiO}_{4}$ (Group I). The lowmagnification micrographs show the complete disk cross section and the absence of any gross change in microstructure adjacent to the lithium ceramic. The high-magnification micrographs show the occurrence of small bubbles in the surface region adjacent to the ceramic. These bubbles lie within a $20-\mu \mathrm{m}$ band adjacent to the surface. These bubbles are most likely helium bubbles formed by helium recoiled from the lithium ceramics into the beryllium disks. There was no apparent gray surface layer as found in the SIBELIUS experiment by Roux et al. (1992). The absence of a gray layer is consistent with the bright, shiny appearance of the disks. 


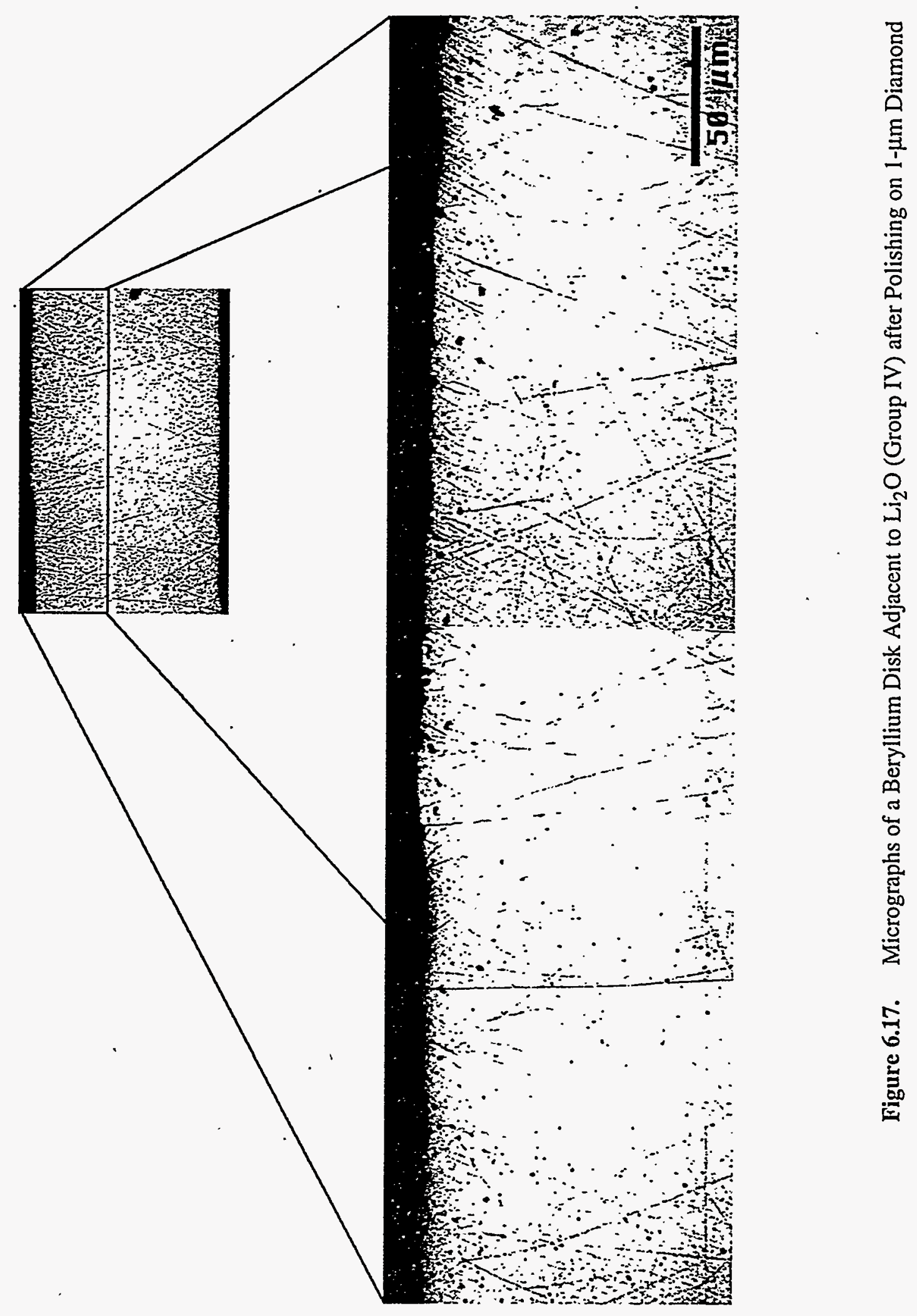




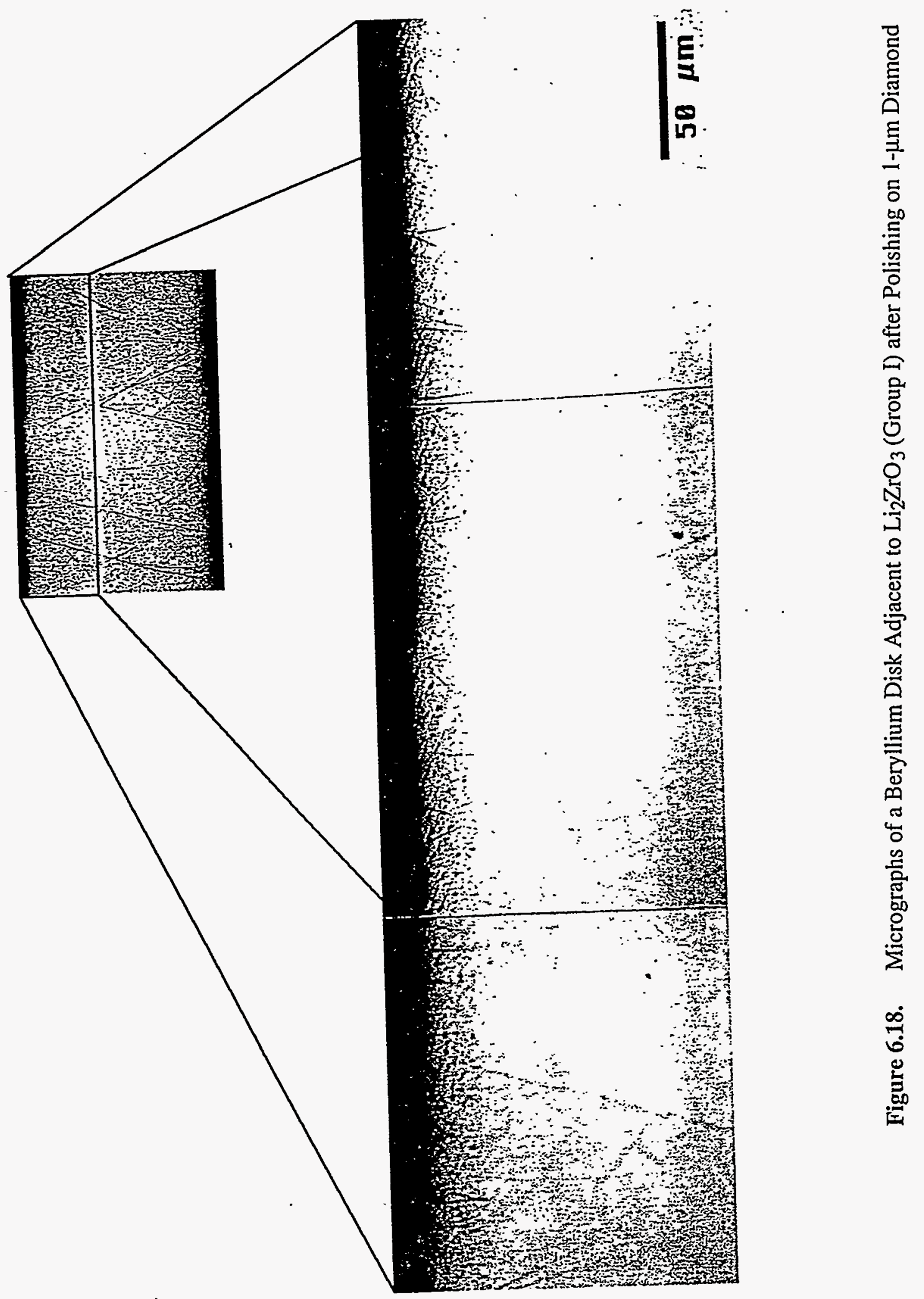




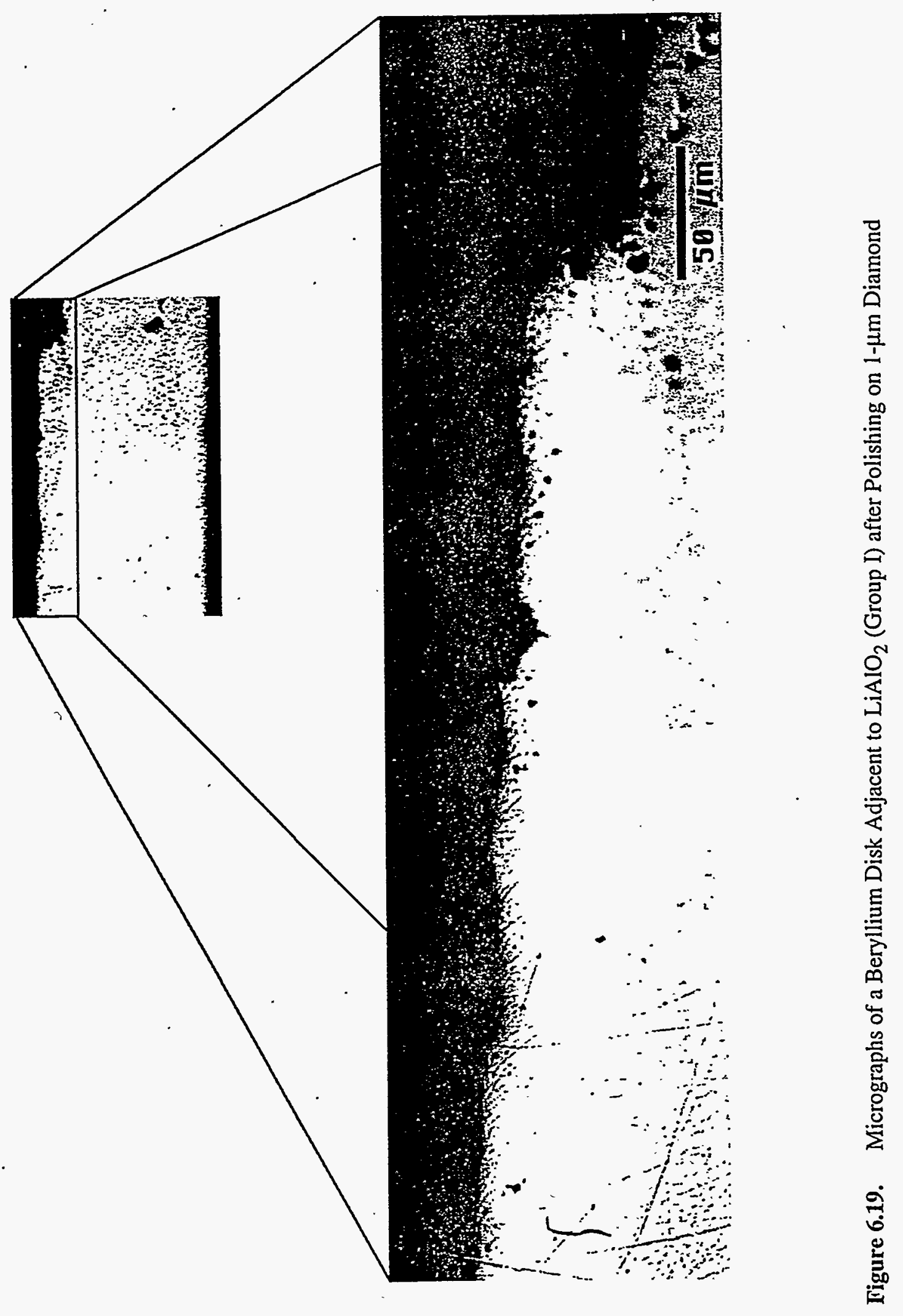




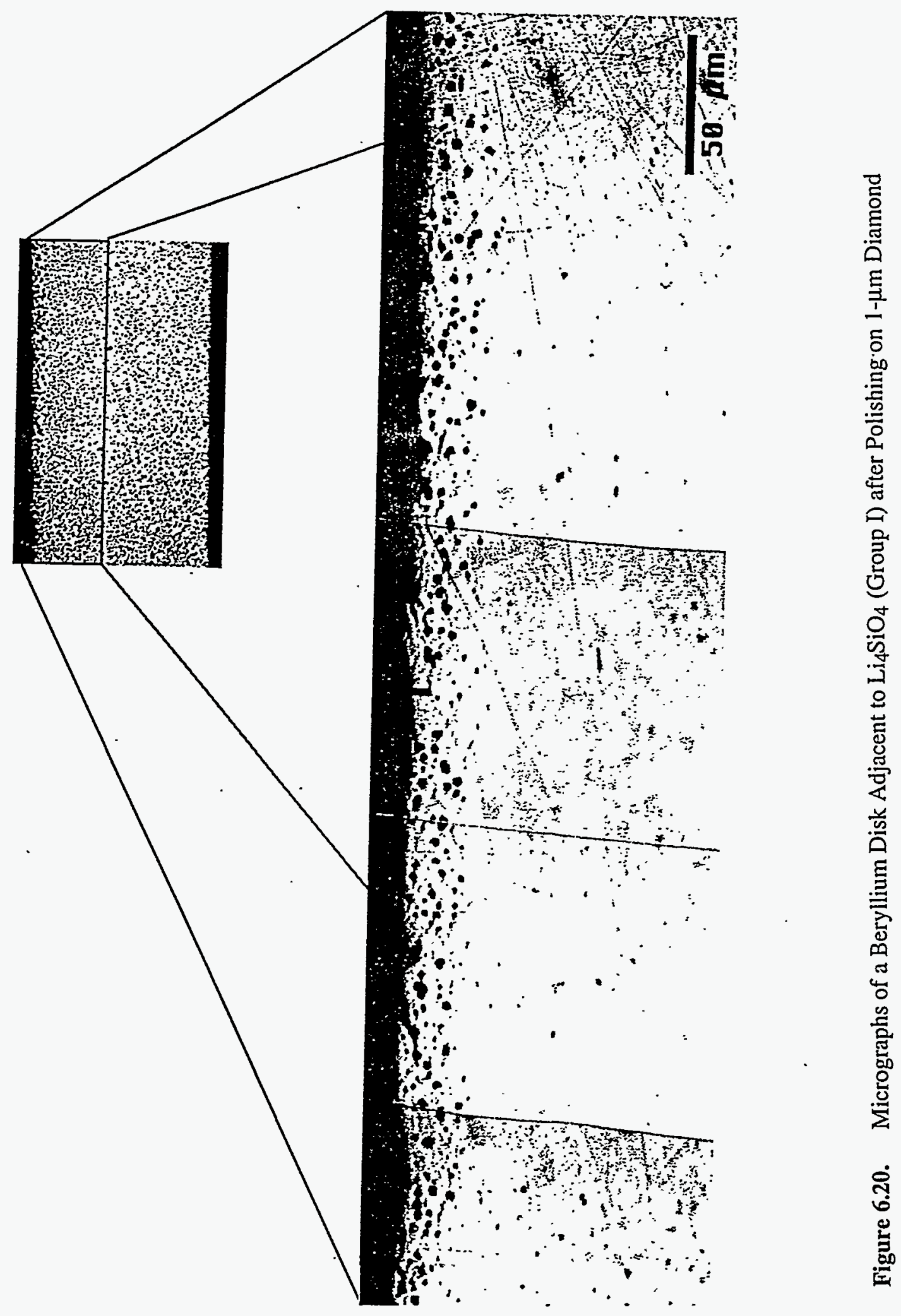




\subsubsection{Tritium/Helium Retention}

Tritium/helium assay measurements were carried out on the beryllium disks Be-1 and Be-2 (Figure 6.16) as indicated in Table 6.11. The measurements were carried out in a manner similar to that described in Section 6.2.5; that is, the disks were melted to effect gas release, followed by an analysis of the associated gases (Baldwin and Hollenberg 1986).

The results of the helium-assay measurements for the beryllium disks in Group I and II capsules are given in Table 6.12. It was expected that the helium retention in disks adjacent to the lithium ceramics (Be-2), particularly for the $6 \mathrm{Li}$-enriched ceramics, would be higher than in those disks adjacent to metal (Be-1) because of the bubbles observed in the metallography that were attributed to recoiled helium (Figures 6.17 through 6.20). In three of the four cases, the helium assay results confirmed that helium retention was higher in the disks adjacent to the ${ }^{6} \mathrm{Li}$ enriched ceramics (Be-2). For the ${ }^{6} \mathrm{Li}$ depleted ceramics, the effect was opposite, and even though a smaller effect would have been expected, an opposite effect was not. It is believed that the difficulty in correctly identifying the positions of the individual disks may have contributed to the inconsistent results. To eliminate the problem of disk identification, the helium-assay results were averaged by taking into account the difference in sample weights. These weighted averages were compared to the calculated values of helium generation in the last column of Table 6.12. For the Group I capsules, the helium retained tended to be larger than the calculated generation rate. For the Group II capsule, the opposite tendency was observed. Such inconsistencies were thought to be due to uncertainties in the calculation of generated tritium.

Table 6.12. Tritium/Helium Assay for Beryllium Disks in the BEATRIX-II Lithium Ceramic-Beryllium Compatibility Capsules

\begin{tabular}{|c|c|c|c|c|}
\hline \multirow[b]{2}{*}{$\underline{\text { Ceramic }}$} & \multicolumn{3}{|c|}{ Tritium/Helium Assay } & \multirow{2}{*}{$\begin{array}{l}\text { Average } \\
\text { Retained/ } \\
\text { Generated }\end{array}$} \\
\hline & $\underline{\mathrm{BE}-1}$ & BE-2 & Average & \\
\hline Group 1 & & Helium & & \\
\hline $\mathrm{Li}_{2} \mathrm{O}$ & 1226 & 2002 & 1518 & 0.87 \\
\hline $\mathrm{Li}_{2} \mathrm{ZrO}_{3}$ & 1870 & 1850 & 1864 & 1.07 \\
\hline $\mathrm{LiAlO}_{2}$ & 1870 & 2135 & 1954 & 1.12 \\
\hline $\mathrm{Li}_{4} \mathrm{SiO}_{4}$ & 1898 & 2022 & 1922 & 1.10 \\
\hline Group II & & Helium & & \\
\hline $\mathrm{Li}_{2} \mathrm{O}$ & 1166 & 784 & $\begin{array}{r}1070 \\
69 ?\end{array}$ & $\begin{array}{l}1.15 \\
074\end{array}$ \\
\hline $\mathrm{LiAlO}_{2}$ & 663 & 035 & $\begin{array}{l}092 \\
663\end{array}$ & $\begin{array}{l}0.14 \\
0.71\end{array}$ \\
\hline $\mathrm{Li}_{4} \mathrm{SiO}_{4}$ & 804 & 一 & 804 & 0.86 \\
\hline Group III & & Tritium & & \\
\hline $\mathrm{Li}_{2} \mathrm{O}$ & 22.1 & 43.0 & 29.1 & 0.85 \\
\hline $\mathrm{Li}_{2} \mathrm{ZrO}_{3}$ & 18.8 & 31.0 & 21.7 & 0.64 \\
\hline $\mathrm{LiAlO}_{2}$ & 19.3 & 29.3 & 24.0 & 0.71 \\
\hline $\mathrm{Li}_{4} \mathrm{SiO}_{4}$ & 20.6 & 48.5 & 34.0 & 1.00 \\
\hline
\end{tabular}

The tritium-assay measurements for the discs in the Group III capsules are given in Table 6.12. In all cases, the disk next to the ceramic (Be-2) has a larger amount of retained tritium than the disk adjacent to metal (Be-1). This higher value suggested that some of the tritium produced in the ceramic has recoiled into the adjacent beryllium disk. As was done for the helium result, a weighted average of the retained tritium was calculated and compared with the calculated amount of tritium generation. The values of retained versus generated tritium tended to be low. This low value may 
indicate that some tritium release has occurred or it may reflect the uncertainty in the tritium generation. 


\subsection{Data Transfers to Modelers and Code Developers}

The BEATRIX-II results represent a significant expansion of the design database for fusion solid-breeder blankets. An interface between the BEATRIX-II experiment and the solid-breeder design groups was established to ensure an efficient transfer of data from BEATRIX-II to individuals involved in formulating models for solid-breeder performance. This interface also provided a means for the solid-breeder modelers and code developers to comment on the irradiation test plan and the postirradiation characterization of the BEATRIX-II experiment. Participants in this interface were from Japan, Canada, and the United States and were called the BEATRIX-II Modelers and Code Developers (MCD). The Phase I Data Summary Report (Slagle and Hollenberg 1994) described the first three data transfers that were held: November 1991, October 1992, and October 1993.

The fourth and final data transfer occurred at a meeting of the MCD on October 1995 in Tokyo, Japan. At this meeting, the complete in situ data set of Phase I and Phase II and the results of the Phase II postirradiation examination were transferred to the MCD. The in situ data set consisted of the complete data compilations from Phase I (Slagle and Hollenberg 1994) and Phase II (Appendix B). These data were supplied in the form of LOTUS 1-2-3 spreadsheets (*.WK3) on 150MB Bernoulli disks. The data were later distributed on $C D$ disks, which were more universally compatible with the MCD members. The postirradiation examination results included tritium retention and microstructural characterization of the Phase II temperature-change and temperaturegradient specimens. 



\subsection{Conclusions}

The purpose of the BEATRIX-II experiment was to evaluate the performance of ceramic solid-breeder materials in a fast neutron environment at extended burnup levels. In addition, the BEATRIX-II experiment provided an excellent testbed for developing methods for monitoring and safely handling tritium during an in situ tritium-recovery experiment that was in operation for over 500 EFPD.

The BEATRIX-II experiment generated an extensive database on the tritium recovery from $\mathrm{Li}_{2} \mathrm{O}$ and $\mathrm{Li}_{2} \mathrm{ZrO}_{3}$ in a fast-neutron environment to extended burnups. The $\mathrm{Li}_{2} \mathrm{O}$ in Phase $\mathrm{I}$ and Phase II of the experiment was irradiated to lithium burnups in excess of $4 \%$ while operating at temperatures from 400 to $1000^{\circ} \mathrm{C}$ The $\mathrm{Li}_{2} \mathrm{ZrO}_{3}$ in Phase II was irradiated to burnups in excess of $5 \%$ while operating at temperatures from 400 to $1100^{\circ} \mathrm{C}$. Both $\mathrm{Li}_{2} \mathrm{O}$ and $\mathrm{Li}_{2} \mathrm{ZrO}_{3}$ were operated in helium sweep gases with additions of 0 to $1.0 \% \mathrm{H}_{2}$. Many of the fusion-blanket design issues pertaining to $\mathrm{Li}_{2} \mathrm{O}$ and $\mathrm{Li}_{2} \mathrm{ZrO}_{3}$ were addressed during this experiment:

- Reference database: The results of the in situ tritium recovery provide a reference database that can be used for predicting the effects of temperature and sweep-gas composition on the tritium release inventories of $\mathrm{Li}_{2} \mathrm{O}$ and $\mathrm{Li}_{2} \mathrm{ZrO}_{3}$ over a wide range of operating conditions.

- Burnup effects on tritium inventory: Tritium-retention measurements at the end of irradiation indicated a very low tritium inventory for both $\mathrm{Li}_{2} \mathrm{O}\left(<0.3\right.$ wppm) and $\mathrm{Li}_{2} \mathrm{ZrO}_{3}(<0.3 \mathrm{wppm})$. In addition, the low tritium inventory changes found in both Phase I and Phase II for the $\mathrm{Li}_{2} \mathrm{O}$ temperature-change specimens after temperature changes indicated that the tritium inventory remained low throughout the test.

- High temperature physical stability at extended burnup: The long-term thermal stability of the Phase I and Phase II temperature-gradient specimens together with the postirradiation microstructure verified the high-temperature physical stability of $\mathrm{Li}_{2} \mathrm{O}$ and the $\mathrm{Li}_{2} \mathrm{ZrO}_{3}$ pebble bed.

- Lithium transport at high temperatures: Only minimal vapor transport of lithium to the plenum regions of the $\mathrm{Li}_{2} \mathrm{O}$ canisters was measured during postirradiation examination $(<0.1$ wt\%).

- Tritium transport due to grain growth at high temperatures: The large-grained columnar regions of the Phase I temperature-gradient $\mathrm{Li}_{2} \mathrm{O}$ solid specimen were found to have extremely low tritium inventories $(<0.06 \mathrm{wppm})$.

- Microstructural changes in $\mathrm{Li}_{2} \mathrm{O}$ : Changes were observed after irradiation to depend upon the local temperature and temperature gradient. At these burnups, the microstructural changes did not interfere with the functionality of the ceramic breeder.

- Interaction of lithium ceramics and beryllium: Lithium ceramics $\left(\mathrm{Li}_{2} \mathrm{O}, \mathrm{Li}_{2} \mathrm{ZrO}_{3}, \mathrm{LiAlO}_{2}\right.$, and $\mathrm{Li}_{4} \mathrm{SiO}_{4}$ ) in contact with beryllium resulted in no observable chemical interaction for lithium burnups up to $4 \%$ and irradiation times up to 500 EFPD.

Based on these results, it was confirmed that $\mathrm{Li}_{2} \mathrm{O}$ and $\mathrm{Li}_{2} \mathrm{ZrO}_{3}$ should be considered as leading candidates for use in a solid-breeder fusion-blanket application. 



\subsection{References}

Alvani, C., M. R. Mancini, F. Alessandrini, and S. Casadio. 1994. "Environmental Attack Effects on $\mathrm{Li}_{2} \mathrm{ZrO}_{3}$ and Properties Evolution as a Function of the Fabrication Route." In: Proceedings of the International Workshop on Ceramic Breeder Interactions, Ed. by N. Roux, pp. 369-378, September 22-24, 1993. Commissariat A L'Energie Atomique, Paris France.

Asaoka, Y., H. Moriyama, and Y. Ito. 1992. "Production Behavior and Its Modeling of Irradiation Defects in Lithium Oxide under Ion Beam Irradiation." Fusion Tech., 21:1944-1948.

Baldwin, D. L., and G. W. Hollenberg. 1986. "Measurement of Tritium and Helium in Fast Neutron Irradiated Lithium Ceramics Using High Temperature Vacuum Extraction.” J. Nucl. Mater. 305:141-143.

Billone, M. C., C. C. Lin, H. Attaya, and Y. Gohar. 1991. "Tritium Retention and Release Analysis for the U.S.-ITER Blanket." Fusion Tech., 19:976-983.

Billone, M. C., W. Dienst, T. Flament, P. Lorenzetti, K. Noda, and N. Roux . 1993. TER Solid Breeder Blanket Materials Database. Argonne National Laboratory, ANL/FPP/TM-263 (November 1963).

Briec, M., J. J. Abassin, C. E. Johnson, M. Amasson, N. Roux, and H. Watanabe. 1988. "The MOZART Experiment: In-Pile Tritium Extraction from Lithium Oxide, Aluminates' Zirconates," In: Proceedings of the 15th Symposium on Fusion Technology, Ed. by A. M. Van Inger, A. NigsenVis, and H. P. Kippel, pp 1105-1111, September 19-23, 1988, Utrecht, Elsevier, The Netherlands..

Gandhi, J. M., and S. C. Saxena. 1968. "Correlated Thermal Conductivity Data of Rare Gases and their Binary Mixtures at Ordinary Pressures," J. Chem. Eng. Data, 13:357-361.

Hall, R. A. O., and D. G. Martin. 1981. "The Thermal Conductivity of Powder Beds: A Modell. Some Measurements on $\mathrm{UO}_{2}$ Vibro-Compacted Microspheres and their Correlation." J. Nucl. Mater., 101:172-183.

Hollenberg, G. W., and D. E. Baker. 1982, "Thermal Properties of Lithium Ceramics for Fusion Applications," presented at the American Ceramic Society Meeting, May 2-5, 1982, HEDL-SA2674-FP.

Hollenberg, G. W., and D. L. Baldwin. 1985. "The Effect of Irradiation on Four Solid Breeder Materials." J. Nucl. Mater., 133 and 134: 242-245.

Kennedy, P., K. Gilchrist, D. Walker, and S. Broughton. 1986. "The Preparation, Characterization and Properties of Lithium Oxide and Lithium Meta-Zirconate Irradiated in the HFR Petten in the Second and Third Exotic Experiment." In: Proceedings 14th Symposium on Fusion Technology, Vol. 2. pp. 1013-1018. Avignon, France.

Knight, R. C., and D. L. Greenslade. 1991. Irradiation Testing of a Niobium-Molybdenum Thermocouple, WHC-SA-1256-FP, Westinghouse Hanford Company, Richland Washington.

Kopasz, J. P., A. K. Fischer, and C. E. Johnson. 1990. "Multiple Activation Energies For Tritium Release from Ceramic Breeders." In: Fabrication and Properties of Lithium Ceramics II: Advances in Ceramics, Vol. 27, Eds. G. W. Hollenberg, and I. J. Hastings, pp. 317. The American Ceramic Society, Westerville, Ohio. 
Kopasz, J. P., C. E. Johnson, and D. L. Baldwin, 1995. "Performance of Ceramic Breeder Materials in the SIBELIUS Experiment." J. Nucl. Mater., 219:259-264.

Masaki, N. M., K. Noda, H. Watanabe, R. G. Clemmer, and G. W. Hollenberg. 1994. "Spectroscopic Study of Lithium Oxide Irradiated by Fast Neutrons." J. Nucl. Mater., 212-215:908-911.

Miller, J. M., R. A. Verrall, D. S. MacDonald, and S. R. Bokwa. 1988. "The CRITIC-I Irradiation of $\mathrm{Li}_{2} \mathrm{O}$-Tritium Release and Measurement." Fusion Tech. 14:649-656.

Miller, J. M., and R. A. Verrall. 1994. "Performance of $\mathrm{Li}_{2} \mathrm{ZrO}_{3}$ Sphere-Pac Assembly in the CRITIC-II Irradiation Experiment." Presented at the Sixth International Conference of Fusion Reactor Materials, J. Nucl. Mater., 212-215:897-901.

Porter, D. L., J. R. Krsul, M. T. Lang, L. C. Walters, and M. Tetenbaum. 1984. "Neutron Irradiation and Compatibility Testing of $\mathrm{Li}_{2} \mathrm{O}$." J. Nucl. Mater., 122 and 123:923-933.

Rodrigo, L., J. M. Miller, S. R. Bokwa, R. E. Johnson, B. M. MacDonald, and J. Senohrabek. 1992 "Tritium Measurement and Monitoring in Experimental and Process Systems with Ionization Chambers." Fusion Tech., 21:629-635.

Rodrigo, L., and D. Yin. 1993. Effect of Impurities on the Measurement of Tritium with Ionization Chambers. AECL-10764, AECL Research, Chalk River, Ontario, Canada.

Roux, N., J. J. Abassin, M. Briec, D. Cruz, T. Flament, and I. Schuster. 1992. "Compatibility Behavior of Beryllium with $\mathrm{LiAlO}_{2}$ and $\mathrm{Li}_{2} \mathrm{ZrO}_{3}$ Ceramics with $316 \mathrm{~L}$ and 1.4914 Steels in SIBELIUS," J. Nucl. Mater., 191-194:168-172.

Slagle, O. D., K. Noda, and T. Takahashi. 1990. "Fabrication of Lithium Ceramic Pellets, Rings and Single Crystals for Irradiation in BEATRIX-II." In: Fabrication and Properties of Lithium Ceramics II: Advances in Ceramics, Vol. 27, Ed. by G. W. Hollenberg and I. J. Hastings, The American Ceramic Society, Westerville, Ohio.

Slagle, O. D., G. W. Hollenberg, and D. L. Baldwin. 1991. "The FUBR-1B Experiment - Tritium Release and Physical Stability of Solid Breeder Materials," J. Nucl. Mater., 843:179-181.

Slagle, O. D., G. W. Hollenberg, D. E. Baker, and T. Kurasawa. 1992. "Effect of Sweep Gas Composition on Ionization Chamber Response in the BEATRIX-II In Situ Tritium Recovery Experiment." In: Proceedings of the International Workshop on Ceramic Breeder Interactions, Ed. by M. Yamawaki, pp. 204-212. October 26-29, 1992, University of Tokyo, Tokyo, Japan.

Slagle, O. D., T. Kurasawa, R. A. Verrall, and G. W. Hollenberg. 1992. "In-Situ Tritium Recovery from $\mathrm{Li}_{2} \mathrm{O}$ Irradiated in Fast Neutron Flux-BEATRIX-II Temperature Change Specimen." J. Nucl. Mater., 191-194:23-29.

Slagle, O. D., and G. W. Hollenberg. 1994. "BEATRIX-II, Phase I: Data Summary Report." PNL10279, Pacific Northwest Laboratory, Richland, Washington.

Slagle, O. D., T. Takahashi, D. L. Baldwin, F. D. Hobbs, K. Noda, G. W. Hollenberg, and R. A. Verrall. 1994. "Postirradiation Examination of BEATRIX-II, Phase I." J. Nucl. Mater., 212215:902-907.

Takahashi, T., and T. Kikuchi. 1980. "Porosity Dependence on Thermal Diffusivity and Thermal Conductivity of Lithium Oxide $\mathrm{Li}_{2} \mathrm{O}$ from 200 to $900^{\circ} \mathrm{C}$." J. Nucl. Mater., 91:93-102. 
Takahashi, T., and H. Watanabe. 1989. "Preparation and Characterization of Lithium Oxide." Fusion Eng. Des., 8:399-405.

Takahashi, T., K. Noda, O. D. Slagle, and F. D. Hobbs. 1994. "Microstructure and Density Changes of $\mathrm{Li}_{2} \mathrm{O}$ during Irradiation in BEATRIX-II, Phase I." Fusion Eng. Des., 28:271-277.

Takahashi, T., K. Noda, O. D. Slagle, F. D. Hobbs. 1995. "Microstructure and Density Changes of $\mathrm{Li}_{2} \mathrm{O}$ During Irradiation in BEATRIX-II, Phase I and II." Presented at the International Workshop on Ceramic Breeder Blanket Interactions, October 9-11, 1995. Kyoto, Japan.

Tanaka, S., D. Yamaki, and M. Yamawaki. 1994. "Effects of Surface Heterogeneity on Tritium Release." In: Proceedings of the International Workshop on Ceramic Breeder Blanket Interactions, Ed. by N. Roux, pp. 257. September 22-24, 1993. Commissariat A L'Energie Atomique, Paris, France.

Tetenbaum, M., and C. E. Johnson. 1984. "Partial Pressures of $\mathrm{H}_{2} \mathrm{O}$ Above the Diphasic $\mathrm{Li}_{2} \mathrm{O}(\mathrm{s})-$ LiOH(s,l) System." J. Nucl. Mater., 126:25-29.

Verrall, R. A., J. M. Miller, S. R. Bokwa. 1989a. "CRITIC-I - Instrumented Lithium Oxide Irradiation: Part 2 - First Results." In: Fabrication and Properties of Lithium Ceramics: Advances in Ceramics, Vol. 25, Eds. G. W. Hollenberg and I. J. Hastings, pp. 41. The American Ceramic Society, Westerville, Ohio.

Verrall, R. A., D. H. Rose, J. M. Miller, I. J. Hastings, and D. S. MacDonald. 1989b, "Bubble formation in irradiated $\mathrm{Li}_{2} \mathrm{O}$." In: Proceedings of the Fourth International Conference on Fusion Reactor Materials (ICFRM-4) Kyoto, Japan, December 4-8, 1989. J. Nucl. Mater., 179-181 (1991) 855-858. 

Appendix A

BEATRIX-II, Phase II Experimenter Log 


\section{.}




\section{Appendix A}

\section{BEATRIX-II, Phase II Experimenter Log}

\begin{tabular}{|c|c|c|c|c|c|c|c|c|}
\hline \multirow{3}{*}{$\begin{array}{l}\text { PCN } \\
\text { No. }\end{array}$} & \multirow{3}{*}{$\begin{array}{l}\text { Date } \\
(\mathrm{m}-\mathrm{d}-\mathrm{y})\end{array}$} & \multicolumn{4}{|c|}{$\begin{array}{l}\text { Experimenter Log - Phase II } \\
\text { Ring Specimen }\end{array}$} & \multirow{2}{*}{\multicolumn{2}{|c|}{$\underline{\text { Solid Specimen }}$}} & \multirow[b]{3}{*}{$\underline{\text { Remarks }}$} \\
\hline & & \multicolumn{2}{|c|}{ Temperature } & \multicolumn{2}{|c|}{ Flow Rate/Gas Comp } & & & \\
\hline & & Initia & Final & Initial & Final & Initial & Final & \\
\hline 1 & $5-11-91$ & & & $\mathrm{He}$ & & $\mathrm{He}$ & & Parameter Adjustment \\
\hline 2 & $5-14-91$ & & & $\mathrm{He}$ & & \multirow{2}{*}{\multicolumn{2}{|c|}{ He purge of CEC }} & Purge RE-52771-1 \\
\hline 3 & $5-15-91$ & \multirow{3}{*}{\multicolumn{2}{|c|}{$\begin{array}{l}\text { He Purge of CEC-IC } \\
\text { Secure Purge }\end{array}$}} & $\mathrm{He}$ & & & & \\
\hline 4 & $5-18-91$ & & & $\mathrm{He}$ & & & & Purge RE-52270-1 \\
\hline 5 & $5-19-91$ & & & $\mathrm{He}$ & & \multirow{2}{*}{\multicolumn{2}{|c|}{ He purge of CEC }} & \\
\hline 6 & $5-20-91$ & & & $\mathrm{He}$ & & & & \\
\hline 7 & & & & $\mathrm{He}$ & $0.1 \mathrm{H}_{2}$ & $\mathrm{He}$ & $0.1 \mathrm{H}_{2}$ & \\
\hline \multicolumn{9}{|c|}{ Reactor startup on May 27, 1991} \\
\hline 8 & $5-29-91$ & & & \multicolumn{2}{|c|}{ Increase $\mathrm{CEC}$ volts } & \multicolumn{2}{|l|}{$0.1 \mathrm{H}_{2}$} & \\
\hline 9 & $5-31-91$ & \multicolumn{2}{|c|}{100 to $75 \% \mathrm{He}$} & \multirow{2}{*}{\multicolumn{2}{|c|}{$\begin{array}{l}0.1 \mathrm{H}_{2} \\
0.1 \mathrm{H}_{2}\end{array}$}} & \multicolumn{2}{|l|}{$0.1 \mathrm{H}_{2}$} & \\
\hline 10 & $5-31-91$ & \multicolumn{2}{|c|}{$75 \%$ to $10 \% \mathrm{He}$} & & & \multicolumn{2}{|l|}{$0.1 \mathrm{H}_{2}$} & \\
\hline 11 & $6-2-91$ & 645 & 590 & \multicolumn{2}{|l|}{$0.1 \mathrm{H}_{2}$} & $0.1 \mathrm{H}_{2}$ & & \\
\hline 12 & $6-3-91$ & 590 & 535 & \multicolumn{2}{|l|}{$0.1 \mathrm{H}_{2}$} & $0.1 \mathrm{H}_{2}$ & & \\
\hline 13 & $6-4-91$ & 535 & 645 & $0.1 \mathrm{H}_{2}$ & & $0.1 \mathrm{H}_{2}$ & & \\
\hline 14 & $6-6-91$ & 645 & & Purge CE & $C-0.1$ & $0.1 \mathrm{H}_{2}$ & & Purge RE-52270-1 \\
\hline 15 & $6-7-91$ & 645 & & Take Cali & ample & $0.1 \mathrm{H}_{2}$ & & CEC Cell Failed \\
\hline 16 & $6-8-91$ & 645 & & Purge CE & C -0.1 & $0.1 \mathrm{H}_{2}$ & & \\
\hline 17 & $6-10-91$ & 645 & & Take Cali & ample & $0.1 \mathrm{H}_{2}$ & & $t=16: 58$ \\
\hline 18 & $6-10-91$ & 645 & & $0.1 \mathrm{H}_{2}$ & $\mathrm{He}$ & 100 & 200 & \\
\hline 19 & $6-12-91$ & 645 & & Purge CEC & $\mathrm{C}-\mathrm{He}$ & 200 & & \\
\hline 20 & $6-13-91$ & 645 & & Take Cali & ample & 200 & & $t=14: 53$ \\
\hline 21 & $6-14-91$ & 645 & & $\mathrm{He}$ & $0.1 \mathrm{H}_{2}$ & 200 & 100 & \\
\hline 22 & $6-17-91$ & 645 & 590 & $0.1 \mathrm{H}_{2}$ & & $0.1 \mathrm{H}_{2}$ & $\mathrm{He}$ & \\
\hline 23 & $6-18-91$ & 590 & 535 & $0.1 \mathrm{H}_{2}$ & & $\mathrm{He}$ & & $50 \mathrm{~mL} \mathrm{He}$ \\
\hline 24 & $6-19-91$ & 535 & & $0.1 \mathrm{H}_{2}$ & & $\mathrm{He}$ & & $50 \mathrm{He}+31 \% \mathrm{H}_{2}$ \\
\hline 25 & $6-19-91$ & 535 & & $0.1 \mathrm{H}_{2}$ & & $\mathrm{He}$ & & $50 \mathrm{He}+61 \% \mathrm{H}_{2}$ \\
\hline 26 & $6-19-91$ & 535 & & $0.1 \mathrm{H}_{2}$ & & $\mathrm{He}$ & & $50 \mathrm{He}+131 \% \mathrm{H}_{2}$ \\
\hline 27 & $6-19-91$ & 535 & & $0.1 \mathrm{H}_{2}$ & & $\mathrm{He}$ & & $50 \mathrm{He}+501 \% \mathrm{H}_{2}$ \\
\hline 28 & $6-19-91$ & 535 & 645 & $0.1 \mathrm{H}_{2}$ & & $\mathrm{He}$ & & $50 \mathrm{~mL} \mathrm{He}$ \\
\hline 29 & $6-21-91$ & 645 & & $0.1 \mathrm{H}_{2}$ & $0.01 \mathrm{H}_{2}$ & $\mathrm{He}$ & $0.01 \mathrm{H}_{2}$ & \\
\hline 30 & $6-23-91$ & 645 & & $0.01 \mathrm{H}_{2}$ & & $0.01 \mathrm{H}_{2}$ & $0.1 \mathrm{H}_{2}$ & \\
\hline 31 & $6-24-91$ & 645 & 590 & $0.01 \mathrm{H}_{2}$ & & $0.1 \mathrm{H}_{2}$ & & \\
\hline 32 & $6-26-91$ & 590 & 535 & $0.01 \mathrm{H}_{2}$ & & $0.1 \mathrm{H}_{2}$ & & \\
\hline 33 & $6-28-91$ & 535 & 645 & $0.01 \mathrm{H}_{2}$ & & $0.1 \mathrm{H}_{2}$ & & \\
\hline 34 & $6-30-91$ & 645 & & $0.01 \mathrm{H}_{2}$ & $0.1 \mathrm{H}_{2}$ & $0.1 \mathrm{H}_{2}$ & $0.01 \mathrm{H}_{2}$ & \\
\hline 35 & $7-2-91$ & 645 & & $0.1 \mathrm{H}_{2}$ & $\mathrm{He}$ & $0.01 \mathrm{H}_{2}$ & $0.1 \mathrm{H}_{2}$ & \\
\hline 36 & $7-6-91$ & 645 & 590 & $\mathrm{He}$ & & $0.1 \mathrm{H}_{2}$ & & \\
\hline 37 & $7-8-91$ & 590 & 535 & $\mathrm{He}$ & & $0.1 \mathrm{H}_{2}$ & & \\
\hline 38 & $7-9-91$ & 535 & & $\mathrm{He}$ & & $0.1 \mathrm{H}_{2}$ & $\mathrm{He}$ & \\
\hline 39 & $7-10-91$ & 535 & 645 & $\mathrm{He}$ & & $\mathrm{He}$ & & \\
\hline 40 & $7-11-91$ & 645 & & $\mathrm{He}$ & - & $\mathrm{He}$ & $0.1 \mathrm{H}_{2}$ & \\
\hline 41 & $7-12-91$ & 645 & & $\mathrm{He}$ & $0.01 \mathrm{H}_{2}$ & $0.1 \mathrm{H}_{2}$ & & $\mathrm{t} 0=10: 47$ \\
\hline 42 & $7-14-91$ & 645 & & $0.01 \mathrm{H}_{2}$ & $0.1 \mathrm{H}_{2}$ & $0.1 \mathrm{H}_{2}$ & & \\
\hline 43 & $7-16-91$ & 645 & 590 & $0.1 \mathrm{H}_{2}$ & & & & \\
\hline 44 & $7-17-91$ & 590 & 528 & $0.1 \mathrm{H}_{2}$ & & & & . \\
\hline
\end{tabular}

A.1 
Experimenter Log - Phase II (contd)

\begin{tabular}{|c|c|c|c|c|c|}
\hline \multirow{3}{*}{$\begin{array}{l}\text { PCN } \\
\text { No. }\end{array}$} & \multirow{3}{*}{$\frac{\text { Date }}{(m-d-y)}$} & \multicolumn{3}{|c|}{ Ring Specimen } & \multirow{2}{*}{$\begin{array}{l}\text { Solid Specimen } \\
\text { Flow Rate/Gas Comp }\end{array}$} \\
\hline & & Temperature & Flow & s Comp & \\
\hline & & $\underline{\text { Initial }}$ & Initial & Final & Initial \\
\hline
\end{tabular}

Remarks.

End of cycle 12A.1: Reactor shutdown on July 20, 1991

$\begin{array}{ll}45 & 7-18-91 \\ 46 & 7-22-91 \\ 47 & 7-23-91 \\ 48 & 7-24-91 \\ 49 & 7-25-91 \\ 50 & 7-25-91 \\ 51 & 7-26-91 \\ 52 & 7-26-91 \\ 53 & 7-27-91 \\ 54 & 7-29-91\end{array}$

N/A

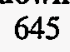

$100 \%$ Helium

Start of Cycle 12-A.2; July 30, 1991

$\begin{array}{llll}55 & 8-5-91 & 530 & 645 \\ 56 & 8-6-91 & 645 & 645 \\ 57 & 8-7-91 & 645 & 590 \\ 58 & 8-8-91 & 590 & 530 \\ 59 & 8-9-91 & 530 & 645 \\ 60 & 8-10-91 & 645 & 530 \\ 61 & 8-11-91 & 530 & 645 \\ 62 & 8-13-91 & 645 & \\ 63 & 8-15-91 & 645 & \\ 64 & 8-17-91 & 645 & \\ 65 & 8-19-91 & 645 & \end{array}$

GetterBed XX-52280-2 Changeout

$\begin{array}{lll}66 & 8-21-91 & 645 \\ 67 & 8-25-91 & 645 \\ 68 & 8-27-91 & 645 \\ 69 & 8-28-91 & 645 \\ 70 & 8-31-91 & 645 \\ 71 & 9-5-91 & 645 \\ 72 & 9-8-91 & 645 \\ 73 & 9-9-91 & 645 \\ 74 & 9-10-91 & 645 \\ 75 & 9-11-91 & 645 \\ 76 & 9-12-91 & 645 \\ 77 & 9-13-91 & 645 \\ 78 & 9-14-91 & 645 \\ 79 & 9-15-91 & 645 \\ 80 & 9-16-91 & 645 \\ 81 & 9-17-91 & 645 \\ 82 & 9-18-91 & 645 \\ 83 & 9-19-91 & 645\end{array}$

$645 \quad 0.1 \mathrm{H}_{2}$

$0.1 \mathrm{H}_{2}$

$0.1 \mathrm{H}_{2}$

$0.1 \mathrm{H}_{2}$

$0.1 \mathrm{H}_{2}$

$0.1 \mathrm{H}_{2}$

$0.1 \mathrm{H}_{2}$

$0.1 \mathrm{H}_{2}$

$\mathrm{He}$

$0.01 \mathrm{H}_{2}$

$0.1 \mathrm{H}_{2}$

$0.1 \mathrm{H}_{2}$

$\mathrm{He}$

$0.01 \mathrm{H}_{2}$

$0.1 \mathrm{H}_{2}$

$0.1 \mathrm{H}_{2}$

$\mathrm{He}$

$\mathrm{He}$

$0.01 \mathrm{H}_{2}$

$0.01 \mathrm{H}_{2}$

$0.1 \mathrm{H}_{2}$

$0.1 \mathrm{H}_{2}$

$0.1 \mathrm{H}_{2}$

$0.1 \mathrm{H}_{2}$

$0.1 \mathrm{H}_{2}$

$0.1 \mathrm{H}_{2}$

$0.1 \mathrm{H}_{2}$

$0.1 \mathrm{H}_{2}$

$0.1 \mathrm{H}_{2}$
$\mathrm{He}$

Purge $\# 9,1 \% \mathrm{H}_{2}$

$0.1 \mathrm{H}_{2}$

Purge Stopped

$\mathrm{He}$

$0.1 \mathrm{H}_{2}$

$\mathrm{He}$

$0.057 \% \mathrm{H}_{2}$ $0.107 \% \mathrm{H}_{2}$ $0.5 \% \mathrm{H}_{2}$ $0.206 \% \mathrm{H}_{2}$ $0.107 \% \mathrm{H}_{2}$ $0.057 \% \mathrm{H}_{2}$

Temperature adjustment

$0.1 \mathrm{H}_{2}$

$0.1 \mathrm{H}_{2}$

$0.1 \mathrm{H}_{2}$

$0.1 \mathrm{H}_{2}$

$0.1 \mathrm{H}_{2}$

$\mathrm{He} \quad 0.1 \mathrm{H}_{2}$

$0.01 \mathrm{H}_{2} \quad 0.1 \mathrm{H}_{2}$

$0.01 \mathrm{H}_{2}$

tOR=11:35,

$0.1 \mathrm{H}_{2} \quad 0.01 \mathrm{H}_{2}$

tOS $=13: 08$
$0.1 \mathrm{H}_{2}$

$\mathrm{He} \quad 0.1 \mathrm{H}_{2} \quad \mathrm{He}$

$0.01 \mathrm{H}_{2} \mathrm{He} \quad 0.1 \mathrm{H}_{2}$

$0.1 \mathrm{H}_{2}$

$0.1 \mathrm{H}_{2}$

$0.1 \mathrm{H}_{2} \quad \mathrm{He}$

$\mathrm{He} \quad \mathrm{He}$

$\mathrm{He} \quad 0.1 \mathrm{H}_{2} \quad 187 \mathrm{Ci} / \mathrm{m}^{3}$

$0.01 \mathrm{H}_{2} \quad 0.1 \mathrm{H}_{2}$

25 CEC:75 MS

$0.1 \mathrm{H}_{2} \quad 25 \mathrm{CEC}: 75 \mathrm{MS}$

SO CEC:50 MS

$0.1 \mathrm{H}_{2}$

$50 \mathrm{IG} 0.1 \mathrm{H}_{2}$ to CEC IC

$0.1 \mathrm{H}_{2}$

$0.1 \mathrm{H}_{2}$

Purge CEC IC

Purge MS IC

$\mathrm{He}$

$0.1 \mathrm{H}_{2}$

$0.1 \mathrm{H}_{2} \quad \mathrm{He}$

$146 \mathrm{Ci} / \mathrm{m}^{3}$

t0R $=9: 46$

Calibrate

RE-52270-1

Calibrate

RE-52270-2

Flow Rate Test

Purge RE-52270-1

Purge RE-52270-2

Secure Purges 
Experimenter Log - Phase II (contd)

Ring Specimen

\begin{tabular}{|c|c|c|c|c|}
\hline \multirow[b]{2}{*}{ PCN } & \multirow[b]{2}{*}{ Date } & & \multirow[b]{2}{*}{ Flow Rate/Gas Comp } \\
\hline & & Temperature & Flow Rate/Gas Comp & \\
\hline No. & $(m-d-y)$ & Initial & Initial & Initial \\
\hline
\end{tabular}

Remarks

Reactor Shutdown on September 21, 1991

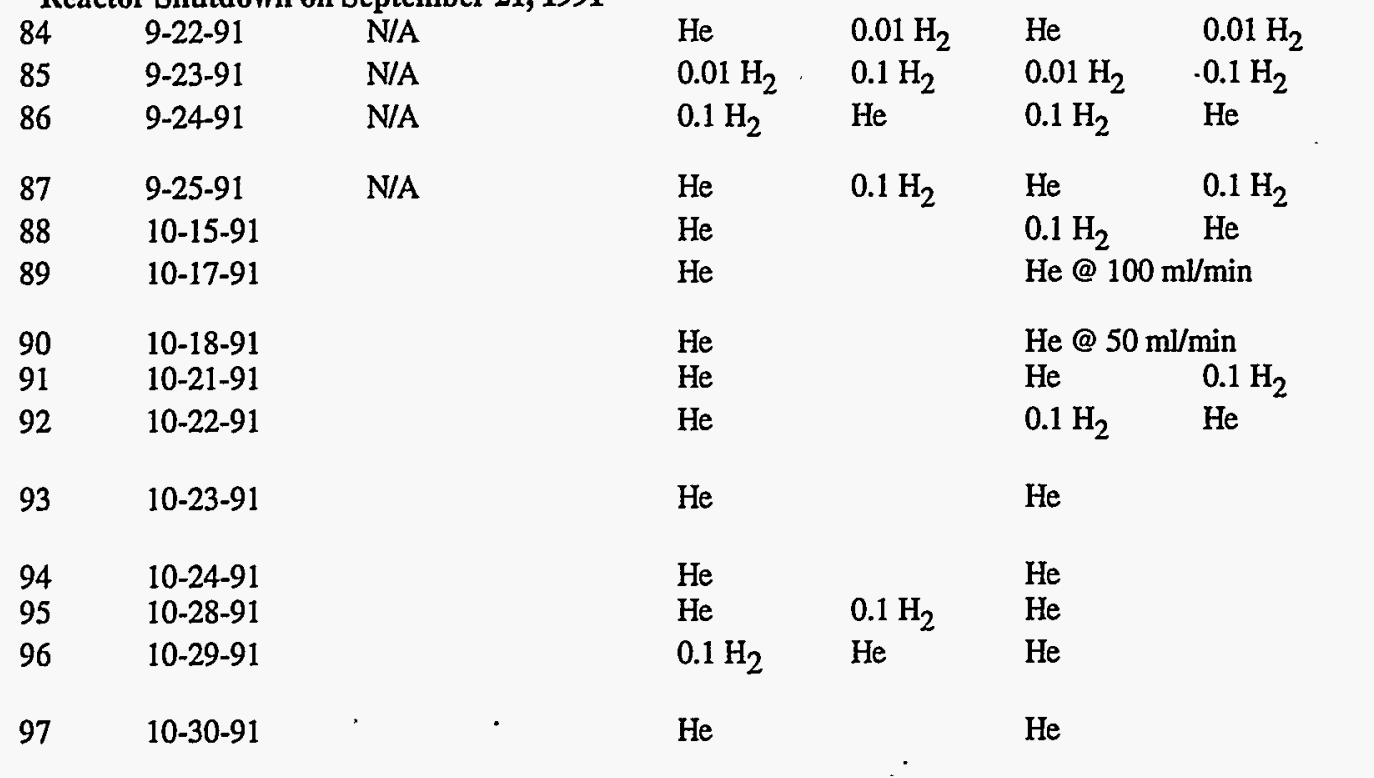

$98 \quad 10-31-91$

99 Injection Gas changed to $1.0 \% \mathrm{H}_{2}$

CEC voltage to -0.9

$\mathrm{V}$

\author{
Purge \\ RE-52271-1(He) \\ Stop Purge

Purge
RE-52271-1(0.1 $\left.\mathrm{H}_{2}\right)$
Purge
RE-52271-2(0.1 H $)$
Stop Purge
Purge
RE-52270-1(0.1 H $\left.\mathrm{H}_{2}\right)$
Purge
RE-52270-2(0.1 $\left.\mathrm{H}_{2}\right)$
Stop Purge \\ Stop Purge
}

Reactor Power @ 75\% Reactor Power@ 90\%

$0.1 \mathrm{H}_{2}$

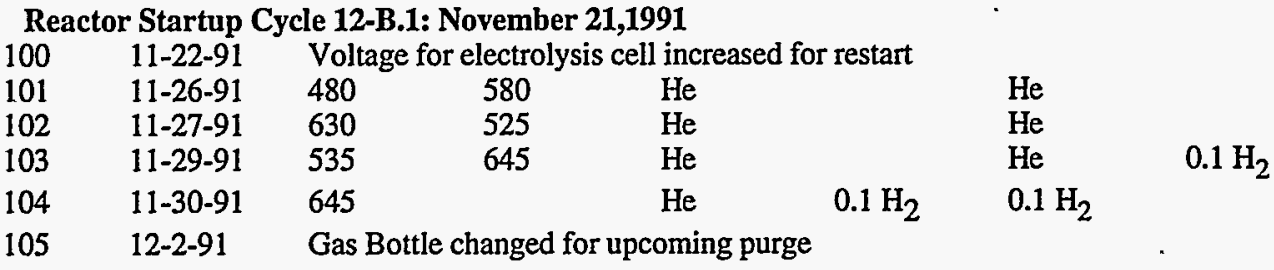

On December 2, 1991 the instrumentation lost power at 9:00 - Data interruption Expected

\begin{tabular}{|c|c|c|c|c|c|c|c|}
\hline 106 & $12-3-91$ & 645 & 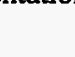 & $0.1 \mathrm{H}_{2}$ & & $0.1 \mathrm{H}_{2}$ & \\
\hline 107 & $12-4-91$ & 645 & . & $0.1 \mathrm{H}_{2}$ & & $0.1 \mathrm{H}_{2}$ & \\
\hline 108 & $12-5-91$ & 645 & & $0.1 \mathrm{H}_{2}^{2}$ & $\mathrm{He}$ & $200 \mathrm{mI} / \mathrm{min}$ & \\
\hline 109 & $12-7-91$ & 645 & & $\mathrm{He}$ & & $200 \mathrm{ml} / \mathrm{min}$ & \\
\hline 110 & $12-8-91$ & 645 & & $\mathrm{He}$ & & $200 \mathrm{ml} / \mathrm{min}$ & \\
\hline 111 & $12-9-91$ & 645 & & $\mathrm{He}$ & $0.1 \mathrm{H}_{2}$ & $0.1 \mathrm{H}_{2}$ & \\
\hline 112 & $12-11-91$ & 645 & 535 & $0.1 \mathrm{H}_{2}$ & & $0.1 \mathrm{H}_{2}$ & \\
\hline 113 & $12-12-91$ & 535 & & $0.1 \mathrm{H}_{2}$ & $\mathrm{He}$ & $0.1 \mathrm{H}_{2}$ & $\mathrm{He}$ \\
\hline 114 & $12-14-91$ & 535 & & $\mathrm{He}$ & $0.01 \mathrm{H}_{2}$ & $\mathrm{He}$ & $0.01 \mathrm{H}_{2}$ \\
\hline 115 & $12-16-91$ & 535 & & $0.01 \mathrm{H}_{2}$ & $0.1 \mathrm{H}_{2}$ & $0.01 \mathrm{H}_{2}$ & $0.1 \mathrm{H}_{2}{ }^{2}$ \\
\hline $\begin{array}{l}116 \\
117\end{array}$ & $\begin{array}{l}12-17-91 \\
12-18-91\end{array}$ & $\begin{array}{l}535 \\
535\end{array}$ & & $0.1 \mathrm{H}_{2}$ & $\mathrm{He}$ & $0.1 \mathrm{H}_{2}$ & $\mathrm{He}$ \\
\hline 118 & $12-22-91$ & 535 & & $\mathrm{He}$ & $0.01 \mathrm{H}_{2}$ & $\mathrm{He}$ & $0.01 \mathrm{H}_{2}$ \\
\hline 119 & $12-24-91$ & 535 & & $0.01 \mathrm{H}_{2}$ & $0.1 \mathrm{H}_{2}$ & $0.01 \mathrm{H}_{2}$ & $0.1 \mathrm{H}_{2}$ \\
\hline 120 & $12-27-91$ & 535 & & $0.1 \mathrm{H}_{2}$ & $0.01 \mathrm{H}_{2}$ & $0.1 \mathrm{H}_{2}$ & $0.01 \mathrm{H}_{2}$ \\
\hline 121 & $12-29-91$ & 535 & & $0.01 \mathrm{H}_{2}$ & $\mathrm{He}$ & $0.01 \mathrm{H}_{2}$ & $\mathrm{He}$ \\
\hline 122 & $12-31-91$ & 535 & & $\mathrm{He}$ & & $\mathrm{He}$ & $0.1 \mathrm{H}_{2}$ \\
\hline
\end{tabular}

Purge

RE-52270-1(0.1\%

$\mathrm{H}_{2}$ )

Gas Sample XN-7-2

Purge

RE-52270-1(He)

Gas Sample XN-7-2 
Experimenter Log - Phase II (contd)

Ring Specimen Solid Specimen

\begin{tabular}{|c|c|c|c|c|c|c|}
\hline \multirow{3}{*}{$\begin{array}{l}\mathrm{PCN} \\
\text { No. }\end{array}$} & \multirow{3}{*}{$\frac{\text { Date }}{(m-d-y)}$} & & \multirow{3}{*}{$\begin{array}{l}\text { Flow Ra } \\
\text { Initial }\end{array}$} \\
\hline & & \multicolumn{2}{|c|}{ Temperature } & \multicolumn{2}{|c|}{ Flow Rate/Gas Comp } & \\
\hline & & Initial & Final & Initial & Final & \\
\hline 123 & $1-2-92$ & 535 & & $\mathrm{He}$ & $0.1 \mathrm{H}_{2}$ & $0.1 \mathrm{H}_{2}$ \\
\hline 124 & $1-4-92$ & 535 & 645 & $0.1 \mathrm{H}_{2}$ & & $0.1 \mathrm{H}_{2}$ \\
\hline 125 & $1-6-92$ & 645 & & $0.1 \mathrm{H}_{2}^{\circ}$ & & $0.1 \mathrm{H}_{2}$ \\
\hline 126 & $1-7-92$ & 645 & & $0.1 \mathrm{H}_{2}$ & & $0.1 \mathrm{H}_{2}$ \\
\hline 127 & $1-8-92$ & 645 & & $0.1 \mathrm{H}_{2}$ & & $0.1 \mathrm{H}_{2}$ \\
\hline 128 & $1-9-92$ & 645 & 590 & $0.1 \mathrm{H}_{2}$ & & $0.1 \mathrm{H}_{2}$ \\
\hline 129 & $1-10-92$ & 590 & 535 & $0.1 \mathrm{H}_{2}$ & & $0.1 \mathrm{H}_{2}$ \\
\hline 130 & $1-11-92$ & 535 & 645 & $0.1 \mathrm{H}_{2}$ & & $0.1 \mathrm{H}_{2}$ \\
\hline 131 & $1-12-92$ & 645 & 535 & $0.1 \mathrm{H}_{2}$ & & $0.1 \mathrm{H}_{2}$ \\
\hline 132 & $1-13-92$ & 535 & 645 & $0.1 \mathrm{H}_{2}$ & & $0.1 \mathrm{H}_{2}$ \\
\hline
\end{tabular}

Comp

Remarks

Purge RE-52270-1

Purge RE-52270-2

Purge RE-52271-1

Calibration

RE-52271-1

Purge RE-52271-2

Calibration

RE-52271-2

Reactor shutdown January 15, 1992 at 0000 hrs

$\begin{array}{lllllll}133 & 1-16-92 & \text { N/A } & 0.1 \mathrm{H}_{2} & \mathrm{He} & 0.1 \mathrm{H}_{2} & \mathrm{He} \\ 134 & 1-23-92 & \text { N/A } & \mathrm{He} & & \mathrm{He} & \\ 135 & 1-25-92 & & \mathrm{He} & 0.1 \mathrm{H}_{2} & \mathrm{He} & 0.1 \mathrm{H}_{2}\end{array}$

Reactor Startup on January 29, 1992

\begin{tabular}{|c|c|c|c|c|c|c|}
\hline 136 & $1-29-92$ & 535 & 645 & $0.1 \mathrm{H}_{2}$ & & $0.1 \mathrm{H}_{2}$ \\
\hline 137 & $1-31-92$ & 645 & & $0.1 \mathrm{H}_{2}$ & & $0.1 \mathrm{H}_{2}$ \\
\hline 138 & $2-1-92$ & 645 & & $0.1 \mathrm{H}_{2}$ & & $0.1 \mathrm{H}_{2}$ \\
\hline 139 & $2-2-92$ & 645 & & $0.1 \mathrm{H}_{2}$ & $\mathrm{He}$ & $200 \mathrm{cc} / \mathrm{min}$ \\
\hline 140 & $2-4-92$ & 645 & & $\mathrm{He}$ & & $200 \mathrm{cc} / \mathrm{min}$ \\
\hline 141 & $2-5-92$ & 645 & & $\mathrm{He}$ & & $200 \mathrm{cc} / \mathrm{mi}$ \\
\hline 142 & $2-6-92$ & 645 & & $\mathrm{He}$ & $0.1 \mathrm{H}_{2}$ & $0.1 \mathrm{H}_{2}$ \\
\hline 143 & $2-8-92$ & 645 & 590 & $0.1 \mathrm{H}_{2}$ & & $0.1 \mathrm{H}_{2}$ \\
\hline 144 & $2-10-92$ & 590 & 535 & $0.1 \mathrm{H}_{2}$ & & $0.1 \mathrm{H}_{2}$ \\
\hline 145 & $2-12-92$ & 535 & 590 & $0.1 \mathrm{H}_{2}$ & & $0.1 \mathrm{H}_{2}$ \\
\hline
\end{tabular}

Purge RE-52270-1

Calibration Sample

Purge RE-52270-1

Calibration Sample

Remove Calibration

Sample

Getterbed

Replacement

146 Replace gaskets in calibration sampler on solid specimen

$147 \quad 2-13-92$

590

590

$0.1 \mathrm{H}_{2}$

148 2-14-92

645

645

$0.1 \mathrm{H}_{2}$

$0.1 \mathrm{H}_{2}$

2-15-92

$0.1 \mathrm{H}_{2}$

535

$0.1 \mathrm{H}_{2}$

645

$0.1 \mathrm{H}_{2}$

$0.1 \mathrm{H}_{2}$

$0.1 \mathrm{H}_{2}$

$0.1 \mathrm{H}_{2}$

535

645

2-19-92

$\begin{array}{lll}153 & 2-20-92 & 645 \\ 154 & 2-22-92 & 645\end{array}$

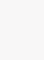

$155 \quad 2-24-92 \quad 590$

590

$\mathrm{He}$

$0.1 \mathrm{H}_{2}$

$0.1 \mathrm{H}_{2}$

$50 \mathrm{cc} / \mathrm{min} \quad$ Locate Leak

Purge RE-52271-1

Abort Purge

Purge RE-52271-1

Purge RE-52271-2

Secure Purge

\section{5}

590

$\mathrm{He}$

$0.1 \mathrm{H}_{2}$

$\mathrm{He}$

$0.1 \mathrm{H}_{2}$

2-26-92 535

$\mathrm{He}$

$0.1 \mathrm{H}_{2}$

$\begin{array}{llll}157 & 2-28-92 & 590 & 645 \\ 158 & 3-1-92 & 645 & 535\end{array}$

$159 \quad 3-3-92 \quad 535 \quad 645$

$\mathrm{He}$

$0.1 \mathrm{H}_{2}$

$\mathrm{He} \quad 0.1 \mathrm{H}_{2}$

$\mathrm{He} \quad 0.1 \mathrm{H}_{2}$

He $\quad 0.01 \mathrm{H}_{2} \quad 0.1 \mathrm{H}_{2}$

$0.01 \mathrm{H}_{2} \quad 0.1 \mathrm{H}_{2} \quad 0.1 \mathrm{H}_{2}$

$0.1 \mathrm{H}_{2} \quad 0.1 \mathrm{H}_{2}$

$0.1 \mathrm{H}_{2} \quad 1.0 \mathrm{H}_{2}$

$0.1 \mathrm{H}_{2} \quad 0.1 \mathrm{H}_{2}$

$1.0 \mathrm{H}_{2}$

Purge RE-52270-2

$0.1 \mathrm{H}_{2} \quad 0.1 \mathrm{H}_{2}$

Purge RE-52270-1

Secure Purge 
Experimenter Log - Phase II (contd)

Ring Specimen Solid Specimen

\begin{tabular}{|c|c|c|c|c|c|c|}
\hline \multirow{2}{*}{$\begin{array}{l}\mathrm{PCN} \\
\text { No. }\end{array}$} & \multirow{2}{*}{$\frac{\text { Date }}{(m-d-y)}$} & \multicolumn{2}{|c|}{ Temperature } & \multicolumn{2}{|c|}{ Flow Rate/Gas Comp } & \multirow{2}{*}{$\begin{array}{l}\text { Flow R } \\
\text { Initial }\end{array}$} \\
\hline & & Initial & Final & Initial & Final & \\
\hline 166 & $3-12-92$ & 645 & 590 & $0.1 \mathrm{H}_{2}$ & - & $0.1 \mathrm{H}_{2}$ \\
\hline 167 & $3-13-92$ & 590 & 535 & $0.1 \mathrm{H}_{2}$ & & $0.1 \mathrm{H}_{2}$ \\
\hline 168 & $3-14-92$ & 535 & 645 & $0.1 \mathrm{H}_{2}$ & & $0.1 \mathrm{H}_{2}$ \\
\hline 169 & $3-15-92$ & 645 & 535 & $0.1 \mathrm{H}_{2}$ & & $0.1 \mathrm{H}_{2}$ \\
\hline 70 & $3-16-92$ & 535 & 645 & $0.1 \mathrm{H}_{2}$ & & $0.1 \mathrm{H}_{2}$ \\
\hline
\end{tabular}

Reactor Shutdown 0830 March 19, 1992

$\begin{array}{lllllll}171 & 3-21-92 & \text { N/A } & 0.1 \mathrm{H}_{2} & \mathrm{He} & 0.1 \mathrm{H}_{2} & \mathrm{He} \\ 172 & 4-6-92 & \text { N/A } & \mathrm{He} & & \mathrm{He} & \end{array}$



Appendix B

Corrected/Compiled Database 



\section{Appendix B}

\section{Corrected/Compiled Database}

An overall summary of the BEATRIX-II, Phase II, experimental database was compiled to form two smaller, more manageable databases. The original 26 prime data channels that formed the experimental database of the irradiation phase of the Phase I experiment were reduced to the most important 20. The data set was condensed further by increasing the time interval of the data from 2 minutes to 6 minutes. The dataset was then segregated into two separate spreadsheets, one containing the data for the temperature-change canister and one for the temperature-gradient canister. Each of these canister spreadsheets included only the data applicable to the respective canister, i.e., 15 of the total 20 data channels. Table B.1 lists the 15 columns (A through $\mathrm{O}$ ) included in each spreadsheet and the distribution of the data between the temperature-change canister (ring) and temperaturegradient canister (solid) spreadsheets.

The data compilation is very similar to the data compilation carried out in the Phase I Data Summary Report. One notable difference is a slight change in notation that was made in Phase II in an attempt to clarify the data-correction process. The tritium associated with the tritium generation rate is denoted $G$ in this report (see Equation 3.7) but in the Phase I report is was denoted as $\mathrm{G}_{\mathrm{EX}}$.

The relationships used in correcting the ion-chamber response for sweep-gas composition and ion-chamber background are described in Section 3.1 of this report. The apparent tritium concentrations determined from the measured ion-chamber response in a sweep gas of $\mathrm{x} \%$ hydrogen and the ion-chamber calibration curves ( $\mathrm{T}_{\mathrm{IC}}$ in Equation 3.4 of this report) are listed in Columns $\mathrm{N}$ and $O$ of the spreadsheets (Table B.1), respectively, for the ion chambers after the ceramic electrolysis cell (CEC) and the molecular sieves. Columns $\mathrm{P}$ through AE in Table B.2 list the additional spreadsheet columns that were calculated and used in the interpretation of the tritium recovery results. Columns $T$ and $U$ are the final tritium concentrations for the $\mathrm{CEC}\left(\mathrm{T}_{\mathrm{He}}\right)$ and the molecular-sieve ionization chambers after correction for sweep-gas composition and background (Equation 3.5). The sweep-gas enhancement factors of $0,1.1,1.3$, and 1.4 were entered in Columns $\mathrm{P}$ and $\mathrm{Q}$ of the spreadsheet and corresponded to hydrogen additions of $0,0.01,0.1$, and $1.0 \%$. The CEC ionchamber backgrounds (Column $\mathrm{R}$ ) are deduced from a comparison of the tritium concentration in Column $\mathrm{T}\left(\mathrm{T}_{\mathrm{He}}\right.$, Equation 3.5 of this report) with the tritium concentration extrapolated from the ionchamber calibration in Column $\mathrm{AC}$ ( $\mathrm{G}$, Equation 3.7 of this report). The background for the molecular-sieve ion chamber in Column $S$ was set qualitatively on the basis of keeping a constant value of HTO (Column V) concentration in the reference condition and maintaining a positive quantity of HTO during off-reference operation. The tritium recovery rate (Column $W$ ) and the total recovered tritium (Column $\mathrm{X}$ ) were used to compile the total tritium recovered during the experiment (Table 5.1). Column $\mathrm{AB}$ is the correction term to correct measured tritium concentration at calibration $\left(G_{C}\right)$ to other times in the irradiation cycle $(G)$. This correction term takes into account changing neutron flux and lithium burnup. The relationship between $G_{C}$ and $G$ is given in Equation 3.7, Section 3.1.5 of this report. The extrapolated calibration concentration is given in Column AC. Column $\mathrm{AE}$ is the ratio of recovered tritium (Column $\mathrm{T}$ ) to that generated $(\mathrm{AD})$.

The final compiled data for the ring and solid specimen were plotted for each reactor cycle. Two plots were made to describe a given specimen in a given cycle. The first plot contains the total tritium concentration, $T_{H e}($ Column $T)$, the sweep-gas enhancement factor (Column $P$ ), and the ionchamber background (Column R). The second plot includes the ratio of recovered/generated tritium (Column AE) and the average inner-specimen temperature (Column M). The sweep-gas 
compositions are indicated on both plots. The two plots for each canister in each of the four cycles are included in Figures C.1 through C.16.

The complete database in the form of spreadsheets as described in Tables B.1 and B.2 have been compiled in LOTUS 1-2-3 format (**.WK1) and stored on a compact disk (CD) and on 150 MB Bernoulli disks. Bernoulli disks are compatible with "BERNOULLI BOXES" that are available from Iomega Corporation, 1821 West 4000 South, Roy, Utah 84067. The database is available, and requests for the data should be addressed to the BEATRIX-II Task Manager (G. W. Hollenberg, Pacific Northwest National Laboratory P. O. Box 999, Richland, Washington 99352).

Table B.1. Data Channels Selected for Final Compilation

\begin{tabular}{|c|c|c|}
\hline \multirow[b]{2}{*}{ Description } & \multicolumn{2}{|c|}{$\begin{array}{l}\text { Spreadsheet Colum } \\
\text { in Data Compilation }\end{array}$} \\
\hline & Ring & \\
\hline Elapsed Time from Start of Spreadsheet (hour) & A & A \\
\hline Date & $\mathrm{B}$ & $\mathrm{B}$ \\
\hline Time of Day (Fraction) & $\mathrm{C}$ & $\mathrm{C}$ \\
\hline Ring Specimen Sweep Gas Moisture (ppm) & $\mathrm{D}$ & \\
\hline Moisture after the Ring Specimen IC (ppm & E & \\
\hline Solid Specimen Sweep Gas Moisture (ppm) & & $\mathrm{D}$ \\
\hline Moisture after the Solid Specimen IC (ppm) & & $\mathrm{E}$ \\
\hline Ring Specimen Sweep Gas Flow (CEC) (mL/min) & $\mathbf{F}$ & \\
\hline Ring Specimen Sweep Gas Flow (MSD) (mL/min) & G & \\
\hline Solid Specimen sweep Gas Flow (CEC) (mL/min) & & F \\
\hline Solid Specimen Sweep Gas Flow (MS) (mL/min) & & G \\
\hline Self-Powered Neutron Detector (Relative) & $\mathrm{H}$ & $\mathrm{H}$ \\
\hline Temperature of the Glovebox $\left({ }^{\circ} \mathrm{C}\right)$ & I & I \\
\hline Solid Specimen Outer Temperature $\left({ }^{\circ} \mathrm{C}\right)$ & & $\mathbf{J}$ \\
\hline Solid Specimen Center Temperäture - Top $\left({ }^{\circ} \mathrm{C}\right)$ & & $\mathrm{K}$ \\
\hline Solid Specimen Center Temperature - Bottom $\left({ }^{\circ} \mathrm{C}\right)$ & & L \\
\hline Ring Specimen Outer Temperature $\left({ }^{\circ} \mathrm{C}\right)$ & $\mathrm{J}$ & \\
\hline Ring Specimen Inner Temperature No. $1\left({ }^{\circ} \mathrm{C}\right)$ & $\mathrm{K}$ & \\
\hline Ring Specimen Inner Temperature No. $2\left({ }^{\circ} \mathrm{C}\right)$ & $\mathrm{L}$ & \\
\hline Average Inner Ring Temperature $\left({ }^{\circ} \mathrm{C}\right)$ & $\mathbf{M}$ & \\
\hline Average Inner Solid Temperature $\left({ }^{\circ} \mathrm{C}\right)$ & & $\mathrm{M}$ \\
\hline Ring Specimen Sweep Gas Tritium (CEC) $\left(\mathrm{Ci} / \mathrm{m}^{3}\right)$ & $\mathbf{N}$ & \\
\hline Ring Specimen Sweep Gas Tritium (MS) $\left(\mathrm{Ci} / \mathrm{m}^{3}\right)$ & $\mathrm{O}$ & \\
\hline Solid Specimen Sweep Gas Tritium (CEC) $\left(\mathrm{Ci} / \mathrm{m}^{3}\right)$ & & $\mathbf{N}$ \\
\hline Solid Specimen Sweep Gas Tritium (MS) $\left(\mathrm{Ci} / \mathrm{m}^{3}\right)$ & & $\mathrm{O}$ \\
\hline
\end{tabular}

$\mathrm{CEC}=$ the sweep gas line through the CEC

$\mathrm{MS}=$ the line for the molecular sieve

IC $=$ the ion chamber 
Table B.2. Calculated Columns in the Data Compilation Spreadsheet

Spreadsheet Column

$P$

$\mathrm{Q}$

$\mathrm{R}$

S

$\mathrm{T}$

$\mathrm{U}$

V

$\mathrm{W}$

$\mathrm{X}$

$\mathrm{Y}$

Z

$\mathrm{AA}$

$\mathrm{AB}$

$A C$

$\mathrm{AD}$

$\mathrm{AE}$
Description

CEC Ion Chamer Enhancement Factor $\left(\mathrm{Ci} / \mathrm{m}^{3}\right)$

MS Ion Chamber Enhancement Factor $\left(\mathrm{Ci} / \mathrm{m}^{3}\right)$

CEC Ion Chamber Background $\left(\mathrm{Ci} / \mathrm{m}^{3}\right)$

MS Ion Chamber Background $\left(\mathrm{Ci} / \mathrm{m}^{3}\right)$

Total Tritium Concentration, $\mathrm{T}_{\mathrm{He}}-$ Corected $\left(\mathrm{Ci} / \mathrm{m}^{3}\right)$

HT Tritium Concentration - Corrected $\left(\mathrm{Ci} / \mathrm{m}^{3}\right)$

HTO Tritium - Corrected $\left(\mathrm{Ci} / \mathrm{m}^{3}\right)$

Total Tritium Recovery Rate $(\mathrm{Ci} / \mathrm{s})$

Tritium Recovered in Time Interval (Ci)

Approximate EFPD

Relative Flux Level (Equation 3.7)

Effective Full Power Days in Present Cycle (Days)

Generation Rate Correction for Flux and Burnup

Generated Tritium Concentration, $\mathrm{G}\left(\mathrm{Ci} / \mathrm{m}^{3}\right)$

Tritium Generation Rate (Corrected) (Ci/s)

Recovered/Generated Tritium 
Jołoey uo!padso Jaqueyo 40I

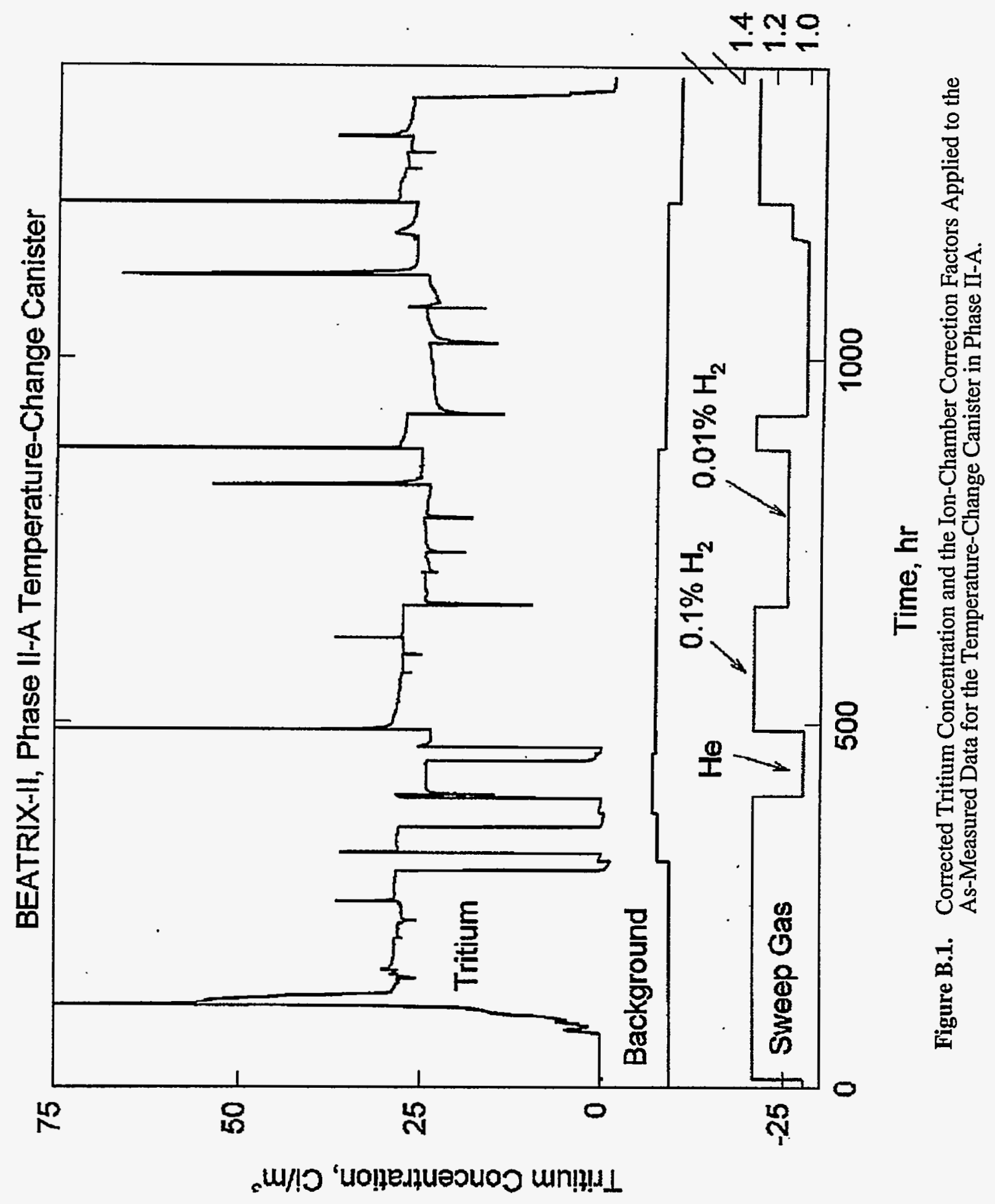




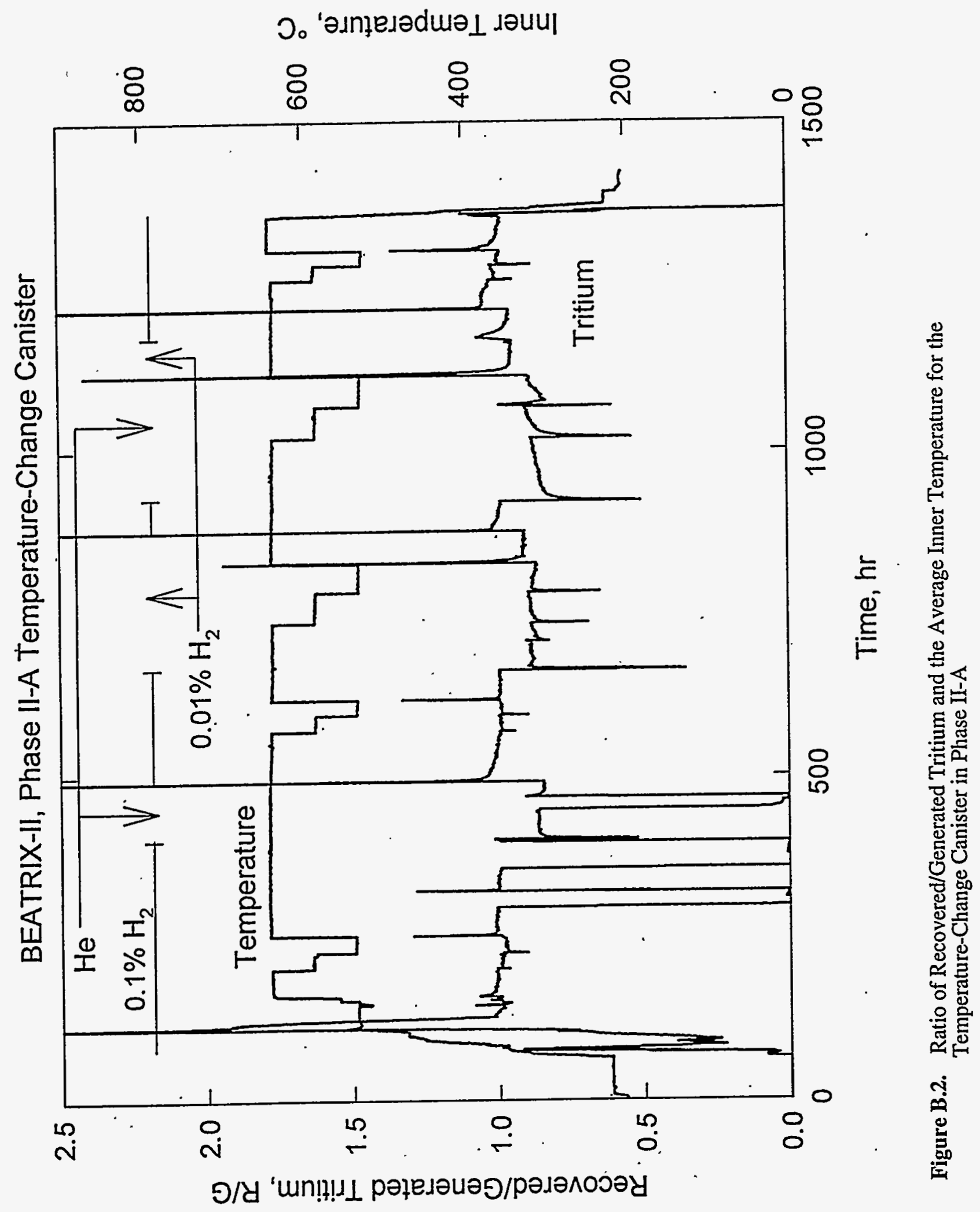




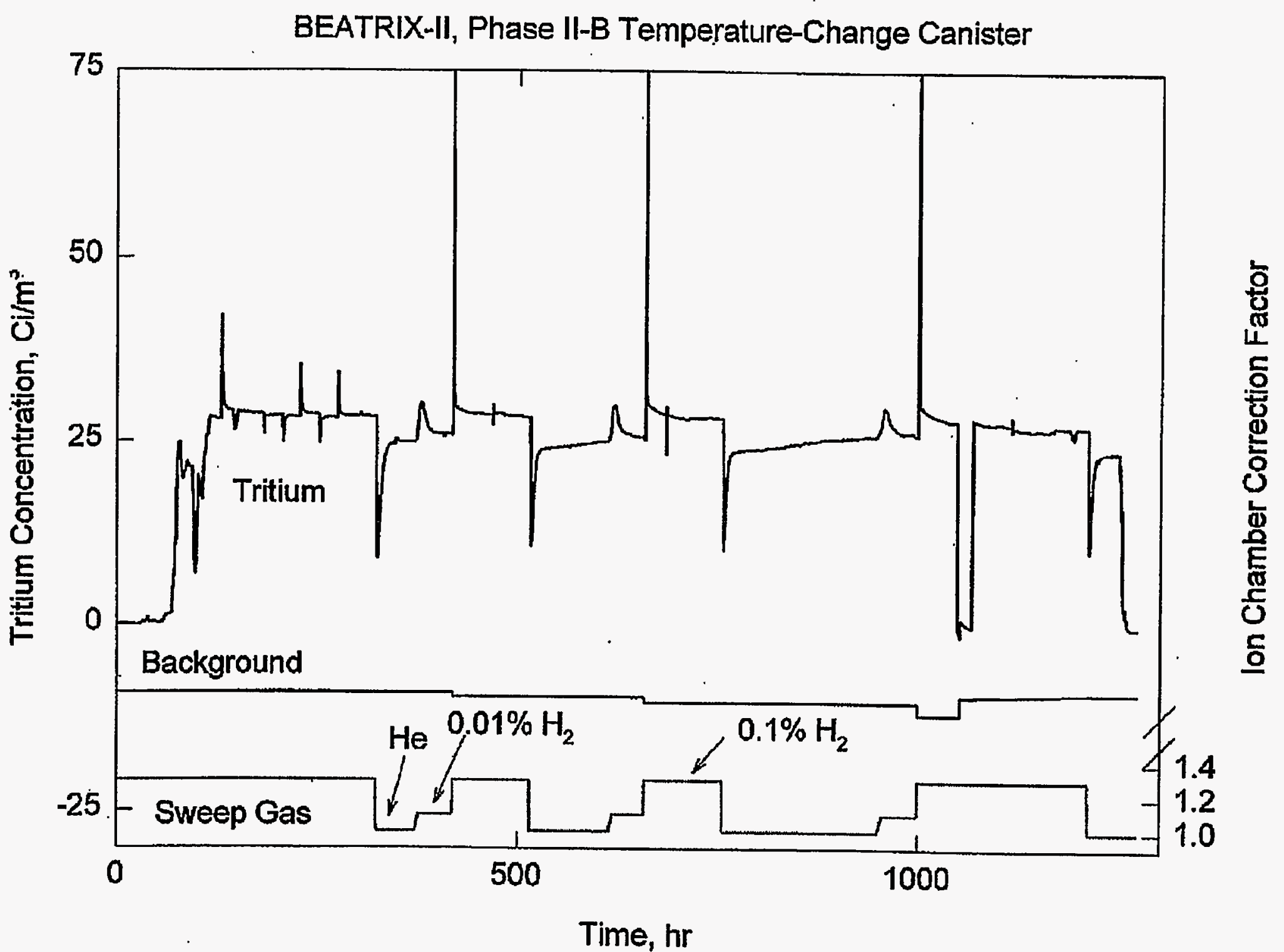

Figure B.3. Corrected Tritium Concentration and the Ion-Chamber Correction Factors Applied to the As-Measured Data for the Temperature-Change Canister in Phase II-B 


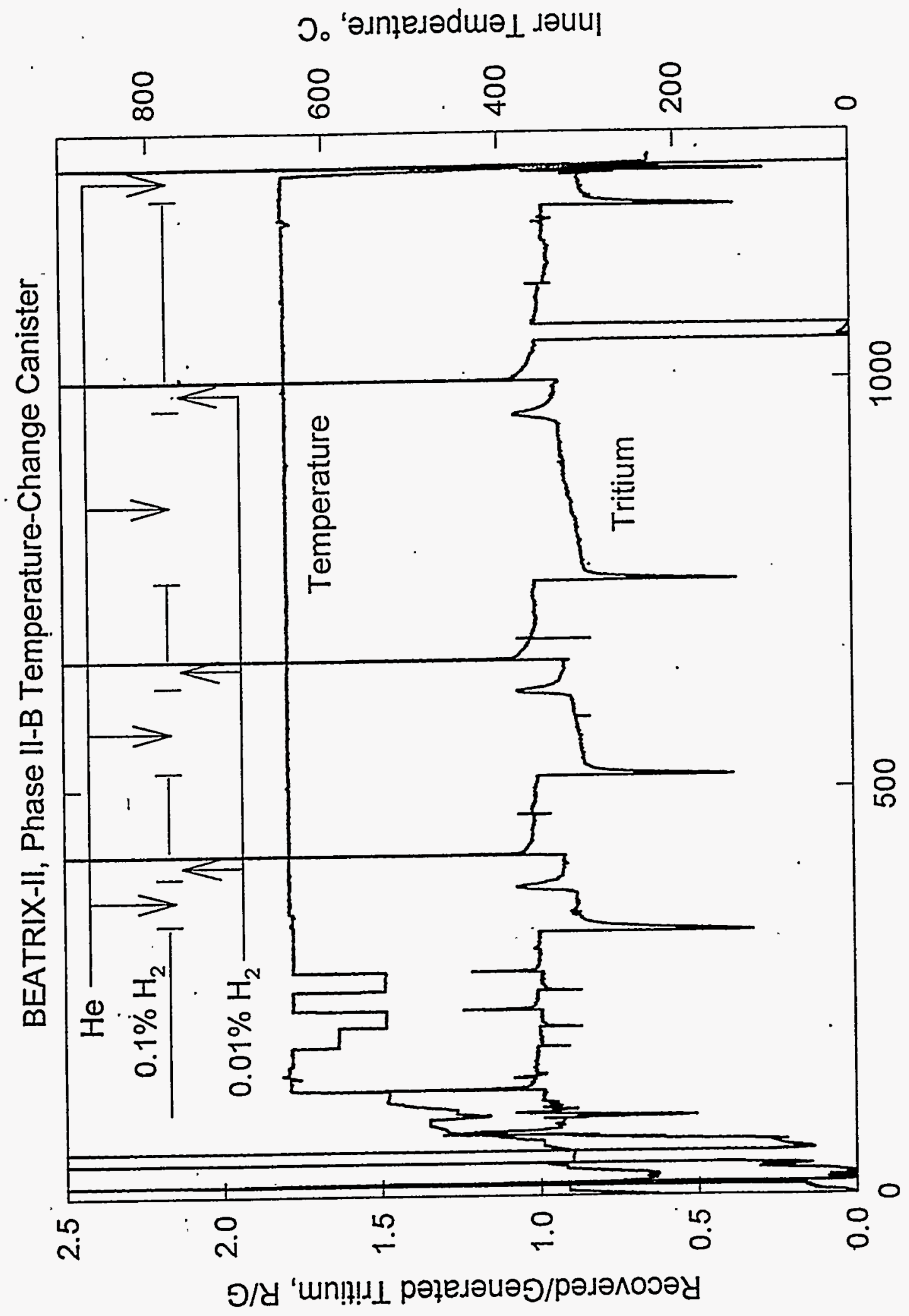

·.

苞 


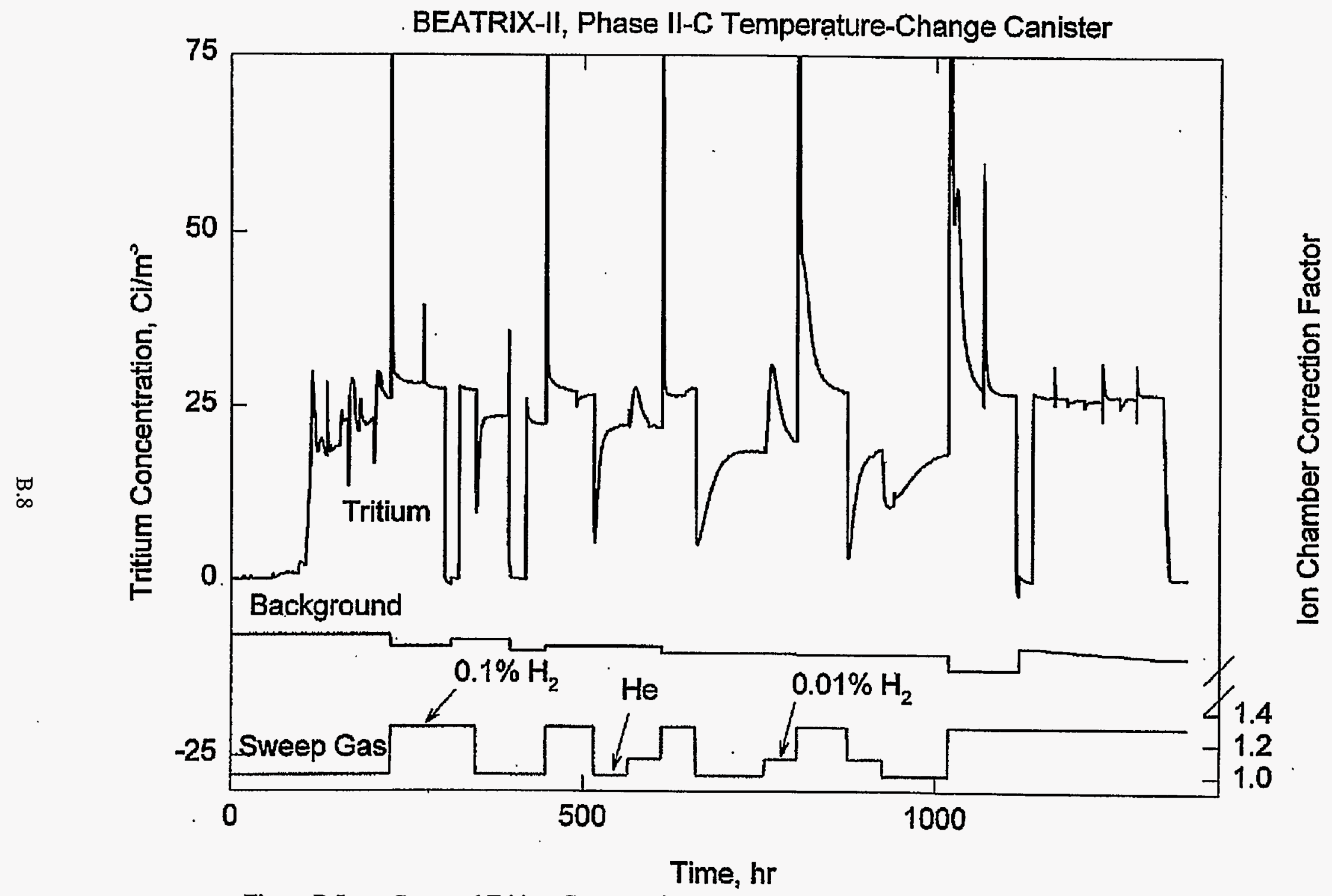

Figure B.5. Corrected Tritium Concentration and the Ion Chamber Correction Factors Applied to the As-Measured Data for the Temperature-Change Canister in Phase II-C 


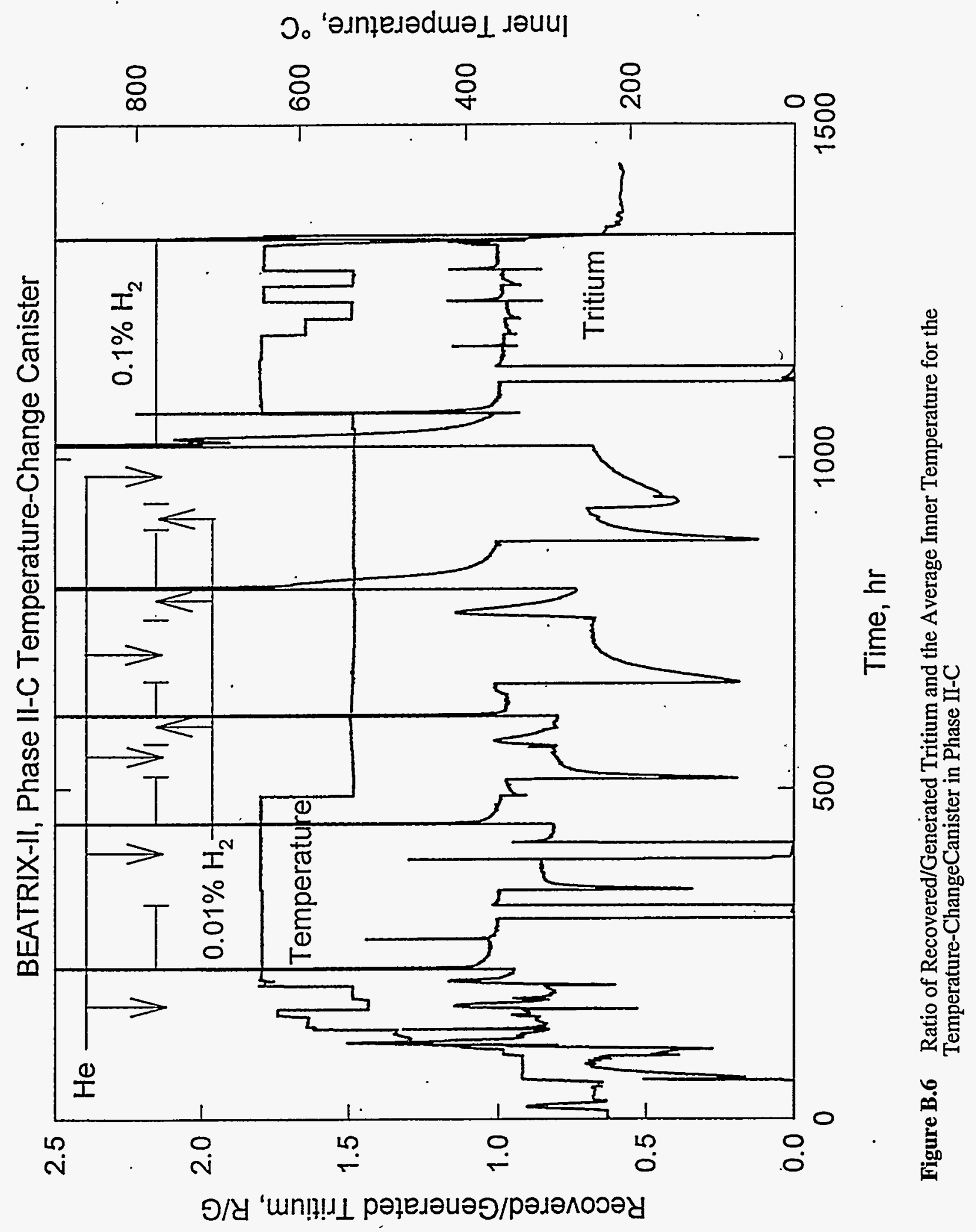




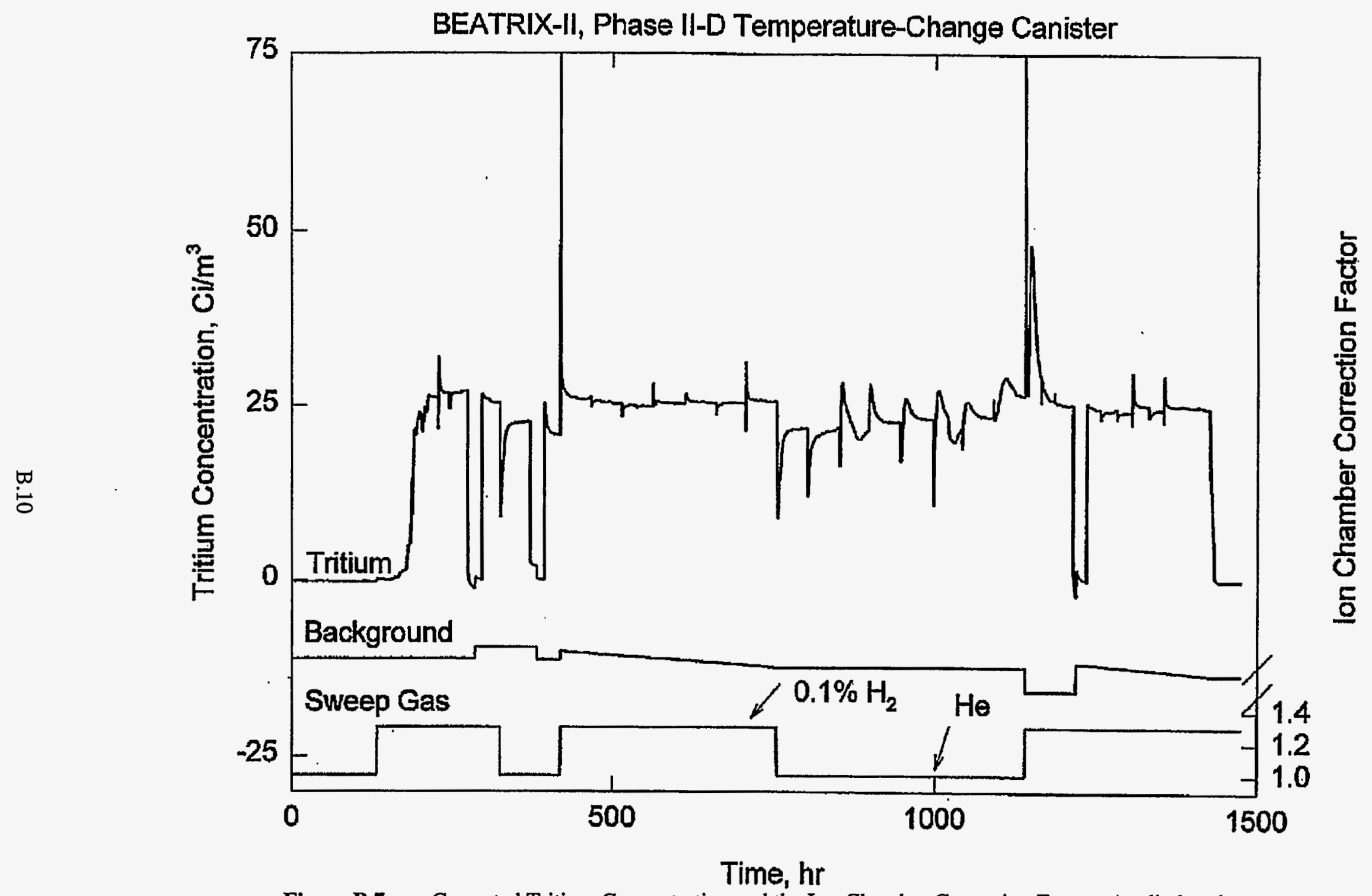

Figure B.7. Corrected Tritium Concentration and the Ion-Chamber Correction Factors Applied to the As-Measured Data for the Temperature-Change Canister in Phase II-D 


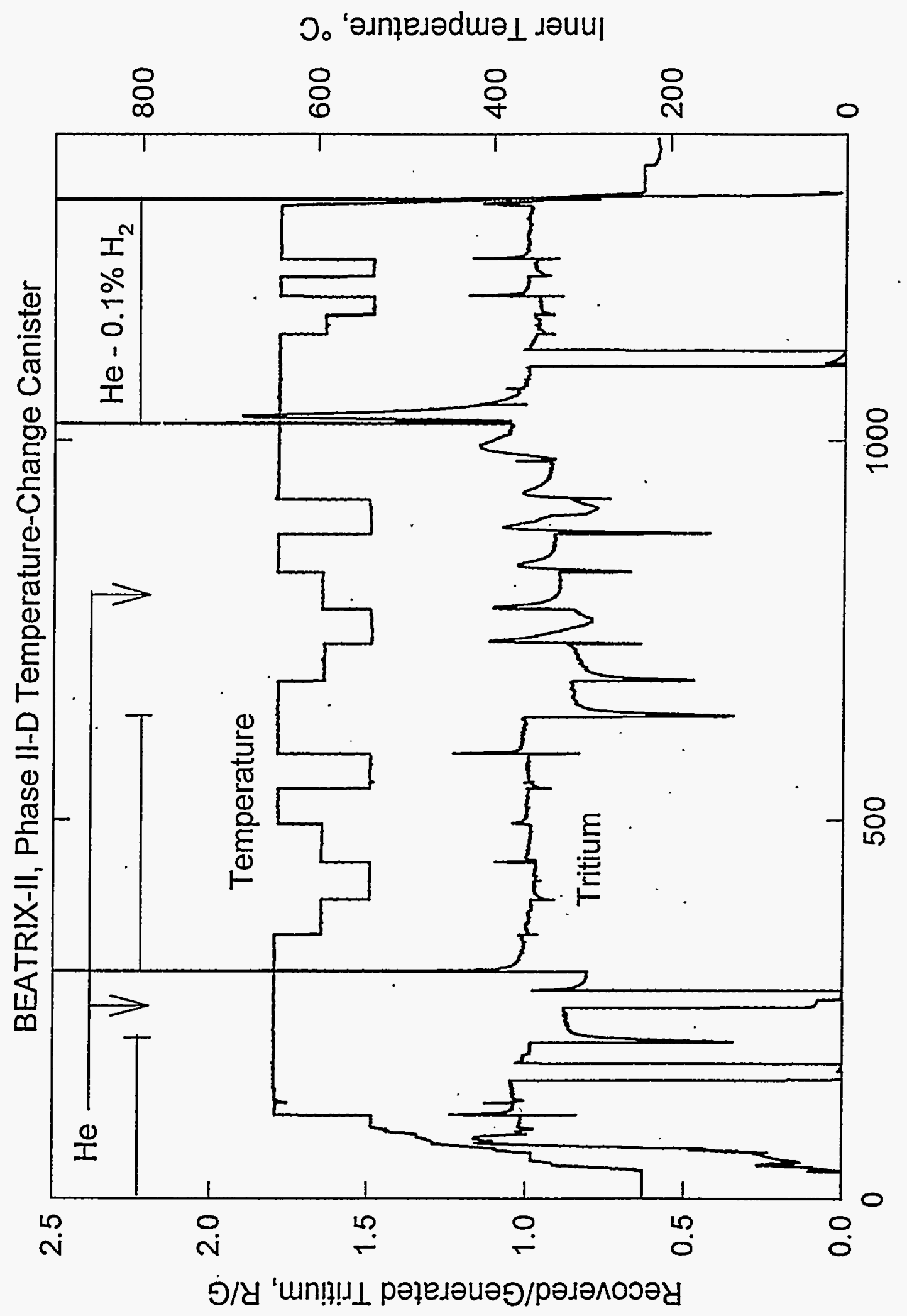

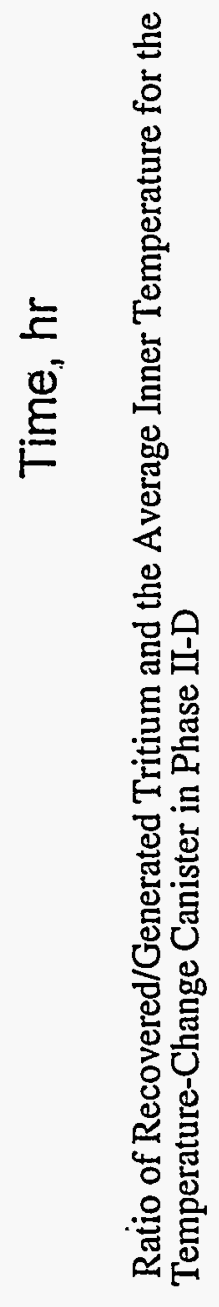




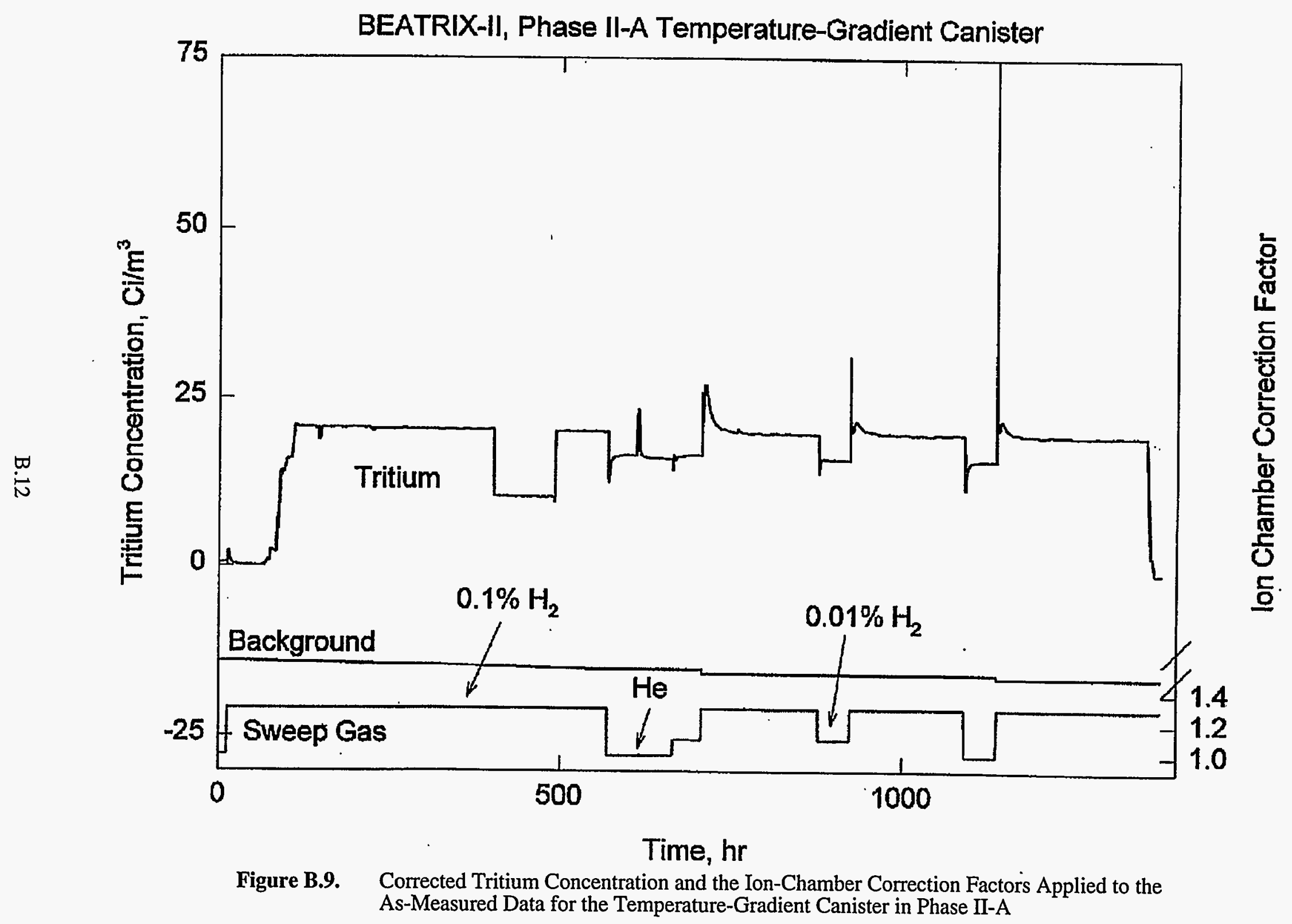




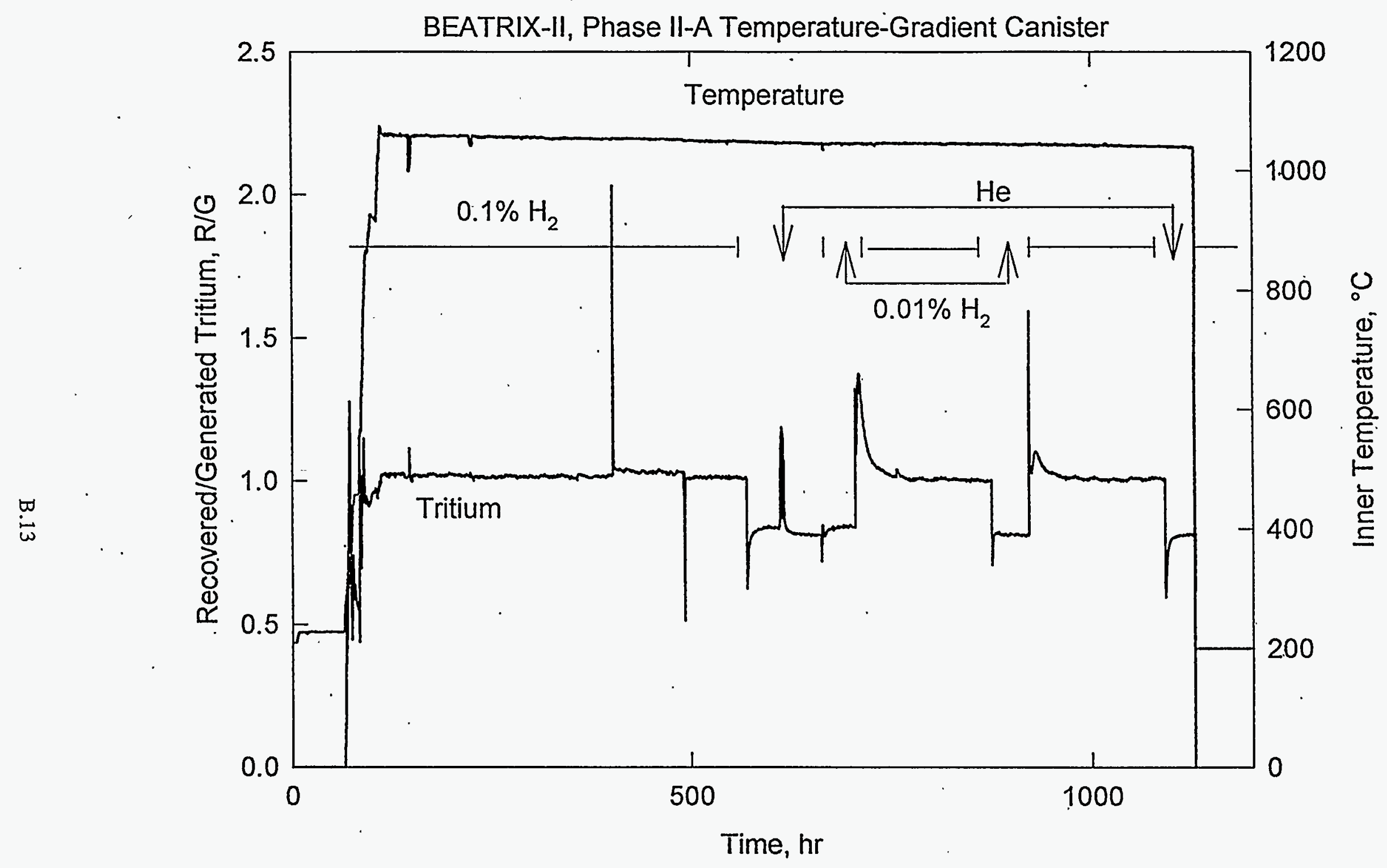

Figure B.10 Ratio of Recovered/Generated Tritium and the Average Inner Temperature for the Temperature-Gradient Canister in Phase II-A 


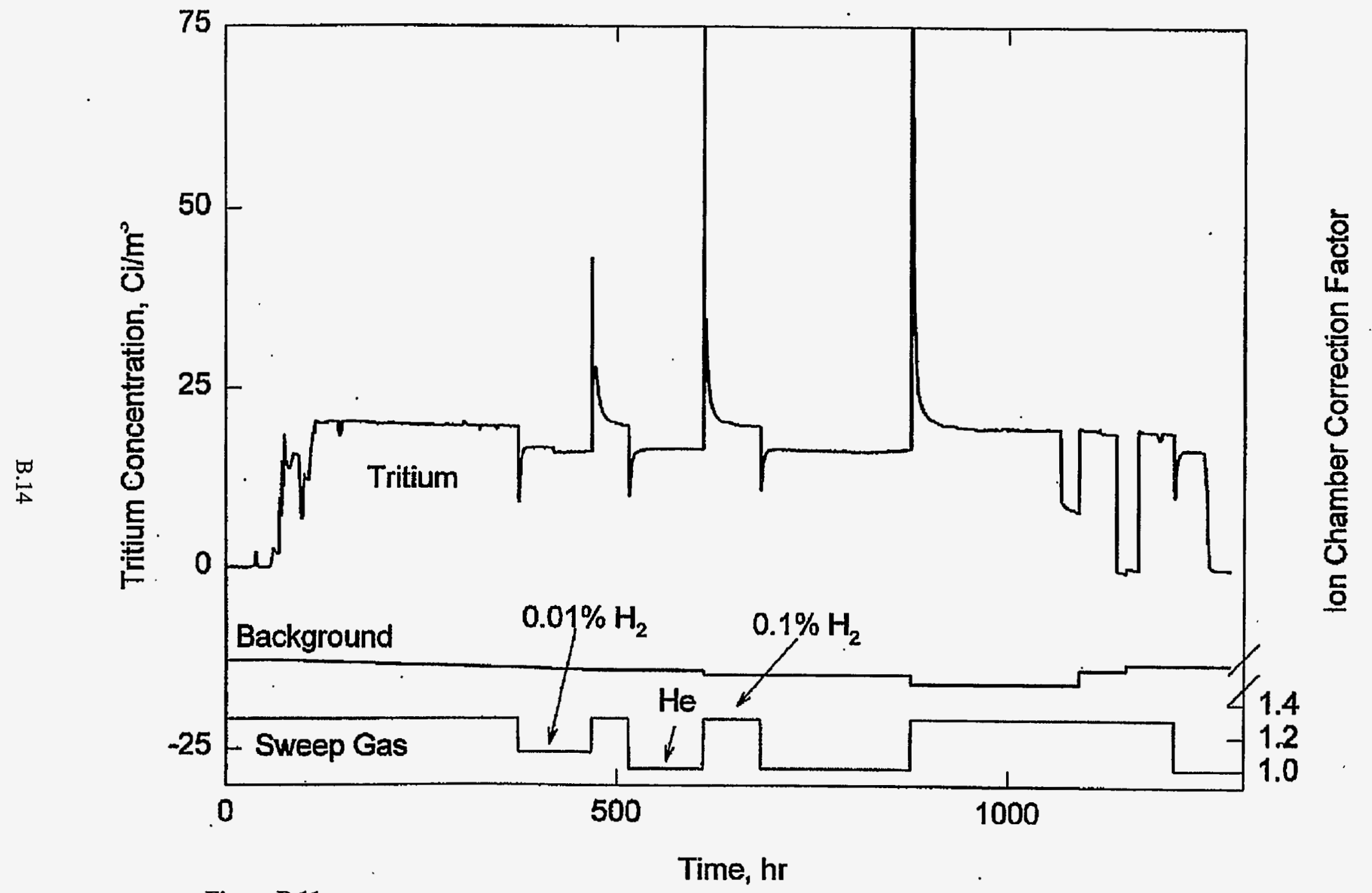

Figure B.11.

Corrected Tritium Concentration and the Ion-Chamber Correction Factors Applied to the As-Measured Data for the Temperature-Gradient Canister in Phase II-B 


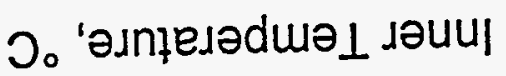

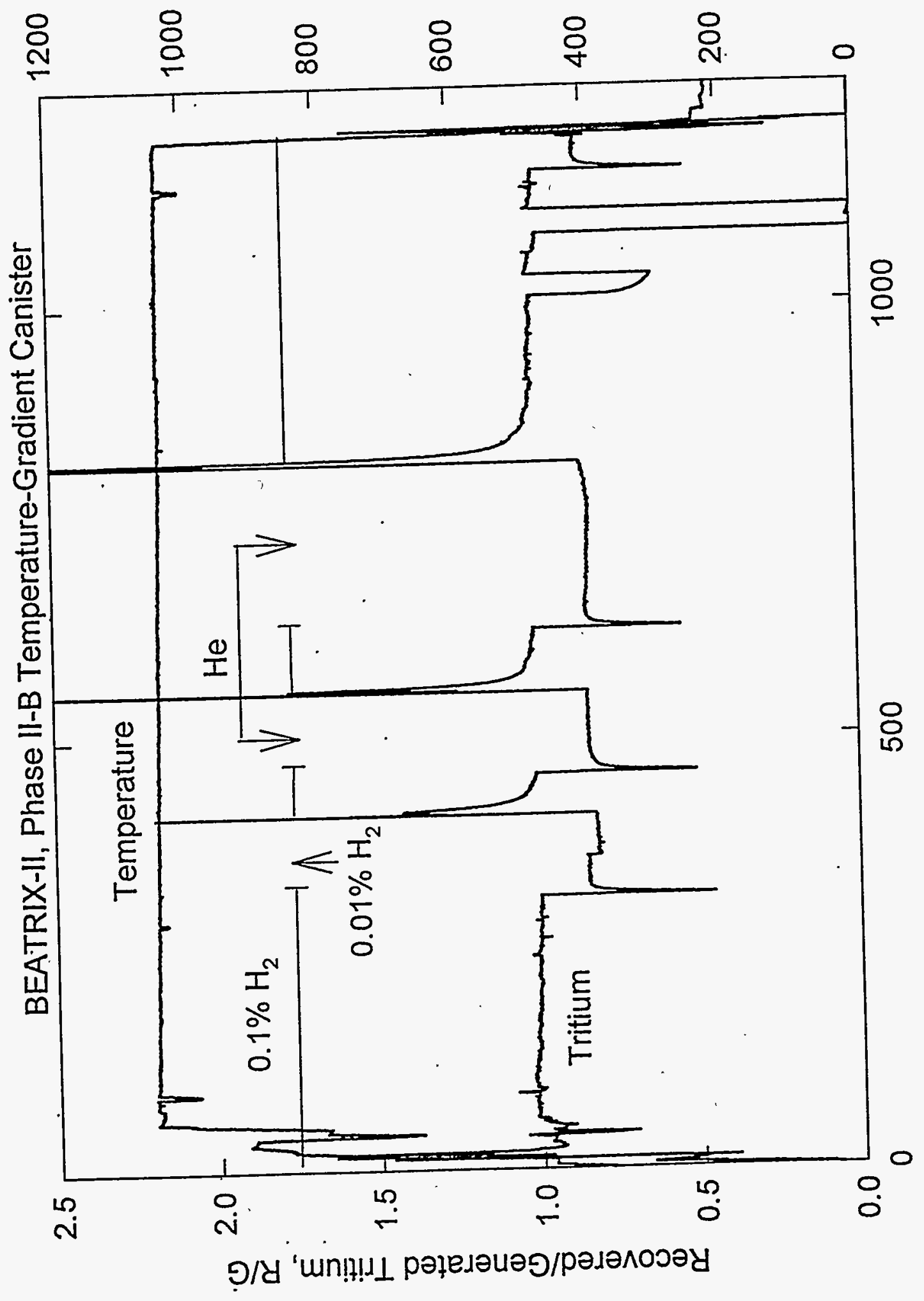

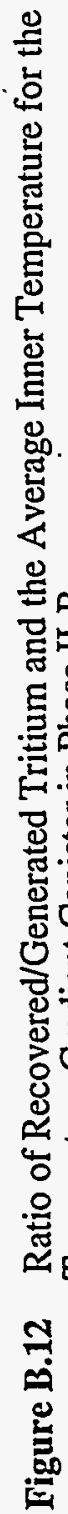




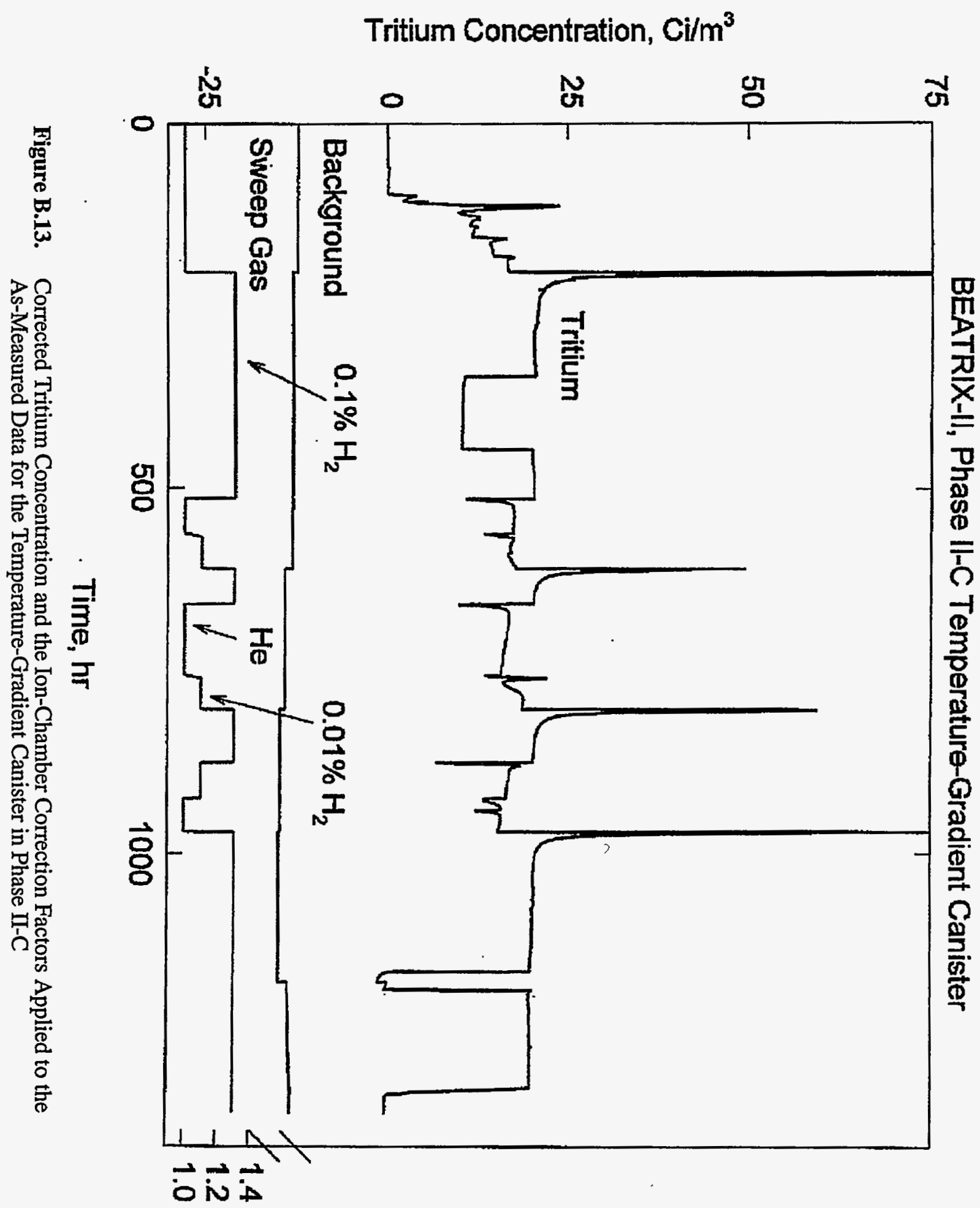

Ion Chamber Correction Factor 


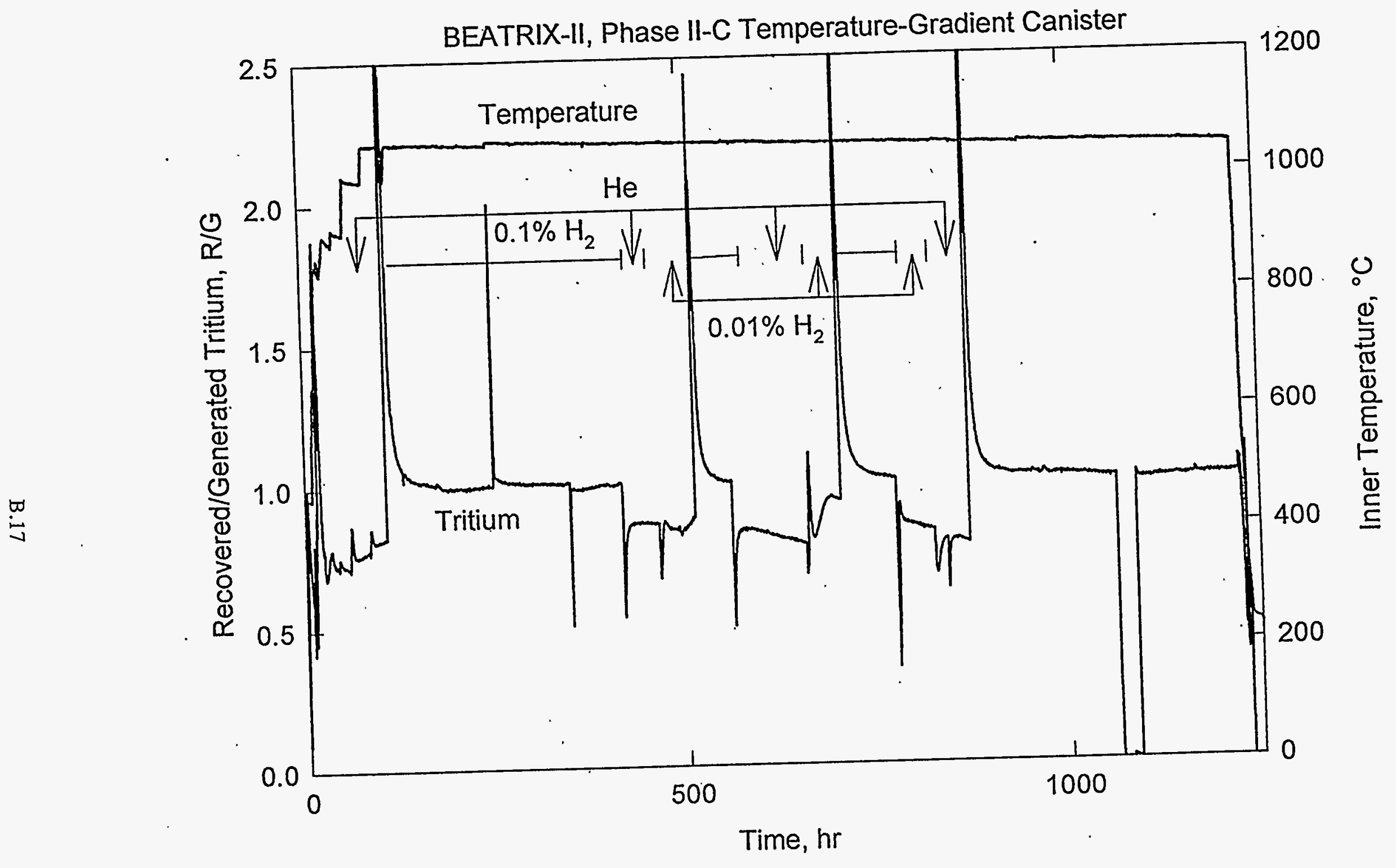

Figure B.14 Ratio of Recovered/Generated Tritium and the Average Inner Temperature for the Temperature-Gradient Canister in Phase II-C 


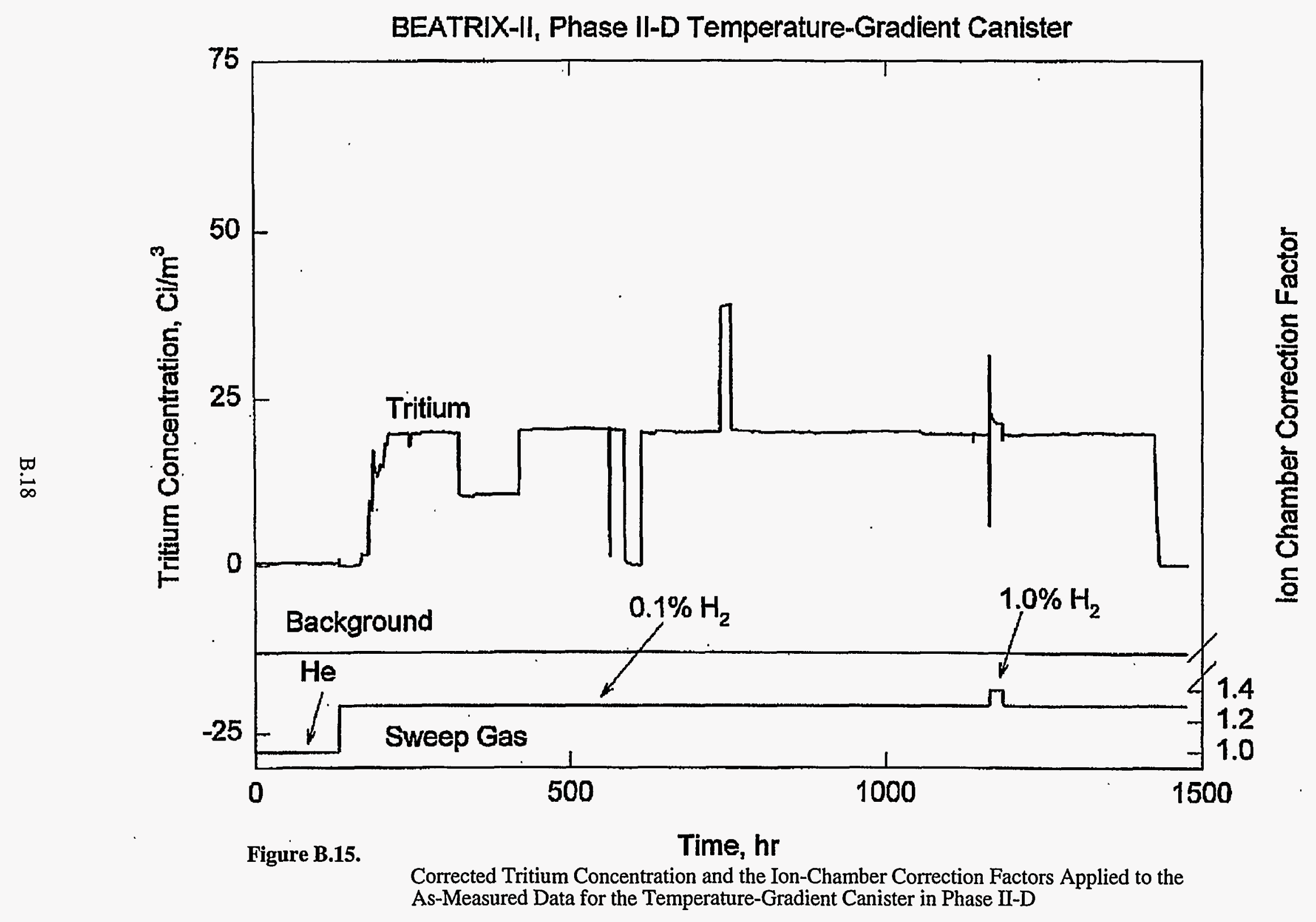




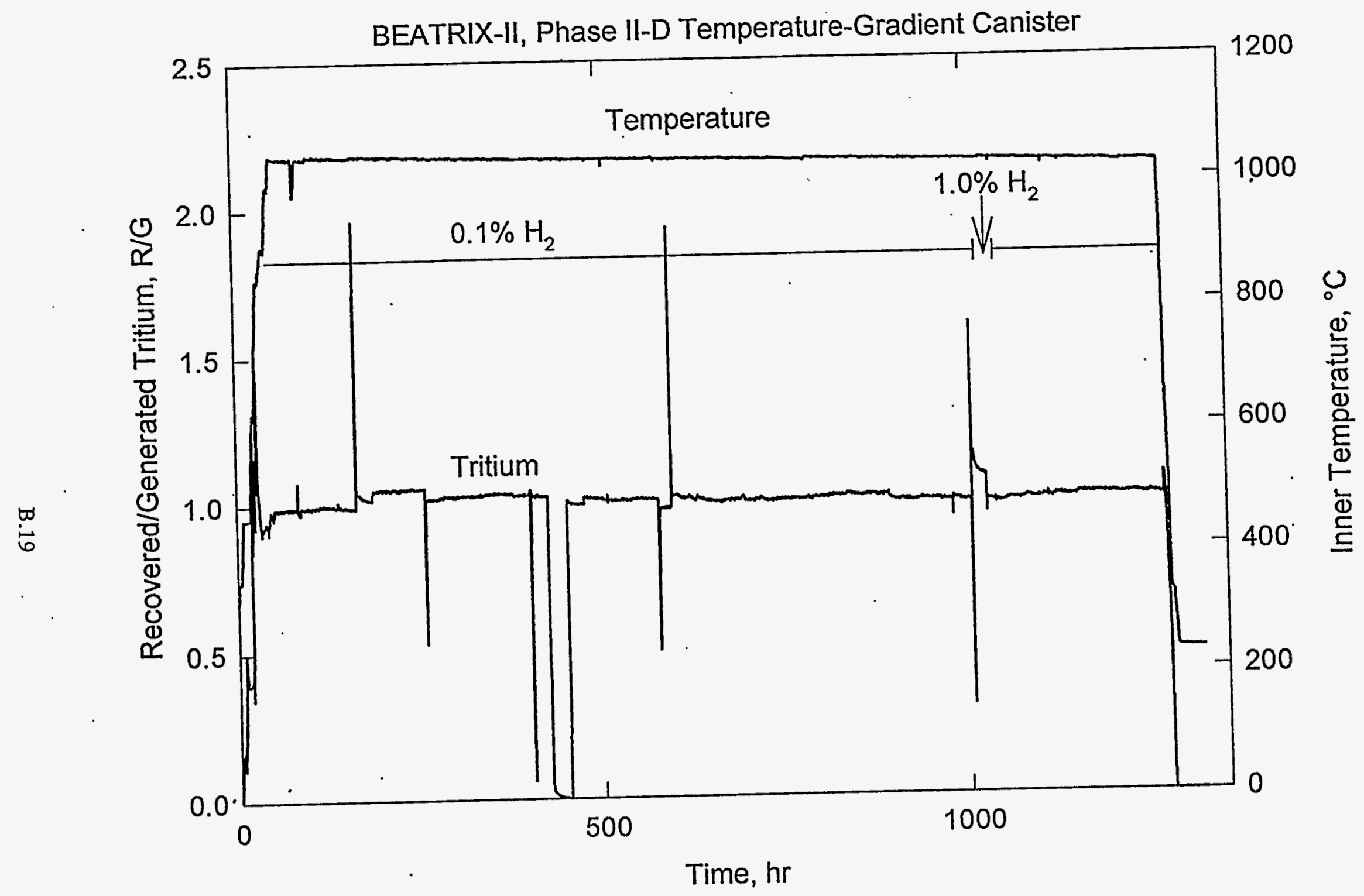

Figure B.16 Ratio of Recovered/Generated Tritium and the Average Inner Temperature for the Temperature-Gradient Canister in Phase II-D 


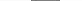




\section{Distribution}

No. of

Copies

\section{OFFSITE}

2 DOE/Office of Scientific and Technical Information

S. E. Berk

ER-533, GTN

U.S. Department of Energy

Office of Fusion Energy

Washington, D.C. 20545

R. E. Price

ER-533, GTN

U.S. Department of Energy

Office of Fusion Energy

Washington, D.C. 20545

F. W. Wiffen

ER-533, GTN

U.S. Department of Energy

Office of Fusion Energy

Washington, D.C. 20545

C. C. Baker

US ITER Program Office

University of California

San Diego

9500 Gilman Drive, BIdg 302

La Jolla, CA 92093

J. L. Anderson

Los Alamos National Laboratory

P.O. Box 1663

Los Alamos, NM 87545

C. G. Bathke

Los Alamos National Laboratory

P.O. Box 1663

Los Alamos, NM 87545

M. C. Billone

Argonne National Laboratory

9700 South Cass Avenue

Argonne, IL 60439
No. of

Copies

\section{OFFSITE}

S. W. Tam .

Argonne National Laboratory 9700 South Cass Avenue Argonne, IL 60439

D. K. Sze Argonne National Laboratory 9700 South Cass Avenue Argonne, IL 60439

C. E. Johnson

Argonne National Laboratory 9700 South Cass Avenue Argonne, IL 60439

J. P. Kopasz

Argonne National Laboratory 9700 South Cass Avenue Argonne, IL 60439

R.F. Mattas Argonne National Laboratory 9700 South Cass Avenue Argonne, IIL 60439

C. Wong General Atomic P.O. Box 85608 San Diego, CA 92121-1194

M. Abdou School of Engineering and Applied Science UCLA

Boelter Hall 405 Hilgard Avenue Los Angeles, CA 90024 
No. of

Copies

FOREIGN

R. E. Green

Atomic Energy of Canada Ltd.

Research Company

Chalk River Nuclear Laboratory

Chalk River, Ontario

Canada KOJ 1 JO

J. M. Miller

Atomic Energy of Canada Ltd.

Research Company

Chalk River Nuclear Laboratory

Chalk River, Ontario

Canada KOJ $1 \mathrm{JO}$

\section{R. A. Verrall}

Atomic Energy of Canada Ltd.

Research Company

Chalk River Nuclear Laboratory

Chalk River, Ontario

Canada KOJ 1JO

E. O. Moeck

Atomic Energy of Canada Ltd.

Research Company

Chalk River Nuclear Laboratory

Chalk River, Ontario

Canada KOJ 1 JO

H. K. Rae

Atomic Energy of Canada Ltd.

Research Company

Chalk River Nuclear Laboratory

Chalk River, Ontario

Canada KOJ 1JO

3 I. J. Hastings

Atomic Energy of Canada Ltd.

344 Slater Street

Ottawa, Ontario

Canada KJA 0J4
No. of

Copies

\section{FOREIGN}

G. J. Phillips

Atomic Energy of Canada Ltd.

Research Company

Chalk River Nuclear Laboratory

Chalk River, Ontario

Canada KOJ $1 \mathrm{JO}$

D. P. Dautovich

Canadian Fusion Fuels

Technology Project

2700 Lakeshore Road West

Mississauga

Ontario L5J 1K3

Canada

P. Gierszewski

Canadian Fusion Fuels

Technology Project

2700 Lakeshore Road West

Mississauga

Ontario L5J 1K3

Canada

K. Wong

Canadian Fusion Fuels

Technology Project

2700 Lakeshore Road West

Mississauga

Ontario L5J 1K3

Canada

T. Kondo

Tohoku University

Dept. of Machine Intelligence

and Systems Engineering

Aramaki, Aoba-ku, Sendai

980 Japan 
No. of

Copies

FOREIGN

T. Kurasawa

Dept. of Fusion

Engineering Research

NAKA Fusion Research

Establishment

Japan Atomic Energy Research

Institute

NAKA-Machi Naka-gun

Ibaraki-ken 311-0

Japan

Y. Okuno

Dept. of Fusion

Engineering Research

Japan Atomic Energy Research Institute

Tokai-mura Naka-gun

Ibaraki-ken 319-11

Japan

20 K. Noda

Department of Materials Science and Engineering

Japan Atomic Energy Research

Institute

Tokai-mura Naka-gun

Ibaraki-ken 319-11

Japan

T. Takahashi

Department of Materials Science and Engineering

Japan Atomic Energy Research

Institute

Tokai-mura Naka-gun

Ibaraki-ken 319-11

Japan

H. 'Yoshida

Department of ITER Project

801-1, Mukouyama, Naka-machi,

Naka-gun, Ibaraki-ken, 311-01

Japan
No. of

Copies

\section{FOREIGN}

H. Moriyama

Department of Nuclear

Engineering

Kyoto University

Yoshida, Sayko-ku

Kyoto 606-01

Japan

T. Terai

Department of Nuclear

Engineering

University of Tokyo

Hongo, Bunkỳo-ku

Tokyo 7-3-1

Japan

M. Yamawaki

Department of Nuclear

Engineering

Faculty of Engineering

University of Tokyo

7-3-1 Hongo, Bunkyo-ku, Tokyo

Japan

S. Tanaka

Department of Nuclear

Engineering

Faculty of Engineering

University of Tokyo

7-3-1 Hongo, Bunkyo-ku, Tokyo

Japan

Y. Gohar

ITER Joint Work Site

Max-Planck-Intit. f. Plasmaphysik

Boltzmannstr. 2.

D-85748 Garching bei Munche

Germany 
No. of

Copies

No. of

Copies

\section{FOREIGN}

R. Raffray

ITER Joint Work Site

Max-Planck-Intit. f. Plasmaphysik

Boltzmannstr. 2.

D-85748 Garching bei Munche

Germany

F. Tehranian

ITER Joint Work Site

Max-Planck-Intit. f. Plasmaphysik

Boltzmannstr. 2.

D-85748 Garching bei Munche

Germany

\section{ONSITE}

1 DOE Richland Operations Office

D. D. Green, K8-50

2 Westinghouse Hanford Company

R. E. Bauer, L6-37

R. J. Puigh, H0-31

26 Pacific NW National Laboratory

D. L. Baldwin, P7-22

M. D. Freshley, K9-85

G. W. Hollenberg, P7-20 (20)

R. H. Jones, P8-15

B. F. Saffell, K5-22

D. J. Senor, P8-10

B. D. Shipp, K1-73

O. D. Slagle, P8-10

Technical report Files (5) 